University of Rhode Island

DigitalCommons@URI

Open Access Master's Theses

1973

\title{
A Two Depth Averaged Numerical Temperature Model of Narragansett Bay
}

John J. Alfano

University of Rhode Island

Follow this and additional works at: https://digitalcommons.uri.edu/theses

\section{Recommended Citation}

Alfano, John J., "A Two Depth Averaged Numerical Temperature Model of Narragansett Bay" (1973). Open Access Master's Theses. Paper 982.

https://digitalcommons.uri.edu/theses/982

This Thesis is brought to you for free and open access by DigitalCommons@URI. It has been accepted for inclusion in Open Access Master's Theses by an authorized administrator of DigitalCommons@URI. For more information, please contact digitalcommons-group@uri.edu. 


\title{
A TWO DIMENSIONAL DEPTH AVERAGED NUMERICAL
}

TEMPERATURE MODEL OF NARRAGANSETT BAY

\author{
BY \\ JOHN J. ALFANO
}

A THESIS SUBMITTED IN PARTIAL FULFILLMENT OF THE REQUIREMENTS FOR THE DEGREE OF

MASTER OF SCIENCE

IN

OCEAN ENGINEERING

UNIVERSITY OF RHODE ISLAND

1973 


\section{MASTER OF SCIENCE THESIS}

OF

JOHN J. ALFANO

Approved:

Thesis Committee:

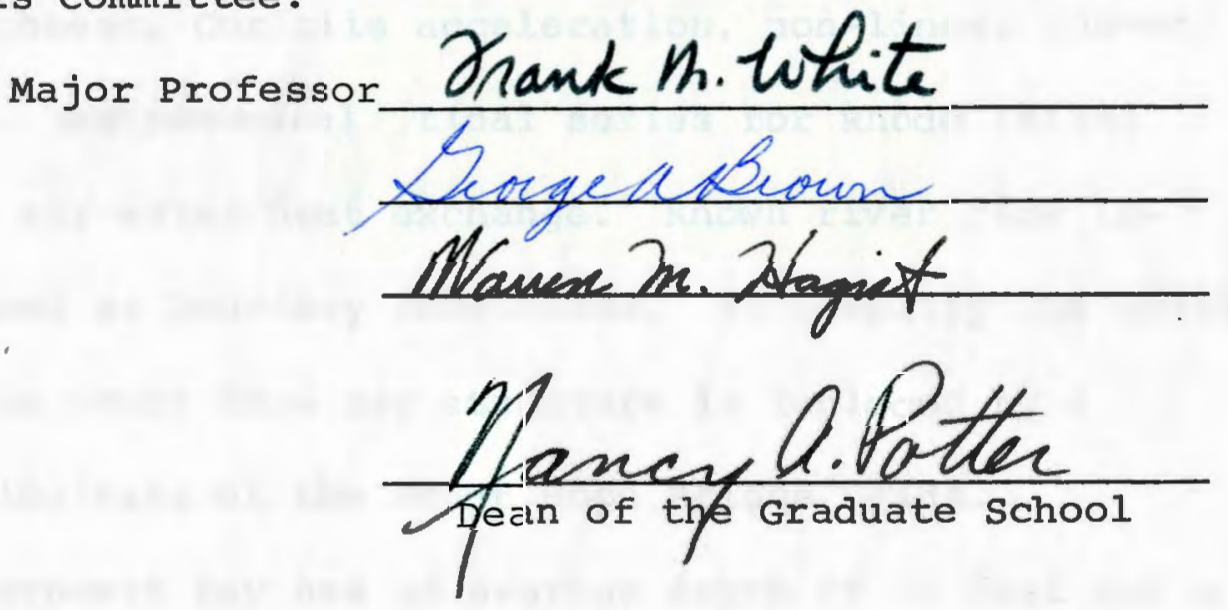

UNIVERSITY OF RHODE ISLAND

1973 


\section{ABSTRACT}

The numerical temperature model proposed in this thesis approximates the temperature distributions produced by natural or man made conditions in Narragansett Bay. The model approximates the temperature distribution by averaging the vertical structure over depth. A two dimensional, planar coordinate system continuously specifies the temperatures within the bay. A hydrodynamic model calculates the necessary velocities and depths required by the thermal model. The combined thermal-hydraulic model calculates bottom roughness, coriolis acceleration, non-linear convective terms, astronomical tidal series for Rhode Island Sound, and air-water heat exchange. Known river flow inputs are used as boundary conditions. To simplify the model geometry the Mount Hope Bay structure is replaced by a boundary flow rate at the Mount Hope Bridge grids.

Narragansett Bay has an average depth of 32 feet and a length of approximately 24 nautical miles with a maximum width of six nautical miles. By specifing a total of 325 square grids with eleven boundary grids $1 / 2$ nautical mile in length the model approximates the features of the estuary. Verification of the model is achieved through conservation of mass analysis and comparison of predicted temperatures 
for given meteorological and water temperature data. The model is used to predict the thermal fields from a proposed power plant near Rome Point in the West Passage of Narragansett Bay. By specifying plant flow rates and dispersion coefficients characteristic temperature field conditions are observed. Under specified plant operating conditions, a maximum temperature rise of $5.5^{\circ} \mathrm{C}$ above ambient in the discharge grid is predicted. For a temperature rise of $5.5^{\circ} \mathrm{C}$ the area encompassed by the $1^{\circ} \mathrm{C}$ excess isotherm is approximately two square miles while the $0.5^{\circ} \mathrm{C}$ isotherm area is about four square miles. Temperature isotherms over a tidal cycle retain the same general shape, especially in the far field where temperatures fall below $0.4^{\circ} \mathrm{C}$ excess. This model can simulate salinity or other non-decaying constituents if appropriate boundary condition changes are made.

In summary, the thermal model gives valuable insight into natural and man-made temperature distributions that will aid the marine scientist in preserving and understanding the dynamics of Narragansett Bay. 


\section{ACKNOWLEDGEMENT}

Although computer modeling is primarily a struggle between the modeler and the model it would be a grave injustice not to mention the support I received from my committee. In particular Dr. Frank White's encouraging words on the model, this thesis and other related matters deserve commendation. During the darkest days Dr. George Brown's help proved invaluable as well as Professor Warren Hagist's encouraging support.

It is unfortunate that certain ultimate goals were not achieved but the confidence and love of my wife clarified my perspective and stimulated this work. We weathered the storm together.

Mr. Kurt Hess's constant support and patience went beyond the normal bounds of friendship.

Miss Linda Weinreich, showing profitable enthusiam with the many drafts made the manuscript into a thesis. 
ABSTRACT $\ldots \ldots \ldots \ldots \ldots \ldots \ldots \ldots \ldots \ldots \ldots \ldots \ldots \ldots \ldots \ldots \ldots \ldots$

LIST OF TABLES........................

LIST OF FIGURES........................

CHAPTER

I. INTRODUCTION.....................

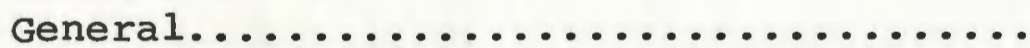

Historical Data................... 2

Applications...................... 16

Approach.......................... 17

Verification..................... 23

Concluding Remarks................. 23

II. MODEL DEVELOPMENT..................... 25

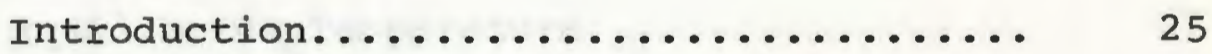

Dispersion...................... 32

Finite Difference Approximations........ 36

Differencing Comments.............. 40

III. TEMPERATURE AND AIR WATER INTERFACE BOUNDARY CONDITIONS AND VERIFICATION DATA RELATIONSHIPS.

Air Water Interface-Surface Heat Transfer

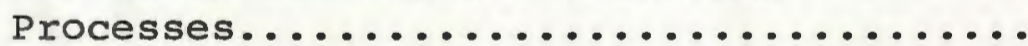


Incident Solar Radiation Heat-Transfer

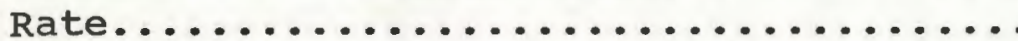

Reflected Solar Radiation Heat-Transfer

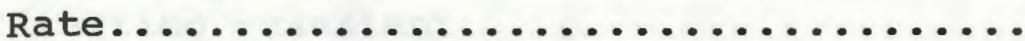

Incident Atmospheric Radiation Heat-

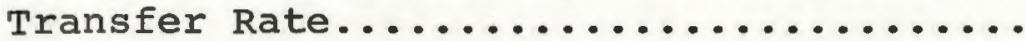

Reflected Atmospheric Radiation Heat-

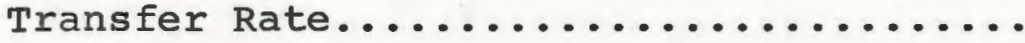

Back Radiation Heat-Transfer Rate From Water Surface...................

Air Vapor Pressure, EA.............

Saturated Vapor Pressure (Due Point Temperature) ....................

Evaporation Heat-Transfer Rate..........

Evaporation Mass Flow Rate........... 62

Conduction Heat-Transfer Rate......... 62

Model Formulation................ 64

Equilibrium Temperature............ 67

Exchange Coefficient.............. 68

IV. COMPUTER MODEL SUMMARY.............. 71

Preliminary Model Details........... 71

Model Application for Narragansett Bay, Hydrodynamics section................

Model Applications for Narragansett Bay Thermal section...................

V. GENERAL STUDIES OF TEMPERATURE MODEL 
Effect of the Differences............

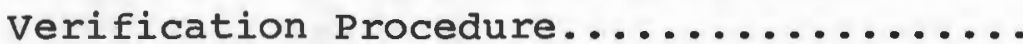

starting Transient................

Dispersion Coefficient............... 104

VI. COMPARISON OF CALCULATED RESULTS AND

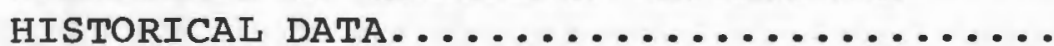

Background....................... 107

Model Simulation conditions............ 108

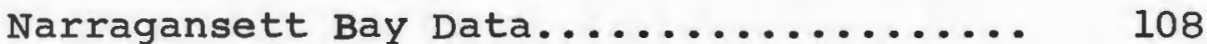

Evaluations...................... 114

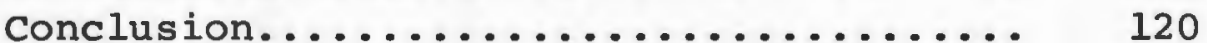

VII. THERMAL MODEL PREDICTIONS................ 121

Power Plant Location................. 121

Introduction to Experimental Runs....... 121

Experimental Run 1 (The Natural Conditions in Narragansett Bay as Predicted

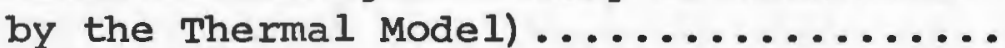

Experimental Run 2 (The Natural conditions in the Bay with a Power Plant as the Heat source) ..................

Experimental Run 3 (This Predicts only the Temperature Increase Due to Heat Load From a Power Plant or Forced Temperature Rise) ...................

Experimental Run 4 (Forced Temperature

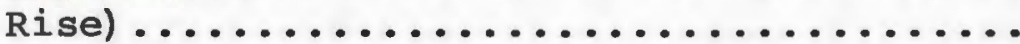


Long Term Variations in Surface Discharge Box for a High Dispersion Coefficient.

Experimental Run 5 (Forced Temperature Rise with $50 \%$ Increase in Flowrate......

Experimental Run 6, (Forced Temperature

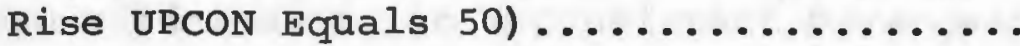

Interpretation of Average and worst Bay Conditions on the siting of the Power

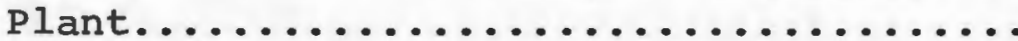

General Comments................... 153

VIII. CONCLUSIONS....................... 155

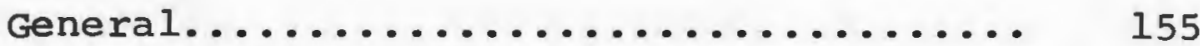

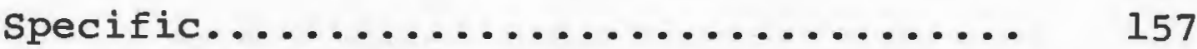

IX. RECOMMENDATIONS...................... 159

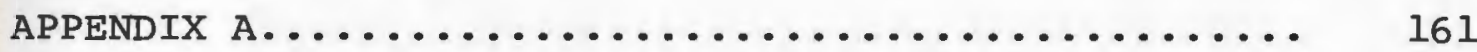

Introduction........................ 161

Terminology.......................... 161

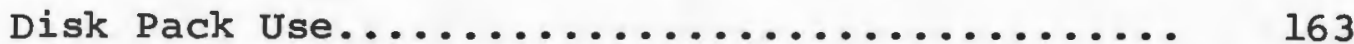

Disk Pack Utilities..................... 171

Acknow ledgement....................... 173

Selected Bibliography................... 173

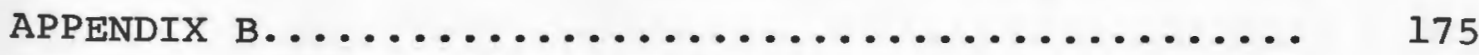

Hydordynamic Model..................... 175

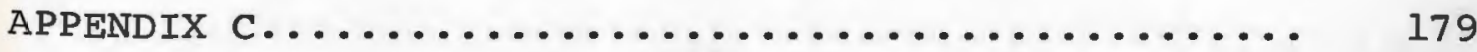


APPENDIX

General

Expansion of the Finite-Difference Equation.... 186

APPENDIX E

Upstream Differencing in a Consistent Divergent Flow Pattern.

Conservation of Mass... 200

APPENDIX F 203 REFERENCES. 260 


\section{LIST OF TABLES}

TABLE

Page

1.1 Temperature Data, 1879-1956............

1.2 Temperature Data, 1956-1958............. 5

1.3 Temperature Data, 1958-Present........... 6

1.4.a Hydrodynamic Concentration Models......... 19

1.4.b Hydrodynamic Concentration Models........ 20

3.1 Reflected Solar Radiation constants...... 55

3.2 Air Vapor Pressure Constants............ 58

3.3 Wind Velocity Function Parameters........ 60

3.4 Evaporation Formula Measurement Para-

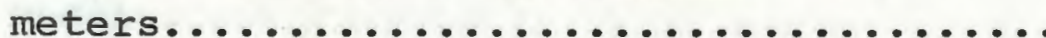

3.5 Linearized Vapor Pressure Constant, BETA (Reference 12)

4.1 Lunar Constituent Analysis of Flow Under Mt. Hope Bridge...................

6.1 Newport Temperature Data, (41) Grid

6.2 Cruise III, Hicks (37) Temperature

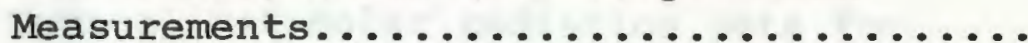

7. 1 Program variables.................... 124

7.2 Run 4, General Tidal and Thermal Results for $\operatorname{Run} 4 \ldots \ldots \ldots \ldots \ldots \ldots \ldots \ldots \ldots \ldots . \ldots \ldots$

APPENDIX E

E.1 Differencing Schemes on Spatial Concen-

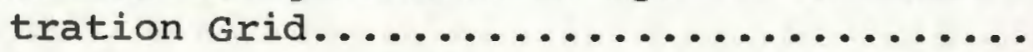


LIST OF FIGURES

FIGURE

Page

1.1 Model Components..................

1.2 Monthly Surface Water Temperature for

Newport, Rhode Island and Brenton's

Reef (31)

1.3 Surface water Temperature, Mt. Hope Bay

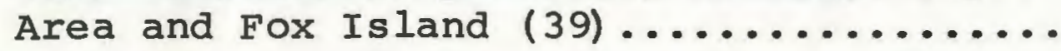

1.4 Monthly Water Surface Temperature Averages for Newport and Narragansett

Marine Lab Pier $(41,38) \ldots . . . \ldots \ldots . .$.

1.5 Surface water Temperatures at Fox Island and whale Rock, 1967, (46) .............

2.1 Coordinate and Variable scheme for the Model...........................

2.2 Space staggered Grid system............

2.3 Boundary Conditions.................

2.4 One Dimensional Concentration Scheme.....

3.1 Schematic, Surface Heat Transfer Process

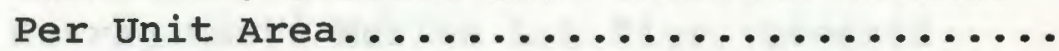

3.2 Temperature, Pressure and Velocity Profiles Near Interface..................

3.3 Typical Net Solar Radiation Data for

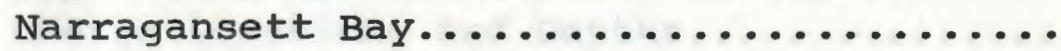

4.1 Grid system for Narragansett Bay.........

4.2 Depth Specification................

4.3 North-South Temperature Profile......... 
4.5 Narragansett Bay Zonal Divisions.........

4.6 Rome Point Area....................

5.1 Energy Balance for Bay, Uniform Tempera-

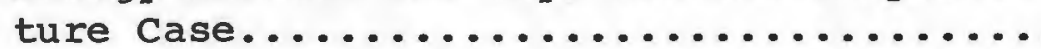

5.2 Phases of Transient Response for Forced Temperature Rise and Tidal Averages.......

101

5.3 The Establishment of the steady state Tidaly Averaged Values of Forced Temperature Rise as a Function of Diffusion Coefficient for Grid $m=35, n=5 \ldots \ldots \ldots$

5.4 Graphical Representation of Minimum Value of Dispersion Coefficient for Rome Point $, \mathrm{m}=36, \mathrm{n}=5 \ldots \ldots \ldots \ldots \ldots \ldots \ldots \ldots$

6.1 Narragansett Marine Lab Pier Location

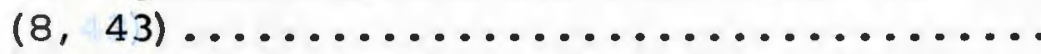

6.2 Daily Temperature Pattern at T.F. Green Airport (56) ......................

6.3 Solar Input, Eppley Laboratory, Newport, Rhode Island.

6.4 Narragansett Marine Lab Pier, General Location and Depths.

6.5 Narragansett Marine Lab Temperatures (38).

7.1 Rome Point Area with Model Grids, Discharge Locations and Depths.............

7.2 Run 1 Bay Temperature at 68 Hours........

7.3 Run 1, Natural Thermal Field at 68 Hours

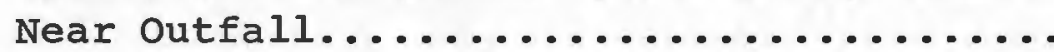

7.4 Run 2 Thermal Field with Heat Source at 68 Hours for Narragansett Bay........... 
7.5 Forced Temperature Rise From Runs 1 and 2.

7.6 Forced Temperature Rise From Run 3.......

7.7 Run 4, Thermal Field at 128 Hours........

7.8 Run 4, Thermal Field at 130 Hours.......

7.9 Run 4, Thermal Field at 132 Hours........

7.10 Run 4, Thermal Field at 134 Hours........

7.11 Run 4, Thermal Field at 136 Hours....... 140

7.12 Run 4, Thermal Field at 138 Hours........ 141

7.13 Run 4, Thermal Field at 140 Hours........

7.14 Run 4, Tidal Averaged Thermal Field, 128-140 Hours.

7.15 Run 4, Tidal Motion in the West Passage... 144

7. 16 Tidal Effects on the $0.4^{\circ} \mathrm{C}$ Isotherm.......

7.17 Run 2, Temperature Variations for Grid $n=5, m=6$

7.18 Run 4, QIN $=2000 \mathrm{cfs,} \mathrm{UPCON}=100 ;$ Run

5, $Q I N=3000 \mathrm{cfs}, \mathrm{UPCON}=100 ;$ Run 6 , $\mathrm{QIN}=2000 \mathrm{cfs}, \mathrm{UPCON}=50$.

APPENDIX A

A.1 Overlay flow Chart................... 170 APPENDIX C

C.1 Spatial Arrangement of Variables on Grids.

APPENDIX D

D.1 Left closed Boundary 
FIGURE

Page

D.2 Right Closed Boundary.............. 191

D.3 Left Open Boundary................. 193

APPENDIX E

E.1 One Dimensional Differencing Scheme...... 194

E.2 One Dimensional Concentration Scheme..... 198

E. 3 Divergent Flow Around the North Tip of Conanicut Island, Jamestown, Rhode Island. 199

E.4 Divergent Flow Instability............ 200

E.5 One Dimensional Five Grid Scheme........ 201 


\section{INTRODUCTION}

\section{A. GENERAL}

A model tries to represent the salient characteristics of a system so that the user can gain insight into the governing features of the particular site. This thesis explains the implementation of a model that will predict vertically-averaged temperature distribution in Narragansett Bay. The thermal model, as it is called, uses a tidal model (Hess, 4) to provide the necessary hydrodynamic structure in the bay. The hydrodynamic inputs are velocity, tidal elevation, and bottom friction. The thermal model then predicts the effect of thermal convection and diffusion as well as the heat exchange that takes place at the air-water interface for specified locations or grids. Pertinent meterological data must be read in for periods of simulation. In essence, the model predicts the movement or mixing of heat subject to eleven known boundary conditions around the bay.

The model is a digital computer program, written in Fortran language, that uses over three hundred $1 / 2$ by $1 / 2$ nautical mile cells to represent the characteristic features of the bay. The model is two dimensional in that 
it determines a temperature value for each cell volume in both a general north-south and east-west direction.

with this model, marine life behavior and electric generating plant thermal discharges can be studied. Other applications, such as salinity prediction, are possible with minor model modifications.

To begin this study, a breakdown of main model components is shown in Figure 1.1. It can be seen that to understand the convective, diffusive and time varying quantities we must rely on a hydrodynamic model that will simulate the transporting medium accurately. The grouping of these terms, in block diagram form, indicates no interaction of constituent on flow behavior. If the model had a vertical structure, one would couple the hydrodynamic model with constituent model through the vertical buoyancy flux term, creating a much more difficult problem and many more cells.

\section{B. HISTORICAL DATA}

General historical information consists of data obtained from various cruises and buoy measurements taken in and around the bay area during the last 100 years. Tables $1.1,1.2$, and 1.3 present a summary of temperature informa- 


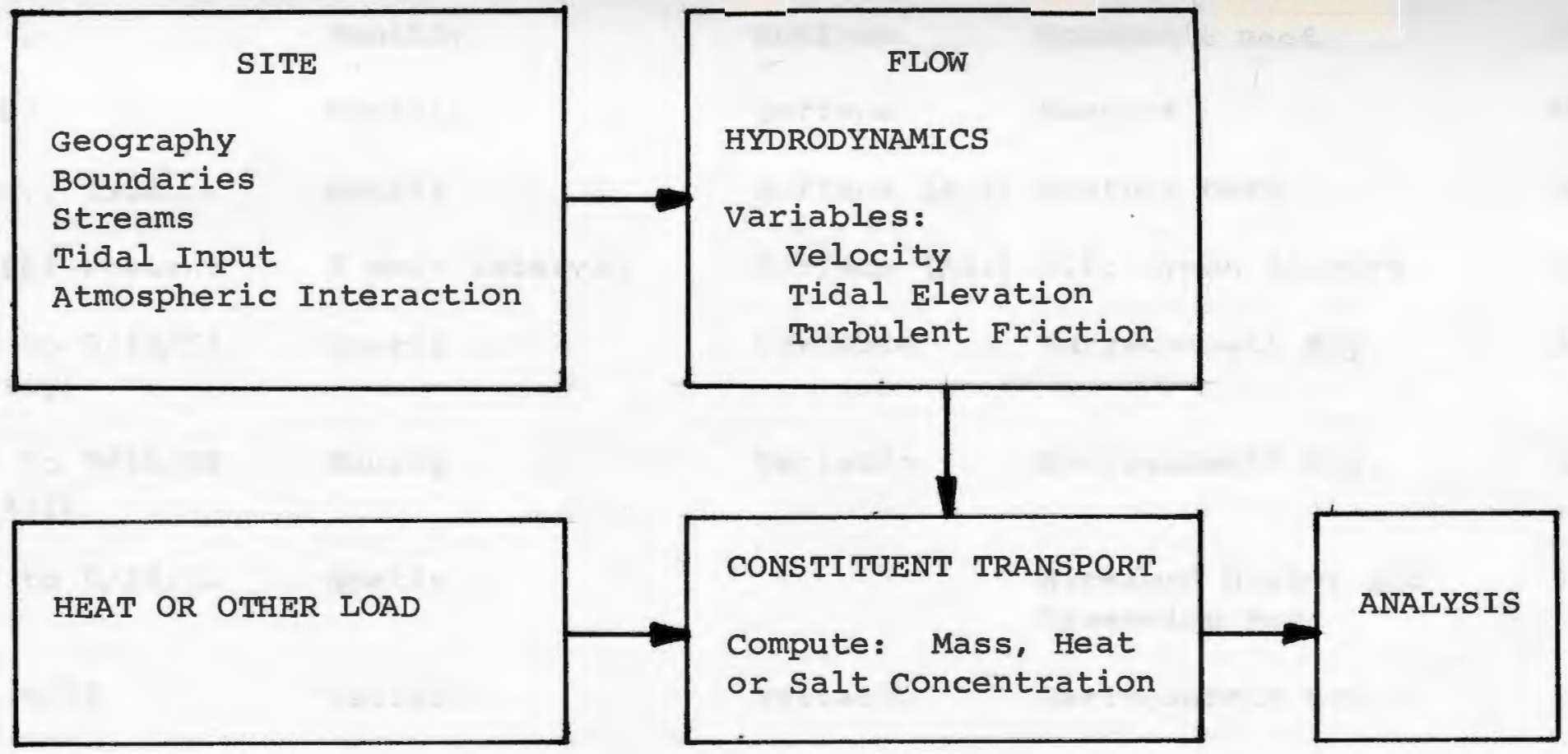

FIGURE 1.1. MODEL COMPONENTS 
PERIOD

$1879-1942$

$1881-1883$

1905-Dec. , 1966

Jan., 1967-Present

$8 / 24 / 51$ to $9 / 18 / 51$

(Not Daily)

$2 / 19 / 52$ to $9 / 16 / 52$

(Not Daily)

$4 / 16 / 50$ to $9 / 28 / 52$ weekly

$6 / 51$ to $9 / 52$

Variable

$2 / 1-21 / 56$ (Cr. 14)

Hourly

$4 / 2-20 / 56$ (CR. 15)

TIME

Monthly

Monthly

Hourly

Hourly

Hourly
3 Hour Interval

variable

Narragansett Bay

Wickford Harbor and Greenwich Bay

Variable

Variable

Narragansett Bay

Narragansett Bay

Variable

Narragansett Bay

\section{REFERENCE}

31

31

56

56

32

32

58

34

(mostly

isotherms)

34

TABLE 1.1. TEMPERATURE DATA, 1879-1956 


\section{PERIOD}

6/11-28/56 (Cr. 18)

8/6-10/56 (CR. 19)

$9 / 1 / 56$ to $12 / 31 / 56$

$1 / 22$ to $2 / 6 / 57$ (Cr.1) Hourly

$4 / 10$ to $4 / 18 / 57$ (Cr.2) Hourly

$7 / 15$ to $7 / 19 / 57$ (Cr.3) Hourly
(Cr. 4)

$2 / 7$ to $1 / 29 / 58$

$1 / 1$ to $12 / 31 / 57$

$5 / 18 / 57$ to $3 / 18 / 58$
Hourly

weekly

Daily (Max., Min.)

Weekly $\underline{\text { PROBE }}$

Variable

Variable

Surface

Variable

Variable

Variable

Variable

LOCATION

REFERENCE

35

Narragansett BaY

Narragansett Marine Lab Pier

Narragansett Bay

Narragansett Bay

Narragansett Bay

Narragansett Bay

sfc., Bot.

Narragansett Marine Lab

Surface

Narragansett Marine Lab 38

Surface

Mt. Hope Bay, Fox

Island 
PERIOD

$8 / 55$ to $12 / 58$

1959

Summer 1959

1960

$7 / 19 / 63$ to $7 / 64$

1960 to 1966
1967 to Present
$3 / 71$ to $10 / 71$
$6 / 72$ to $8 / 72$

\section{TIME}

Monthly

Daily (Available)

Daily (Average)

Hourly

Daily (Average)

Period

Monthly

Daily (Available)

Weekly

Continuous

Daily (Max., Min.)

Hourly

\section{PROBE}

Surface

Surface

SurfaceBottom

Surface

Variable

Surface

Surface

Near Bottom

Variable

\section{LOCATION}

Newport, R.I.

Narragansett Marine Lab 40

Upper Narragansett Bay

Narragansett Marine Lab

43

R.I. Sound (Isotherms)

Newport, R.I.

Fox Island, Whale Rock

46

East of Saunderstown

$\left(71^{\circ} 25^{\prime}, 41^{\circ} 30^{\prime} 30^{\prime \prime}\right)$

47

Narragansett Bay 
tion for the Narragansett Bay. This compilation of data provides some understanding of boundary conditions and very general spacial variations throughout the bay.

First, the Brenton's Reef Data (31) provides an estimate for the monthly surface temperature for the lower bay boundary condition. The averaged monthly temperature for Brenton's Reef is shown in Figure 1.2. For the thermal model, the average value during the prediction period is read off Figure 1.2 and specified as the Rhode Island Sound boundary condition. Included in reference 31 is a brief temperature record for Newport during the period May, 1881 to March, 1883 and the average values are also seen in Figure 1.2.

The data collected by wehe (32) is given in chart form with longitude and latitude, date, time in minutes, various depths, temperature of water $\left({ }^{\circ} F\right)$, salinity, oxygen, sound velocity, Secchi Disk measurements, sea state, wind direction and magnitude, and weather conditions. The report has 91 pages of data with measurements taken on August 24, 27-31, September 5, 10-12, 14, 17, 18 in 1951, and February 2, 19-22, March 25-27, August 13, 27-29, September 4, 9, 11, 15. 16 in 1952 .

The weekly temperature variations of surface water in 


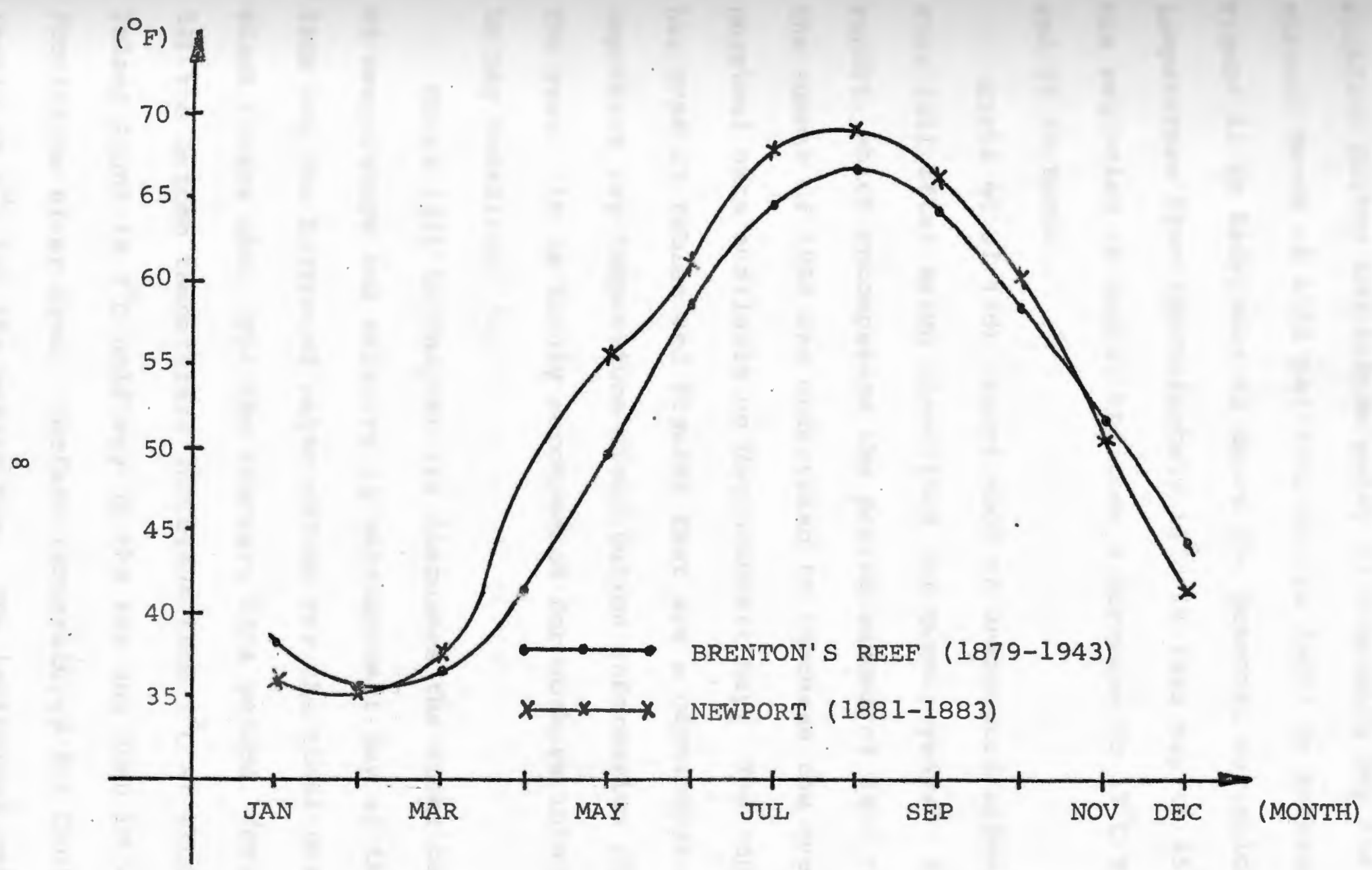

FIGURE 1.2. MONTHLY SURFACE WATER TEMPERATURE FOR NEWPORT, RHODE ISLAND AND BRENTON'S REEF (31) 
wickford Harbor and bottom water in Greenwich Bay for May through March of 1951 and 1952 can be found in Reference 33. Figure 11 in Reference 33 shows the seasonal variation of temperature from approximate $1 \mathrm{y} 16^{\circ} \mathrm{C}$ in late May to $25^{\circ} \mathrm{C}$ at the beginning of August and then a decrease to $17^{\circ} \mathrm{C}$ for the end of september.

Hicks et al (58) report made an unexpected appearance this fall after being classified for twenty years. This report, which encompasses the period summer of 1951 through the summer of 1952 was undertaken to increase the overall physical data available on Narragansett Bay. The report has over 25 tables and figures that are a cornucopia of important bay temperature distribution information throughout the year. It is highly recommended for workers interested in Bay modeling.

Hicks (34) in Chapter III discusses the distribution of temperature and salinity in Narragansett Bay at the surface and the bottom of water column for the tidal period, slack before ebb. For the February 1956 period, (Cruise, 14) the bottom temperature increases from $1^{\circ} \mathrm{C}$ at Rhode Island sound to $3^{\circ} \mathrm{C}$ half way up the bay and down to $2^{\circ} \mathrm{C}$ in Providence River area. Surface temperatures for Cruise 14 remain at $2^{\circ} \mathrm{C}$ for the entire bay. The isothermal pattern 
for the April 1956 period (Cruise 15) is very irregular, with variations in bottom water from $1^{\circ} \mathrm{C}$ to $7^{\circ} \mathrm{C}$ while the surface water is $3^{\circ} \mathrm{C}$ in Rhode Is land sound and increases to $10^{\circ} \mathrm{C}$ in the Providence River.

Hicks (34) undertook two more cruises one in June (cruise 18) and another in August, 1956 (Cruise 19). The isothermal pattern for the June cruise shows a surface temperature variation of $19^{\circ} \mathrm{C}$ at Rhode Island sound to $20^{\circ} \mathrm{C}$ in the Providence River while the bottom water changes from $11^{\circ} \mathrm{C}$ to $17^{\circ} \mathrm{C}$ respectively. For the second cruise, the temperature variation in the surface water was about $4^{\circ} \mathrm{C}$ or the difference between $23^{\circ} \mathrm{C}$ in the Providence River compared with $19^{\circ} \mathrm{C}$ in the lowest portions of the bay. The bottom water varied from $20^{\circ} \mathrm{C}$ in the upper portion of the bay to about $17^{\circ} \mathrm{C}$ in the Rhode Island Sound.

Continuous temperature readings were taken at the Narragansett Marine Laboratory on a Bristol Recorder. These temperature readings were reduced into maximum and minimum values $(36,38)$ and then to just a daily average $(40,43)$. The average values for each month are listed and these are plotted against the Brenton's Reef data (31) to estimate how weather conditions affect general bay behavior. Hicks (37), in a comprehensive report, presents temper- 
ature data in four quarterly cruises. In this report are tables estimating seasonal temperature trends and ranges as well as vertical distribution of temperature during the various cruises. In addition, his Figure 14 (37) shows the surface and bottom temperature variation at Narragansett Marine Lab Pier for the period February, 1957 through June, 1958. The information for this figure is contained in Appendix Table 5 (37) for which temperature data is taken about once a week.

Weekly surface water temperatures for Mt. Hope Bay and Fox Island for the interval May 18, 1957 to March 18, 1958 were taken by Herman (39). The general temperature pattern can be seen in Figure 1.3.

Since August, 1955, surface water temperature data $(41,45)$ has been gathered at Newport, Rhode Island. The surface water temperatures are measured several times a week and these data sheets (available) are compiled into monthly maximum, mean maximum, mean, mean minimum, and minimum temperatures. The temperature variations for Narragansett Marine Lab Pier and Newport are shown in Figure 1.4.

The Corps of Engineer Survey (42) did extensive measurements during the summer of 1959 in the portion of Narragansett 


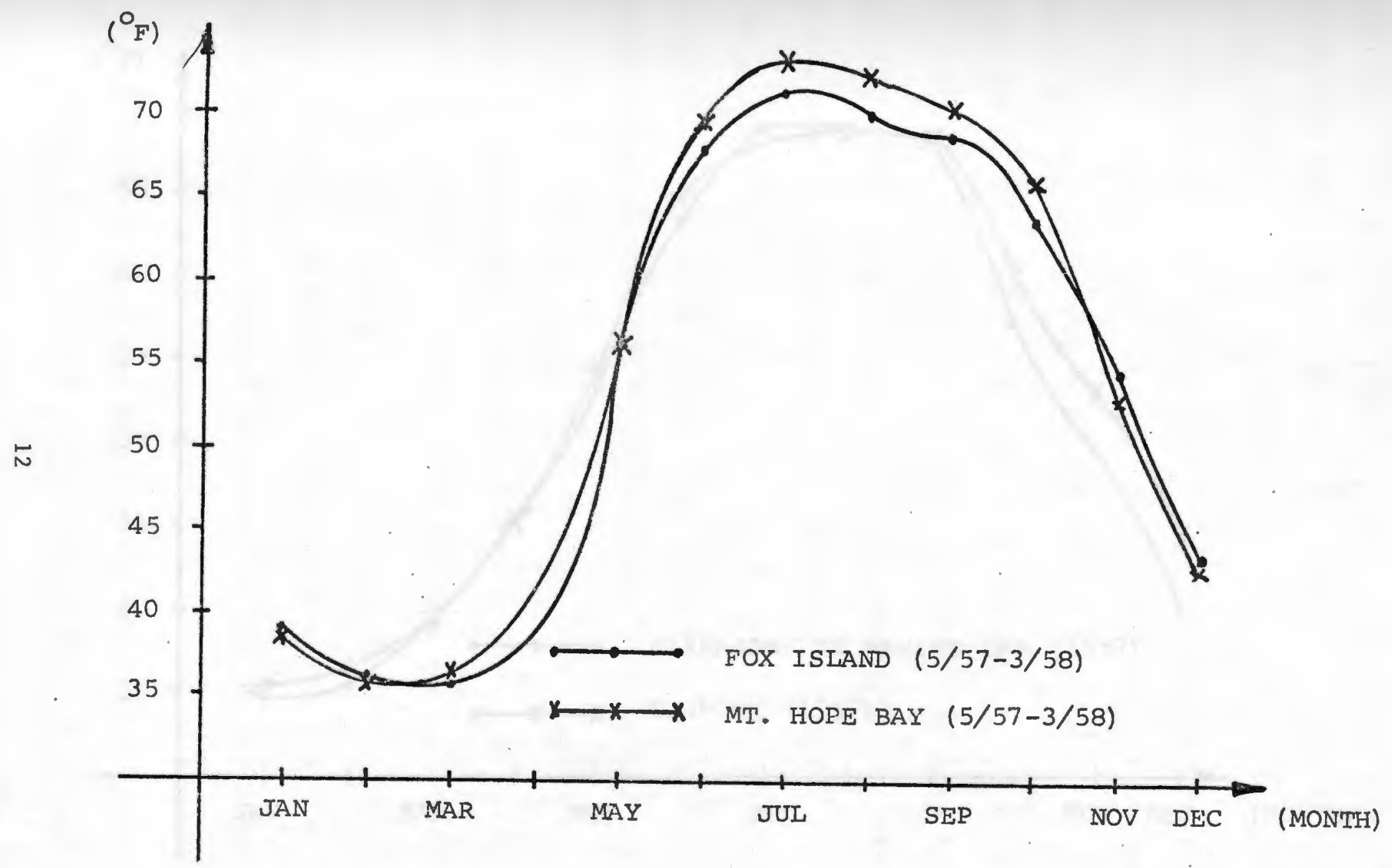

FIGURE 1.3. SURFACE WATER TEMPERATURE, MT. HOPE BAY AREA AND FOX ISLAND (39) 


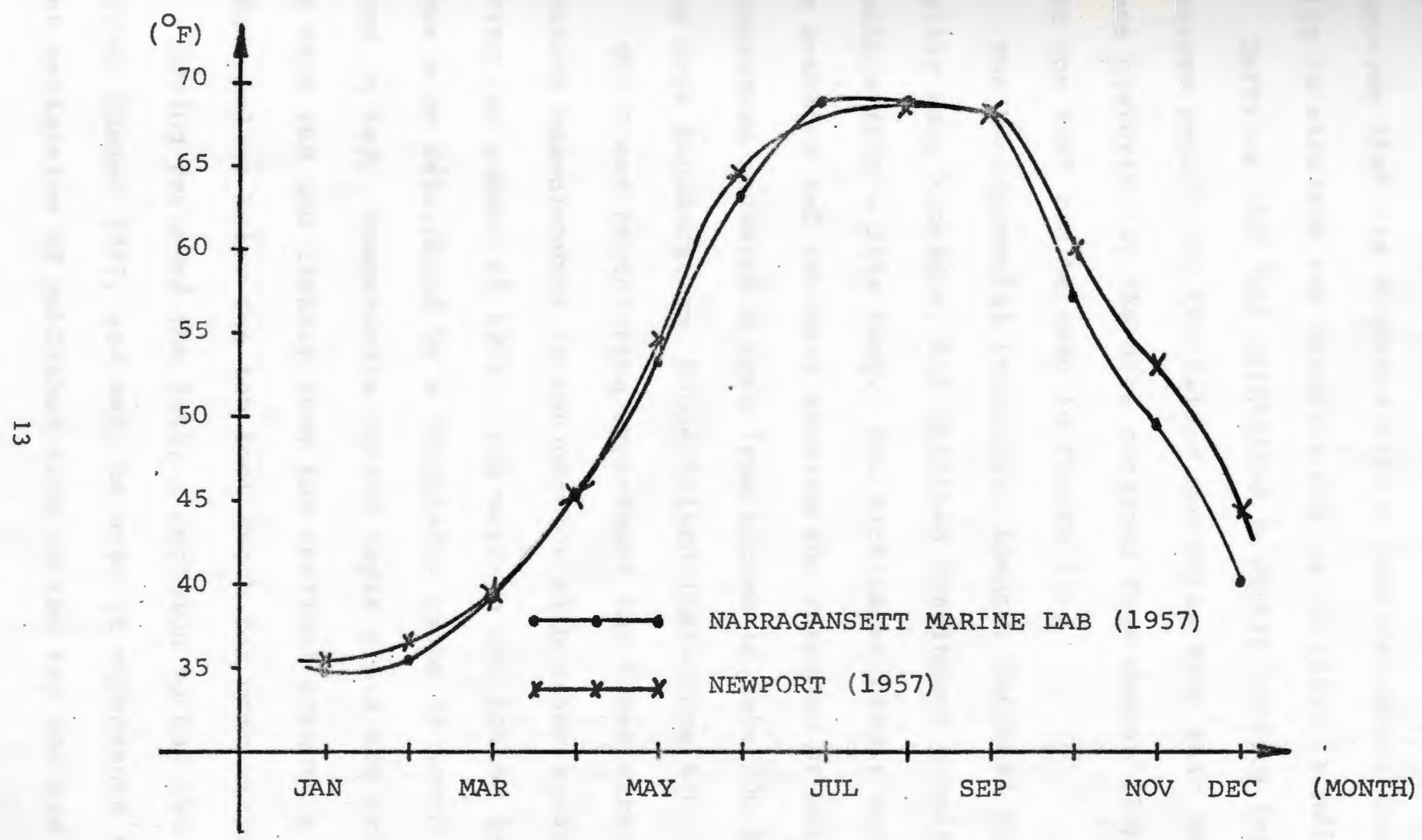

FIGURE 1.4. MONTHLY WATER SURFACE TEMPERATURE AVERAGES FOR NEWPORT AND NARRAGANSETT MARINE LAB PIER (41, 38) 
Bay north of Prudence Island. The report includes average isotherms that are compared with a physical model that was built to simulate bay dynamics during hurricane conditions. Jeffries (46) has maintained a weekly surface temperature record for Fox Island and whale Rock that complements historically the data obtained from Herman (39). This data for 1967 can be seen in Figure 1:5.

The Environmental Protection Agenç, National Water Quality Lab, Kingston, has obtained continuous temperature readings from a data buoy. Mr. Rick Lapan kindly supplied the averaged and raw data showing the response of water temperature measured 8 feet from bottom in water 30 feet deep near Saunderstown, Rhode Island (Reference 47).

The Ocean Engineering Department has taken water temperature measurements in conjunction with other studies during the summer of 1972. The surface and bottom temperatures were determined by a thermistor probe at seven sta-. tions in bay. Temperature versus depth plots are provided for each run and clearly show the vertical structure with a thermocline below the ten foot depth for most stations. Having reviewed the data, a decision to use the period, Summer 1957, was made because it represents the best collection of published data in the bay for use in 


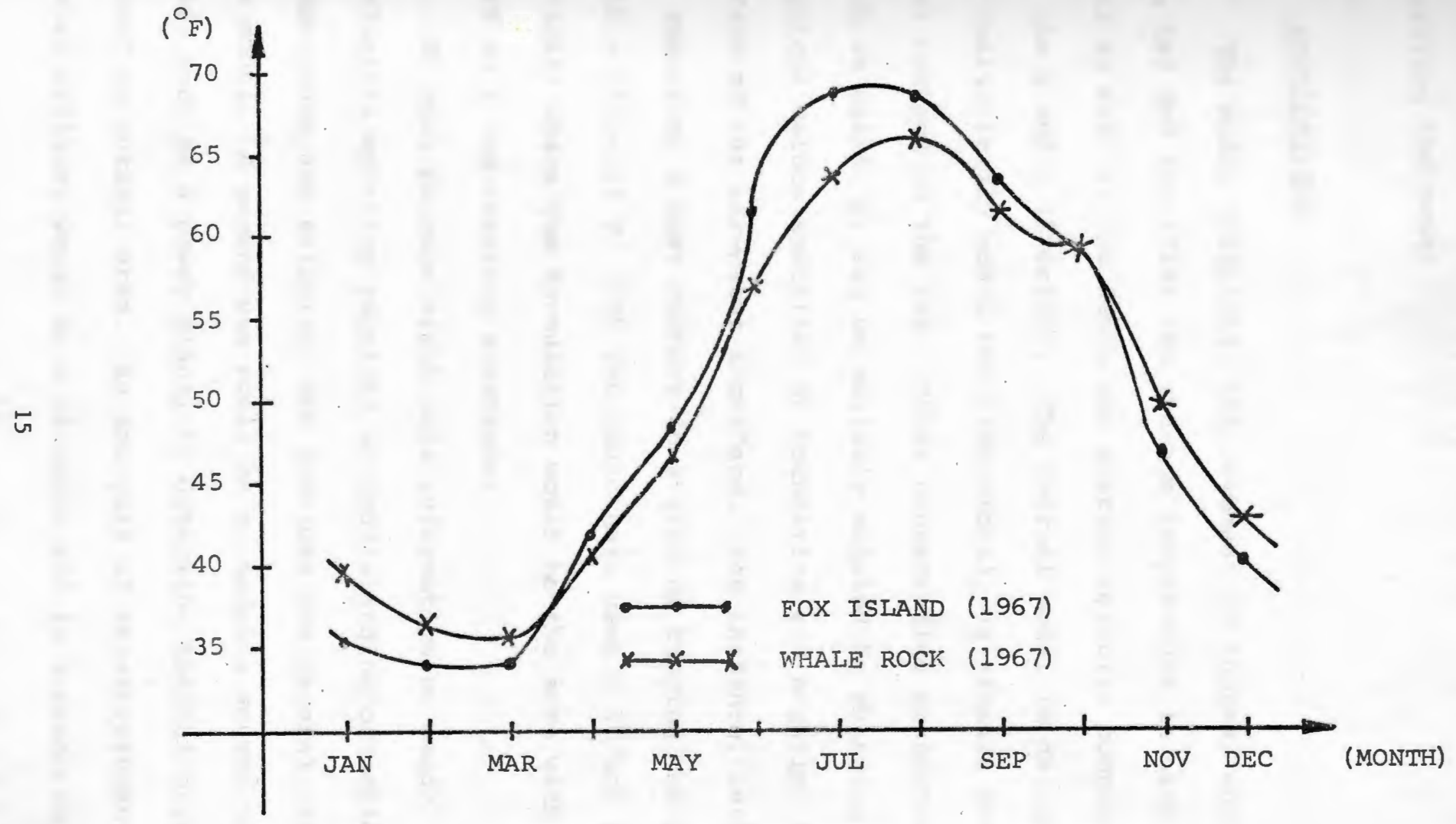

FIGURE 1.5. SURFACE WATER TEMPERATURES AT FOX ISLAND AND WHALE ROCK, 1967, (46) 
verifying the model.

\section{APPLICATIONS}

The model calculates the movement of thermal energy in the bay and specifies the average temperature in each grid as well as the depth and average velocity components in the $x$ and $y$ direction. The thermal model is designed to realistically model two dimensional, vertically averaged heat content in the bay. Other conservative properties, such as salinity, can be suitably modeled by changing physical values specified at boundaries and negating the effect of the air-water interface. For instance, instead of specifing a heat content in a grid by tagging the grid with a value of $\mathrm{T},\left({ }^{\circ} \mathrm{C}\right)$ you could have used $\mathrm{S}(\% \circ)$ for salinity where the formulation would be the same with regard to a non-reacting substance.

To what purpose might this information be used? Biological modeling requires an understanding of ambient temperature and salinity, and provides one general use of the model. A second use would be to model a source of heat, such as a power plant, to determine thermal structure around an outfall area. An analysis of re-entrainment of heated effluent would be a valuable aid in determining de- 
sirable site locations from both a power plant operation and biological viewpoint.

one of the important physical parameters of the bay that determines the mixing of heat is the dispersive term. This dispersive term has a dispersion coefficient that can be varied to simulate various bay conditions. Since most biologists are interested in mixing patterns in the aquatic environment the thermal model and its dispersion coefficient effects would be enlightening for large scale effects.

\section{APPROACH}

Kurt Hess (4) has adapted Leendertse's (1) [pronounced: lee an der' see] two-dimensional, depth averaged model to simulate hydrodynamics of bay. The hydrodynamic model is a computer program that formulates the fluid equations of linear momentum and continuity into a usable finite difference scheme applicable for use on a high speed computer.

The fundamental equations of motion and energy can be formulated into a general finite difference scheme. The specific technique for arranging spatial and time variables are many in number. Anyone is free to choose a method that he feels will work satisfactorily, but the burden of proof 
is on him. Grimsrud (6) conducted an investigation of various methods as well as this author to see if better methods were available for modeling Narragansett Bay. A general summary for hydrodynamic, non-reacting concentration models is presented in Table 1.4 .

Masch et al (57) have followed an approach similar to Leendertse (3) with a slightly different spatial arrangement for grid depth specification. The governing equations are explicitly formulated using forward difference substitutions for the partial derivatives in the time varying concentration-salinity model.

Pritchard (5, Chapter II) develops the equations for a three dimensional dynamic concentration model for an estuary, which includes isobaric slope for the pressure force term. The equations of linear momentum, continuity, salt and energy when applied with phenomenological relations can only be solved by an interative numerical approach given reasonable spatial distributions of velocity, energy and salt. Hess (59) is developing a three dimensional time averaged model that uses tidally averaged values from the two dimensional vertically averaged hydraulic model. This model has six levels that are equally spaced for all grid depth specifications to determine vertical structure. 
MODEL

Assumptions

Application

Influence

Time Scale

Comments
Uniformly vertically mixed water conditions

Estuary-fresh and tidal inlets

wind included

Long Term Lasting Effect

Steady state and time varying salinity capability, 300 grid, prototype available for verification
Vertically averaged with Vertically averaged relative pressure surface slope and cross product of turbulent velocity fluctuation

Estuary-fresh and tidal inlets

wind included

Short or Long Term

No application presented

Jamaica Bay, 2000 components using distribution functions for vertical column

Estuary-fresh and tidal inlets

wind included

Short or Long Term Grids 
MODEL

\section{Boundary}

condition

\section{Reflective boundary}

condition for zero

concentration gradient

at fixed boundary

Computer Time

Dispersion

coefficient

Verification

Error Magnitude
$2 \min . /$ tidal cycle

2, $500 \mathrm{ft}^{2} / \mathrm{sec}$ (Very High)

2-3 ppt, $10-20 \%$ tidal estimation
Not Applicable

Computational

scheme formulates grids next to land as boundary value for row or column

Not Applicable

Realistic

(5-40 $\left.\mathrm{ft}^{2} / \mathrm{sec}\right)$

Not Applicable

$1-2^{\circ} \mathrm{C}, 10 \%$ tidal
$30 \mathrm{~min} . / \mathrm{tidal}$ cycle

Realistic

(5-40 $\left.f t^{2} / \mathrm{sec}\right)$

estimation

TABLE 1.4.b. HYDRODYNAMIC CONCENTRATION MODELS 
Taking a more conservative approach, Pritchard, reduced the three dimensional problem to a two dimensional vertically averaged model that calculates the horizontal velocity components and a time varying slope.

The conservation of dissolved constituent equation is presented and interfaced in development of a solution technique.

The two dimensional formulations are similar to equations used by Leendertse (3) and by Masch et al (57) with two significant differences. The first variance is the inclusion of the slope term for the pressure surfaces due to horizontal variation in density (salinity). The second is the ensemble average of the turbulent velocity fluctuations time averaged for the squared velocity components, $\left(u^{\prime}\right)^{2}$ in $x$ and $\left(v^{\prime}\right)^{2}$ in $y$ direction, and also their cross product ( $\left.u^{\prime} v^{\prime}\right)$. According to Pritchard, the inclusion of these terms will improve model accuracy for a velocity field with a predominant sign.

Since Leedertse (3) had proven workability of a twodimensional, depth averaged water quality model with realistic dispersion, it was decided to convert this into a thermal model that required the hydrodynamic input currently available. This coordination between hydrodynamic and thermal models greatly facilitated implementation and 
eventually led to improvements in boundary condition formulation for the hydrodynamic model.

If a pioneering effort had been undertaken in the development of a different hydrodynamic-thermal model formulations it would have taken considerably more time and effort just to prove feasibility, not to mention prediction ability. One of the major problems in model development is turn around time of one day and slow computational speed of the present computer system at the University of Rhode Island.

It should be made quite clear that the depth averaged model does have limitations if one is very concerned with near field buoyant plumes. The physical dimensions of the bay necessitated a large grid size of about 1000 yards which, in general, makes the input box the entire near field. Yet, with temperature rises of several degrees around the source one would expect stratification in the surrounding grids. This stratification is mixed into the entire depth and the grid displays the average temperature required by the total heat content in the box for any tidal condition. 


\section{E. VERIFICATION}

As previously mentioned, the year 1957 was chosen for verification purposes. The model will be run under identical meterological and boundary conditions for an initial constant temperature field of $21^{\circ} \mathrm{C}$ during the period of verification. In most instances, the data was taken at isolated points either at or near surface water at various times during the day. Keeping this in mind, grid temperature discrepancies between the data points are to be expected, but spatial agreements should be reasonable.

Ideally, a dozen continuous temperature recorders could be dispersed around the bay to measure both vertical and horizontal temperature distributions to verify validity of model beyond question.

\section{F. CONCLUDING REMARKS}

The lengthy discourse on the temperature data for Narragansett Bay provides information for future development of model predictive ability.

The work presented in the following sections will elaborate on the various inputs of model development and implementation. The power plant site was chosen at Rome Point because it appears to be a reasonable first choice 
even though the proposed atomic plant seems doubtful at this time. The experimental runs for the various boundary conditions and siting variables are an outline of the procedure to be followed in making an environmental impact judgement. A comprehensive investigation of power plant siting throughout the bay is beyond the scope of this work. Other applications of the model, such as the salt modeling or biological studies are discussed, but no computer modeling was attempted.

In summary, the thermal model is a very valuable tool that allows the engineer to graphically display natural, natural plus man made and man made temperature fields to serve some useful estuarine requirement. The thermal mödel, in essence, provides the spatial arrangement of water temperatures subject to boundary conditions and source inputs. 


\section{A. INTRODUCTION}

Any modeling procedure is derived from the fundamental equations of nature combined with the pertinent phenomenological relations. The basic differential equations (Bird, 27) to be considered for a Newtonain fluid are as follows: Momentum x:

$$
\begin{aligned}
\frac{\partial u}{\partial t}+u \frac{\partial u}{\partial x}+v \frac{\partial u}{\partial y}+w \frac{\partial u}{\partial z}= & -\frac{1}{e} \frac{\partial p}{\partial x}+f v+\frac{1}{\rho}\left(\frac{\partial \tau}{\partial x} x x\right. \\
& \left.+\frac{\partial \tau}{\partial y} x y+\frac{\partial \tau}{\partial z} x z\right)
\end{aligned}
$$

Momentum $y:$

$$
\begin{aligned}
\frac{\partial v}{\partial t}+u \frac{\partial v}{\partial x}+v \frac{\partial v}{\partial y}+w \frac{\partial v}{\partial z}= & -\frac{1}{\rho} \frac{\partial p}{\partial y}-f u+\frac{1}{\rho}\left(\frac{\partial \tau}{\partial x} y x\right. \\
& \left.+\frac{\partial \tau}{\partial y} y y+\frac{\partial \tau}{\partial x} y z\right)
\end{aligned}
$$

Momentum z:

$$
\begin{aligned}
\frac{\partial w}{\partial t}+u \frac{\partial w}{\partial x}+v \frac{\partial w}{\partial y}+w \frac{\partial w}{\partial z}= & -\frac{1}{\rho} \frac{\partial p}{\partial z}-g+\frac{1}{e}\left(\frac{\partial \tau}{\partial x} z x\right. \\
& \left.+\frac{\partial \tau}{\partial y} z y+\frac{\partial \tau}{\partial z} z\right)
\end{aligned}
$$

where

f - Coriolis parameter, $2 \Omega \sin \phi$

$\tau_{i j}$ - shear stress tensor,

g - gravitational acceleration, $\mathrm{ft}^{2} / \mathrm{sec}$

$\rho$ - density of fluid, $1 b_{m} / \mathrm{ft}^{3}$ 
conservation of mass $(\rho=$ constant):

$$
\frac{\partial u}{\partial x}+\frac{\partial v}{\partial y}+\frac{\partial w}{\partial z}=0
$$

where

$$
\begin{aligned}
& u(x, y, z, t)=\text { velocity in the } x \text { direction } \\
& v(x, y, z, t)=\text { velocity in the } y \text { direction } \\
& w(x, y, z, t)=\text { velocity in the } z \text { direction } \\
& p(x, y, z, t)=\text { pressure }
\end{aligned}
$$

concentration or energy equation:

$$
\begin{gathered}
\rho c_{p}\left(\frac{\partial c}{\partial t}+u \frac{\partial c}{\partial x}+v \frac{\partial c}{\partial y}+w \frac{\partial c}{\partial z}\right)-\frac{\partial}{\partial x}\left(e_{x} \frac{\partial c}{\partial x}\right) \\
-\frac{\partial}{\partial y}\left(e_{y} \frac{\partial c}{\partial y}\right)-\frac{\partial}{\partial z}\left(e_{z} \frac{\partial c}{\partial z}\right)= \\
\text { Terms }
\end{gathered}
$$

where

$$
\begin{aligned}
& c_{p} \text { - specific heat of water in } B t u / 1 b_{m}-O_{F} \\
& e_{i} \text { - the diffusion tensor - molecular and viscous } \\
& s(x, y, z, t) \text { - source term in } B t u / \mathrm{ft}^{3}-\mathrm{sec} \\
& c \text { - non-reacting substance }
\end{aligned}
$$

In this thesis, the dissipation terms are neglected.

At present (2) computational techniques are inadequate to deal with three dimensional fluid flow problems. The approach here is to reduce the equations to a two dimensional system by vertically averaging the $u, v$, and $c$ 
components of the fundamental equations. This is shown in Equation 2.6, in symbolic form

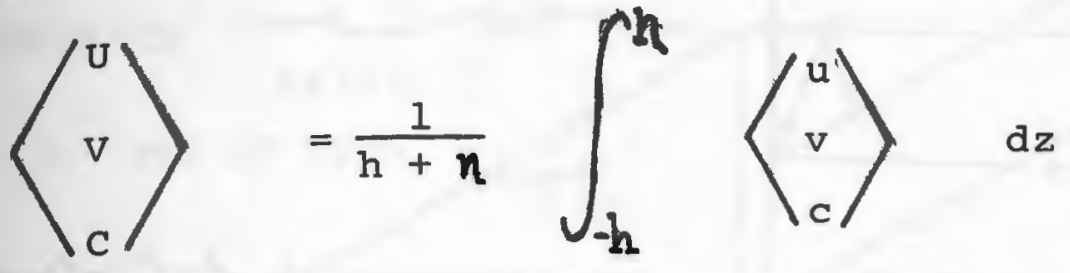

where $\eta$, surface elevation, and $h$, bottom depth, are shown in Figure 2.1. In general, these variables have a distinct vertical distribution. For example,

$$
\begin{aligned}
& u=U\left[1+E_{u}(z)\right] \\
& v=v\left[1+E_{v}(z)\right]
\end{aligned}
$$

where $\mathrm{E}_{\mathrm{u}}$ and $\mathrm{E}_{\mathrm{v}}$ are distribution coefficients.

In order to simplify equations 2.1 to 2.3 , we make two general assumptions. First, that the magnitude of the vertical velocity is much less than the magnitude of horizontal velocity components. Secondly, that the partial derivatives, $\partial / \partial x$ and $\partial / \partial y$ are much less than the vertical term, $\partial / \partial z$. These assumptions reduce equations 2.1 to 2.3 as follows:

$$
\begin{aligned}
& \frac{\partial u}{\partial t}+u \frac{\partial u}{\partial x}+v \frac{\partial u}{\partial y}=-\frac{1}{\rho} \frac{\partial p}{\partial x}+f v+\frac{1}{\rho} \frac{\partial \tau_{x z}}{\partial z} \\
& \frac{\partial v}{\partial t}+u \frac{\partial v}{\partial x}+v \frac{\partial v}{\partial y}=-\frac{1}{\rho} \frac{\partial p}{\partial y}-f u+\frac{1}{\rho} \frac{\partial \tau_{y z}}{\partial z}
\end{aligned}
$$




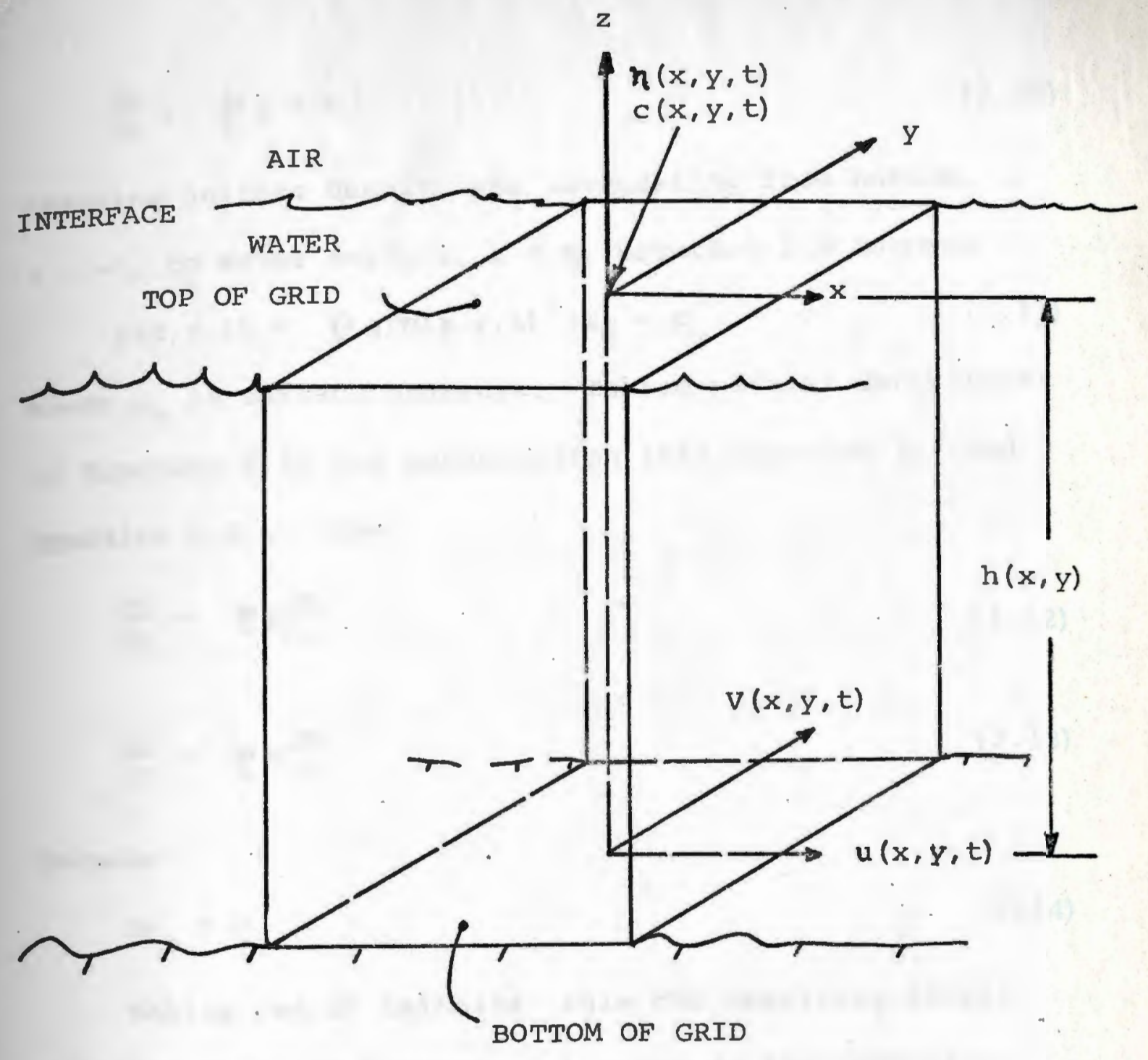

$h(x ; y)$ - Average grid depth

$n(x, y, t)$ - Tidal variation in grid (plus or minus)

FIGURE 2.1. COORDINATE AND VARIABLE SCHEME FOR THE MODEL 


$$
\frac{\partial p}{\partial z}+\rho g=0
$$

Assuming uniform density and integrating from bottom, $z=-h$, to water surface, $z=n$, Equation 2.9 becomes

$$
p(x, y, t)=\rho g[n(x, y, t)-z]+p_{0}
$$

where $p_{0}$ is surface pressure. Taking partial derivatives of Equation 2.10 for substitution into Equation 2.7 and Equation 2.8 we have

$$
\begin{aligned}
& \frac{\partial p}{\partial x}=\rho \frac{\partial \boldsymbol{n}}{\partial x} \\
& \frac{\partial p}{\partial y}=\rho \frac{\partial \boldsymbol{n}}{\partial y}
\end{aligned}
$$

because

$$
D p_{\circ}=0
$$

Making use of Leibnitz' rule the resulting simplification shown by Grimsrud (6) gives us the hydraulic equations in the following form

$$
\begin{aligned}
& \frac{\partial U}{\partial t}+U \frac{\partial U}{\partial x}+v \frac{\partial U}{\partial y}=-g \frac{\partial n}{\partial x}+f V+\frac{1}{\rho(h+n)}\left(\tau_{s x}-\tau_{b x}\right) \\
& \frac{\partial v}{\partial t}+U \frac{\partial v}{\partial x}+v \frac{\partial v}{\partial y}=-\frac{\partial n}{\partial y}-f U+\frac{1}{\rho^{(h+n)}}\left(\tau_{s y}-\tau_{b y}\right)
\end{aligned}
$$




$$
\frac{\partial n}{\partial t}+\frac{\partial(H U)}{\partial x}+\frac{\partial(H V)}{\partial x}=0
$$

where

$$
\begin{aligned}
& \tau_{\mathrm{bi}}-\text { bottom shear stress } \\
& \boldsymbol{\tau}_{\mathrm{si}}-\text { surface shear stress } \\
& \mathrm{H}=\mathrm{h}+\mathrm{n}
\end{aligned}
$$

with boundary condition

$$
w(\boldsymbol{n})=u(\boldsymbol{n}) \frac{\partial \boldsymbol{n}}{\partial x}+v(\boldsymbol{n}) \frac{\partial \boldsymbol{n}}{\partial y}+\frac{\partial \boldsymbol{n}}{\partial t}=\frac{D \boldsymbol{n}}{D t}
$$

The bottom stresses in the $\mathrm{x}$ and $\mathrm{y}$ directions are approximated by the Chezy relationship of the form

$$
\begin{aligned}
& \tau_{b x}=\rho g u \frac{\left(u^{2}+v^{2}\right)^{1 / 2}}{c_{z}^{2}} \\
& \tau_{b y}=\rho g v \frac{\left(u^{2}+v^{2}\right)^{1 / 2}}{c_{z}^{2}}
\end{aligned}
$$

where $c_{z}=$ Chezy coefficient $\left[(8 \mathrm{~g} / \text { friction factor })^{1 / 2}\right]$ and is a function of bottom roughness and depth and calculated from

$$
c_{z}=\frac{1.49}{N}\left(h+n^{1 / 6}\right.
$$

with N - Manning's formula, (len) $1 / 6$ 
The basic model equations now contain all the phenomenological relationships necessary for conversion to a finite difference scheme. Equation 2.5, as yet unmodified, is now time averaged to eleminate the turbulent fluctuations associated with the flow. We introduce, for a vertically averaged substance

$$
c=\frac{1}{h} \int_{h}^{h} c_{a} d z
$$

where

$$
c_{a}(z)=C\left[1+E_{a}(z)\right]
$$

and $\mathrm{E}_{\mathrm{a}}$ is the density distribution function.

Bearing definitions 2.21 and 2.22 in mind we have

$$
\int_{\mathfrak{h}_{h}}^{h} E_{a}(z) d s=0
$$

which actually defines the density distribution function.

Vertical integration of Equation 2.5 and use of

Leibnitz' rule in conjunction with Equations 2.21 and 2.22 we have:

$$
\begin{aligned}
\frac{\partial H C}{\partial t}+ & \frac{\partial\left[\left\langle 1+E_{u}(z) E_{a}(z)\right\rangle U C\right]}{\partial x}+\frac{\partial\left[\left\langle 1+E_{v}(z) E_{a}(z)\right\rangle V C\right]}{\partial y} \\
& =\frac{\partial\left\langle e_{x} \frac{\partial c_{a}}{\partial x}\right\rangle}{\partial x}+\frac{\partial\left\langle e_{y} \frac{\partial c_{a}}{\partial y}\right\rangle}{\partial y}+\frac{\partial\left\langle e_{z} \frac{\partial c_{a}}{\partial z}\right\rangle_{H S}}{\partial z}+H
\end{aligned}
$$


Assuming that Narragansett Bay is well mixed imposes the condition that no differences in mass concentrations exist over vertical structure.

$$
E_{a} \cong 0
$$

Applying the above considerations to the model, Equation 2.24 reduces to

$$
\frac{\partial H C}{\partial t}+\frac{\partial(H U C)}{\partial x}+\frac{\partial(H V C)}{\partial y}=\frac{\partial}{\partial x}\left(H_{x} \frac{\partial C}{\partial x}\right)+\frac{\partial}{\partial y}\left(H D_{y} \frac{\partial C}{\partial y}\right)+H S
$$

where $D_{X}$ and $D_{Y}$ are dispersion coefficients.

In order to develop relations to express adequately

these dispersive terms a brief attempt will be made to investigate the mechanisms of dispersion.

\section{B. DISPERSION}

Dispersion of substances is caused by the mean flow velocity differences that occur in all directions. These variations of velocity, greater in the deeper portions and smaller in the shallow areas, cause stretching and spreading of substances in a non-homogenous fluid. Turbulent diffusion is primarily responsible for the crosssectional spreading that tends to transfer constituents 
from the areas of higher concentration to those of lower concentration.

considering one-dimensional steady flow the longitudinal dispersion coefficient found by Elder (28) is

$$
D_{1}=5.93 \mathrm{Hu} *
$$

where $u^{*}$ - friction velocity (shear stress velocity)

The friction velocity is related to the mean velocity by the relation:

$$
u^{*}=\left(\frac{\mathrm{bx}}{\mathrm{e}^{1 / 2}}\right)^{1 / 2} \mathrm{~g}^{1 / 2} \mathrm{c}_{\mathrm{z}}^{-1}
$$

where $\tau_{b x}$ - bed shear due to $u$, the uniform flow velocity Now combining Equations 2.27 and 2.28 results in

$$
\mathrm{D}_{1}=5.93 \mathrm{Hug}^{1 / 2} \mathrm{C}_{\mathrm{z}}^{-1}
$$

For the lateral turbulent dispersion, perpendicular to the mean flow, Elder (28) obtained:

$$
D_{y}=0.23 \mathrm{Hu} *
$$

oddly enough, this formulation, designed specifically for river flow, underestimated the longitudnal dispersion for river flow. For the slowly time varying flow conditions such as Narragansett Bay it is considered in better agreement. In addition, the longitudinal dispersion is influenced by wind generated local circulation and wave 
action (Wilson \& Masch, 29). Rather naturally, the lateral turbulent diffusion is affected by the same wind and wave processes.

since the longitudinal dispersion coefficient is generally larger, except around a source term than the lateral coefficient, the dispersion is anisotropic. To make the model suitable for arbitrary direction and the influence of large scale substance variations from grid to grid, the general expression for dispersive transport becomes

$$
\frac{\partial\left[\left(E_{x x} \frac{\partial c}{\partial x}+E_{x y} \frac{\partial c}{\partial y}\right) H\right]}{\partial x}+\frac{\partial\left[\left(E_{y x} \frac{\partial c}{\partial y}+E_{y y} \frac{\partial c}{\partial x}\right) H\right]}{\partial y}
$$

where the dispersion coefficients $E_{x x^{\prime}} E_{X Y^{\prime}} E_{Y X}$ and $E_{Y Y}$ are dependent on the current magnitude and direction. The relationship 2.31 more closely models the physical bay situation but requires four dispersion coefficients which are at least as difficult to determine as the two included in Equation 2.26. In addition the coupling of the longitudinal and lateral diffusion coefficient makes the compution cumbersome because it would couple the $x$ and $y$ conservation equations requiring at least twice the effort to solve substance distribution. Realizing the computational limitations of available computer this approach was deemed unacceptable. 
A possible alternate approach by Holley (30) is to compare magnitudes of mass transport by longitudinal dispersion versus advective transport. Since the ratio of dispersion over advection is generally very small, except around outfall areas where steep gradients do exist, the general procedure is to assume that variations in the longitudinal dispersion will not affect the solution. The net result of the above discussion is to assume that the process is isentropic in the sense that there is uncoupled lateral and longitudinal dispersion which are independent functions of velocity, Chezy coefficient and depth in one coordinate direction.

Finally, after all various alternatives were evaluated, the formulation in Equation 2.29 was considered the best choice and is currently being used in the model.

This concludes the introduction of basic differential equations with phenomenological relations as shown below, as the basic equation set for the forthcoming finite difference formulation.

$$
\frac{\partial U}{\partial t}+u \frac{\partial U}{\partial x}+v \frac{\partial U}{\partial y}-f v+g \frac{\partial n}{\partial x}+\frac{U\left(U^{2}+v^{2}\right)^{1 / 2}}{c_{z}{ }^{2} H}=0
$$




$$
\begin{aligned}
& \frac{\partial v}{\partial t}+u \frac{\partial U}{\partial x}+v \frac{\partial v}{\partial y}+f u+\frac{\partial \boldsymbol{\eta}}{\partial x}+\frac{v\left(u^{2}+v^{2}\right)^{1 / 2}}{c_{z}{ }^{2} H}=0 \\
& \frac{\partial \boldsymbol{n}}{\partial t}+\frac{\partial \underline{H U}}{\partial \mathbf{x}}+\frac{\partial(H V)}{\partial y}=0 \\
& \frac{\partial(H C)}{\partial t}+\frac{\partial(H U C)}{\partial x}+\frac{\partial(H V C)}{\partial y}=\frac{\partial}{\partial x}\left(5.93 \mathrm{HUg}^{1 / 2} \mathrm{C}_{z}^{-1}\right) \\
& +\frac{\partial}{\partial y}\left(5.93 \mathrm{HUg}^{1 / 2} \mathrm{C}_{z}^{-1}\right)+\mathrm{s}
\end{aligned}
$$

\section{FINITE DIFFERENCE APPROXIMATIONS}

For the solution of the Equations 2.32 to 2.35 the approach of Leendertse (1) will be followed. In this scheme, the variables $\eta, c, v, u, h$ are arranged, with general coordinate system explanation, as shown in Figure 2.2 .

This scheme has the advantage that for the variable operated upon in time there is a centrally located spatial derivative for the linear term. In the $x$-momentum Equation 2.32, the time-derivative of water level $\left(\mathrm{g} \frac{\partial \vec{n}}{\partial \mathbf{x}}\right)$ is an example of this.

In accordance with the semi-implicit method the timestep is split into two halves, and the time-derivative taken over the half time-step. Semi-implicit means solving 


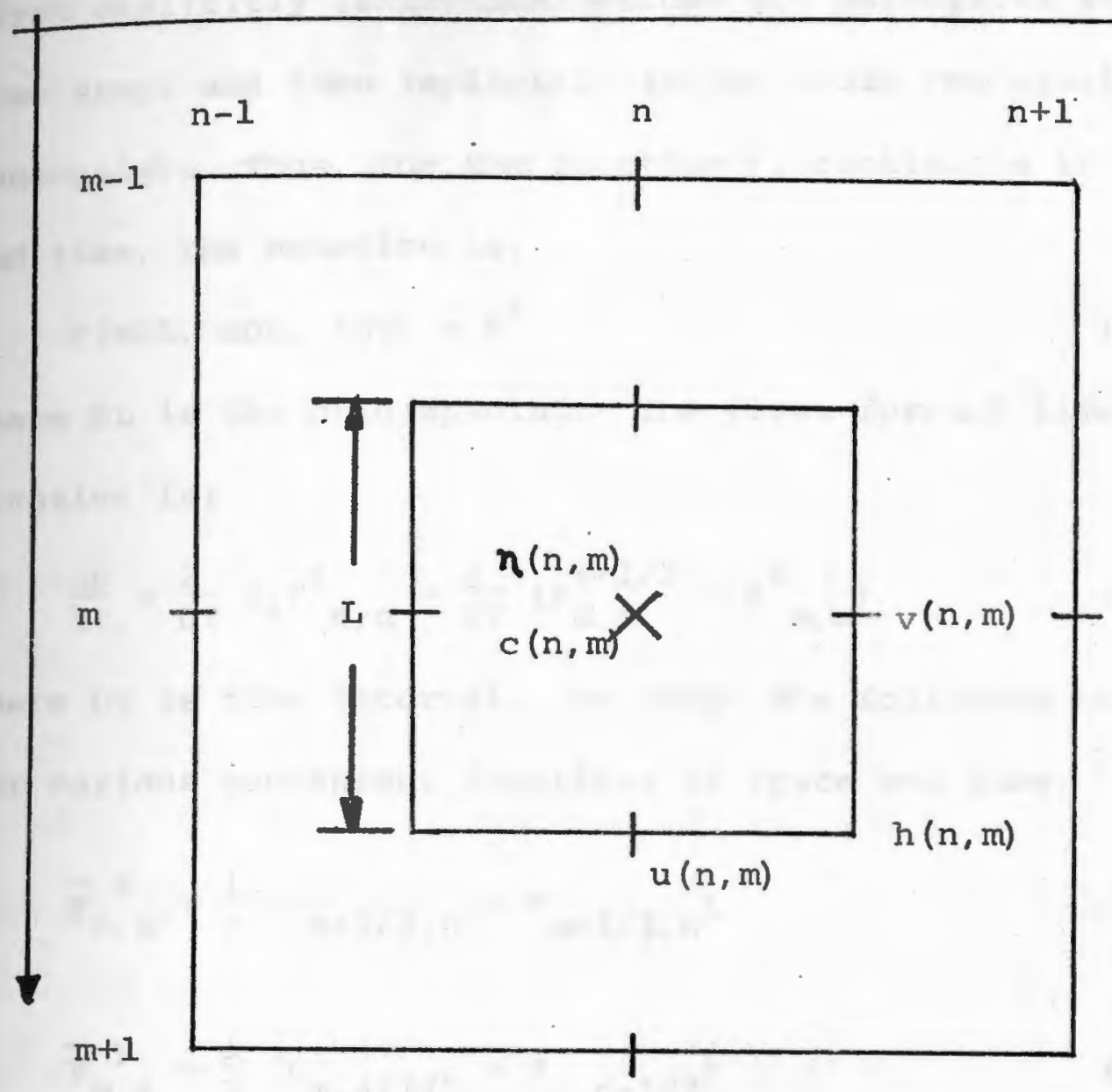

$$
\begin{aligned}
& x_{c}=\left(m-\frac{1}{2}\right) L / 2 \\
& y_{c}=\left(n-\frac{1}{2}\right) L / 2 \\
& \eta_{m, n}=\eta\left(x_{c}, y_{c}\right) \\
& U_{m, n}=u\left(x_{c}+L / 2, y_{c}\right) \\
& v_{m, n}=v\left(x_{c}, y_{c}+L / 2\right) \\
& h_{m, n}=h\left(x_{c}+L / 2, y_{c}+L / 2\right) \\
& c_{m, n}=c\left(x_{c}, y_{c}\right)
\end{aligned}
$$

FIGURE 2.2. SPACE STAGGERED GRID SYSTEM 
first explicitly (individual values are calculated at next time step) and then implicitly (solve whole row simultaneously). Thus, for the function F, continuous in space and time, the notation is:

$$
F(m D L, n D L, t D T)=F^{t}
$$

where DL is the grid spacing. The first forward time derivative is:

$$
\frac{\partial F}{\partial t}=\frac{2}{D T} \delta_{t} F_{m, n}^{t}=\frac{2}{D T}\left(F_{m, n}^{t+l / 2}-F_{m, n}^{t}\right)
$$

where DT is time interval. We adopt the following notation for various convenient functions of space and time:

$$
\begin{aligned}
& \bar{F}_{m, n}^{x}=\frac{1}{2}\left(F_{m+1 / 2, n}+F_{m-1 / 2, n}\right) \\
& \bar{F}_{m, n}^{Y}=\frac{1}{2}\left(F_{m, n+1 / 2}+F_{m, n-1 / 2}\right) \\
& \delta_{x} F_{m, n}=\left(F_{m+1 / 2, n}-F_{m-1 / 2, n}\right) \\
& \delta_{y} F_{m, n}=\left(F_{m, n+1 / 2}-F_{m, n-1 / 2}\right) \\
& \delta_{x}^{*} F_{m, n}=\frac{1}{2}\left(F_{m+1, n}-F_{m, n-1}\right) \\
& \delta_{y}{ }^{*} F_{m, n}=\frac{1}{2}\left(F_{m, n+1}-F_{m, n-1}\right) \\
& \bar{F}_{m, n}=\frac{1}{4}\left(F_{m+1 / 2, n+1 / 2}+F_{m-1 / 2, n+1 / 2}+F_{m+1 / 2, n-1 / 2}\right. \\
& \left.\quad+F_{m-1 / 2, n-1 / 2}\right)
\end{aligned}
$$


The momentum and conservation of mass equations may then be transformed into finite-difference equations and solved for the new value in time for a total of eight equations, four for each time step. The equations are given in Append ix B and D.

The solution of Equations B.1 to B.6 (Appendix B and D) is called by Leendertse a "multi-operation" method, which is a modification of the "leap-frog" method. In the first half time-step, values of $U$ and $\boldsymbol{n}$ are computed implicitly along a grid row in the $\mathrm{x}$-direction at the time $(t+1 / 2)$ DT. Then $V$ is computed at the same time level explicitly. In the second half time-step, $\mathrm{V}$ and $\mathrm{n}$ are computed implicitly at $(t+1)$ DT along grid rows in the $y$-direction, after which $U$ is calculated explicitly at $(t+1) \quad D T$.

In the first half of the time-step, the time derivative of $\mathrm{U}$ in the $\mathrm{x}$-momentum equation is approximated by a backward difference:

$$
\frac{\partial}{\partial t}\left(U^{t+1 / 2}\right)=\frac{2}{D T}\left(U^{t+1 / 2}-U^{t}\right)=f \mathrm{cn}\left(n^{t+1 / 2}\right)
$$

In the second half time-step, a forward difference is used:

$$
\frac{\partial}{\partial t}\left(U^{t+1}\right)=\frac{2}{D T}\left(U^{t+1}-U^{t+1 / 2}\right)=f \operatorname{len}\left(n^{t+1 / 2}\right)
$$


Thus, over a full time-step, the time derivative is a central difference with respect to the water level:

$$
\frac{\partial U}{\partial t}=\frac{U^{t+1}-U^{t}}{D T}=\operatorname{fen}\left(n^{t+1 / 2}\right)
$$

This composite relation defines the leap-frog method.

The set of difference equations for the implicit timestep on $U$ and $\boldsymbol{n}$ may be written as

$$
\text { [A] }\left(U^{t+1 / 2} \text { or } n^{t+1 / 2}\right)=(b)
$$

where $[A]$ is a tridiagonal matrix and (b) is a column vector of known terms. Equation 2.48 may then be solved by Gaussian elimination (see Mitchell (24) for example) for the new values of $U$ and $\eta$ at $(t+1 / 2)$. A similar procedure is used for the second implicit operation involving $\mathrm{V}$ and $\boldsymbol{n}$ at time $(t+1)$. The details are given in (Hess (4), Appendix $\mathrm{B}$ and $\mathrm{C}$ ).

\section{DIFFERENCING COMMENTS}

D.1. Stability

An extensive analytical treatment of stability has been given by Leendertse $(1,2)$ with further comments by Grimsrud (6), Hess (4), and Spaulding (16). Whenever a problem in the physical values produced by a computational scheme occurs by a model user the word 'stability' is gen- 
erally used. Instability may be defined as the unlimited amplifications of errors. This can occur because of the dissimilar nature of upstream or central differencing or the simplified unidimensional dispersion coefficient used with a source with significant temperature gradients.

\section{D.2. Boundary Conditions}

In Figure 2.3, the general boundary conditions format is outlined for the model. Hess (4) summarized the difficulty encountered by Leendertse (I) when handling the spatial derivaties, Equations 2.41 and 2.42. Briefly stated, the convective terms encountered at land boundaries are dropped in the solution of the momentum equation. This effect causes an inaccuracy in the hydraulic model and will create computational problems for a source term with a low dispersion coefficient if the substance varies significantly from grid to grid. Some model users adhere to the policy that the upstream differencing technique (Appendix E), which enhances the dispersion coefficient a thousand fold in the model, should be used. In essence, the model creates far field conditions for a dispersed substance in what is considered the intermediate zone.

A technique that might be used (Spaulding, 16) is an upstream differencing technique around a source and conver- 
IOCATION

source (Power

plant)

Rivers

Mt. Hope Bay

\section{Tidal Flow Rate}

(Variable)

$\mathrm{YDS}^{3} / \mathrm{SEC}$

Tidal Height

(Variable)

YDS
MODEL INPUT

Velocity*Concentration

$(\mathrm{YDS} / \mathrm{SEC})-{ }^{{ }^{\circ} \mathrm{C}}$

Velocity*Concentration at Boundary

$(\mathrm{YDS} / \mathrm{SEC})-{ }^{\circ} \mathrm{C}$

Velocity*concentration at Boundary

$(Y D S / S E C)-{ }^{\circ} \mathrm{C}$

Velocity*Concentration at Boundary

$(\mathrm{YDS} / \mathrm{SEC})-{ }^{\circ} \mathrm{C}$

FIGURE 2.3. BOUNDARY CONDITIONS 
sion to a central differencing scheme (see Appendix E) at some specified distance from source discontinuity. This author prefers, if necessary, to use a formulation suggested by Kurt Hess that would naturally enhance dispersion coefficient for large discontinuities of concentration in the model near a source. This is then an alternative to arbitrarily increasing the dispersion coefficient in the upstream differencing technique, for the entire bay, as shown below.

$$
\begin{aligned}
& D_{m+1 / 2}=D\left[1+\frac{\left(c_{m+1}-c_{m}\right)^{2}}{\left(c_{m+1}+c_{m}\right)^{2}} E\right] \\
& D_{m-1 / 2}=D\left[1+\frac{\left(c_{m}-C_{m-1}\right)^{2}}{\left(c_{m}+c_{m-1}\right)^{2}} E\right]
\end{aligned}
$$

where

$$
\begin{aligned}
& \text { D - is the normal model dispersion coefficient } \\
& \text { E - arbitrary constant of order one. }
\end{aligned}
$$

This means that the centered spacial derivative can be used when the adjacent concentrations are different without having computational problems for suitable values of $\mathrm{E}$. This technique was not used here. 
D.3. Computational Differences for Central and Upstream Differencing

An explanation of the computational problems with regard to upstream and central differencing is now necessary. According to Leendertse (2), certain difficulties are encountered upstream from sources with respect to the convective term. Consider Figure 2.4, and the case of a centered spatial derivative $(A=B=1 / 2)$. Suppose the concentration at $m+1$ is unity, and zero elsewhere. Applying the finite-difference equation at M leads to a decrease

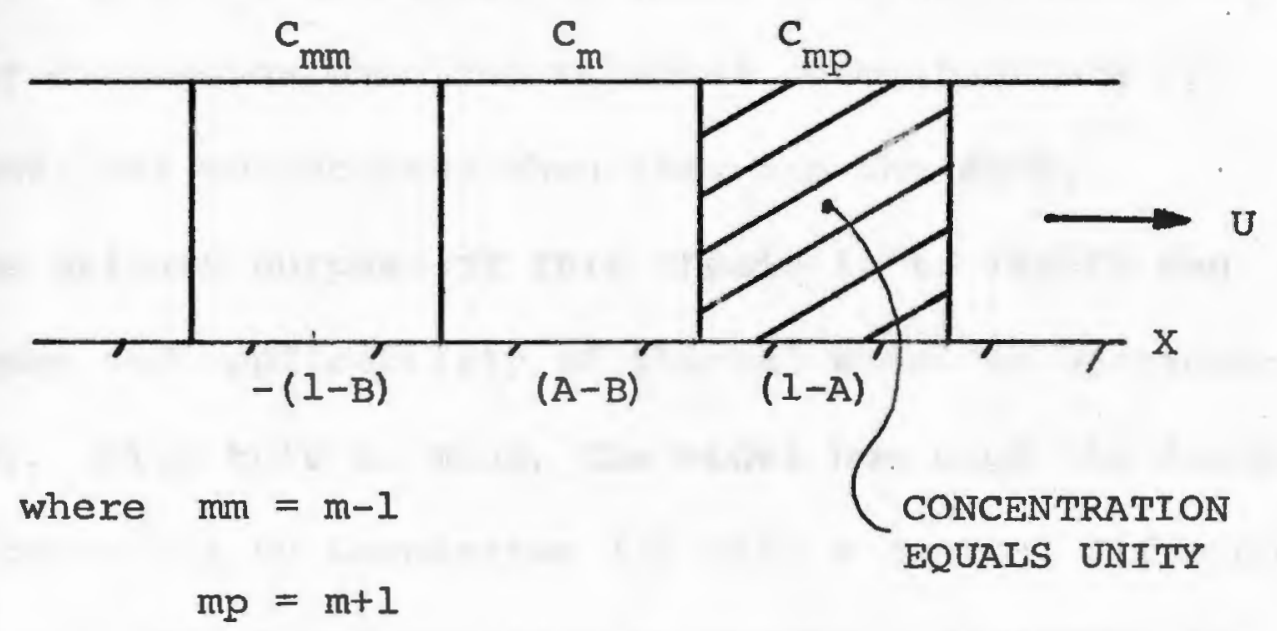

FIGURE 2.4. ONE DIMENSIONAL CONCENTRATION SCHEME

in concentration $c_{m}$. The remedy is to use upstream dif- 
ferencing $(B=0, A=1)$ at grid $m($ or $B=1, A=0$ if $u<$ 0) so that concentration at $m$ will then remain zero.

A few calculations will show that if upstream differencing is used only at $m$, mass will not be conserved elsewhere. Therefore, for consistency, upstream differencing would have to be used everywhere. However, as shown by Leendertse (1, p. 34), this approximation results in an effective increase in the dispersion coefficient.

One possible alternative is to use the centered spatial derivative, and increase the dispersion coefficient artificially as shown before in Equation 2.49, which allows a higher dispersion when the adjacent concentrations are different, but no increase when they are the same. The primary purpose of this thesis is to verify the techniques and applicability of thermal model to Narragansett Bay. With this in mind, the model now uses the formulation conceived by Leendertse (3) with a central differencing scheme. The final decision on whether adjustment in the present dispersion coefficient, using for instance Equation 2.49, will occur after an evaluation of the results. 
III. TEMPERATURE AND AIR WATER INTERFACE BOUNDARY CONDITIONS AND VERIFICATION DATA RELATIONSHIPS

\section{A. AIR WATER INTERFACE-SURFACE HEAT TRANSFER PROCESSES}

The literature, $(5,9,11,12,15,17,25)$, has

treated the heat transfer rate at air-water interface as a formulation of a net heat flux equation which is composed of specific transfer terms by distinguishing air, water and air-water terms.

Figure 3.1 shows the term by term formulation of the heat transfer processes which control the water temperature at the air-water interface. Figure 3.2 shows general temperature, pressure and velocity profiles expected at the interface.

The general continuity equation for the interface is:

$$
\frac{\partial}{\partial t}\left(m_{c v}\right)=\int d w_{\text {in }}-\int d w_{\text {out }}
$$

where

$$
\begin{aligned}
& t \text { - time } \\
& c v \text { - refers to the control volume in Figure } 3.1
\end{aligned}
$$

Since the volume of the control volume is assumed small

$$
m_{c V} \cong 0
$$

Equation (3.1) bécomes) (see Figure 3.1)

$$
0=w_{w}-w_{a}
$$




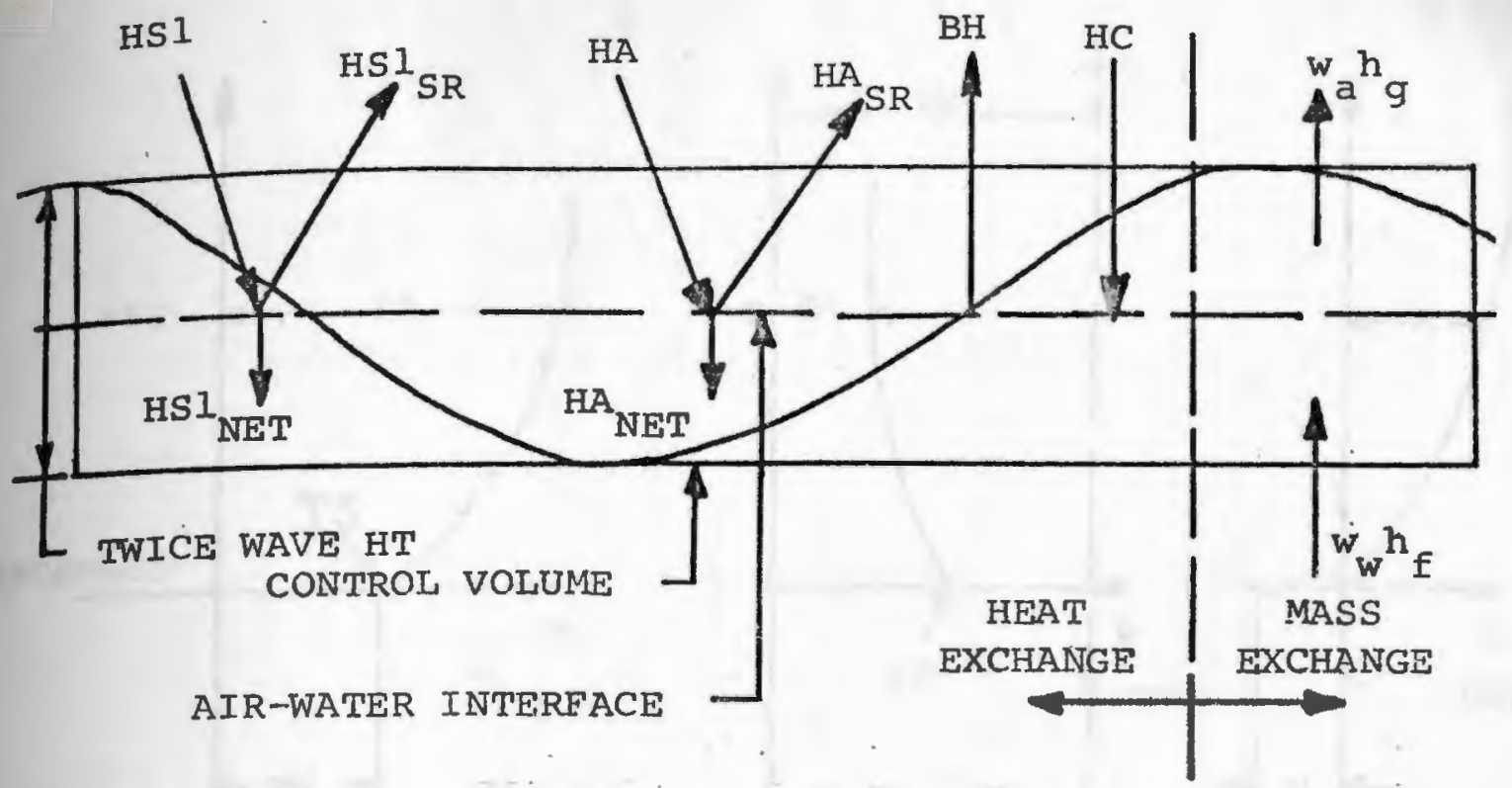

HS1 - incident solar radiation heat transfer rate (HTR)

HSI $_{S R}$ - reflected solar radiation HTR

$\mathrm{HSI}_{\mathrm{NET}}=\mathrm{HSI}-\mathrm{HSI}_{\mathrm{SR}}$

HA - incident atmospheric radiation HTR

${ }_{\mathrm{H}}^{\mathrm{HA}}$ - reflected atmospheric radiation HTR

${ }_{\mathrm{HET}}^{\mathrm{HA}}=\mathrm{HA}-\mathrm{HA}_{\mathrm{SR}}$

BH - back radiation HTR from surface

HC - conduction heat transfer rate from atmosphere side of interface conversion

$w_{a}$ - evaporation mass flow rate, atmosphere side of interface

$w_{w}$ - evaporation mass flow rate, water side of interface

$h_{f}$ - enthalpy, saturated liquid state

$\mathrm{h}_{\mathrm{g}}$ - enthalpy, saturated vapor state

FIGURE 3.1. SCHEMATIC, SURFACE HEAT TRANSFER PROCESS

PER UNIT AREA 

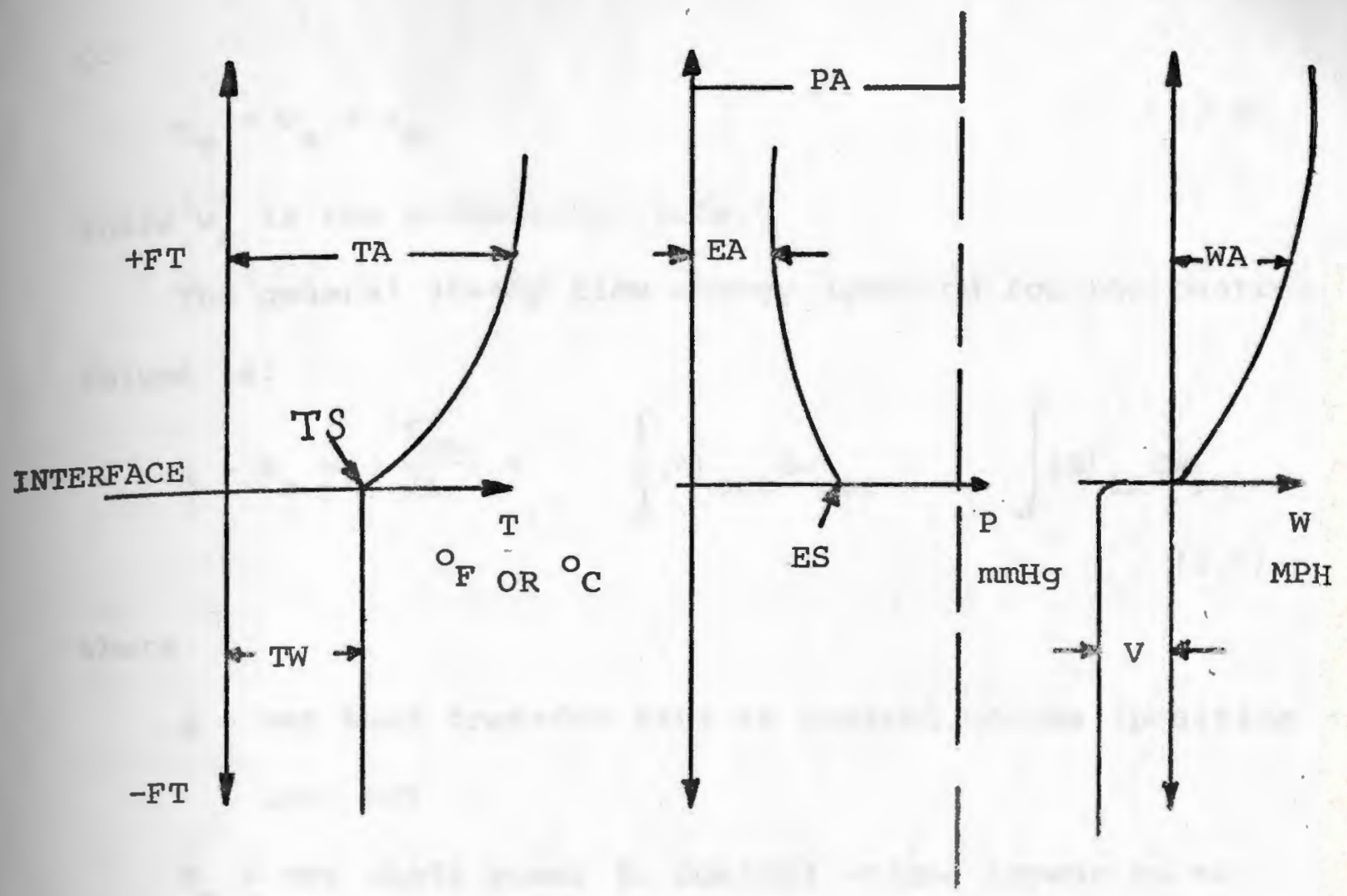

TA - temperature of air.

TS - temperature surface water

$\mathrm{TW}=\mathrm{TS}$ - water temperature, constant for depth of grid

EA - air vapor pressure, function relative humidity, TA

ES - saturated vapor pressure, function of TW

PA-atmospheric pressure

WA - wind velocity in $\mathrm{MPH}$

V - water velocity constant for depth of grid, assumed independent of wind velocity

FIGURE 3.2. TEMPERATURE, PRESSURE AND VELOCITY PROFILES NEAR INTERFACE 
or

$$
w_{w}=w_{a}=w_{e}
$$

where $w_{e}$ is the evaporation rate.

The general steady flow energy equation for the control volume is:

$$
q-P_{x}=\left(\frac{\partial E}{\partial t}\right)+\int(A) \text { out }{ }^{d w} \text { out }-\int(A){ }_{\text {in }} d w_{\text {in }}
$$

where

$q$ - net heat transfer rate to control volume (positive into $\mathrm{cv}$ )

$P_{x}$ - net shaft power to control volume (power to external elements from cv positive)

E - energy inside control volume

$A=\left(h+\frac{z^{2}}{g}+g z\right)$

h - enthalpy

V - velocity

g - acceleration of gravity

$\mathrm{z}$ - height in gravitational field above arbitrary level

Since mass in conserved, as shown in Equation 3.2,

$$
\mathrm{E}_{\mathrm{CV}} \cong 0
$$

Also for conditions in Figure 3.1

$$
\mathrm{P}_{\mathrm{X}}=0
$$




$$
\begin{aligned}
& v=0 \\
& z=0
\end{aligned}
$$

Equation 3.5 with substitution of $3.6,3.7 a, 3.7 b$, and

$3.7 \mathrm{c}$ reduces to

$$
q=w_{e}\left(h_{g}-h_{f}\right)
$$

or

$$
q=w_{e} h_{f g}
$$

where $\mathrm{h}_{f g}$ is the latent heat of vaporization evaluated at the surface temperature, TS. Summing heat transfer rates for control volume in Figure 3.1, Equation 3.9 becomes:

$$
\mathrm{HSl}_{\mathrm{NET}}+\mathrm{HA}_{\mathrm{NET}}-\mathrm{BH}+\mathrm{HC}+\mathrm{HTOT}=\mathrm{w}_{\mathrm{e}} \mathrm{h}_{\mathrm{fg}}
$$

where, by definition

$$
\mathrm{HE}=w_{e^{h}}{ }_{f g}
$$

Equation 3.10 becomes

$$
\mathrm{HSl}_{\mathrm{NET}}+{ }_{\mathrm{NET}}-\mathrm{BH}+\mathrm{HC}+\mathrm{HTOT}-\mathrm{HE}=0
$$

or

$$
-\mathrm{HTOT}=\mathrm{HSl}_{\mathrm{NET}}+\mathrm{HA}_{\mathrm{NET}}-\mathrm{BH}+\mathrm{HC}-\mathrm{HE}
$$

Note that $\mathrm{HE}$ is considered an enthalpy flux and not a heat transfer rate. Reviewing sign convention, we see that if the right hand side (RHS) of Equation 3.13 is positive, HTOT is neqative and the heat transfer across the interface is to the water below the interface. If the RHS of 
Equation 3.13 is negative, HTOT is positive and the heat transfer across the interface is from the water below the interface.

A common formulation found in the literature (Edinger and Geyer, 12) is the grouping of water independent heat exchange rates for solar and atmospheric radiation as shown

$$
\mathrm{HR}=\mathrm{HSI}_{\mathrm{NET}}+\mathrm{HA}_{\mathrm{NET}}
$$

In order to be consistent with current usage of $\mathrm{HC}$ and $\mathrm{HE}$ having the same signs in the heat balance, the following change is made:

$$
\mathrm{HC}=-(-\mathrm{HC})
$$

Finally, the equation used in the model is:

$$
\mathrm{HTOT}=\mathrm{HR}-(\mathrm{BH}+\mathrm{HC}+\mathrm{HE})
$$

In summary, the specific formulation of some of these quantified heat exchange rates into functions of model variables that are both physically complex and interrelated poses a challenge. Each net heat transfer rate, as described in the model, will be discussed with regard to literature formulations and current thinking.

\section{B. INCIDENT SOLAR RADIATION HEAT TRANSFER RATE}

When no solar radiation data is available, a common approach (Harleman, 15, 24) is to formulate the solar radi- 
ation heat transfer rate as a function of a solar constant, solar altitude, normalized radius of earth's orbit, atmospheric transmission coefficient, optical air mass and cloudiness. In wonderlich (19) and List (20) equations for calculating these values can be found.

Fortunately for the Narragansett Bay area, Eppley Laboratory in Newport, Rhode Island have been taking continuous readings of net solar energy since the early 1950's. If no data is read in on an hourly basis the model requires the total solar input for that day or HSl. One can determine what hourly variations, HS2, there would be for clear sky conditions by using the following empirical equations derived from actual solar radiation plots throughout the year:

$$
\begin{aligned}
& \mathrm{D}= \mathrm{HSl}(\mathrm{IDY}) /(1.7+(\mathrm{HSI}(\mathrm{IDY})-100 .) / 350 .) \\
& \mathrm{G}= 2 . \mathrm{PI}(\operatorname{TIMEX}-6 .(1 .+.2 \operatorname{EXP}(-3 .(182 .-\mathrm{ABS}(\mathrm{DAY} \\
&-182 .)) / 182 .))) \\
& \mathrm{T}= 24 .(1 .-.2 \mathrm{COS}(2 . \mathrm{PI} \mathrm{DAY} / 365)) \\
& \mathrm{HS} 2(\mathrm{IDY})=\mathrm{D} \mathrm{SIN}(\mathrm{G} / \mathrm{T}) \\
& \mathrm{HSI}(\mathrm{IDY})=17.85 \mathrm{HS} 2(\mathrm{IDY})
\end{aligned}
$$

where

$$
\begin{aligned}
& \text { HSI (IDY) - total solar input for day IDY } \\
& \text { TIMEX = initial starting time }=0 \text { at } 7 \text { a.m. }
\end{aligned}
$$




$$
\text { DAY = IDY = Day of year, e.g., } 14 \text { July is DAY } 195
$$$$
\mathrm{PI}=3.1416
$$

$17.85=0.2 * 24 \frac{\text { hours }}{\text { day }} / 0.27$

0.2 = Eppley Laboratory scale factor (can also be .1) 0.27 = conversion factor from $\mathrm{Grm}-\mathrm{Cal} / \mathrm{cm}^{2}$ to $\mathrm{Btu} / \mathrm{ft}^{2}$ Since hourly solar data is read in, the final step of determining the affects of cloudiness on above formulation was not pursued. A simple procedure of taking total solar radiation for input day and determining hourly values on this basis and adding or subtracting a certain amount depending on the cloudiness factor for an hour versus average cloudiness factor for a day should bring results within $10-20 \%$ of the true value.

\section{REFLECTED SOLAR RADIATION HEAT-TRANSFER RATE}

The reflected solar radiation heat-transfer rate is usually calculated from the incident solar rate and a solar reflectivity, $\mathrm{R}_{\mathrm{Sr}^{\prime}}$ defined as :

$$
\mathrm{R}_{\mathrm{Sx}}=\frac{\mathrm{HSI}_{\mathrm{Sx}}}{\mathrm{HSI}}
$$

Typical data can be found in Anderson (21). $\mathrm{R}_{\mathrm{sr}}$ can be estimated from the following empirical formula:

$$
\mathrm{R}_{\mathrm{sx}}=\mathrm{a}_{1} \propto \mathrm{b}_{1}
$$




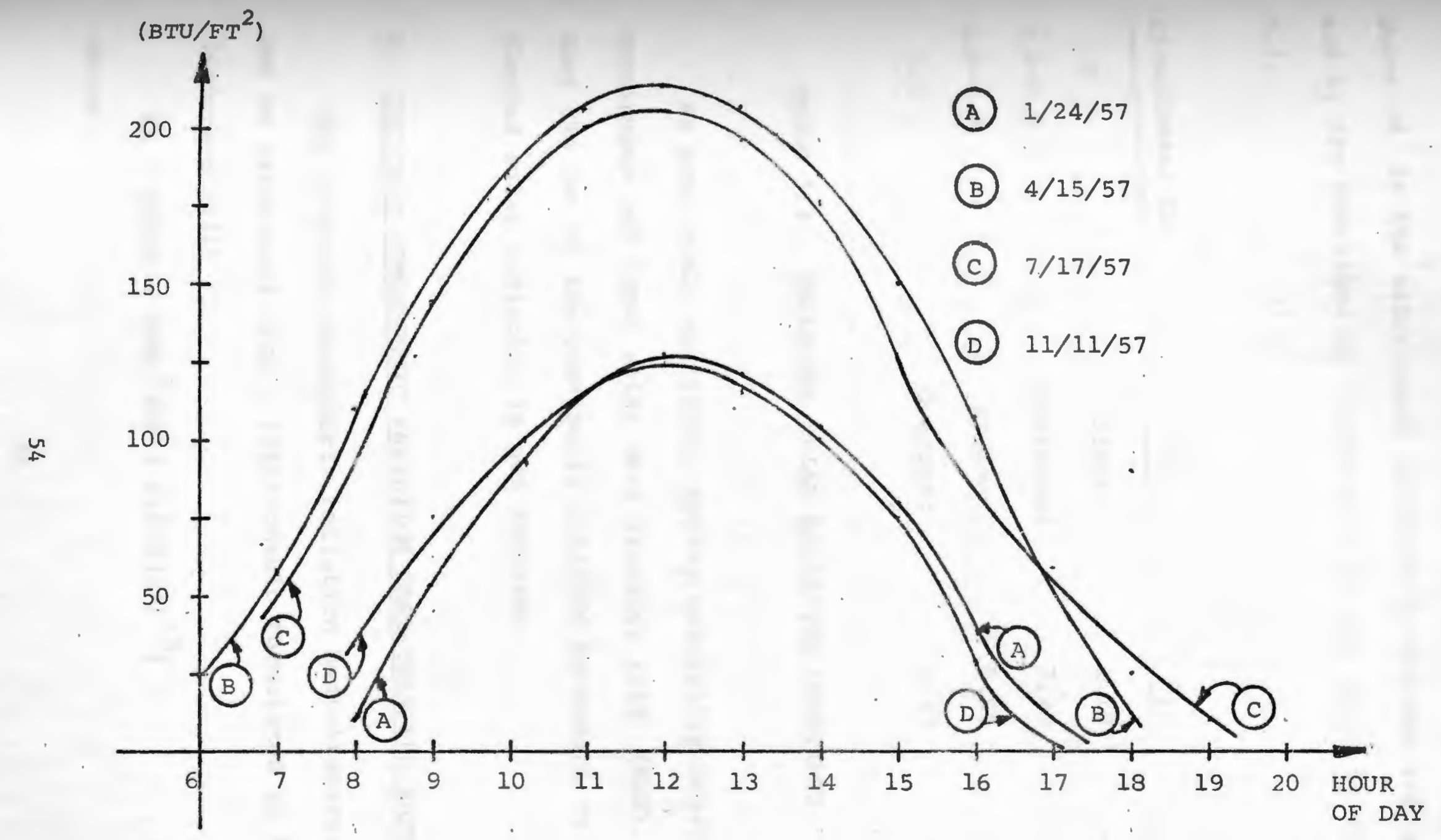

FIGURE 3.3. TYPICAL NET SOLAR RADIATION DATA FOR NARRAGANSETT BAY 
where $\alpha$ is the solar (sun) altitude in degrees and $a_{1}$ and $b_{1}$ are functions of cloudiness, $\mathrm{CL}$, and given in Table 3.1.

cloudiness, CL

0

$0.1-0.5$

$0.6-0.9$

1.0 sky

Clear

Scattered

Broken

Overcast

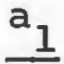

$\mathrm{b}_{1}$

$1.18-0.77$

$2.20 \quad-0.97$

$0.95 \quad-0.75$

0.35

$-1.45$

TABLE 3.1. REFLECTED SOLAR RADIATION CONSTANTS

As previously mentioned, Eppley Laboratory measures continuous net input solar heat transfer rate, (HS2), so that the use of the previously outlined procedure on reflected solar radiation is not required.

\section{INCIDENT ATMOSPHERIC RADIATION HEAT-TRANSFER RATE}

The incident atmospheric radiation heat-transfer rate may be calculated from a relationship formulated by Brunt (Anderson (21))

$$
\mathrm{HA}=\mathrm{SB}(\mathrm{TA}+460)^{4}\left(\mathrm{CB}+0.031(\mathrm{EA})^{.5}\right)
$$

where 
$H A-B t u / f t^{2}-d a y$

SB - Stefan-Boltzman constant, $4.15 * 10^{-8} \frac{\mathrm{Btu}}{\mathrm{ft}^{2} \mathrm{day}^{\circ}{ }_{\mathrm{R}}^{4}}$

TA - air temperature, ${ }_{F}$, (measured six feet above surface)

EA - atmospheric vapor pressure, mmHg (measured six feet above surface)

$\mathrm{CB}$ - coefficient determined by air temperature and $C^{\prime}$ the ratio of the measured solar radiation to the clear sky solar radiation

CL is determined from the total daily solar radiation by integrating the solar radiation curve for a particular day from the pyreheliometer reading and dividing this value by the clear sky solar radiation. The values of TA and CL then determine $\mathrm{CB}$ as shown in Reference 12, Figure 2.5, page 26. The effect on HA can be seen in Reference 12, Figure 2.4, page 25.

The Brunt coefficient may be estimated from the following equation:

$$
C B=.74-{\frac{3.5(96-T A)}{10^{(4+3 C L)}}}^{1.67}
$$

where

$$
\begin{aligned}
& \text { TA - temperature of air in }{ }_{F} \\
& \text { CL - cloudiness ratio }
\end{aligned}
$$


An alternate method, not used in the model for determining HA, from Swinbank (22) is:

$$
\mathrm{HA}=1.2 * 10^{-13}(\mathrm{TA}+460)^{6}\left(1+0.17 \mathrm{CL}^{2}\right)
$$

If less accuracy is desired assume black body radiation in Equation 3.20 and let the second bracket equal 0.87 or emissivity constant.

E. REFLECTED ATMOSPHERIC RADIATION HEAT-TRANSFER RATE

The reflected atmospheric radiation heat-transfer rate is usually calculated from the incident atmospheric rate and an atmospheric reflectivity, $\mathrm{R}_{\mathrm{ar}}$ defined as:

$$
\mathrm{R}_{\mathrm{ar}}=\frac{\mathrm{HA}}{\mathrm{HA}}
$$

The value of $R_{\text {ar }}$ is usually taken as 0.03 (Edinger and Geyer (12)). The result is:

$$
{ }_{\mathrm{HET}}=\mathrm{HA}-\mathrm{HA}_{\mathrm{ar}}=0.97 \mathrm{HA}
$$

\section{F. BACK RADIATION HEAT-TRANSFER RATE FROM WATER SURFACE}

The back radiation heat-transfer from the water surface is calculated from black-body radiation with an emissivity of 0.97 :

$$
\mathrm{BH}=\mathrm{EW} \times \mathrm{SB}(\mathrm{TW}+460)^{4}
$$


where

$$
\begin{aligned}
& \mathrm{BH}-\mathrm{Btu} / \mathrm{ft}^{2}-\text { day } \\
& E W-\text { emissivity of water surface }=0.97 \\
& \mathrm{SB}-\text { Stefan-Boltzmann constant }=4.2 * 10^{-8} \frac{\mathrm{Btu}}{\mathrm{ft}^{2} \mathrm{day} \mathrm{R}^{4}} \\
& \mathrm{TW}-{ }_{\mathrm{O}}
\end{aligned}
$$

\section{G. AIR VAPOR PRESSURE, EA}

EA is empirically determined by first finding partial pressure, PMM as follows:

$$
\mathrm{PMM}=\mathrm{A}-\mathrm{B} \cos (\mathrm{PI}(((\mathrm{TA}-30 .) / 70 .) \mathrm{C}+\mathrm{D}) / 180 .)
$$

and $A, B, C$, and $D$ in mmHg are found in Table 3.2

\begin{tabular}{ccccc}
$\operatorname{TA}\left({ }^{\circ} \mathrm{F}\right)$ & $\mathrm{A}$ & $\mathrm{B}$ & $\mathrm{C}$ & $\mathrm{D}$ \\
\hline $30.00-59.99$ & 94.5 & 90. & 54.5 & 2.5 \\
$60.00-79.99$ & 94.5 & 90. & 51. & 14. \\
$80.00-89.99$ & 94.5 & 90. & 61. & -3.0 \\
$90.00-100.00$ & 99.5 & 100. & 59.5 & 0.
\end{tabular}

TABLE 3.2. AIR VAPOR PRESSURE CONSTANTS

$$
\begin{aligned}
E A= & (P M M-(((T A-30) / 70 .) 3.5+1 .))(R H-10 .) / 90 .+((T A \\
& -30 .) / 70 .) 3.5+1 .
\end{aligned}
$$


where $\mathrm{RH}$ is relative humidity in percent.

\section{H. SATURATED VAPOR PRESSURE (DUE POINT TEMPERATURE)}

The vapor pressure, ES, is found from the simple empirical formula

$$
\mathrm{ES}=99.0-96.0 \cos (3.14(((\mathrm{TW}-30 .) / 50 .) 33 .+7 .) / 180 .)
$$

\section{EVAPORATION HEAT-TRANSFER RATE}

The evaporation heat-transfer rate is calculated from:

$$
H E=f(V)(E S-E A)
$$

where

$$
\begin{aligned}
& \mathrm{HE}=\mathrm{Btu} / \mathrm{ft}^{2}-\mathrm{DAY} \\
& \mathrm{V} \text { - wind velocity measured at specific elevation } \\
& \text { above the water surface, MPH } \\
& \mathrm{f}(\mathrm{V}) \text { - wind velocity function, energy/time-area- } \\
& \quad \text { pressure } \\
& \mathrm{ES} \text { - vapor pressure at water surface temperature, TW } \\
& \mathrm{EA} \text { - vapor pressure measured at specific elevation } \\
& \text { above the water surface at air temperature TA }
\end{aligned}
$$

The wind velocity function $f(v)$ is usually expressed as

$$
f(v)=a_{2}+b_{2} v
$$


Table 3.3 presents typical values of $a_{2}$ and $b_{2}$.

Source $\quad a_{2}\left(B t u / d a y-f t^{2}-m m H g\right) \quad b_{2}\left(B t u / d a y-f t^{2}-m m H g-m p h\right)$

Lake Hefner

Lake colorado

city

Meyer
0

11.4

0

16.8

73
7.3

TABLE 3.3. WIND VELOCITY FUNCTION PARAMETERS

Note that Table 3.3 implies the following set of units on Equations 3.29 and 3.30 .

$$
\begin{aligned}
& \mathrm{HE}-\mathrm{Btu} / \mathrm{ft}{ }^{2}-\mathrm{day} \\
& \mathrm{V}-\mathrm{mph} \\
& {[\mathrm{EA}, \mathrm{ES}-\mathrm{mmHg}]}
\end{aligned}
$$

It should also be noted that certain quantities in Equations 3.29 and 3.30 are time averages and are measured at specified elevations above the water surface. Table 3.4 summarizes these details. 
$\mathrm{V}$

Averaging Elevation
EA, ES Averaging Elevation Period

(Ft.)

Lake Hefner 3 hours

24

3 hours

24

Lake colorado 24 hours

24

24 hours

24

city

Meyer

Monthly

?

?

?

TABLE 3.4. EVAPORATION FORMULA MEASUREMENT PARAMETERS

The Lake Hefner values are more widely used because of the extensive investigative work that went into their formulation but the equation, at best, is a rough approximation of a physical process that is not well defined. When a calculation of the net heat transfer rate is performed the result is of the order of the evaporation rate. Thus, long computer runs and a massive data gathering effort to precisely measure air and water temperature at several elevations in conjunction with wind speed, humidity and wave height measurements are necessary to justify the application of the Lake Hefner values on Narragansett Bay. In summary, improvement on the present formula is very necessary and a plausible research area. 


\section{J. EVAPORATION MASS FLOW RATE}

The evaporation mass flow rate can be estimated from the evaporation heat-transfer rate by:

$$
\frac{w_{f}^{e}}{A}=H E / h_{f g}
$$

where

$$
\begin{aligned}
& w_{e} / A \text { - evaporation mass flow rate, mass/time-area } \\
& \mathrm{HE} \text { - energy/time-area } \\
& \mathrm{h}_{\mathrm{fg}} \text { - latent heat of vaporization at } \mathrm{TW} \text {, energy/mass }
\end{aligned}
$$

with $h_{f g}$ estimated from

$$
h_{f g}=1087-0.54 \mathrm{TW}
$$

for $T W-{ }_{F}$ and $h_{f g}$ in Btu/ $1 b_{m}$. Use of Equations 3.29

through 3.32 with values from Table 3.3 will yield evaporation mass flow rates in $1 \mathrm{~b}_{\mathrm{m}} / \mathrm{ft} \mathrm{t}^{2}$ day.

\section{K. CONDUCTION HEAT-TRANSFER RATE}

The conduction heat-transfer rate is approximated as a fraction of the evaporation heat-transfer rate through the Bowen ratio, B:

$$
-\mathrm{HC}=\mathrm{HE} * \mathrm{~B}
$$

and

$$
B=C_{3} \frac{(T S-T A)}{(E S-E A)} * \frac{P}{760}
$$


where

TS - surface temperature $\left({ }^{\circ} F\right)=T W$

TA - air temperature, ${ }^{O} F$

ES - saturated vapor pressure at water surface temperature, TS

EA - air vapor pressure calculated from air temperature, TA, and relative humidity, $\mathrm{RH}$

P - barametric pressure, mmHG

$c_{3}$ - an experimental constant usually taken as 0.26

(0.24 for smooth water surfaces and 0.28 for rough water surfaces).

Note that a minus sign has been introduced into Equation 3.33 due to the sign convention in Figure 3.1. If TS is less than TA then from Equations 3.33 and 3.34. HTOT will be positive and the heat transfer will be from the air to the water surface in agreement with the sign convention of Figure 3.1 .

Combining Equations 3.29, 3.30, 3.33, and 3.34 yields

$$
H C=-C_{3} f(V)(T S-T A) \frac{P}{760}
$$

or for $\mathrm{P}=760 \mathrm{mmHg}$ we have

$$
\mathrm{HC}=-\mathrm{C}_{3}\left(\mathrm{a}_{2}+\mathrm{b}_{2} \mathrm{~V}\right)(\mathrm{TS}-\mathrm{TA})
$$

Again, emphasis must be placed on the empirical 
nature of conduction heat rate formulation with regard to the Bowen ratio and the wind factor.

\section{MODEL FORMULATION}

Substitution of Equations $3.20,3.25,3.29$, and 3.36 into 3.14 and 3.16 results in the model formula 3.37 , shown below.

$$
\begin{aligned}
\text { HTOT }= & H S 2+\mathrm{SB}(\mathrm{TA}+460)^{4}\left(\mathrm{CB}+.031(\mathrm{EA})^{0.5}\right) \\
& -\mathrm{EW} * \mathrm{SB} *(\mathrm{TW}+460)^{4}-\left(\mathrm{a}_{2}+\mathrm{b}_{2} \mathrm{~V}\right)(\mathrm{ES}-\mathrm{EA}) \\
& -\mathrm{C}_{3}\left(\mathrm{a}_{2}+\mathrm{b}_{2} \mathrm{~V}\right)(\mathrm{TW}-\mathrm{TA})
\end{aligned}
$$

Since ES is a function of water temperature only, we assume that for the time increment used in the model there is no significant error introduced by using the calculated water temperature value from the previous time step. In addition, the previous water temperature values are used to predict current heat exchange rates as shown in Equation 3.37. The other variables, air temperature, wind speed, relative humidity, solar radiation, and cloudiness are given, so one can now determine HTOT directly from Equation 3.37 .

The model vertically averages (no buoyant effects) temperature structure so the energy equation is considered 
linear if the net heat exchange is linear for the temperature range considered. The net heat exchange rate for man made conditions requires only the water temperature excess, assuming that the air and natural water temperature remain unchanged as formulated in the following way:

Forced water
Temperature Rise

or

$$
\begin{aligned}
\mathrm{FTR}= & \mathrm{HS}_{\mathrm{MM}}+\mathrm{HA}_{\mathrm{MM}}-\mathrm{BH}_{\mathrm{MM}}-\mathrm{HE}_{\mathrm{MM}}-\mathrm{HC}_{\mathrm{MM}}-\mathrm{HS}_{\mathrm{N}}+{ }_{\mathrm{HA}} \\
& -\mathrm{BH}_{\mathrm{N}}-\mathrm{HE}_{\mathrm{N}}-\mathrm{HC}_{\mathrm{N}}
\end{aligned}
$$

where MM index means man madecondition, $N$ is natural condition, and FTR equals forced water temperature rise (DELTAT in model). The following assumptions are made with regard to Equation 3.39:

$$
\begin{aligned}
& \text { 1) }{ }^{\mathrm{HS} 2} \mathrm{MM}=\mathrm{HS}{ }_{\mathrm{N}} \text { (net solar input) } \\
& \text { 2) }{ }^{\mathrm{HA}} \mathrm{MM}_{\mathrm{MM}}=\mathrm{f}\left(\mathrm{TA}, \text { cloudiness) }=\mathrm{HA}_{\mathrm{N}}\right. \text { (incoming radiation) } \\
& \text { 3) } \mathrm{BH}_{\mathrm{MM}}=\mathrm{BH}_{\mathrm{N}}+\mathrm{BH}_{\mathrm{FTR}} \text { (back radiation) } \\
& \text { 4) } \mathrm{HE}_{\mathrm{MM}}=\mathrm{HE}_{\mathrm{N}}+\mathrm{HE}_{\mathrm{FTR}} \text { (evaporation) } \\
& \text { 5) } \mathrm{HC}_{\mathrm{MM}}=\mathrm{HC}_{\mathrm{N}}+\mathrm{HC}_{\mathrm{FTR}} \text { (conduction) }
\end{aligned}
$$

Noting that we must know approximate temperature range of water for linearized saturated vapor pressure, ES, we now rewrite 3.39 into the following form: 
(Net Heat Exchange) ${ }_{\text {FTR }}=\mathrm{BH}_{\text {FTR }}+\mathrm{HE}_{\mathrm{FTR}}+\mathrm{HC}_{\mathrm{FTR}}$

where

$$
\begin{aligned}
& { }_{\mathrm{FTR}}^{\mathrm{BH}_{\mathrm{TT}}}=\mathrm{EW} * \mathrm{SB} *\left(\mathrm{TW}_{\mathrm{FTR}}+460\right) 4 \\
& \mathrm{HE}_{\mathrm{FTR}}=\left(\mathrm{a}_{2}+\mathrm{b}_{2} \mathrm{~V}\right) \mathrm{ES} * \mathrm{TW}_{\mathrm{FTR}} \\
& \mathrm{a}_{2}+\mathrm{b}_{2} \mathrm{~V} \text { - wind evaporation function } \\
& \mathrm{ES}-\text { saturated vapor pressure for water temperature } \\
& \text { (mmHg) }
\end{aligned}
$$
${ }_{\text {TWTR }}$ - calculated forced water temperature rise from model $\left({ }^{\circ} \mathrm{C}\right)$

$$
\mathrm{HC}=0.26\left(\mathrm{a}_{2}+\mathrm{b}_{2} \mathrm{~V}\right) \mathrm{TW}_{\mathrm{FTR}}
$$

Linearization of $\mathrm{BH}_{\mathrm{FTR}}$ is done by using the following binomial expansion:

$$
\begin{aligned}
(Y+G)^{m} & =G^{m}+m G^{m-1} Y+\frac{m(m-1)}{2 !} G^{(m-2)} Y^{2} \\
& +\frac{m(m-1)(m-2) G^{m-3} Y^{3}}{3 !}
\end{aligned}
$$

for

$$
\begin{aligned}
& \mathrm{Y}=\mathrm{TW} \\
& \mathrm{G}=460^{\circ} \mathrm{F} \\
& \mathrm{m}=4
\end{aligned}
$$

Equation 3.41 becomes 


$$
\begin{aligned}
(T W+460)^{4}= & (460)^{4}\left(1+4 * T W / 460+6 *(T W / 460)^{2}\right. \\
& +4 *(T W / 460)^{3}+(T W / 460)^{4}
\end{aligned}
$$

and neglecting the last three terms as small we have

$$
\mathrm{BH}_{\mathrm{FTR}}=\mathrm{EW}(460)^{3} 4 \mathrm{TW} F \mathrm{FTR}
$$

The use of the forced temperature rise for a heated effluent is ideal because it allows predictions that are much less sensitive to inaccuracies in the meterological data being used. This method improves predictive confidence for intelligent "worst case" analysis by separately considering maximum temperature rise during tidal cycle coupled and the maximum natural rise, say, during a hot summer day. As an add to understanding the tidal excursions of isotherms and the maximum value and location they attain, the forced temperature rise calculations are very valuable especially if one is concerned with small temperature differences of the order of $0.1{ }^{\circ} \mathrm{C}$ in the far field.

\section{EOUILIBRIUM TEMPERATURE}

If the net heat transfer rate, HTOT, to the water, as given in Equation 3.37 is zero the grid point water temperature is then said to be at its equilibrium temperature, TE. Therefore, Equation 3.37 becomes: 


$$
\begin{aligned}
0= & H S 2+S B(T A+460)^{4}\left(C B+.031(E A)^{1 / 2}\right) \\
& -E W * S B(T E+460)^{4}-\left(a_{2}+b_{2} V\right)(E S-E A) \\
& -C_{3}\left(a_{2}+b_{2} V\right)(T E-T A)
\end{aligned}
$$

Solving Equation 3.44 in terms of $T E$ requires at worst an iterative procedure because the saturated vapor pressure function, ES is calculated from the equilibrium temperature. In actuality, the solution of Equation 3.43 requires about six iterations in the computer model for five place accuracy. In the next section, the heat exchange coefficient approach will be used to actually calculate the equilibrium coefficient.

\section{N. EXCHANGE COEFFICIENT}

The use of Newton's law of cooling, Equation 3.45, is essential for making an engineering estimate of the equilibrium temperature.

$$
\mathrm{Q}=\mathrm{K} * \mathrm{DT}
$$

where

Q - heat transfer rate (HTOT in model) normal to grid surface area (Btu/ft $\left.{ }^{2}-d a y\right)$

K - idealized heat transfer coefficient (Btu/ft ${ }^{2}-$ day- ${ }^{\circ}$ ) 


$$
D T \text { - temperature difference }(T E-T W)\left({ }^{O} F\right)
$$

By subtracting Equation 3.44 from 3.37 it follows that

$$
\begin{aligned}
\text { Нтот }= & -\left[\text { EW * SB }\left[(T W+460)^{4}-(T E+460)^{4}\right]\right. \\
& \left.+\left(a_{2}+b_{2} V\right)(E S-E E)+C_{3}\left(a_{2}+b_{2} V\right)(T W-T E)\right]
\end{aligned}
$$

where $\mathrm{EE}$ is saturated vapor pressure evaluated at $\mathrm{TE}$. Now by combining 3.45 and 3.46 and solving for $K$ we have the relationship

$$
\begin{aligned}
K= & E W * S B\left[(T W+460)^{4}-(T E+460)^{4}\right] \\
& +\left(a_{2}+b_{2} V\right)(E S-E E)+C_{3}\left(a_{2}+b_{2} V\right)(T W-T E) /(T W-T E)
\end{aligned}
$$

By using the bionomial expansion and neglecting second and higher order terms in Equation 3.41 and Equation 3.48 the linear vapor pressure approximation, BETA, shown below

$$
\mathrm{ES}-\mathrm{EE}=\mathrm{BETA}(\mathrm{TW}-\mathrm{TE})
$$

where BETA is found in Table 3.5, we have, from Equations 3.46 to 3.48 ,

$$
\mathrm{K}=4 \mathrm{EW} * \mathrm{SB} 460^{3}+\left(\mathrm{a}_{2}+\mathrm{b}_{2} \mathrm{~V}\right)\left(\mathrm{C}_{3}+\mathrm{BETA}\right)
$$

After substitution of

$$
\mathrm{EW}=0.97 \text { and } \mathrm{SB}=4.2 \times 10^{-8} \frac{\mathrm{Btu}}{\mathrm{ft}^{2} \text {-day }{ }^{\mathrm{O}_{\mathrm{R}}}}
$$


memperature Range ${ }^{O} F$

BETA (mmHg ${ }^{\circ}{ }^{-1}$ )

$\begin{array}{ll}40-50 & 0.291 \\ 50-60 & 0.405 \\ 60-70 & 0.553 \\ 70-80 & 0.774 \\ 80-90 & 0.990 \\ 90-100 & 1.289\end{array}$

TABLE 3.5. IINEARIZED VAPOR PRESSURE CONSTANT, BETA (REFERENCE 12)

The final result is:

$$
\mathrm{K}=15.7+\left(\mathrm{a}_{2}+\mathrm{b}_{2} \mathrm{~V}\right)\left(\mathrm{C}_{3}+\mathrm{BETA}\right)
$$

where $K$ has units of $B t u / f t^{2}-$ day ${ }^{\circ} F$ and $a_{2}, b_{2}, V, c_{3}$, BETA are all constants. Finally, we substitute 3.37 and 3.50 into Fourier's law, Equation 3.45, and the result is:

$$
\mathrm{TE}=\frac{\mathrm{HTOT}}{\mathrm{K}}+\mathrm{TW}
$$

Equation 3.51 now is used to calculate the equilibrium temperature in the model. 


\section{A. PRELIMINARY MODEL DETAILS}

\section{A. 1. General}

The computational scheme is controlled from the main section of the computer program by calling subprograms in order with suitable comments inserted to guide user through model operation. Pertinent hydrodynamic information for Narragansett Bay can be found in Kurt Hess's, Numerical Tidal Model of Narragansett Bay (4). Following the general computational procedure in the main section of the thermal model we encounter the following input control parameters :

$$
\begin{aligned}
& \text { IPRIND - Number of 4-minute intervals after which } \\
& \text { temperature displays are read into storage. } \\
& \text { If IPRIND equals } 15 \text {, it does this once an } \\
& \text { hour. } \\
& \text { HSI(IDY) - Total daily solar radiation for day-IDY } \\
& \text { (not used if hourly values are available) } \\
& \text { RDCNP - Logical variable, if true, one should specify } \\
& \text { temperature field. If false program defaults } \\
& \text { to a constant bay temperature field of ar- } \\
& \text { bitrary specification, TBNB. }
\end{aligned}
$$


A.2. Computation Parameters

DELTAT - Logical variable, if true, model will

calculate temperature above ambient

(forced temperature rise, FTR) where we

now define boundary temperature to be

nearly zero:

TMHOPE $=.00001^{\circ} \mathrm{C}$

TRIVER $=.00001^{\circ} \mathrm{C}$

TSOUND $=.00001^{\circ} \mathrm{C}$

- If false, the model calculates ambient

plus forced temperature rise

TBNB - Arbitrary temperature field specification

UPCON - Variable that increases dispersion coefficient, same for $x$ and $y$ direction with a range of values from 2 to 500 $\mathrm{yd}^{2} /$ sec. (Dived by 5.93 from Equation 2.27)

TIN - Temperature increase in condenser $\left({ }^{\circ} \mathrm{C}\right)$

QIN - Condenser flow rate (cfs)

SITE - Various location choices for surface or submerged discharge from heat source NPRINT(I) - Print out of velocity and temperature field, first index must be 1 and all numbers thereafter must be 
in increments of 15 or 30, e.g., 1

$15,30,60,75,105 \ldots$

A. 3. Main Body of Program

Subroutine HEATIN - Specifies source term and indices for power plant siting

Subroutine INVAL - Reads and writes all initial values for program

Subroutine OPENED - Specifies all hydrodynamic and thermal boundary conditions

Subroutine UPNFHT - Claculates V! and SEP on column. $\mathrm{n}$ (north-south) for first

$$
\text { half timestep }
$$

where

$$
\begin{array}{ll}
U P=u^{t+1 / 2} & U=u^{t} \\
\text { SEP }=n^{t+1 / 2} & S E=n^{t} \\
V P=v^{t+1 / 2} & v=v^{t}
\end{array}
$$

so " $\mathrm{P}$ " means higher time level in notation seen above

Subroutine VPMFHT - Calculates VP on row $m$ (east-west) for first half timestep 
contained within subroutine VPMFHT are the following: a. Subroutine WATDEP - Heat exchange values that are a function of water temperature

b. Subroutine WATIND - Heat exchange values that are independent of water temperature

c. Subroutine AZ - Calculates the average bay temperature from a total of six arbitrary subdivisions

d. Subroutine PRINT - Controls all print punch operations as well as timestep reallocation for variables

Subroutine VPMSHT - Computes VP and SEP on column m second half timestep

Subroutine UPNSHT - Computes SEP on row $\mathrm{n}$ second half timestep

Subroutine DISPLY - Graphical output of thermal model at end of the computational run. Calls IBM subroutine PLOT at the end of the computer run

Subroutine ANALYZE - Tidal pattern real vs. actual 
A. 4. Data

$$
\begin{aligned}
& \text { YR - Year, e.g., } 57 \text { for } 1957 \\
& \text { DAY - Day of Year, e.g., } 194 \text { for July } 17 \\
& \text { THR - Hour in Day, e.g., } 17 \\
& \text { TMIN - Minute, e.g., } 48 \\
& \text { TMHOPE - Mt. Hope temperature condition } \\
& \text { TRIVER - River temperature conditions around bay } \\
& \text { TSOUND - Rhode Island Sound temperature condition. }
\end{aligned}
$$

\section{A.5. Execution Parameters}

IMODES $=2$, for central and, 1 for upstream

$$
\text { differencing }
$$

IPUNCH - timestep at which model will punch out data

$$
\begin{aligned}
& \text { AT - half timestep }=120 \mathrm{sec} \\
& \text { MAXST - computational length, MAXST/15 = number } \\
& \text { of hours real time }
\end{aligned}
$$

\section{B. MODEL APPLICATION FOR NARRAGANSETT BAY, HYDRODYNAMICS}

\section{SECTION}

\section{B.1. Introduction}

Now that the fundamentals of the computer scheme have been discussed, the model may be applied to the 
specific case of Narragansett Bay. This requires the selection of the grid net which describes the Bay geography, with physical data on grid depths and bottom friction read in. The hydrodynamic boundary conditions are given as time varying functions at Mt. Hope Bay and Rhode Island Sound. The following sections outline the application procedure.

B.2. Grid Net Selection

Few, if any, guidelines exist for the selection of an optimum grid system for a water body, especially one like Narragansett Bay with its complicated geography. The first step taken, however, was the choice of the water boundaries. The area of the Bay to be modeled is bounded on the south by Rhode Island Sound, on the east by the entrance of Mt. Hope Bay, and the north at the narrowing of the Seekonk River. This area represents about twothirds of the entire Bay. The portion excluded, Mt. Hope Bay and the Sakonnet River, comprises another estuarine system, and is connected to the main part of the Bay by a narrow passage.

Secondly, the computation scheme imposes a minimum of two grids per row or columns in the field. Thus, the narrowest channel must be at least two grids wide. These critical areas occur in the lower Bay, in the East and west 
Passages, and in the upper Bay in the Providence River (Figure 4.1). Therefore, a grid length of one-half nautical mile (1012.7 yds.) was chosen. The resulting grid net consists of 314 water and 11 water-boundary grids within the rectangular (19 by 48) field for a total of 325 grids. The model axis has been rotated 10.1 degrees clockwise from the true north-south direction for more accurate representation of the shore geometry.

\section{B.3. Model Time step Selection}

One important property of the implicit solution method is its unconditional numerical stability, (values need only be bounded) regardless of time step. However, the size of the time step has an effect on the accuracy of the solution.

Leendertse (1) has shown that the solution is accurate when Equation 4.1, shown below, is less than 5 .

$$
\frac{\mathrm{AT}}{\mathrm{L}}\left(\mathrm{gh}_{\max }\right)^{1 / 2} \leq 5
$$

where

$$
\begin{aligned}
& \text { AT - time step } \\
& \text { I - grid length } \\
& \text { g - acceleration of gravity } \\
& h_{\max }=\text { maximum bay depth }
\end{aligned}
$$




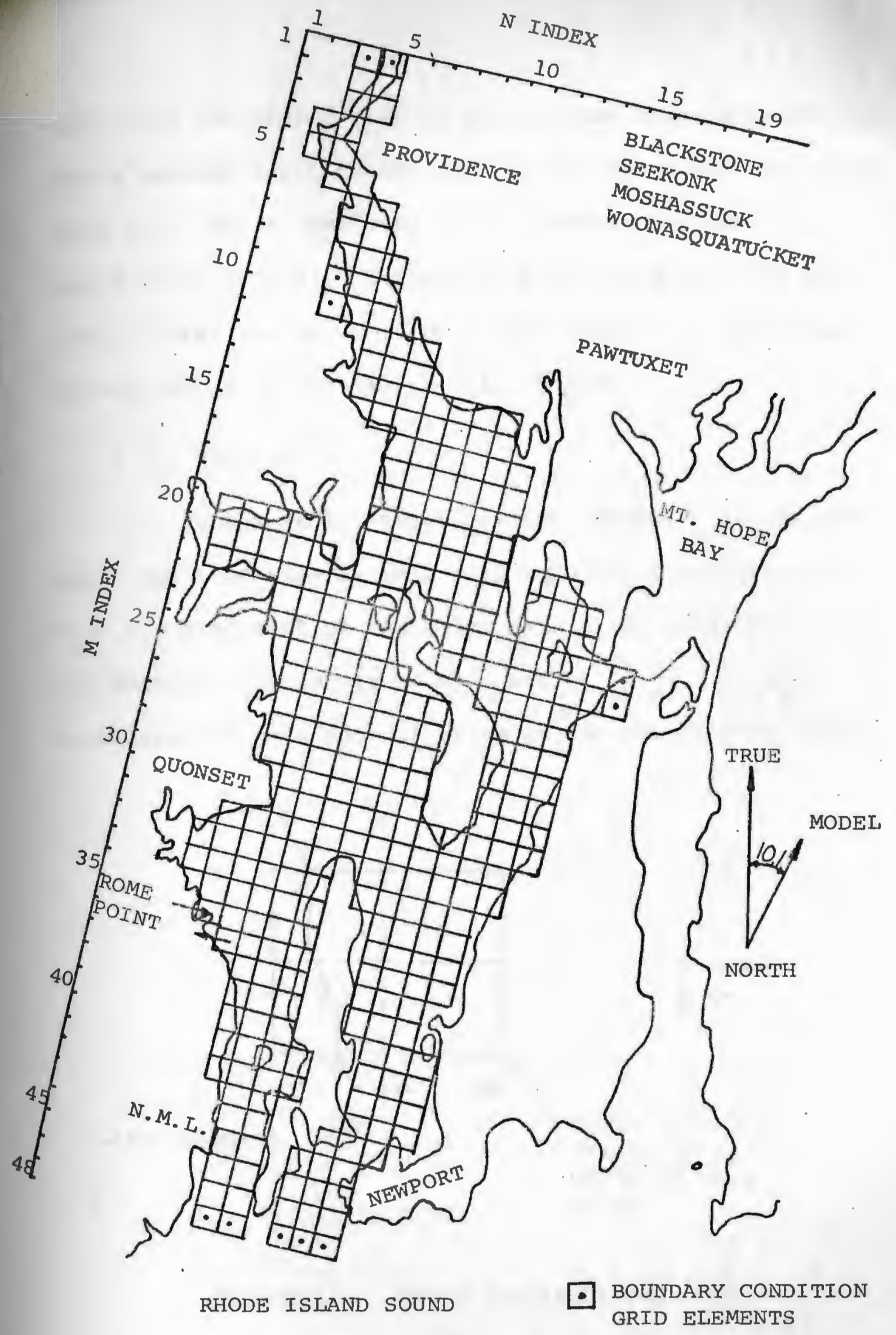

FIGURE 4.1. GRID SYSTEM FOR NARRAGANSETT BAY 
Note that the factor $\sqrt{g h}$ is the maximum long-wave celerity. For a maximum depth of 152 feet in the bay a grid length of 3038 feet, and a time step of 220 seconds Equation 4.1 has a value of 4.91. Therefore, a time step, AT, of this size or less insures good accuracy, especially since the average depth of the Bay is only 30 feet.

\section{B.4. Bay Depths}

Bathymetric variations are accounted for in the depth specification at each grid square. In accordance with the placement of variables within the grid, Figure 4.2 , the depth in the corner of the grid at $\left(x_{c}+1 / 2, y_{c}+1 / 2\right)$ is entered as data for all grids in the computation field.

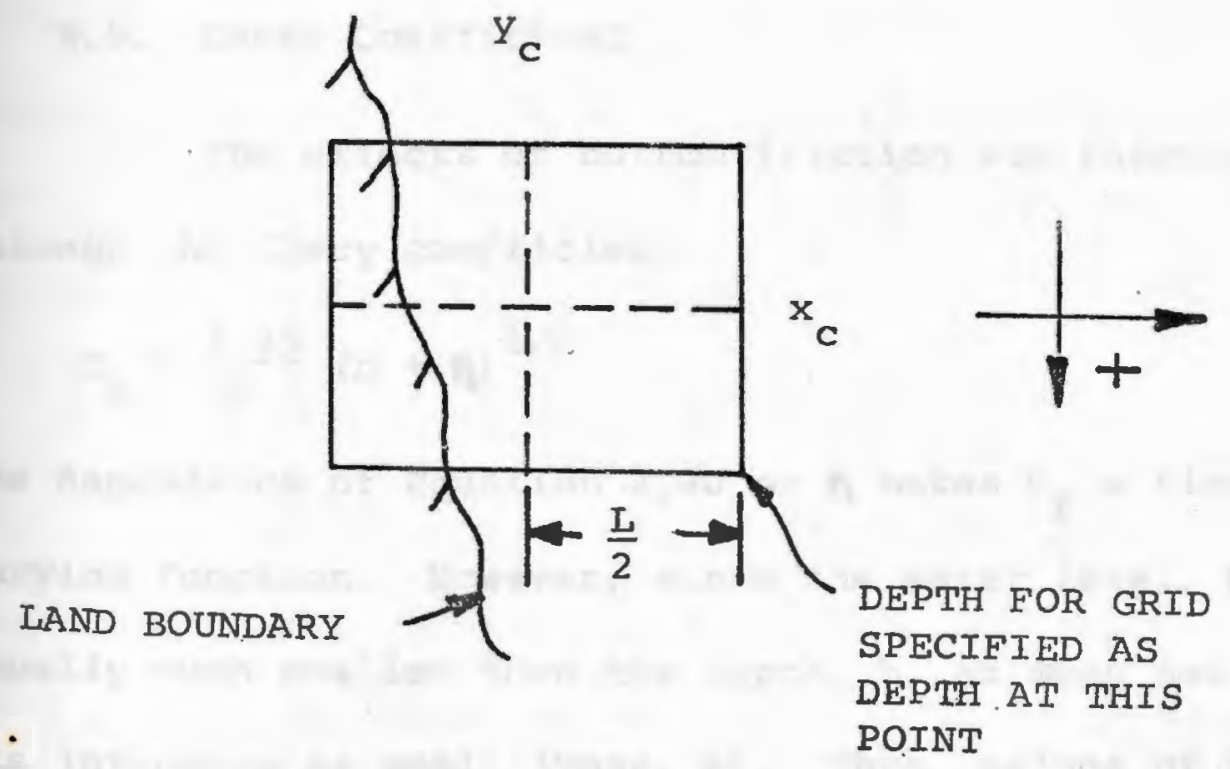

FIGURE 4.2. DEPTH SPECIFICATION 
The number entered is the actual depth at mean sea level at that point on the grid, and not the average depth over the grid square as shown in Figure 4.2. Depths may also be entered without harm at grid squares outside the computation field, such as those adjacent to water grids.

General information on the bathymetry was obtained from the U.S. Coast and Geodetic Survey chart No. 353, which gives depths at mean low water. It should be noted that while such charts are useful, certain small-scale features may not be evident from them. For certain critical locations, therefore, depth surveys would be quite useful. These were carried out in the West Passage at the Jamestown Bridge, and at the Mt. Hope Bridge.

\section{B. 5. Chezy Coefficient}

The effects of bottom friction are introduced

through the Chezy coefficient

$$
c_{z}=\frac{1.49}{N}(h+n)^{1 / 6}
$$

The dependence of Equation 2.20 on $\boldsymbol{\eta}$ makes $\mathrm{C}_{\boldsymbol{z}}$ a timevarying function. However, since the water level, $\boldsymbol{\eta}$, is usually much smaller than the depth, $h$, at mean sea level, its influence is small (Hess, 4). Thus, values of $\mathrm{C}_{2}$ are computed at the start of each run (for $\boldsymbol{\eta}=0$ ), and are 
not changed afterward.

The selection of the Manning factor ( $\mathrm{N}$ in $\mathrm{ft}^{1 / 6}$ ) poses a somewhat more difficult problem, due to the lack of extensive studies for rivers and bays. Masch and Brandes (49), for example, use values between 0.018 and 0.054, which corresponds to "rubble set in cement" and "natural river channels: winding, with pools and shoals", respectively, in a table given by Henderson (50). The essential concept is bottom roughness, which varies considerably in an area as large as Narragansett Bay. For approximation, then, the Manning factor was taken as a linear function of $\mathrm{m}$, the north-south section number:

$$
N(m)=\operatorname{Navg}(1.3-0.6 \mathrm{~m} / \mathrm{max})
$$

which varies from 1.3 Navg in the Providence River to 0.7Navg at the mouth of the Bay. The average value, Navg, was determined from comparisons of predicted and observed velocities, and was taken as 0.020 .

\section{B.6. Rhode Island Sound Boundary}

The primary driving force at the mouth of Narragansett Bay is the astronomical tide, and thus is entered as a water level boundary condition at that location, grids $\mathrm{m}=48, \mathrm{n}=8,9,11,12,13$. The coast and Geodetic Survey regularly collects and analyzes tidal elevations at 
several locations around the Bay. The primary stations are at Newport, Bristol, and Providence, and the data obtained is used to calculate the amplitude and phase angle of the twenty or so largest tidal constituents (51). A number of secondary stations have been occupied, and the times of high and low water relative to Newport are given for them in reference 51 .

The tidal forcing function may be represented by the sum of several sinusoidally varying terms, each with a specified amplitude, angular speed, and phase angle (52). The phase angle is taken relative to Greenwich, England; the amplitude is modified by a function of lunar position, $f_{\overline{7}}$ The equation for the water level, $\boldsymbol{\eta}$, is

$$
\eta(t)=H_{0}+\sum_{\bar{n}}^{\bar{n}}(t) H_{n} \cos \left[w_{n} t+\left(v_{0}+u\right)_{n}-k_{n}\right]
$$

where

$$
\begin{aligned}
& \mathrm{H}_{0}-\text { the height of the mean sea level above the datum } \\
& \text { (mean low water) }
\end{aligned}
$$

and for each constituent, $\bar{n}$.

$$
\begin{aligned}
& f_{n}(t) \text { - amplitude factor depending on the position } \\
& \quad \text { of the moon's line of nodes } \\
& H_{n} \text { - amplitude of the constituent } \\
& w_{\pi} \text { - angular speed (degrees per hour) of the constituent }
\end{aligned}
$$


$\left(v_{0}+u\right)_{n}-v a l u e$ of the equilibrium agrument when $t=0$

$k_{\bar{h}}$ - epoch (angular phase difference from Greenwich)

$t$ - time (hours) from reference time

The values of $\mathrm{H}_{0^{\prime}} \mathrm{H}_{\mathbf{h}^{\prime}}$ and $\mathrm{k}_{\mathrm{h}}$ are calculated for each tide station. The angular speed (w), lunar node function $\frac{f_{n}}{n}$ and equilibrium agrument $\left(v_{0}+u\right)_{n}$ can be calculated from knowledge of astronomical motions, and are tabulated in reference 52. (See Hess (4), Subroutine KURIH).

The tide at the lower boundary is calculated at each of the end grids $(m=48, n=8,9,11-13)$ by an equation of the form 4.3. The tide at the intermediate grids is obtained by linear interpolation. The amplitude and epoch of each constituent used at the boundary is derived from the analysis of tidal data taken at three previously mentioned stations. The tidal values will be improved by data obtained from the Ocean Engineering Department's, Whale Rock tide gauge.

Several other types of boundary conditions are included in the model, and can be used in various hydrodynamic experiments. (See Hess (4), Chapter II).

\section{B.7. Providence River Boundaries}

The boundaries located in the northern part of 
the Bay represents river flows and are velocity boundary conditions in the model. The Providence Harbor is the sum of several rivers, while the Pawtuxet River joins the Providence River further down the Bay. Several smaller river flows into the Bay are neglected because their discharge flow rates would have no noticeable affect on local fluid motions.

The total volumetric flow rate from the BlackstoneSeekonk, Moshassuck, and Woonasquatucket Rivers is entered at boundary grid $m=1, n=3$ and 4 to simplify the model grid system in that region. The mean annual flow rate, about 890 cfs including discharge from the city of Providence, is fairly small compared to tidal flowrate so that local velocities do not differ significantly in the area as a result. The daily average flowrate may either be obtained from surface water records (53) or estimated from the ratio of monthly to yearly mean discharges.

The Pawtuxet River boundary $(m=10$ and $11, n=4)$ is handled in the same manner as the Providence Harbor boundary.

B.8. The Mt. Hope Boundary

The boundary at the entrance to Mt. Hope Bay probably is the most difficult to model accurately. The 
local geography does not permit the use of the Bristol Harbor tide as a water level boundary condition, so a tidal velocity, based upon the volumetric flowrate, is used.

The total flow under the Mt. Hope Bridge is determined by tidal differences, river discharges, and wind effects. The tidal flow results from water level variations between the Narragansett and Mt. Hope Bays where the Mt. Hope Bay is also connected to the Rhode Island sound by the Sakonnet River. Also, a certain fraction of the fresh water discharge into the Mt. Hope Bay, primarily from the Taunton River (mean annual flowrate of $660 \mathrm{cfs}$ ), passes under the bridge. Local winds may contribute to daily variations in the flow, but they are neglected since no data on wind currents is available.

The earliest available measurement of the flow under the bridge were reported by Haight (54), who used a 7 foot pole and three current meters on August 7 and 8, 1930. Recent measurements, Binkerd (55), (August 5 and 18, 1971) were taken by using several poles spaced across the section under the bridge. The general approach of analyzing the data used by Haight was applied to the newer observations. Due to the nature of the bay geometry, Haight (54) 
showed that the currents due to the lunar $\left(M_{2}, M_{4}\right.$, and $\left.M_{6}\right)$ constituents of the tide accounted for most of the obtained current. The flowrate can then be approximated by

$$
q=\sum_{k=1}^{3} q_{k} \cos \left[\frac{2 \times P I X k}{12.42}\left(t-t a u_{k}\right)\right]
$$

where $q$ is the flowrate, and tau the time to first flood after high water. The flowrate was deduced from the 1930 data by integrating the velocity over the depth, and multiplying by a weighted area under the bridge $\left(90,600 \mathrm{ft}^{2}\right)$. The flowrates for the other observations were calculated by summing the products of the pole velocity and the incremental area; the resultant values were adjusted for the tidal range and smoothed. A weighted average was then analyzed, by a least squares technique, using an equation similar to 4.4. The results are shown in Table 4.1.

Time to

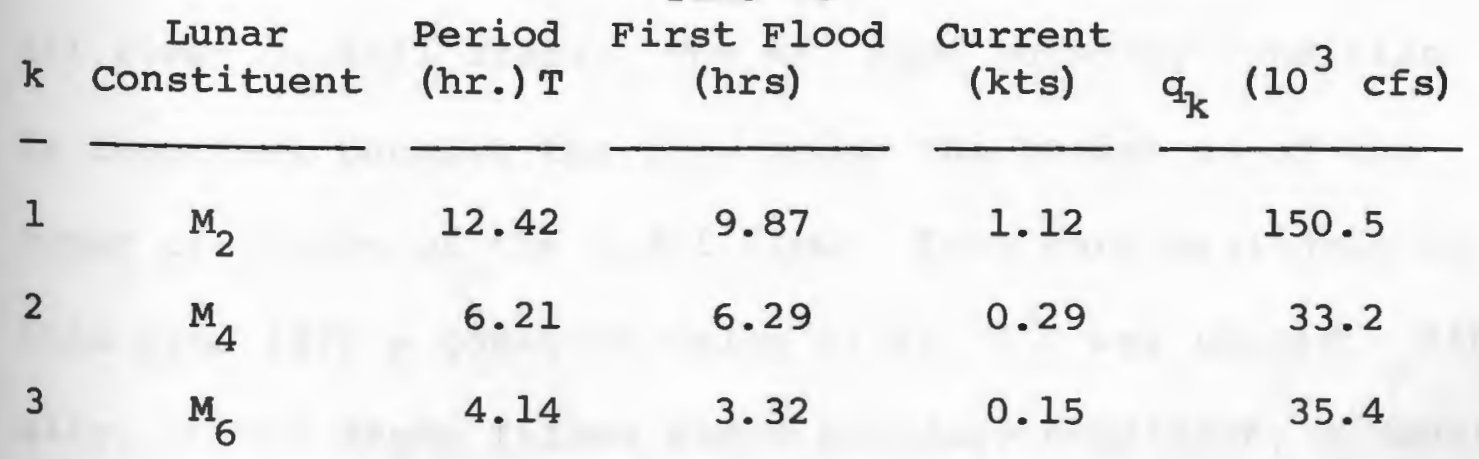

TABLE 4.1. LUNAR CONSTITUENT ANALYSIS OF FLOW UNDER MT. HOPE BRIDGE 
The tidal velocity is obtained by dividing the flowrate, $q$, by the area at the boundary.

The portion of the Taunton River discharge passing under the bridge is obtained from Hicks, (57), who estimated the river outflow from the ebb flowrates through each Bay passage. The value used here is $72 \%$ of the annual mean flow or 475 cfs.

c. MODEL APPLICATIONS FOR NARRAGANSETT BAY - THERMAL SECTION

c. 1. Boundary Conditions

As previously mentioned in the hydrodynamic section, the river flow rates are small compared to tidal flow and as a consequence the river temperature boundary conditions around the bay have no noticeable affect on spatial heat variations. Nevertheless, a constant value of $22.20^{\circ} \mathrm{C}$ was chosen to represent mid-summer conditions at all river outfall areas. The Mt. Hope boundary condition is important because the flow under the bridge is of the order of $10-20 \%$ of the tidal flow. From data available at this time (37) a constant value of $21.75^{\circ} \mathrm{C}$ was chosen. Finally, at the Rhode Island sound boundary condition, a constant value of $18.5^{\circ} \mathrm{C}$ is used (31). It is quite obvious that the fixed Rhode Island sound boundary condition will represent 
the greatest source of inaccuracy in the model. A proposed improvement would be to vary the boundary condition as a function of tidal velocity across lower east and west passage as shown in Equation 4.5

$$
\begin{aligned}
& \text { Rhode Island temperature } \\
& \text { boundary condition }
\end{aligned}=18.65+\frac{A m p l * V e l}{\mathrm{Vel}_{\max }}
$$

where

18.65 is now the average value of the boundary condi.tion Ampl $=.15^{\circ} \mathrm{C}-$ half temperature tidal excursion Vel - tidal velocity (yds/sec)

$\mathrm{Vel}_{\max }$ - maximum tidal velocity - taken as $.125 \mathrm{yds} / \mathrm{sec}$ Temperature excursion was determined by plotting at a typical North-South temperature profile shown in Figure 4.3.

The use of Equation 4.5 would help model boundary condition by taking into account, in an approximate way, the flow of warm water back into the bay.

\section{C.2. Thermal Model Modes}

The model can operate under various schemes that are shown in Table 4.2. These were formulated to help isolate the various heat transfer processes involved in simulating both natural and man-made conditions. Mode I is most commonly used. 


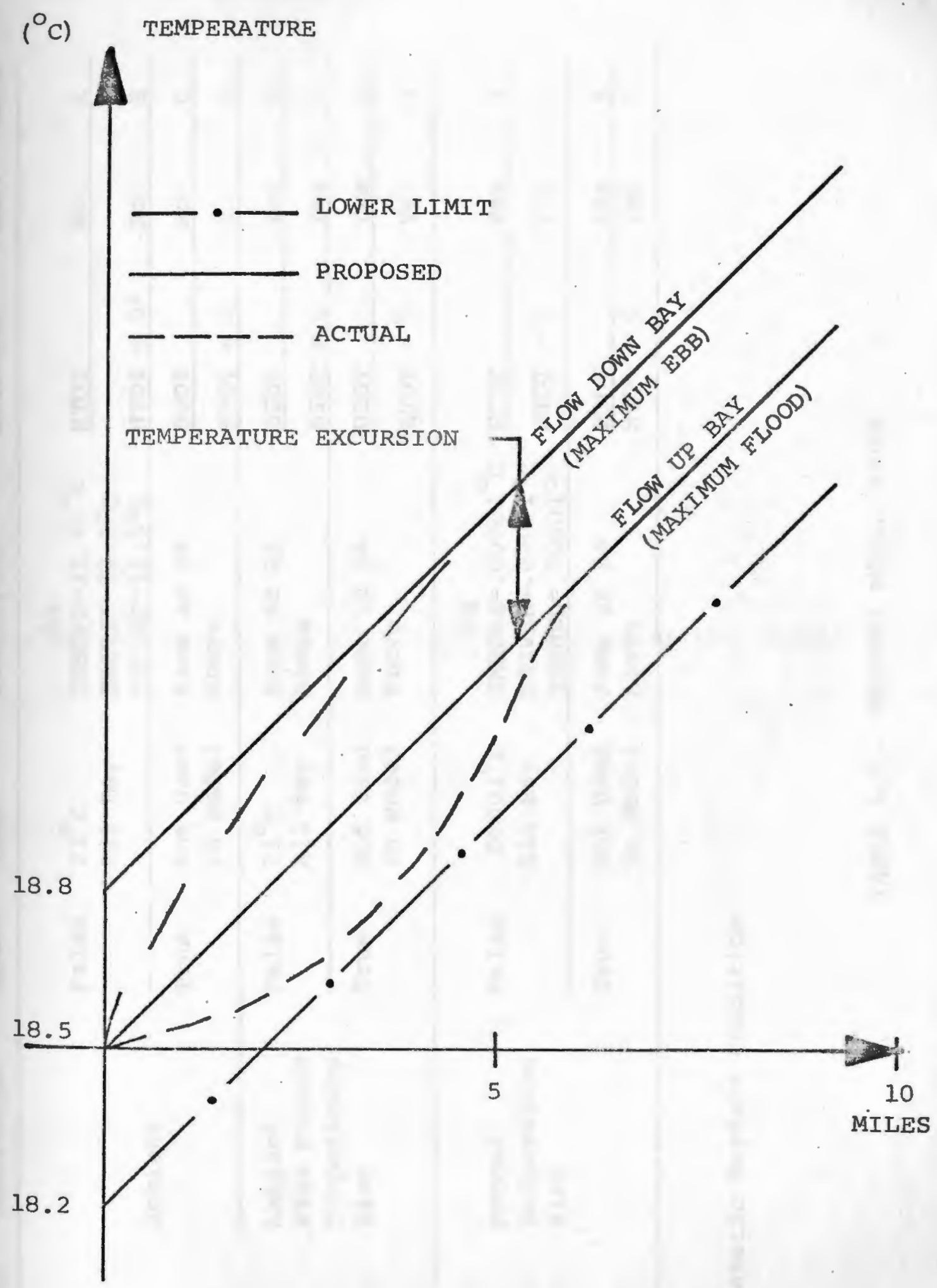

FIGURE 4.3. NORTH-SOUTH TEMPERATURE PROFILE 


\begin{tabular}{|c|c|c|c|c|c|c|c|}
\hline DELTAT & CONDITIONS & RDCNP & TBNB & $\begin{array}{l}\text { BOUNDARY } \\
\text { CONDITIONS }\end{array}$ & $\begin{array}{l}\text { NET HEAT } \\
\text { EXCHANGE }\end{array}$ & $\begin{array}{l}\text { POWER } \\
\text { PLANT }\end{array}$ & MODE \\
\hline \multirow{4}{*}{ False } & \multirow{2}{*}{ Ambient } & False & $\begin{array}{l}21^{\circ} \mathrm{C} \\
\text { All Bay }\end{array}$ & $\begin{array}{l}\text { AA } \\
\text { TMHOPE }=21.75^{\circ} \mathrm{C} \\
\text { TRIVER }=22.2^{\circ} \mathrm{C} \\
\text { TSOUND }=18.5^{\circ} \mathrm{C}\end{array}$ & $\begin{array}{l}\text { HTOT } \\
\text { HTOT }=0 *\end{array}$ & No & A \\
\hline & & True & $\begin{array}{l}\text { Not Used } \\
\text { in Model }\end{array}$ & $\begin{array}{l}\text { Same as AA } \\
\text { Above }\end{array}$ & $\begin{array}{l}\text { HTOT } \\
\text { HTOT }=0\end{array}$ & No & C \\
\hline & \multirow{2}{*}{$\begin{array}{l}\text { Ambient } \\
\text { Plus Forced } \\
\text { Temperature } \\
\text { Rise }\end{array}$} & False & $\begin{array}{l}21^{\circ} \mathrm{C} \\
\text { Ali Bay }\end{array}$ & $\begin{array}{l}\text { Same as AA } \\
\text { Above }\end{array}$ & $\begin{array}{l}\text { HTOT } \\
\text { HTOT }=0\end{array}$ & Yes & $E$ \\
\hline & & True & $\begin{array}{l}\text { Not Used } \\
\text { in Model }\end{array}$ & $\begin{array}{l}\text { Same as AA } \\
\text { Above }\end{array}$ & $\begin{array}{l}\text { HTOT } \\
\text { HTOT }=0\end{array}$ & $\frac{\text { Yes }}{\text { Yes }}$ & $\frac{G}{H}$ \\
\hline \multirow[t]{2}{*}{ True } & \multirow[t]{2}{*}{$\begin{array}{l}\text { Forced } \\
\text { Temperature } \\
\text { Rise }\end{array}$} & False & $\begin{array}{l}.00001^{\circ} \mathrm{C} \\
\text { All Bay }\end{array}$ & $\begin{array}{l}\text { BB } \\
\text { TMHOPE }=.00001^{\circ} \mathrm{C} \\
\text { TRIVER }=.00001^{\circ} \mathrm{C} \\
\text { TSOUND }=.00001^{\circ} \mathrm{C}\end{array}$ & $\begin{array}{l}\text { HTOT } \\
\text { HTOT }=0\end{array}$ & $\begin{array}{l}\text { Yes } \\
\text { Yes }\end{array}$ & $I$ \\
\hline & & True & $\begin{array}{l}\text { Not Used } \\
\text { in Mode1 }\end{array}$ & $\begin{array}{l}\text { Same as BB } \\
\text { Above }\end{array}$ & $\frac{\mathrm{HTOT}}{\mathrm{HTOT}=0}$ & $\frac{\text { Yes }}{\text { Yes }}$ & $\frac{\mathrm{K}}{\mathrm{L}}$ \\
\hline
\end{tabular}

* Adiabatic Surface condition

TABLE 4.2. THERMAL MODEL MODES 
c. 3. Net Heat Exchange

The value of HTOT, the net heat exchange transfer rate, is obtained from Equation 3.37. This is read into the model by the following formulation:

$$
\begin{aligned}
& \text { HTOT } \times \text { AREA }=\frac{\text { Btu }}{f t^{2}-d a y} \times \text { GSA } \times \frac{\mathrm{yd}^{2} \times 9 \mathrm{ft}^{2} / \mathrm{yd}^{2}}{(24 \cdot \mathrm{hr} / \mathrm{day})(3600 \mathrm{sec} / \mathrm{hr})} \\
& \text { Heat into box }=\frac{9 \times \mathrm{GSA}}{24 \times 3600} \quad \frac{\mathrm{Btu}}{\mathrm{sec}}=Q
\end{aligned}
$$

where GSA - grid surface area

but $Q=m c_{p} D T$

and

Q - heat transfer rate per unit time

$c_{p}$ - specific heat of water at constant pressure

$\mathrm{DT}=$ temperature change in box per unit time

Combining 4.7 and 4.8 and solving for DT we have:

$$
\begin{aligned}
\mathrm{DT}= & \frac{Q}{\mathrm{mc}}=\frac{9 \times \mathrm{GSA}}{\mathrm{p}} \times \mathbf{3 6 0 0} \times \\
& 64 \frac{1 \mathrm{~m}_{\mathrm{m}}}{\mathrm{ft}}\left[\mathrm{GSA} \mathrm{yd}^{2} * \frac{9 \mathrm{ft}^{2}}{\mathrm{yd}^{2}}\right] * \operatorname{Depth}(\mathrm{yd}) * \frac{3 \mathrm{ft}}{\mathrm{yd}}
\end{aligned}
$$

Consolidating, the result is

$$
\mathrm{DT}=\frac{\text { HTOT }}{24 * 3600 * 64 * 3 * \text { Depth }}={ }_{\mathrm{F} / \mathrm{sec}}
$$

for a depth of 30 feet the final result is 


$$
T=\frac{\text { HTOT }}{1.66 * 10^{7}} \circ_{\mathrm{F} / \mathrm{sec}}
$$

For a value of HTOT $=10 \mathrm{Btu} / \mathrm{ft}^{2}$-day, the net heat flux, we have

$$
\begin{aligned}
\mathrm{DT} & =\frac{10 * 86,400}{1.66 * 10^{7}} \\
& =\frac{8.6 * 10^{5}}{1.66 * 10^{7}}=.052^{\circ} \mathrm{F} / \mathrm{day}
\end{aligned}
$$

For one year we would have

$$
T=.052 * 365=19^{\circ} \mathrm{F}
$$

which is of the order of the annual variation in the Narragansett Bay area.

The read in variables required for computing Equation 3.37 are the following:

TA - temperature of the air, OF (T.F. Green Airport, (56))

$\mathrm{RH}$ - Relative humidity, percent (T.F. Green Airport; (56))

HS2 (1) - Hourly solar radiation parameter $\left(\mathrm{grm}-\mathrm{cal} / \mathrm{cm}^{2}\right.$ ) (scale factor of .2 from Eppley Laboratory, Unpublished)

WA - Wind speed, miles per hour (T.F. Green Airport, (56)) ANG - Direction that wind blows from, degrees (T.F. 
Green Airport, (56))

CLDCVR - Percent of sky covered with clouds (T.F.

$$
\text { Green Airport, (56)) }
$$

c.4. Power Plant

To determine power plant requirements, the cooling water rate per unit power must be known (see Figure 4.4).

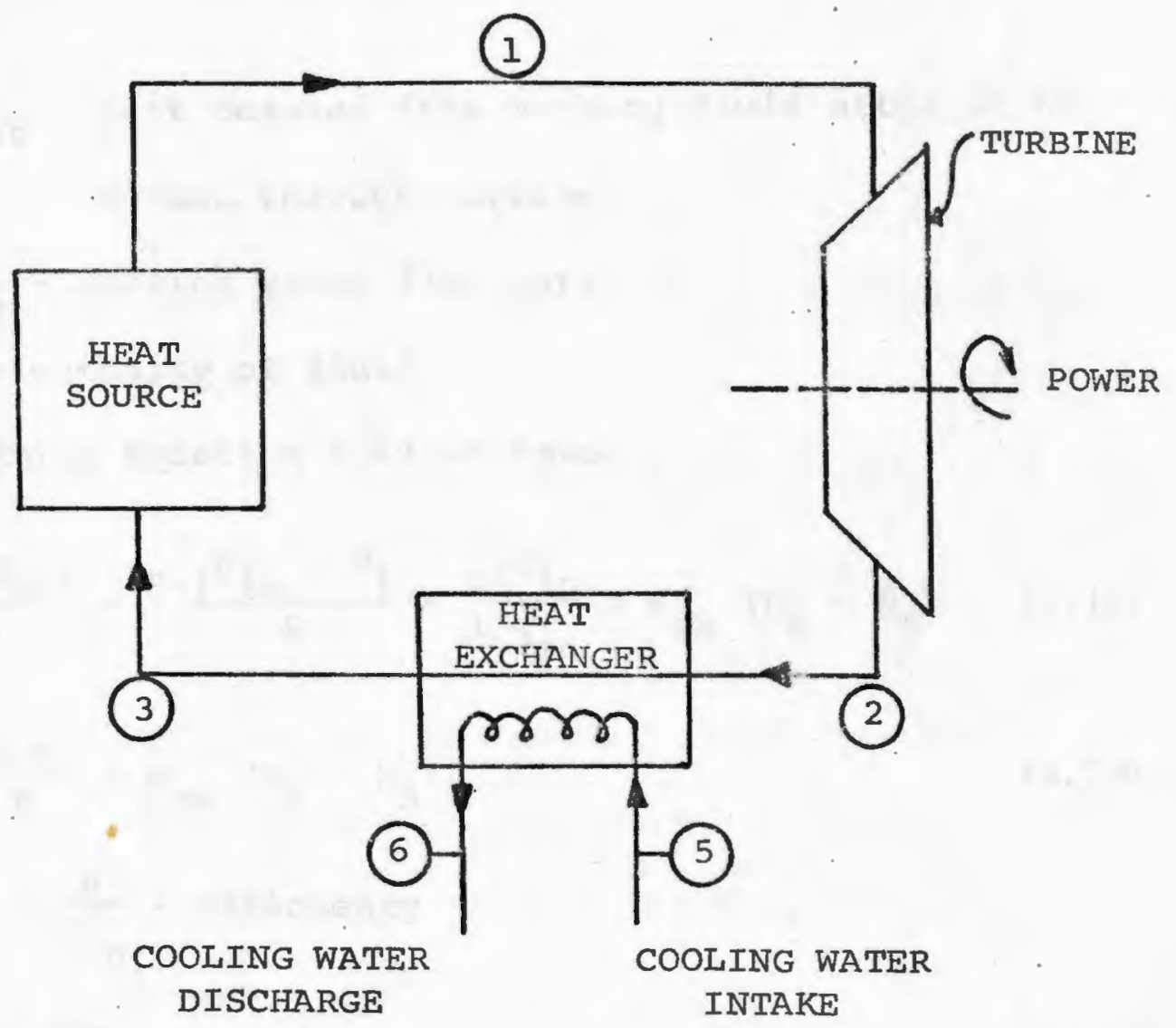

FIGURE 4.4. POWER PLANT SCHEMATIC 
A straightforward calculation is presented using the steady flow energy equation

$$
\begin{aligned}
& q-p_{x}=w_{c w}\left[\left(h_{6}+\frac{v_{6}^{2}}{2}+z_{6}\right)-\left(h_{5}+\frac{v_{5}^{2}}{2}+z_{5}\right)\right] \\
& \left.q_{\text {out }}-0=w_{c w}\left[h_{6}+0+0\right]-\left(h_{5}+0+0\right)\right] \\
& q_{\text {out }}=w_{c w}\left(h_{6}-h_{5}\right)
\end{aligned}
$$

where

$$
\begin{aligned}
& q_{\text {out }} \text { - heat removed from working fluid after it has } \\
& \text { passed through turbine } \\
& W_{C W} \text { - cooling water flow rate } \\
& h \text { - enthalpy of fluid }
\end{aligned}
$$

Transforming Equation 4.17 we have

$$
\begin{aligned}
& \frac{P \cdot q_{\text {out }}}{P}=\frac{P \cdot I^{q_{\text {in }}}-P_{I}}{P} * \frac{1 / q_{\text {in }}}{1 / q_{\text {in }}}=w_{C w}\left(h_{6}-h_{5}\right) \\
& \frac{P(l-E)}{E}=w_{C w}\left(h_{6}-h_{5}\right)
\end{aligned}
$$

where $E=\frac{p}{q_{\text {in }}}-$ efficiency

for $h=c_{p} D T c w$

and $\mathrm{DT}_{\mathrm{CW}}$ - temperature increase, ${ }_{\mathrm{F}}$, in cooling water through heat exchanger 
Equation 4.19 becomes, after a little rearranging

$$
\frac{W_{C W}}{P}=\frac{1-E}{E} \frac{1}{C_{P} D T}
$$

Assuming

$$
\begin{aligned}
& \mathrm{E}=\text { plant efficiency }=40 \% \\
& \mathrm{C}_{\mathrm{p}}=1 \mathrm{Btu} / 1 \mathrm{~b}_{\mathrm{m}}{ }_{\mathrm{F}} \\
& \mathrm{DT}_{\mathrm{CW}}=20^{\circ} \mathrm{F}
\end{aligned}
$$

Equation 4.20 is now

$$
\frac{\mathrm{W}_{\mathrm{CW}}}{\mathrm{P}}=\frac{1-.4 / .4}{\mathrm{Btu} / \mathrm{hr}} * \frac{1 \mathrm{~b}_{\mathrm{m}}{ }^{\circ} \mathrm{F}}{1 \mathrm{Btu} \times 20^{\circ} \mathrm{F}} * \frac{3413 \mathrm{Btu} / \mathrm{hr}}{\mathrm{Kw}} * \frac{10^{3} \mathrm{kw}}{\mathrm{Mw}}
$$

which results in

$$
\begin{aligned}
\frac{W_{C W}}{P} & =255.97 * 10^{3} \frac{1 b_{m}}{h r M w} * \frac{\mathrm{ft}^{3}}{641 b_{m}}+\frac{h r}{3600 \mathrm{sec}} \\
& =1.1 \frac{\mathrm{cfs}}{\mathrm{Mw}}
\end{aligned}
$$

For a plant with an 1800 megawatt capacity we would need approximately 2000 cfs for a rated efficiency of $40 \%$. The data used in the model is summarized as follows:

$$
\begin{aligned}
& \mathrm{W}_{\mathrm{CW}}=2000 \mathrm{cfs}=\mathrm{QIN} \\
& \mathrm{DT}_{\mathrm{CW}}=12^{\circ} \mathrm{C}=\mathrm{TIN}
\end{aligned}
$$

These two values represent reasonable values but certain engineers might prefer to use a cooling water rate 
based on $1500 \mathrm{cfs} / 1,000$ megawatts or a $\mathrm{DT}_{\mathrm{CW}}=25^{\circ} \mathrm{F}$. There are so many possible choices of flow rates, temperature increases and site locations that the model is structured to handle these many personal preferences in user production runs.

Also, it should be kept in mind, that a power plant generally has an average power production rate below the 95\% maximum output rate under peak load conditions to further complicate environmental studies.

\section{c. 5. Bay Zonal Divisions}

The bay was divided into six major geographically similar sections each with various subsections that comprise the main hydrodynamic elements of the model. This is seen in Figure 4.5. The Rome Point area will affect primarily zone 1 .

\section{C.6. Rome Point Area}

An enlarged section of Narragansett Bay map Figure 4.10 for the Rome Point area is seen in Figure 4.6 . In the prediction portion of this report, isotherms will be drawn in, with average temperature values included in each box. 


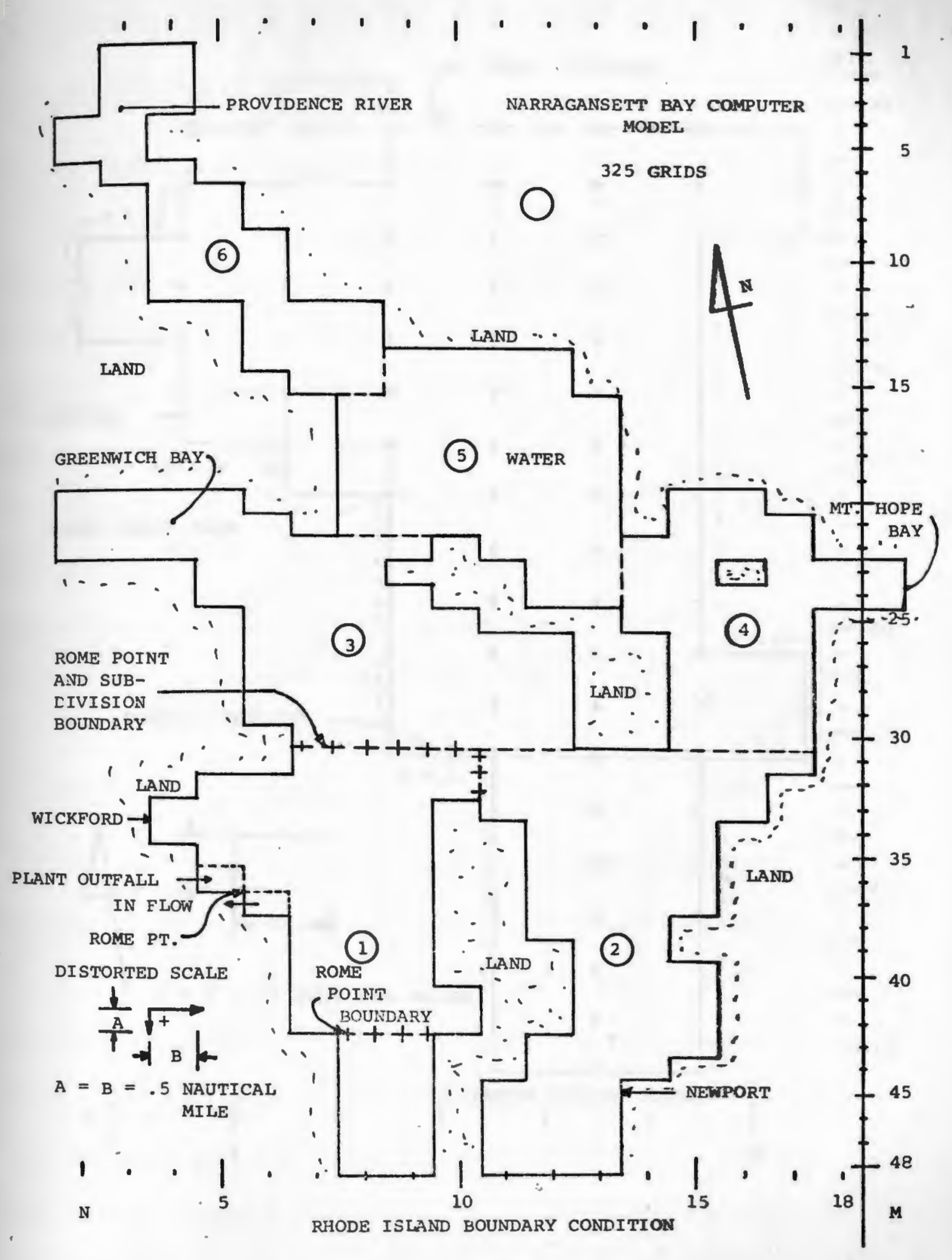

FIGURE 4.5. NARRAGANSETT BAY ZONAL DIVISIONS 


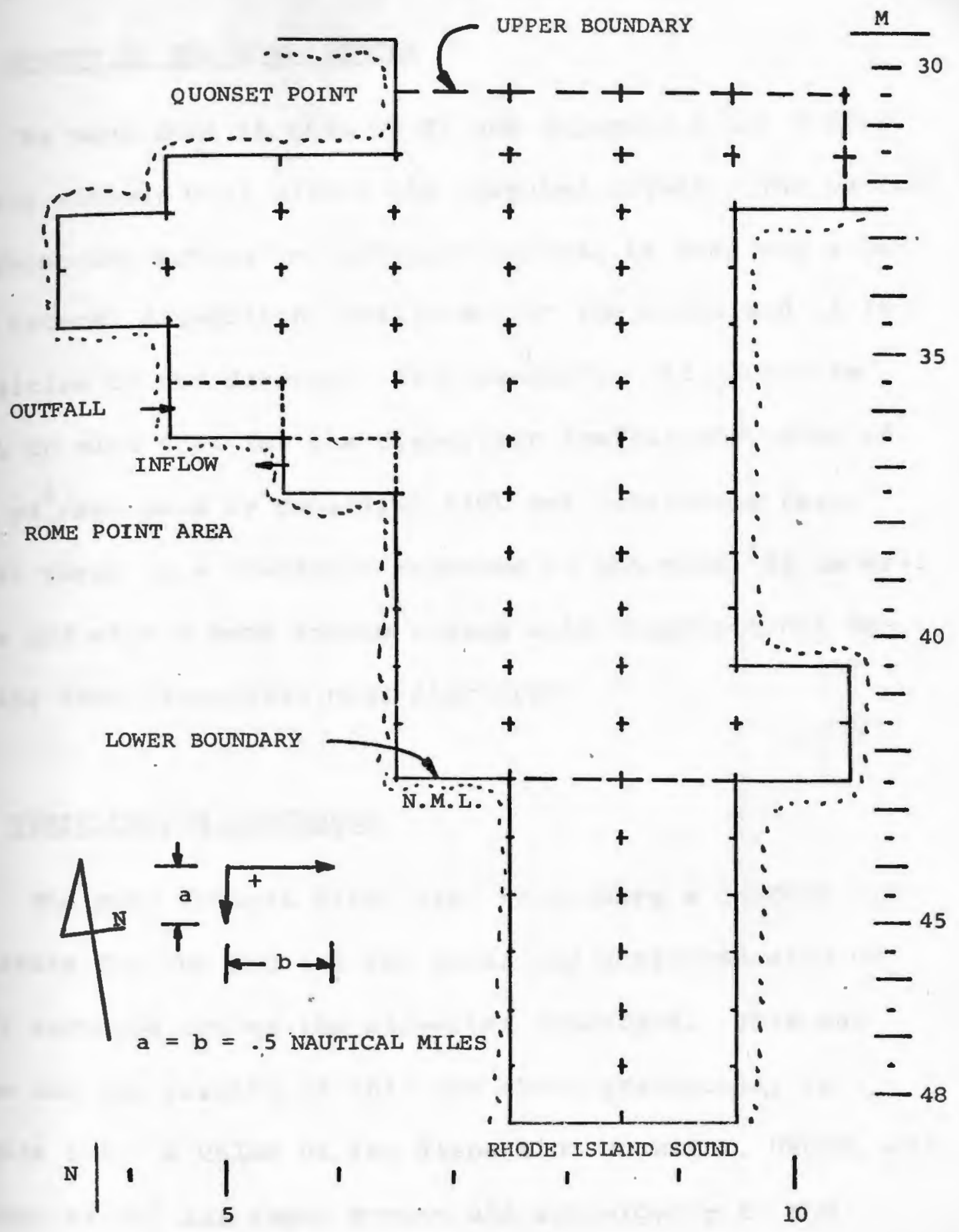

FIGURE 4.6 - ROME POINT AREA 
V. GENERAL STUDIES OF TEMPERATURE MODEL BEHAVIOR

\section{A. EFFECT OF THE DIFFERENCES}

As mentioned in Chapter II and Appendix D the differencing schemes will affect the computed values. The central differencing scheme is preferred because it does not alter the natural dispersion coefficient in the model and is insensitive to the divergent flow patterns. It should be kept in mind that for the dispersion coefficient value of $5.0 \mathrm{yd}^{2} / \mathrm{sec}$ used by sapulding (16) and considered realistic there is a transient resporse j.r the model of several days and with a heat source causes wild computational behavior that propaugates near öischarge.

\section{B. VERIFICATION PROCEDURE}

The most logical first step is to have a uniform temperature for the Bay and its exits and entrances with no heat exchange across the air-water interface. This was done and the results of this are shown graphically in Figure 5.1. A value of the dispersion constant, UPCON, was chosen as 500 for rapid mixing and convergence to the steady state bay temperature. This procedure required two hours of computer time.

The energy loss is only $0.03 / 21: 00$ or 0.14 percent arop 


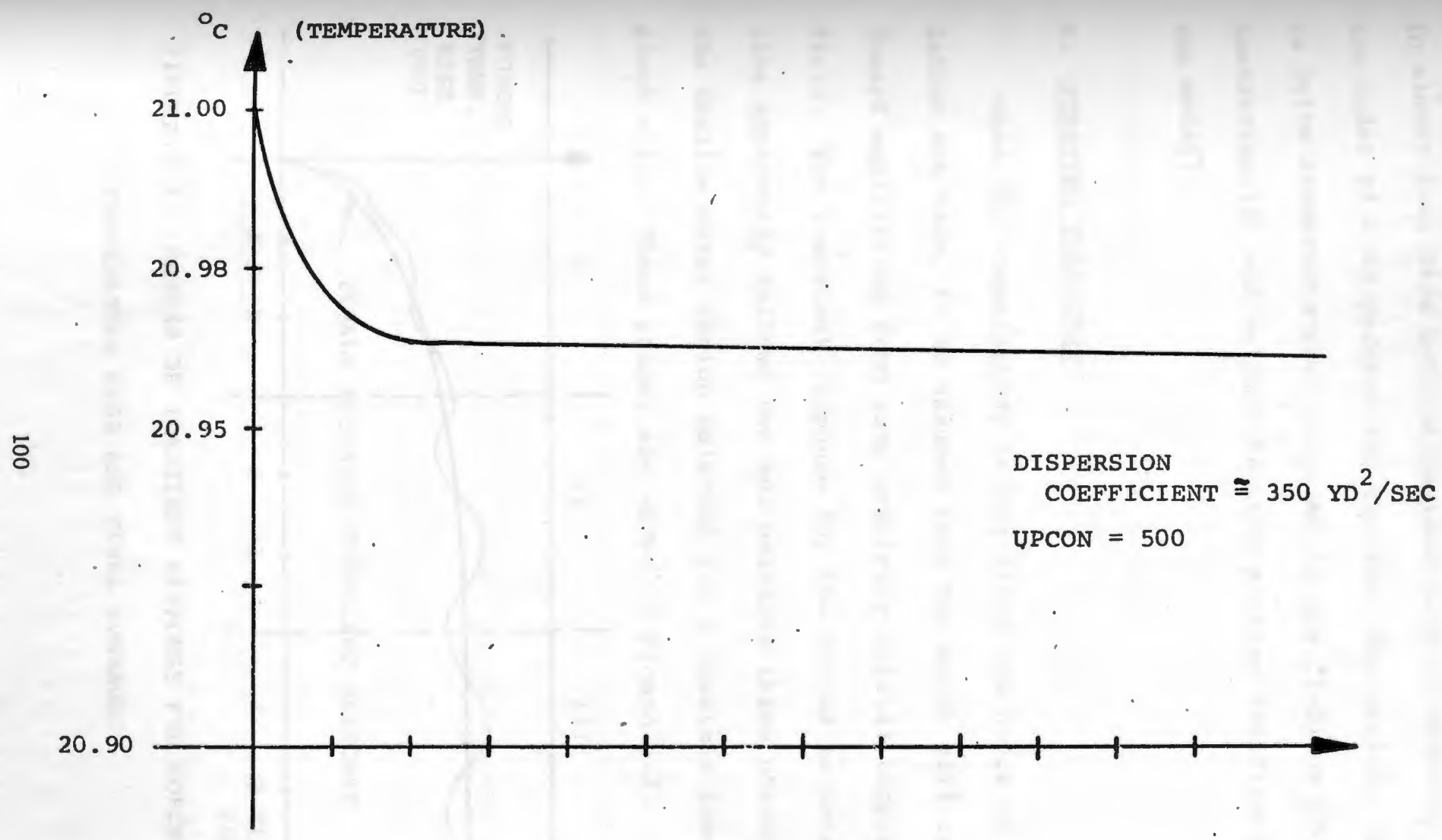

FIGURE 5.1. ENERGY BALANCE FOR BAY, UNIFORM TEMPERATURE CASE 
in almost four days but the maximum rate of decrease is of the order of 0.05 percent for the four day period. This is quite acceptable when compared to the findings of Leendertse (2) and establishes the primary verification of the model.

\section{c. STARTING TRANSIENT}

When the computations during first few hours of simulation are made, it is assumed that the model will tend toward equilibrium from some arbitrary initial temperature field. The transient response for the forced temperature rise apparently follows two and possibly three phases for the shallow water region selected for a possible power plant site. These phases are shown in Figure 5.2.

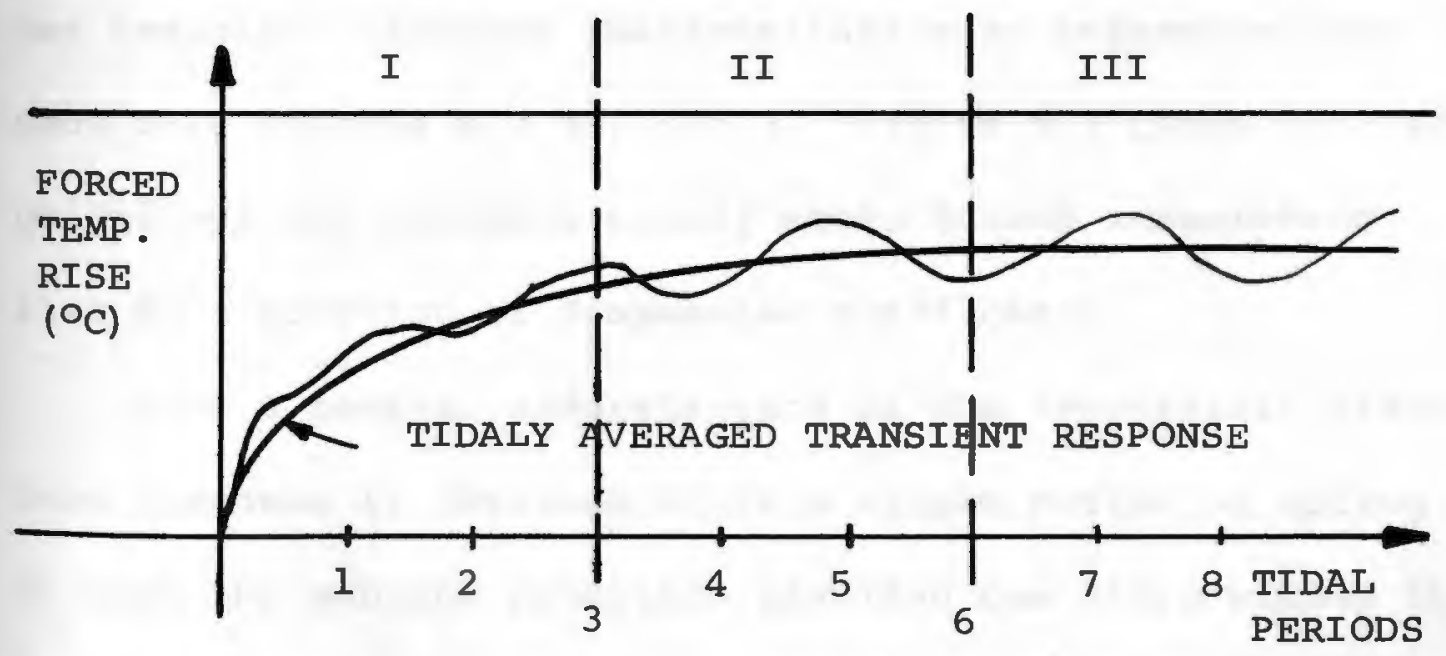

FIGURE 5.2. PHASES OF TRANSIENT RESPONSE FOR FORCED TEMPERATURE RISE AND TIDAL AVERAGES 
Phase I is primarily the rapid increase in the temperature to within 80-90 percent of the steady state value. Steady state means that the apparent temperature average from tidal cycle to tidal cycle is at most a gradual but regular change. Phase II will consist of the alignment of the temperature peaks and dips with some sort of tidal regularity. Finally, Phase III, not always distinct from II, will represent the level at which we have established some steady state value for the forced temperature rise. Further investigation is necessary to determine how steady state values vary over an average monthly variation of tidal cycles. The steady state is emphasized as the apparent average of the temperature oscillation that may itself have a much larger period of oscillation. Each grid has its own transient response characteristics so reference here is made only to grid $m=35, n=5$. Figure 5.3 gives general guidelines for reaching steady state forced temperature rise as a function of dispersion coefficient.

Once a general understanding of the temperature transient response is obtained it is a simple matter of adding it onto the ambient condition provided one stays within the bounds of the linearization assumptions explained in chapter III, Section L. 


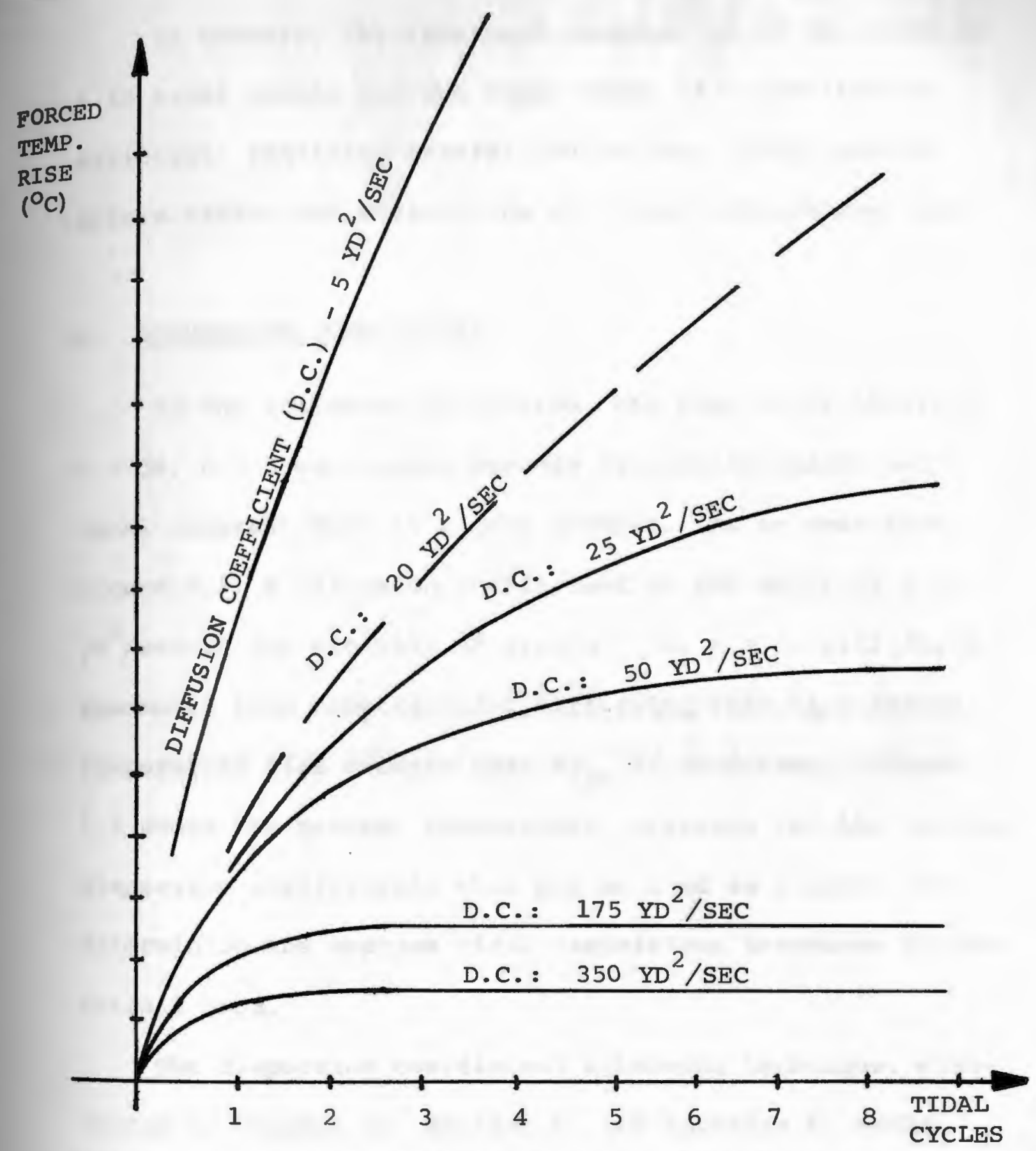

FIGURE 5.3. THE ESTABLISHMENT OF THE STEADY STATE TIDALY AVERAGED VALUES OF FORCED TEMPERATURE RISE AS A FUNCTION OF DIFFUSION COEFFICIENT FOR GRID $m=35, n=5$ 
In summary, the transient response is of the order of 5-10 tidal cycles for the lower range of dispersion coefficient; requiring careful preliminary investigation before making any evaluations of forced temperature rise.

\section{DISPERSION COEFFICIENT}

In the following discussion, the Rome Point location $m=36, n=5$ was chosen because its shallow depth and local interest make it a good example. As is seen from Figure 5.3, a diffusion coefficient of the order of 5-20 $\mathrm{yd}^{2} / \mathrm{sec}$ in the vicinity of grid $\mathrm{m}=36, \mathrm{n}=5$, will force the model into computational difficulty, that is, a forced temperature rise greater than $\mathrm{DT}_{\mathrm{CW}}$ of condenser. Figure 5.3 shows the general temperature increases for the various dispersion coefficients that may be used as a guide for determining the average tidal temperature increases in the outfall area.

The dispersion coefficient enhancing technique, elaborated in Chapter II, Section D, and Appendix D, would enable one to use a value of 5-20 $\mathrm{yd}^{2} / \mathrm{sec}$ in the model and would be as close to the real conditions as possible. At this stage in the development of the model, it was decided to use the value of $50 \mathrm{yd}^{2} / \mathrm{sec}$ throughout the bay as a 


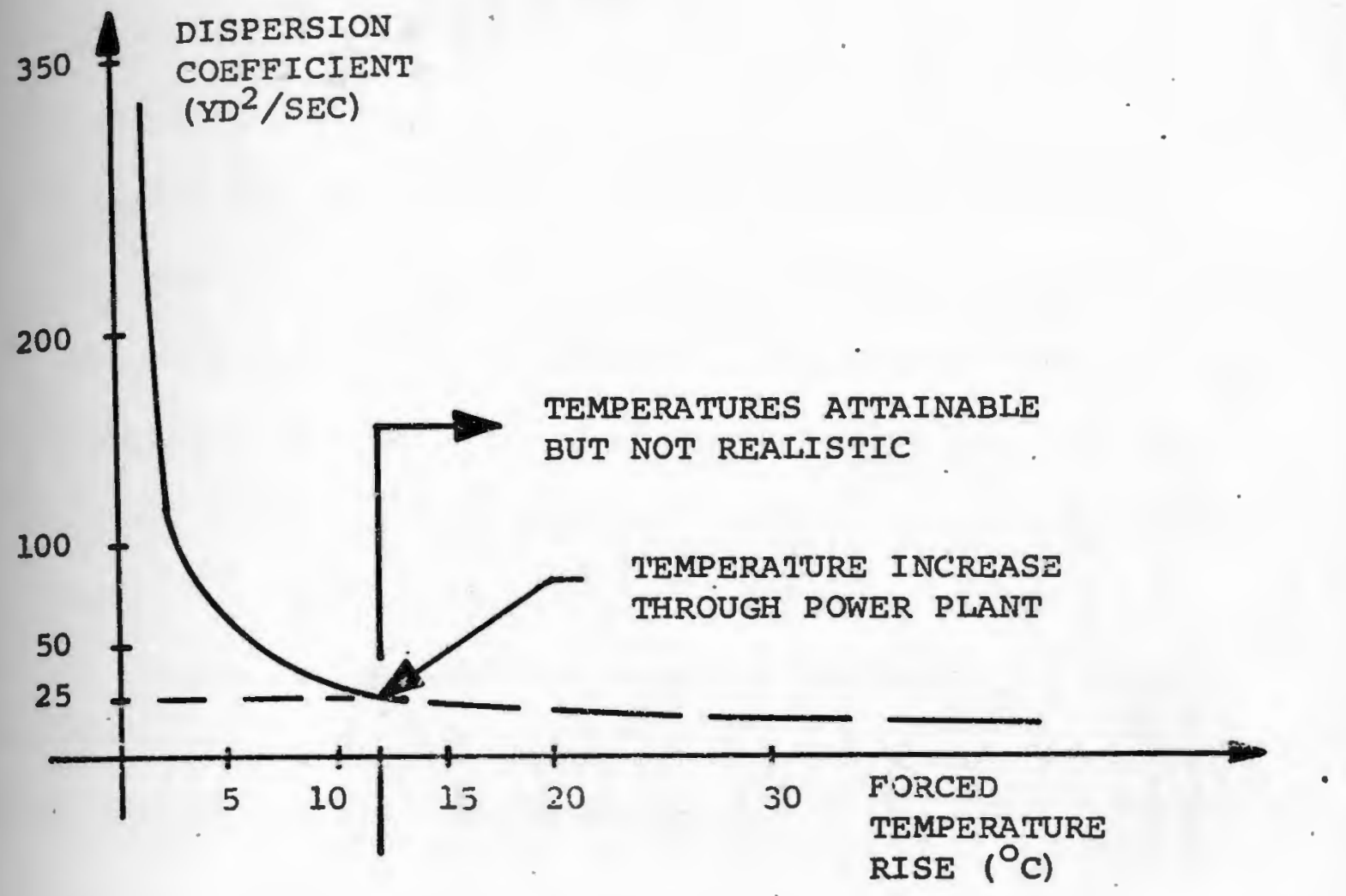

FIGURE 5.4. GRAPHICAL REPRESENTATION OF MINIMUM VALUE OF DISPERSION COEFFICIENT FOR ROME POINT,

$$
m=36, n=5
$$

first estimate in determining the general isotherm pattern around the discharge. With a grid size of about 1000 yards and the model interest in the far field it is felt that the results for a dispersion coefficient of the order of 50 
$y d^{2} /$ sec (UPCON $\left.=100\right)$ would be satisfactory. 
VI. COMPARISON OF CALCULATED RESULTS AND HISTORICAL DATA

\section{A. BACKGROUND}

Given the necessary meterological data, solar inputs, and boundary conditions it is feasible to predict the bay temperature field through thermal model calculations. In any model verification procedure, the comparison between measured and computed values is difficult because of the small area encompassed by measurements versus the larger $1 / 2$ by $1 / 2$ nautical mile area of the model grids. Since model averages vertical water temperature column, surface to bottom temperature measurements continuously taken on area wide basis, are required to achieve more realistic verification criterion. Being realistic, the reference period July, 1957 was chosen to give insight on where the model and measurements are most divergent because of the dissimilar nature of the model and the historical measurements.

This does not mean that the model has little value, which it does have for large scale simulation, but rather that measurements should be taken on a length and time scale comparable to the model. The summer of 1957 was chosen for comparison because it contains the heaviest concentration of temperature data taken in Narragansett Bay. 


\section{B. MODEL SIMULATION CONDITIONS}

The following conditions were adopted for comparison procedure (see next page).

\section{NARRAGANSETT BAY DATA}

c.1. Narragansett Marine Lab Pier The data obtained from Hicks (37) and Day (38) is plotted in Figure 6.1 along with the computer results. In addition, the lower boundary condition derived from the average of July measurements at Brenton's Reef (31) was changed arbitrarily from 18.5 to $19.5^{\circ} \mathrm{C}$ and this result is also shown in Figure 6.1 .

It is quite clear that the model grid predictions are between $1.0^{\circ} \mathrm{C}$ and $2^{\circ} \mathrm{C}$ too low.

\section{c.2. Newport, Rhode Island}

The Newport Data (41) as presented in Table 6.1 shows reasonable agreement with data.

$\begin{array}{llcl}\text { DATE } & \text { TIME } & \text { MEASURED } & \text { MODEL } \\ \text { JulY } 16 & 11: 30 & 20.0^{\circ} \mathrm{C} & 19.85^{\circ} \mathrm{C} \\ \text { July } 17 & 11: 30 & 20.0^{\circ} \mathrm{C} & 19.90^{\circ} \mathrm{C} \\ \text { July } 18 & 14: 10 & 21.67^{\circ} \mathrm{C} & 20.20^{\circ} \mathrm{C} \\ \text { (Table continued) } & & & \end{array}$


DATE

TIME

MEASURED

MODEL

Monthly Average

Morning

$20.1^{\circ} \mathrm{C}$

$20.0^{\circ} \mathrm{C}$

TABLE 6.1. NEWPORT TEMPERATURE DATA, (41) GRID

LOCATION $\mathrm{n}=15, \mathrm{~m}=40$

c.3. Bay Data

Hicks (37) undertook cruise III between July 15 to July 19, 1957 with a total of 19 stations around the bay. In most cases at least four depth measurements were taken at each station and the average of these was used as a comparison with the model as shown in Table 6.2.

The agreement is good for stations where the temperature in the water column is rather uniform. For the Rhode Island Sound station, where the bottom temperatures go as low as $15.3^{\circ} \mathrm{C}, 3.2^{\circ} \mathrm{C}$ cooler than any temperature in the bay thermal field, the average of measured values are about $0.5^{\circ} \mathrm{C}$ too low.

C.4. Meterological Data

The air temperature measurements taken at T.F. Green Airport (56) can be seen in Figure' 6.2 and they show no extreme activity for this period. Although the monthly 


\begin{tabular}{|c|c|c|}
\hline $\begin{array}{l}\text { VARIABWE } \\
\text { NUMBER }\end{array}$ & CONDITIONS & VALUE \\
\hline 1 & YEAR (YR) & 57. \\
\hline 2 & DAY & 195. \\
\hline 3 & THR (HOUR) & 17. \\
\hline 4 & TMIN (MINUTE) & 48. \\
\hline 5 & TMHOPE (Temperature Mt. Hope Bay) & $21.75^{\circ} \mathrm{C}$ \\
\hline 6 & TRIVER (Temperature of Rivers) & $22.2^{\circ} \mathrm{C}$ \\
\hline 7 & TSOUND (Temperature of R.I. Sound) & $18.50^{\circ} \mathrm{C}$ \\
\hline 8 & TBNB (Temperature Field) & $21.0^{\circ} \mathrm{C}$ \\
\hline 9 & $\begin{array}{l}\text { IMODES (1-Upstream; 2-Central } \\
\text { Differencing) }\end{array}$ & 2 \\
\hline 10 & RDCNP (Temperature Read In, ${ }^{\circ} \mathrm{C}$ ) & False \\
\hline 11 & $\begin{array}{l}\text { UPCON (Dispersion Coefficient } \\
\text { Constant) }\end{array}$ & $\begin{array}{l}500 \times \text { Elder's } \\
\text { Value/5.93 }\end{array}$ \\
\hline 12 & $\begin{array}{l}\text { QIN (Source Flow Rate CFS, i.e. } \\
\text { Power Plant) }\end{array}$ & 0.0 \\
\hline 13 & $\begin{array}{l}\text { TIN (Cooling water Temperature } \\
\text { Increase) }\end{array}$ & $12^{\circ} \mathrm{C}$ \\
\hline 14 & SITE (Power Plant Output and Input) & $\begin{array}{l}100 \text { (F low Out: } \\
n=5, \quad m=36 . \\
\text { Flow In: } n=6, \\
m=37)\end{array}$ \\
\hline 15 & Plotting Time & 96 Hours \\
\hline 16 & Program No. & 12271 \\
\hline 17 & Date of Run & $1 / 26 / 73$ \\
\hline
\end{tabular}




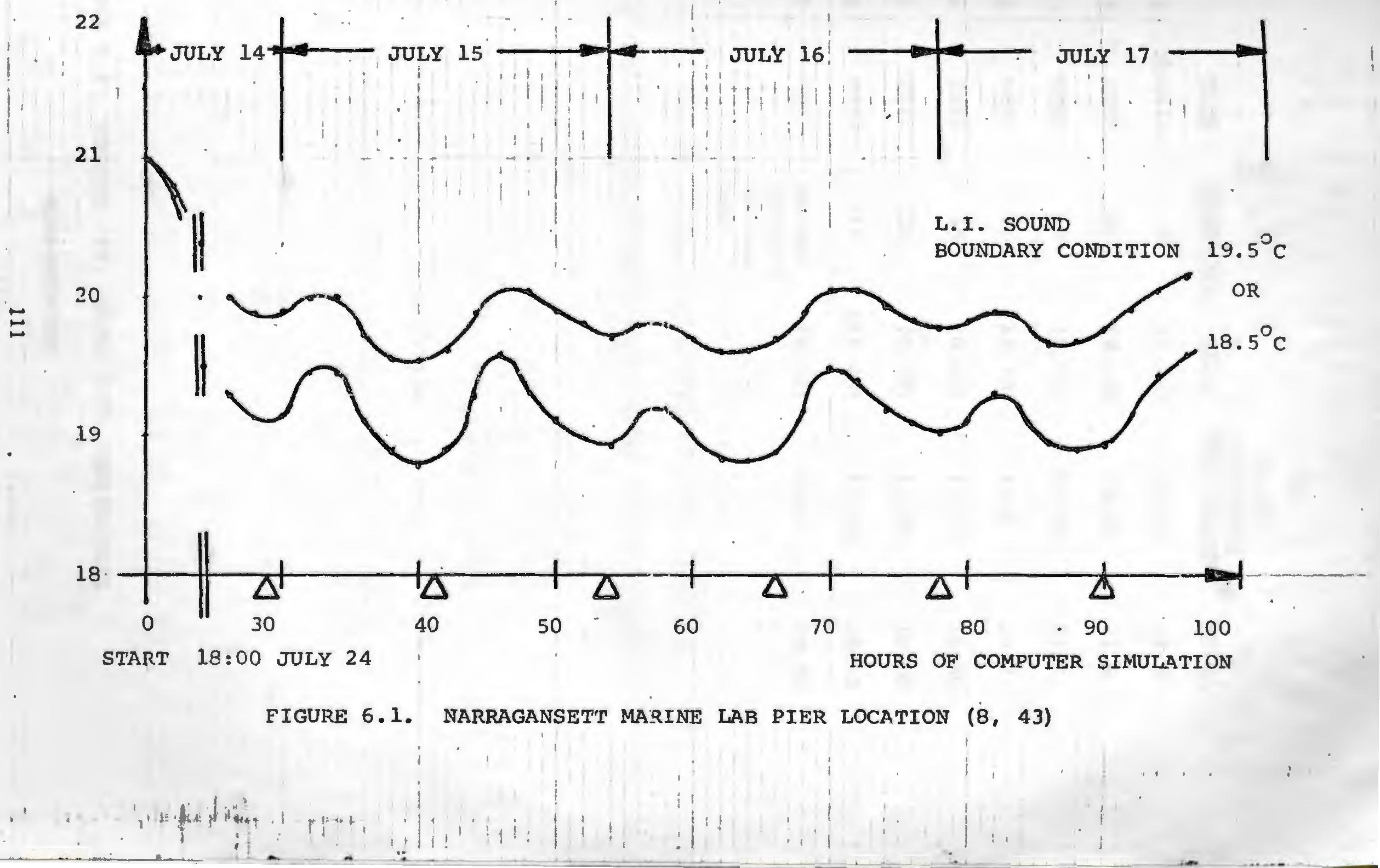




\begin{tabular}{|c|c|c|c|c|c|c|}
\hline DATE & & TIME & STATION & GRID & $\frac{\text { AVERAGED }}{\text { MEASUREMENT }}$ & $\begin{array}{r}{ }^{\circ} \mathrm{C} \\
\text { MODEL } \\
\end{array}$ \\
\hline July & 15 & Morning & 5 & $(3,21)$ & 23.00 & 22.9 \\
\hline July & 15 & 0855 & 10 & $(9,28)$ & 21.40 & 21.8 \\
\hline July & 15 & 0810 & 13 & $(8,33)$ & 20.60 & 21.7 \\
\hline July & 16 & 0850 & 14 & $(13,38)$ & 18.5 & 20.2 \\
\hline July & 16 & 1058 & 15 & $(8,41)$ & 18.75 & 18.50 \\
\hline July & 16 & 1012 & 16 & $(8,48)$ & 17.90 & 18.50 \\
\hline July & 16 & 0950 & 17 & $(12,48)$ & 17.10 & 18.50 \\
\hline July & 17 & 1445 & $\begin{array}{l}\text { Narra- } \\
\text { gansett } \\
\text { Marine } \\
\text { Lab }\end{array}$ & $(8,43)$ & 21.0 & 19.50 \\
\hline
\end{tabular}




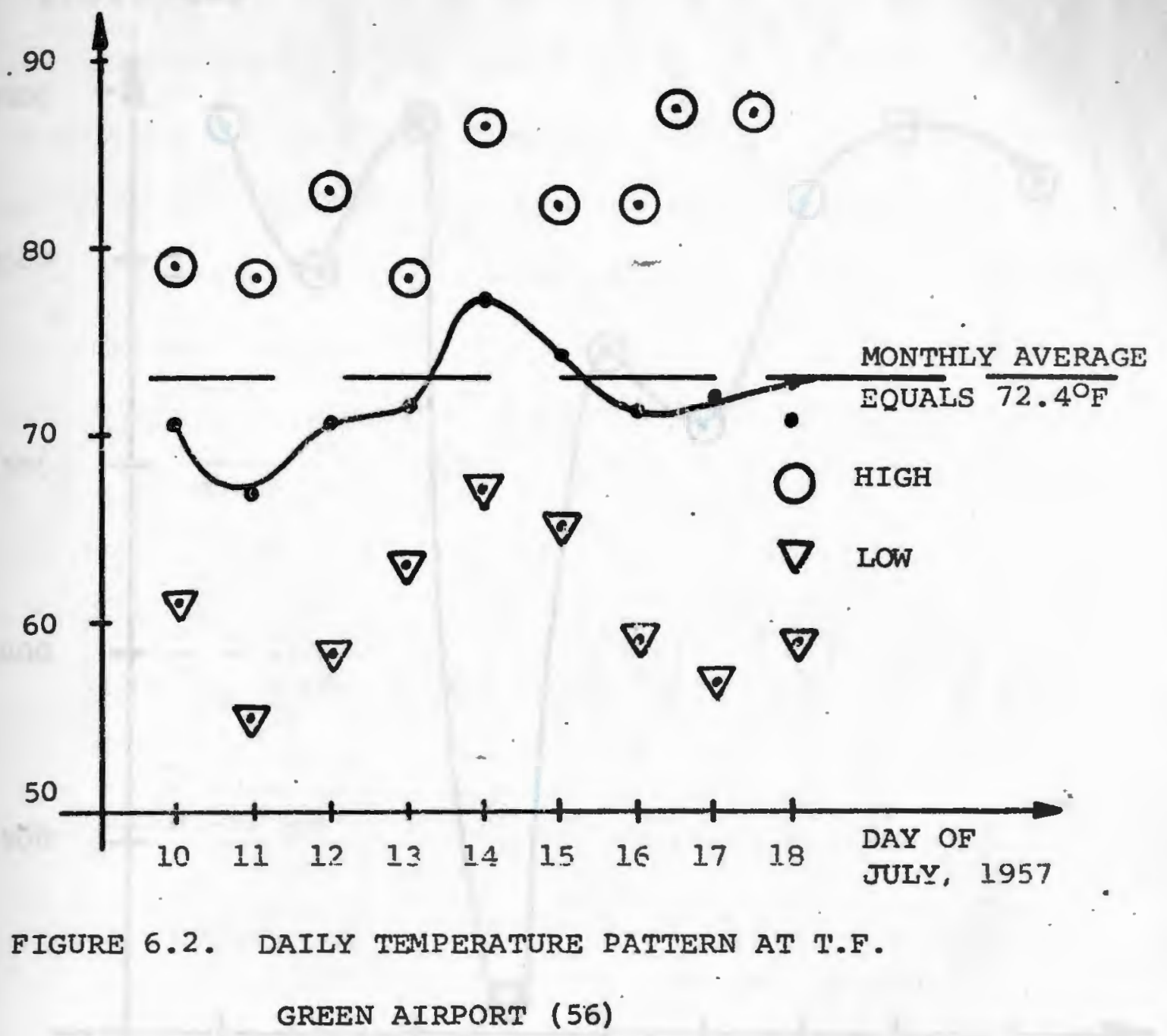

average was $1.0^{\circ} \mathrm{C}$ above normal, wind speeds were in the 10-12 M.P.H. normal range and relative humidity was about 67 percent or within normal range for this measurement period.

Solar input, as recorded at the Eppley Laboratory, Newport, Rhode Island can be seen in Figure 6.3. The solar input for this period is about 25 percent 


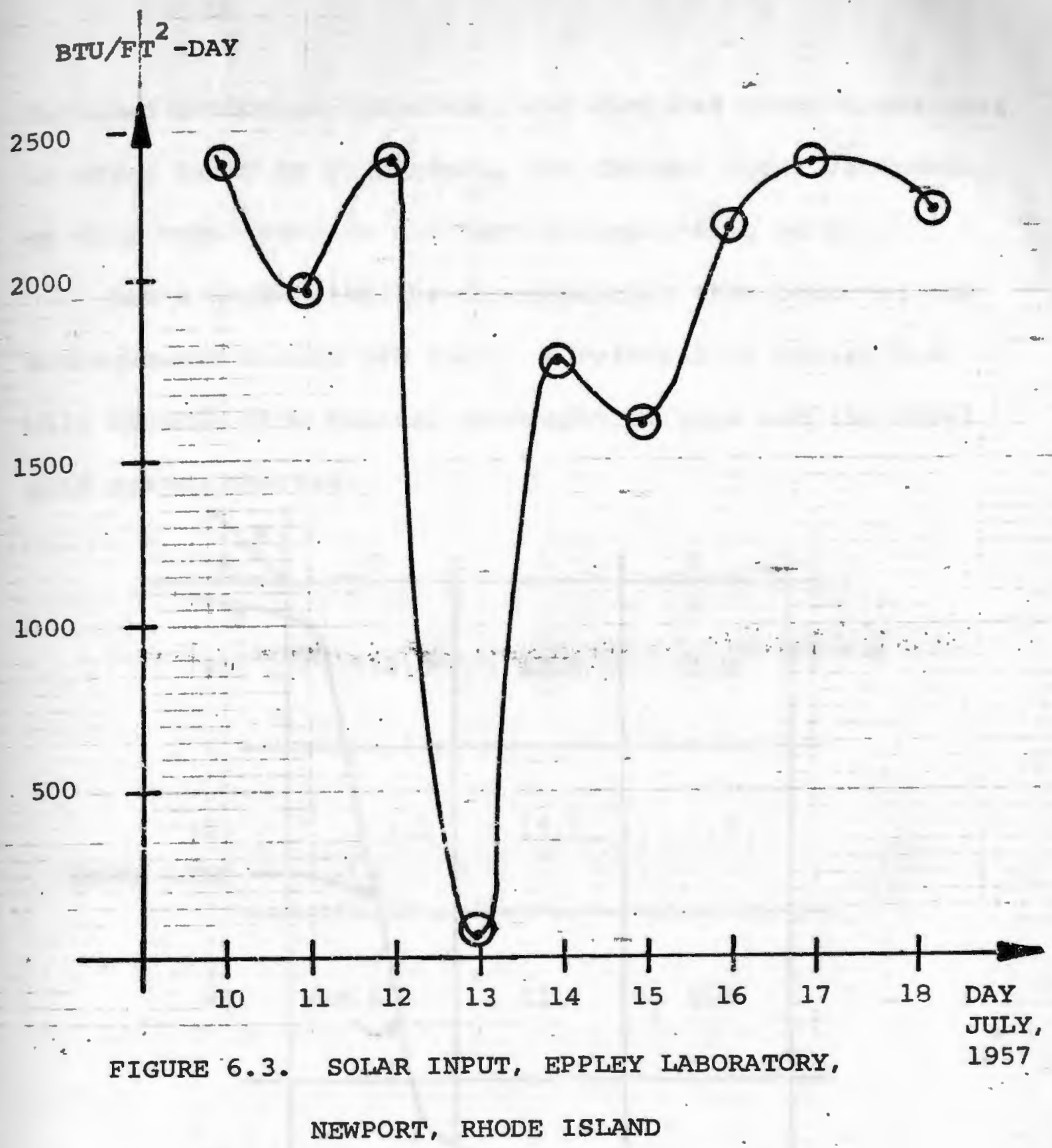

above tine average monthly value of $1920 \mathrm{Btu} / \mathrm{ft}^{2}$-day.

\section{EVALUATIONS}

With the discrepancies in the predicted versus actual values of water temperature, it is certainly not clear that this form of verification is realistic or profitable. With regard to Masch et al (57), where comparisons between 
detailed prototype, physical, and computer predictions were in error by 10 to 25 percent, the thermal model variances, of this magnitude, do not seem disappointing at all.

Let's begin with the discrepancies that occur at the Narragansett Marine Lab Pier. A referral to Figure' 6.4 will clearly show general geographical area and the model grid system overlay.

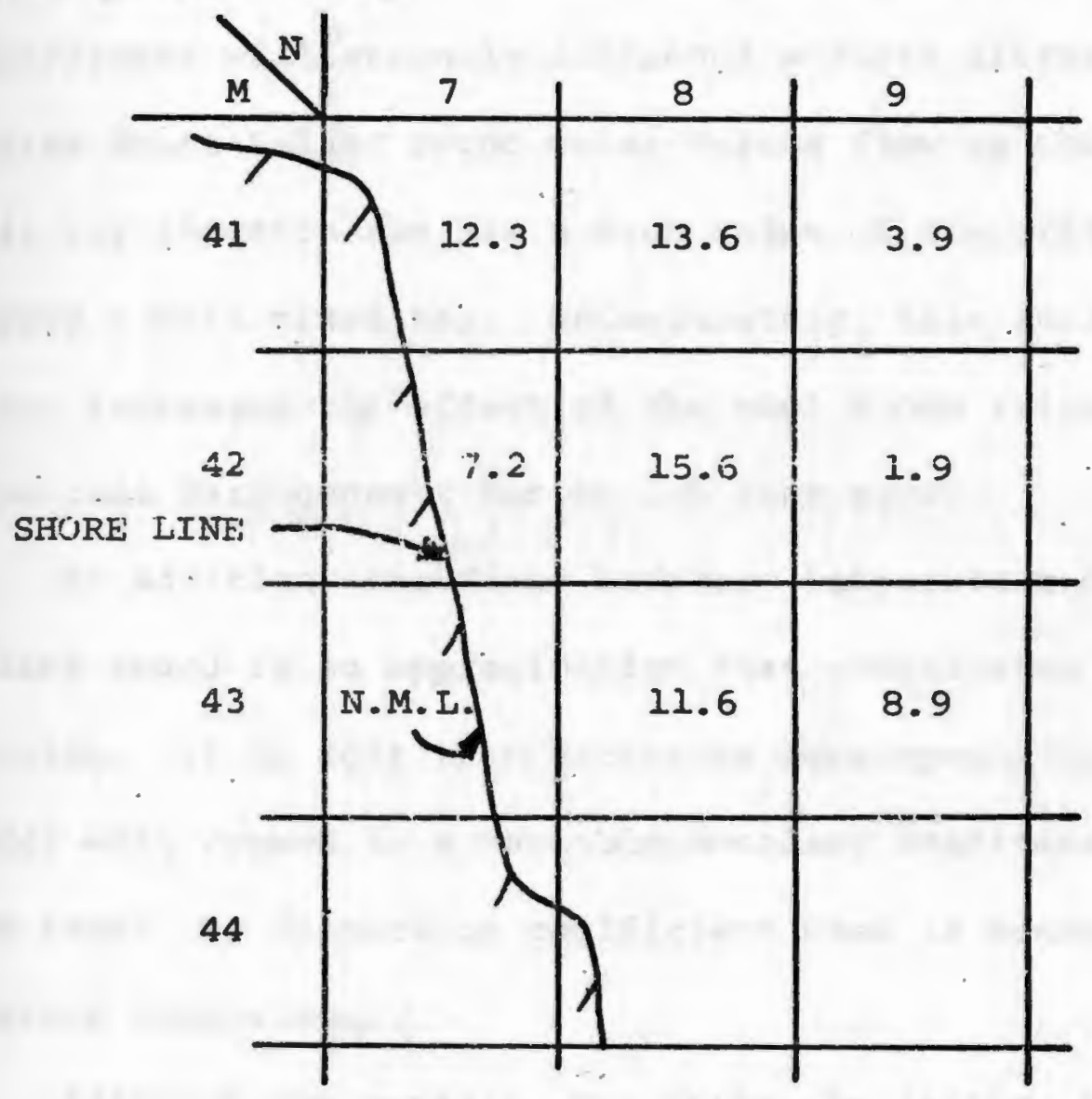

ALI DEPTHS IN YARDS

FIGURE 6.4. NARRAGANSETT MARINE LAB PIER, GENERAL LOCATION AND DEPTHS 
The model can include grid $(7,43)$ with a depth of 7.2 yards which would be a much better representation for the Narragansett Marine Lab than the originally chosen grid $(8,43)$, with a depth of 15.6 yards. The temperatures in grid $(7,42)$, directly north of a more desirable grid $(7,43)$, averaged $0.5^{\circ} \mathrm{C}$ above those in grid $(8,43)$. Since the proposed box would also be a corner box, the dispersion coefficient will strongly influence western diffusion of cooler Rhode Island sound water during flow up the bay. This verification run has a high value of dispersion to insure a well mixed bay. Unfortunately, this inflated value increases the effect of the cool Rhode Island Sound flow past Narragansett Marine Lab Pier area.

In addition, the fixed boundary temperature for Rhode Island sound is an approximation that complicates the prediction. It is felt that extensive development of the model with regard to a variable boundary condition for one tenth the dispersion coefficient used is necessary to improve comparison.

Although not certain, Dr. Hicks, by letter, has expressed a belief that the water temperature data at Marine Lab (38) was taken by a Bristol Recorder from a source at an unspecified depth below the surface and possibly flushed 
through a holding tank with a capacity of several hundred gallons. It is interesting to note that the temperature data obtained by Hicks (37) shows that temperature differences at Narragansett Marine Lab Pier between top and bottom water for the period February 1952 to January 1958 averages $0.2^{\circ} \mathrm{C}$. Referring back to Day (38) we also observe that temperature variations of a $4^{\circ} \mathrm{C}$ during the day at Narragansett Marine Lab Pier appear to be larger than common sense tidal flushing estimates. In Figure 6.5, it is seen for July 9 and 13 that with low solar input, temperature maximum decreases about $0.5^{\circ} \mathrm{C}$ while minimum temperature is unaffected. It appears that with this low solar input, we should be able to estimate depth of the water column if the solar energy is considered evenly distributed. We have,

$$
\begin{aligned}
\text { Solar Input } & =2000 \mathrm{Btu} / \mathrm{ft}^{2} \text { (half day) } \\
& =\text { Mass } * \mathrm{C}_{\mathrm{p}} * \mathrm{DT}
\end{aligned}
$$

where $\mathrm{DT}=.5^{\circ} \mathrm{C}$

$$
\begin{aligned}
& 1000 \frac{\mathrm{Btu}}{\mathrm{ft}^{2}(\mathrm{full} \text { day })}=\text { Depth } \mathrm{x} \text { Unit Area } \mathrm{x} \frac{64 \frac{\mathrm{lb}}{\mathrm{m}}}{\mathrm{ft}^{3}} \\
& x^{1} \frac{\mathrm{Btu}}{\operatorname{lo}_{\mathrm{m}} \mathrm{O}_{\mathrm{F}}} \times \frac{.9^{\circ} \mathrm{F}}{\mathrm{DaY}}
\end{aligned}
$$

after rearranging 



$$
\text { Depth }=20 \mathrm{ft}
$$

with a measured depth of about 20 feet, we conclude that the water temperature variations do follow the above simplistic formulation. Also note in Figure 6.5 the unexplainable $2^{\circ} \mathrm{C}$ temperature increase of minimum temperature on July 17. This sudden increase of $2^{\circ} \mathrm{C}$, in mean water temperature at the Narragansett Marine Lab Pier contributes substantially to the disagreement between the model and measurements because it increases the average water temperature by $1.5^{\circ} \mathrm{C}$. This sudden change in water temperature shows the variability of taking measurements in shallow, inshore water.

This lengthy discussion on the Narragansett Marine Lab Pier temperature measurements can only be resolved by first conducting an extensive detailed area survey around the pier in conjunction with accurate Rhode Island Sound temperature boundary condition measurements. As will be true for all temperature measurements to be discussed, we would have to establish a meterological station closer to the bay, preferrably on the Narragansett Marine Lab Pier to more accurately represent the input conditions.

For the Newport Data (41) agreement was good while for Hicks (37) the data agreed if the vertical structure 
was homogenous. It should be noted that if the $15-16^{\circ} \mathrm{C}$ bottom water temperatures for Rhode Island Sound stations were not included in vertical average the agreement between predicted and actual values would be closer.

\section{E. CONCLUSION}

This attempt at thermal model verification with field measurements while enlightening for general temperature variation shows quite clearly how formidable a task it is to have grid locations agree with temperature measurements to a \pm 5 percent. Since the desired type of measurements for improved verification work would entail about 10 continuously operating data stations which are beyond the scope of department capability no further verification attempts were initiated. Dr. Eidinger (5) discusses the seemingly impossible task of the model verification with field measurements, an undertaking that no one has yet done successfully.

The lack of detailed model spatial agreement with measured temperature data should not detract from the information the model does predict of a more general nature. 


\section{THERMAL MODEL PREDICTIONS}

\section{A. POWER PLANT LOCATION}

The thermal model can place a heat source simulating an electric generating plant in any of the 314 non-boundary grids. The selection of the Rome Point area was made because the area is of local interest and the relative shallow water depth of 10 feet provides a good indication of the computational effectiveness of the model for a specific value of the dispersion coefficient. From a utility viewpoint, the surface discharge in the Rome Point grid, $\mathrm{n}=5$, $m=36$, is inexpensive to construct and the land boundary at $n=6, m=36$ affords reentrainment protection from the intake grid located at $n=6, m=37$ or southeast of the intake.

The general geometry at the Rome Point site can be seen in Figure 7.1. The shaded area covers the most likely intake and discharge locations.

\section{B. INTRODUCTION TO EXPERIMENTAL RUNS}

The following experimental sections will contain various results that clearly show the effectiveness of the thermal model in predicting isothermal patterns around 


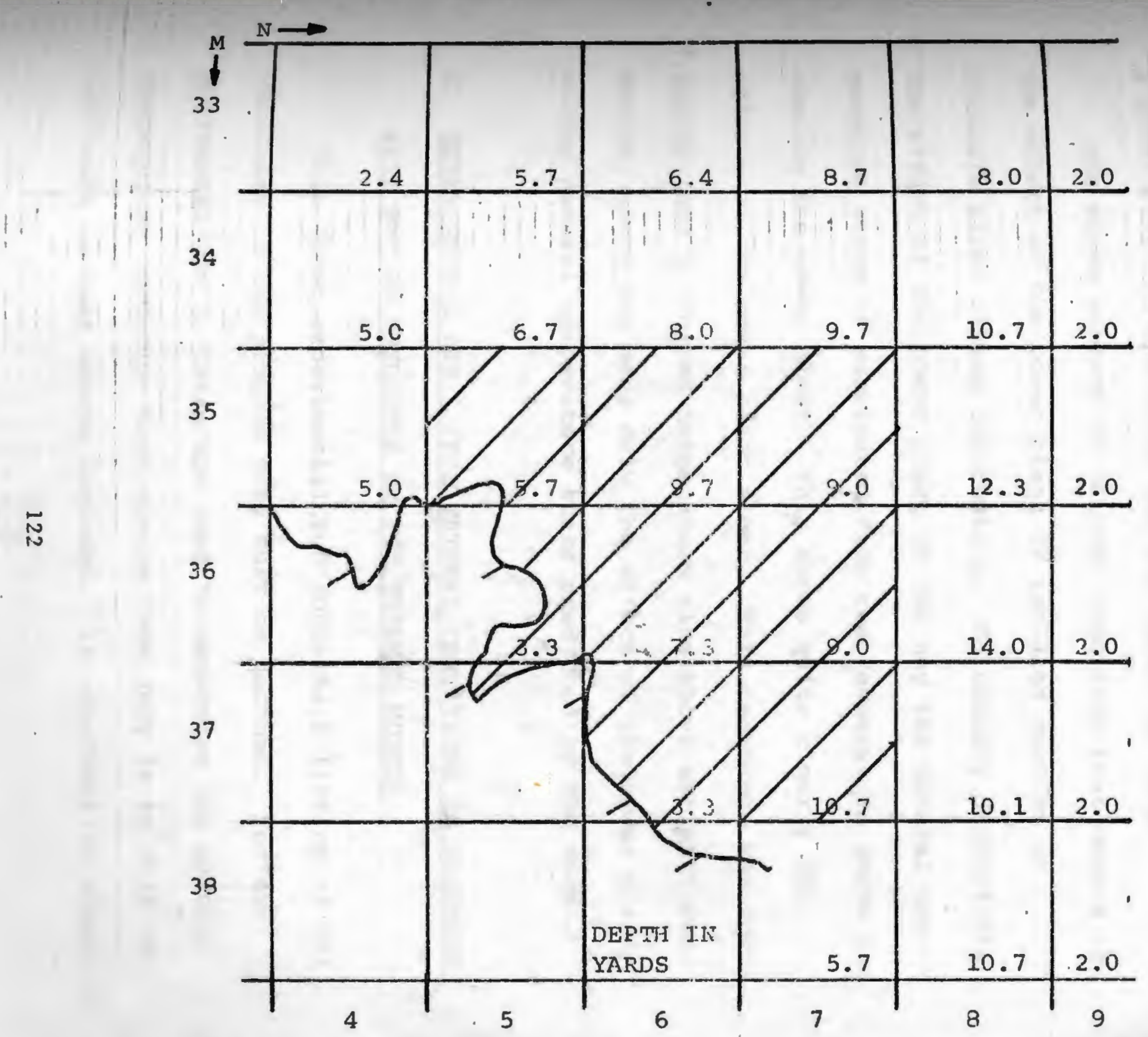

FIGURE 7.1. ROME POINT AREA WITH MODEL GRIDS, DISCHARGE LOCAATIONS AND DEPIHIS 
a particular heat source. The natural or non-power plant predictions show the thermal patterns that can be measured in the bay. The natural plus power plant predictions are an indication of the thermal pattern that would occur with a power plant in operation for the specified data.

The above ambient or natural condition that occurs if the effect of the power plant is isolated results in valuable plant siting information. To clearly demonstrate the effect of the power plant on the bay the natural temperature state is subtracted from the temperature state including the power plant. This shows quite clearly the effects of the power plant alone. This technique was formulated into a 'forced temperature rise above ambient' condition, where one sees only the effect of the power plant on the natural temperature state predicted by the model.

\section{EXPERIMENTAL RUN 1 (THE NATURAL CONDITIONS IN NARRAGAN- SETT BAY AS PREDICTED BY THE THERMAL MODEL)}

This first experimental run contains a listing of all variables in the program that must be defined. For experimental run 1 , these are used to determine the natural temperature condition that occurs from July 14 to July 18 , 1957 with no heat source included. In an effort to simplify 
the discussion of the following experimental runs only the variables that are different from run 1 are listed.

\section{TABLE 7.1. PROGRAM VARIABLES}

\section{VARIABLE}

NUMBER

1 YEAR

2

3

4

5 TMHOPE (Temperature for the Mt.

Hope Bay Boundary Condition, (B.C.))

6 TRIVER (Temperature for the

$22.2^{\circ} \mathrm{C}$

River B.C.)

7 TSOUND (Temperature for the Rhode $18.50^{\circ} \mathrm{C}$

Island Sound B.C.)

8 TBNB (Temperature Field in the

$21.0^{\circ} \mathrm{C}$

Bay)

9 IMODES (1-Upstream; 2-Central

Differencing)

10
RDCNP (Temperature field read in, False $\left.{ }^{\circ} \mathrm{C}\right)$ 
11

UPCON (Dispersion Coefficient

500

Constant Times Elder's Value)

12

QIN (Source Flow Rate, cfs)

0.0

13 TIN (Cooling water Temperature

$$
12.0^{\circ} \mathrm{C}
$$

Increase Through Plant)

14 SITE (Power Plant output and

100 (Flow Out:

Input Grids specified)

$n=5, m=36$.

Flow In: $\mathrm{n}=6$, $\mathrm{m}=37$ )

15 DELTAT (Logical Variable. If True

true the model calculates

forced temperature rise, if

false it calculates natural

condition with or without

power plant

16 Plotting Time

68 Hours

17 Program Number

12271

18 Date of Run

$1 / 26 / 73$

\section{c.1. Comments}

The temperature fields, as shown in Figure 7.2

and Figure 7.3, represent a typical display pattern. The relative similarity of isotherms with regard to shape and 


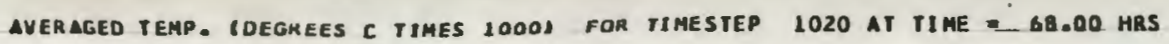

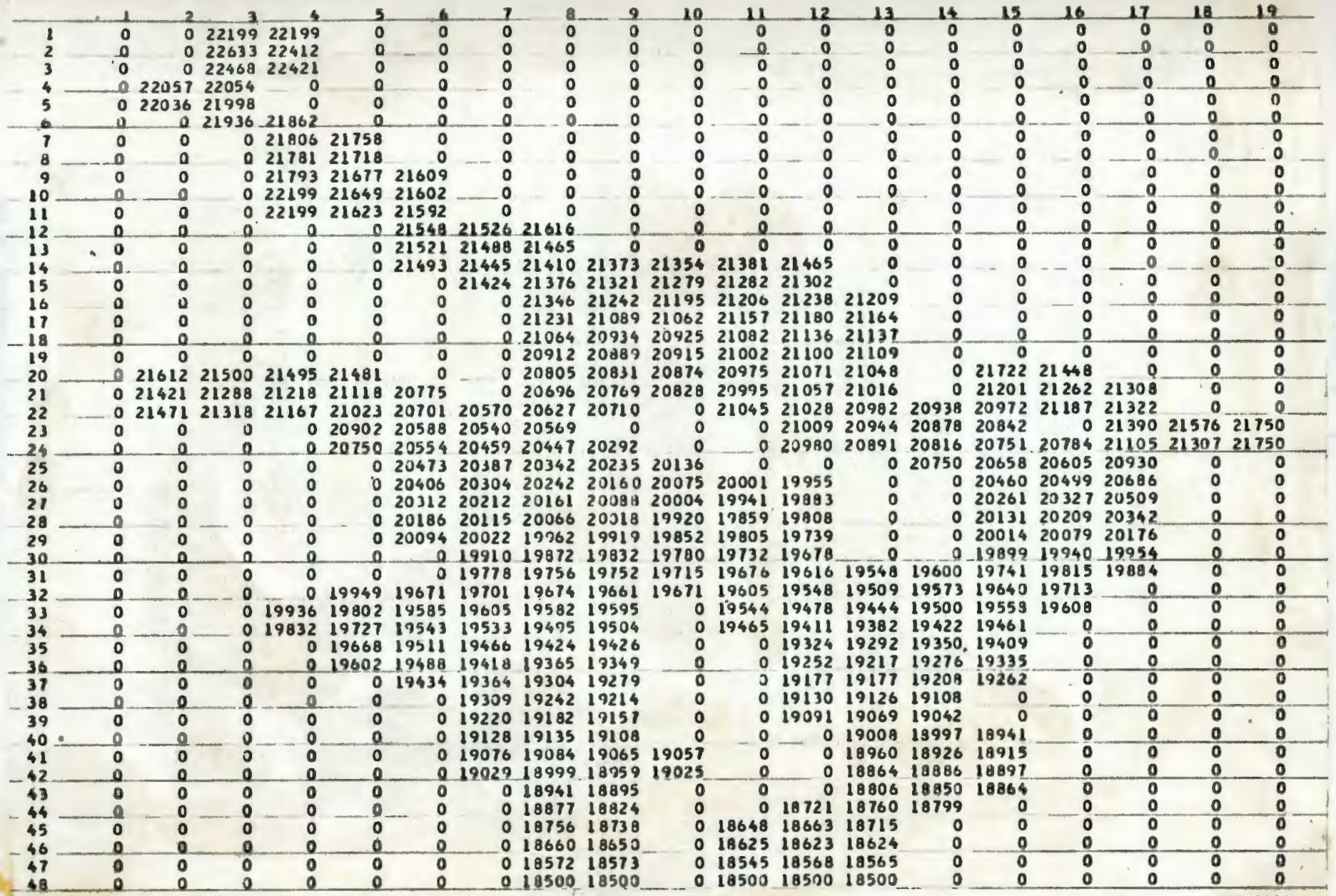

FIGURE 7.2. RUN 1 BAY TEMPERATURE AT 68 HOURS 


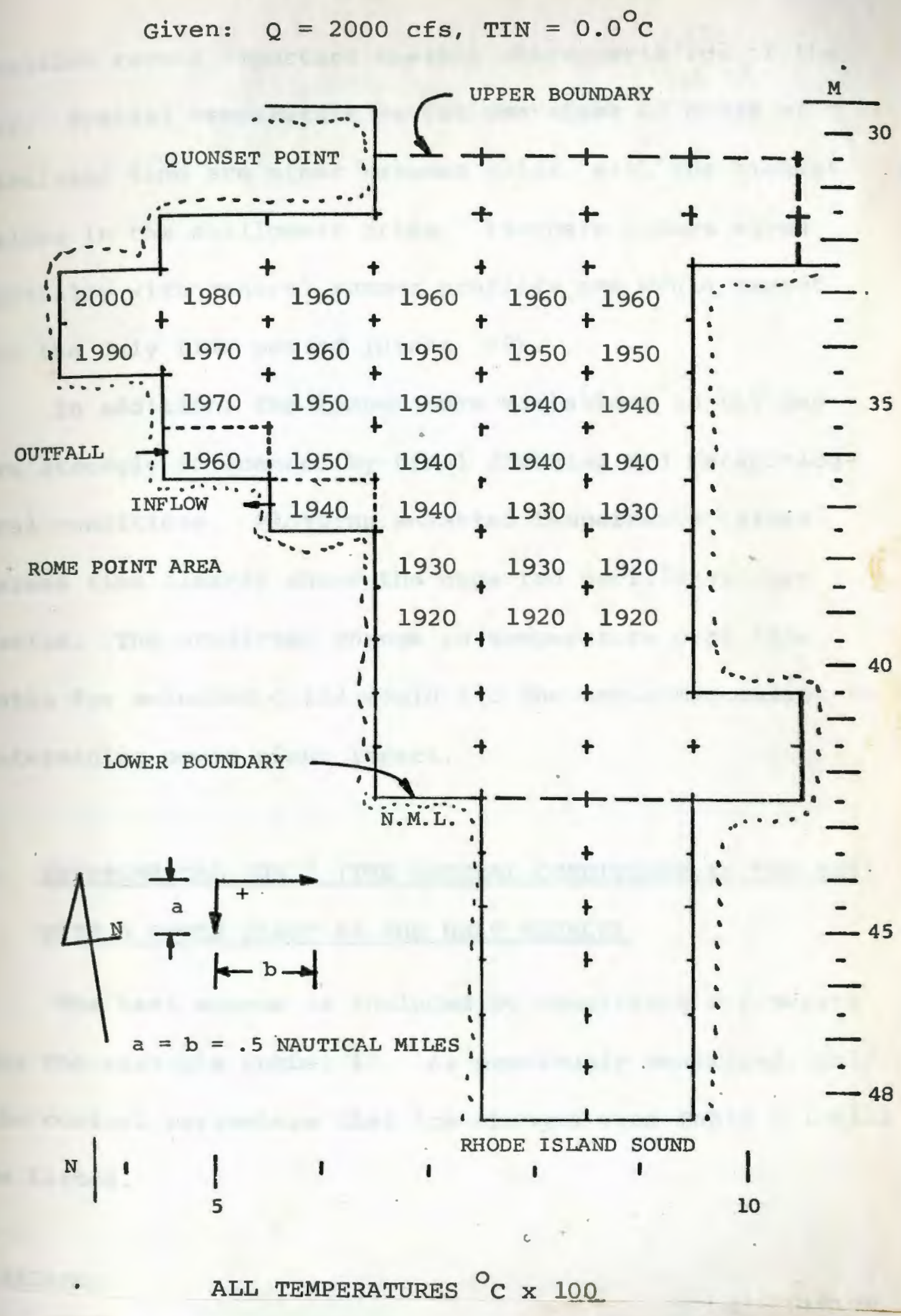

FIGURE 7.3. RUN 1, NATURAL THERMAL FIELD AT 68 HOURS NEAR OUTFALL 
position reveal important thermal characteristics of the bay. Spatial temperature variations after 68 hours of simulated time are minor between grids, with the highest values in the shallowest grids. Isotherm values agree spatially with general summer profiles one would expect for the July time period (Hicks, 58).

In addition, the temperature variations in the bay are strongly influenced by tidal flushing and meteorological conditions. Plotting selected temperature values versus time clearly shows the expected oscillatory behavior. The predicted change in temperature over time ratio for selected grids would aid the environmentalist in determining power plant impact.

D. EXPERIMENTAL RUN 2 (THE NATURAL CONDITIONS IN THE BAY WITH A POWER PLANT AS THE HEAT SOURCE)

The heat source is included by specifying a flowrate for the variable number 12. As previously mentioned, only the control parameters that are changed from Table 7.1 will be listed.

\section{VARIABLE}

NUMBER CONTROL PARAMETER SPECIF ICATION 
17 Program Number

18 Date of Run
11770

$1 / 25 / 73$

D.1. Comments

A typical model predicted heat source distribution in the natural environment can be seen in Figure 7.4. If one subtracts the natural conditions shown in Figure 7.3 from the power plant condition in Figure 7.4 one then obtains Figure 7.5 which shows the forced temperature rise resulting from the heat source in the model.

E. EXPERIMENTAL RUN 3 (THIS PREDICTS ONLY THE TEMPERATURE INCREASE DUE TO HEAT LOAD FROM A POWER PLANT OR FORCED TEMPERATURE RISE)

This run calculates only temperature excess above natural conditions by the variable changes listed below. If the formulation is correct, the thermal field prediction for run 3 should equal the difference in thermal fields between runs 2 and 1 . 
5 TMHOPE (Temperature Mt. Hope Bay) $0.00^{\circ} \mathrm{C}$

6 TRIVER (Temperature of all $0.00^{\circ} \mathrm{C}$

Rivers)

7 TSOUND (Temperature for the $0.00^{\circ} \mathrm{C}$

Rhode Island Sound)

8 TBNB (Temperature Field in the $0.00^{\circ} \mathrm{C}$

Bay)

12 QIN (Source Flow Rate, cfs) 2000

15 DELTAT (Logical Variable. If True

true the model calculates

forced temperature rise, if

false it calculates natural

conditions with or without

power plant)

E.1. Comments

Figure 7.6 shows the result of the forced temperature rise without the natural conditions included. These values are nearly identical to Figure 7.5 and serve to prove the correctness of the forced temperature rise formulation in run 3. 


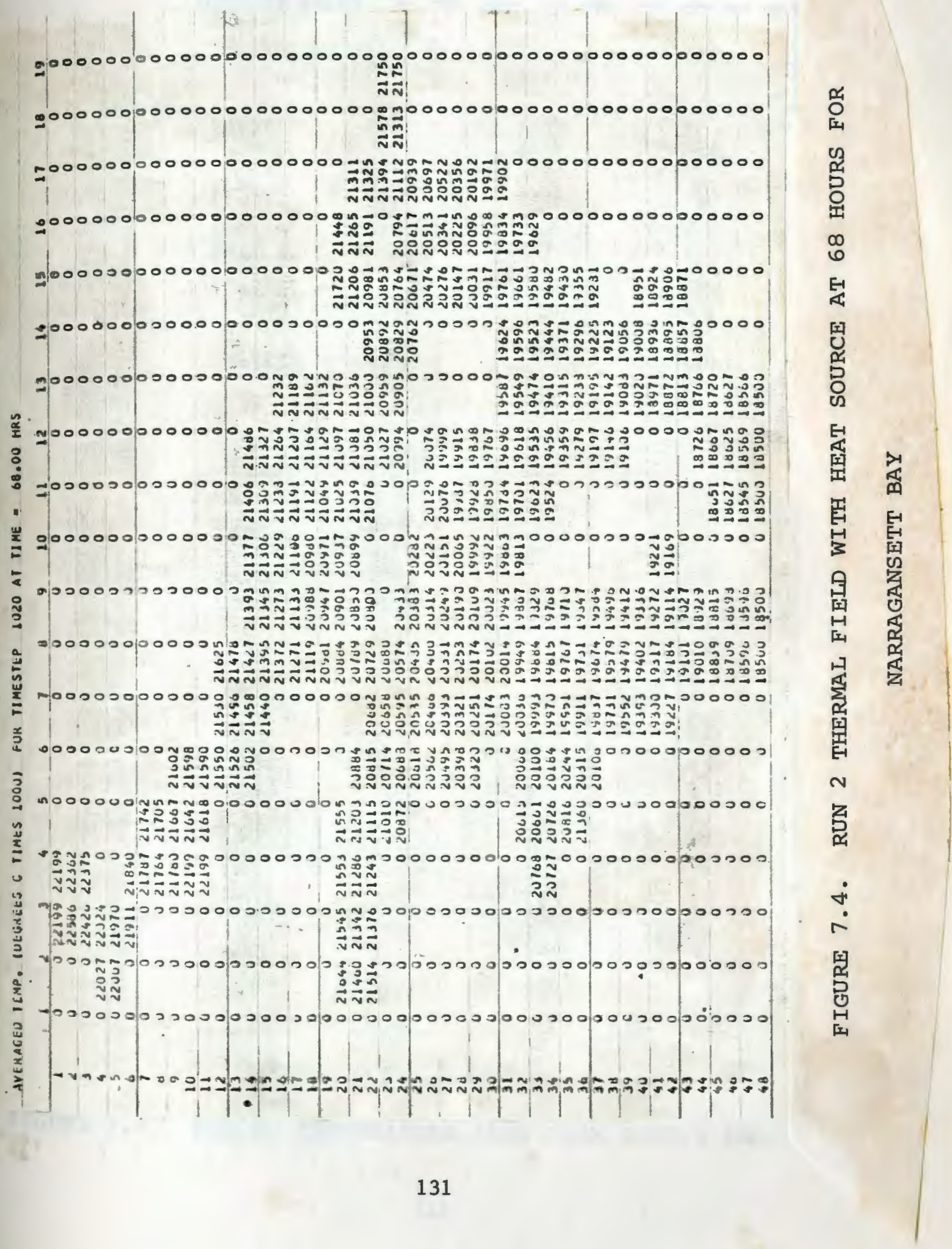


Given: $Q=2000 \mathrm{cfs}, \operatorname{TIN}=12.0^{\circ} \mathrm{C}$

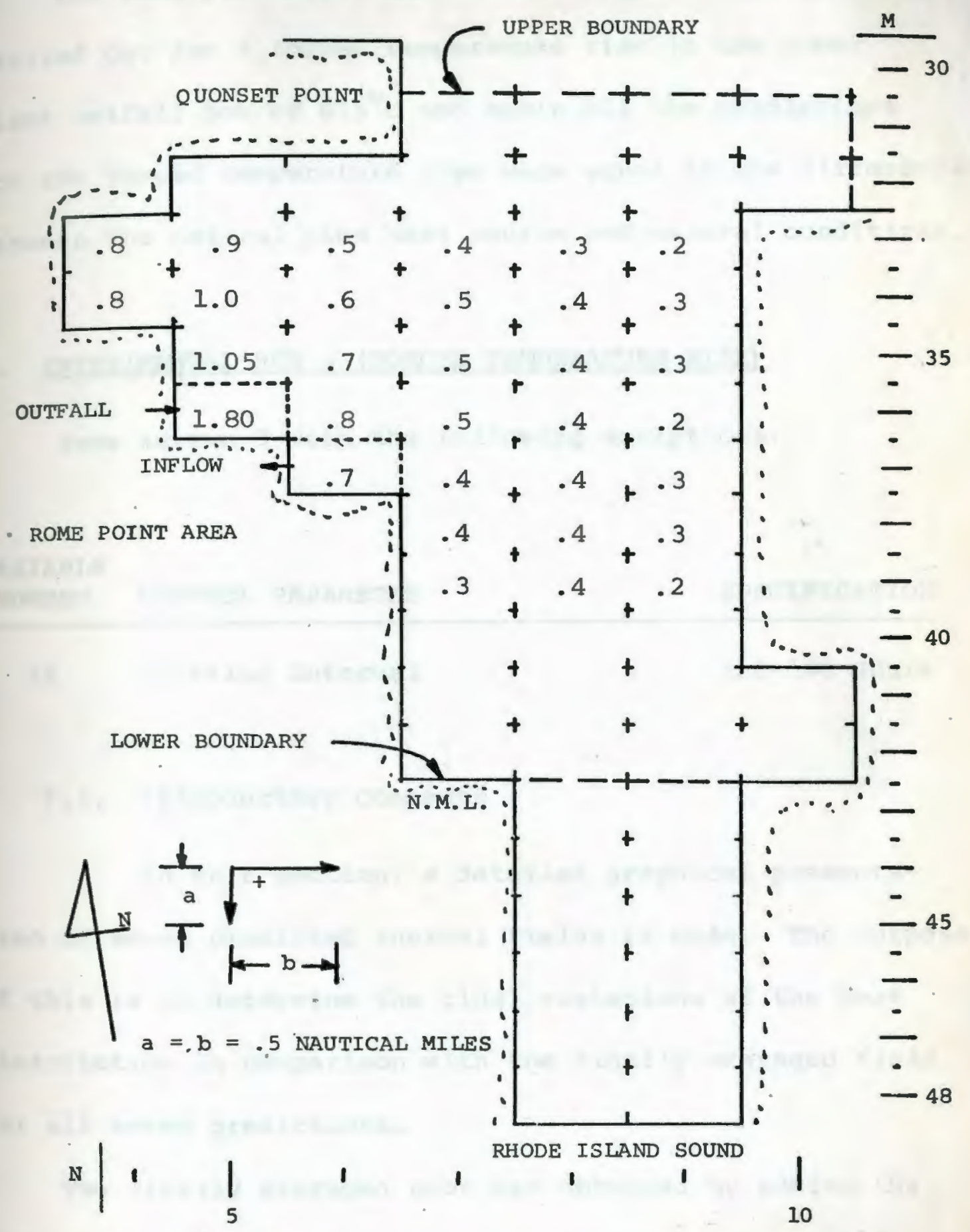

ALL TEMPERATURES ${ }^{\circ} \mathrm{C}$

FIGURE 7.5. FORCED TEMPERATURE RISE FROM RUNS I AND 2 
The same procedure indicated for runs 1 through 3 was carried out for a forced temperature rise in the power plant outfall box of $6.5^{\circ} \mathrm{C}$ and again all the predictions for the forced temperature rise were equal to the difference between the natural plus heat source and natural conditions.

\section{F. EXPERIMENTAL RUN 4 (FORCED TEMPERATURE RISE)}

Same as run 3 with the following exceptions:

\section{VARIABLE}

NUMBER CONTROL PARAMETER

SPECIFICATION

$16 \quad$ Plotting Interval

128-140 Hours

F.1. Introductory Comments

In this section, a detailed graphical presentation of seven predicted thermal fields is made. The purpose of this is to determine the tidal variations of the heat distribution in comparison with the tidally averaged field for all seven predictions.

The tidally averaged plot was obtained by adding the values at $130,132,134,136$, and 138 hours to one half the values at 128 and 140 hours and dividing by six. This weighting procedure was chosen because it allowed the 
Given: $Q I N=2000 \mathrm{cfs}, \operatorname{TIN}=12^{\circ} \mathrm{C}$

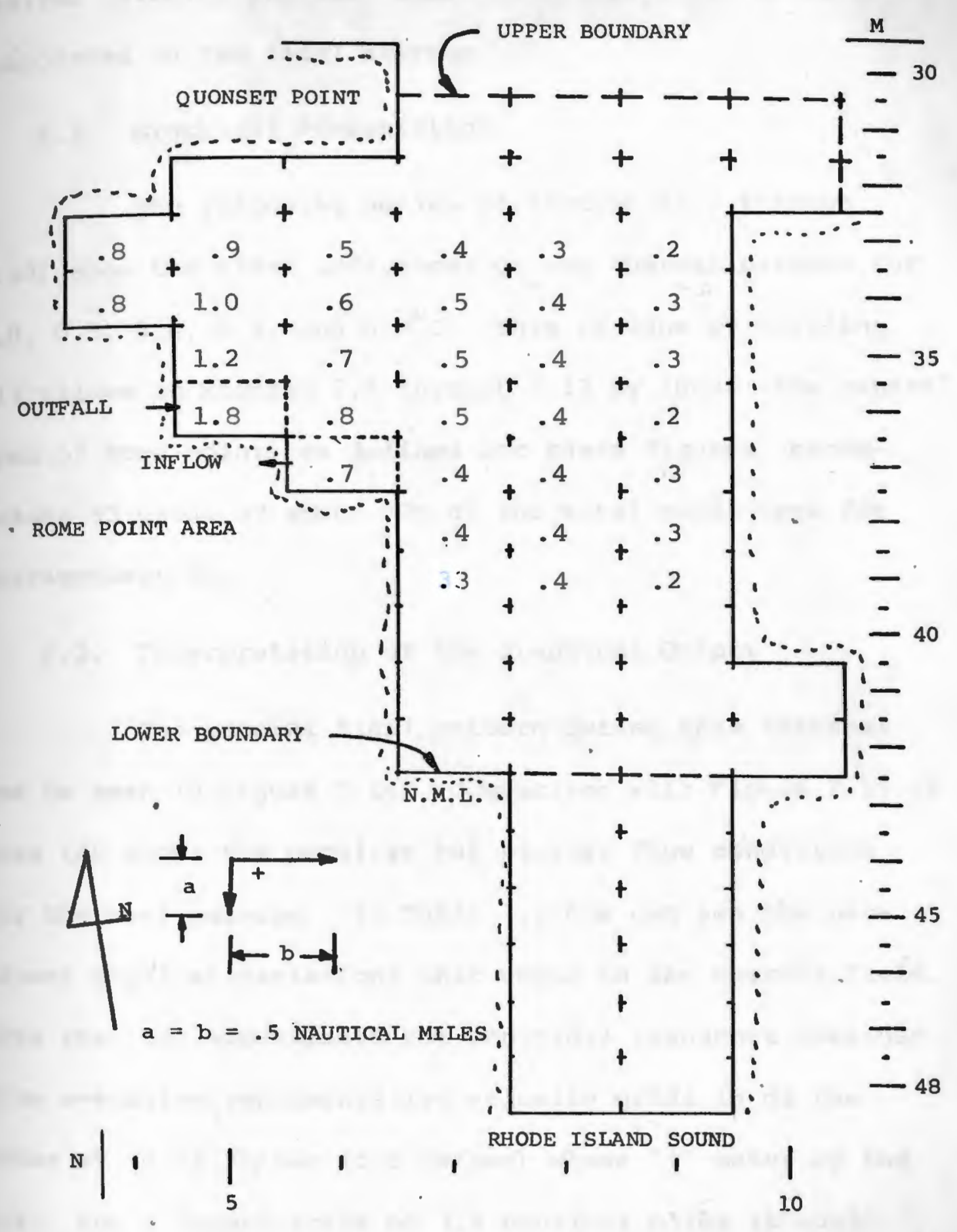

ALL TEMPERATURES ${ }^{\circ} \mathrm{C}$

FIGURE 7.6. FORCED TEMPERATURE RISE FROM RUN 3 
desired velocity profile, shown in Figure 7.15 , to be incorporated in the tidal average.

F.2. Graphical Presentation

The following series of figures ( 7.7 through

7.14) show the tidal influences on the thermal pattern for $1.0,0.5,0.4,0.3$, and $0.2^{\circ} \mathrm{C}$. This is done by dividing all values in Figures 7.6 through 7.13 by 1000 . The general area of Rome Point, as defined for these figures, encompasses 53 grids or about $17 \%$ of the total model area for Narragansett Bay.

F.3. Interpretation of the Graphical output

The general tidal pattern during this interval can be seen in Figure 7.14. Comparison with Figure 7.15 of Hess (4) shows the peculiar but similar flow conditions for the west passage. In Table 7.1 one can see the pertinent physical variations that occur in the thermal field. Note that the approximate net non-tidal transport obtained from averaging representative velocity grids is of the order of $+0.02 \mathrm{ft} / \mathrm{sec}(0.6 \mathrm{~cm} / \mathrm{sec})$ where "+" means up the bay. For a length scale of 3.5 nautical miles it would take a heated particle from Rome Point roughly two weeks to pass out of the Rome Point area if we assumed a net 
Given: QIN $=2000 \mathrm{cfs}, \operatorname{TIN}=12^{\circ} \mathrm{C}$

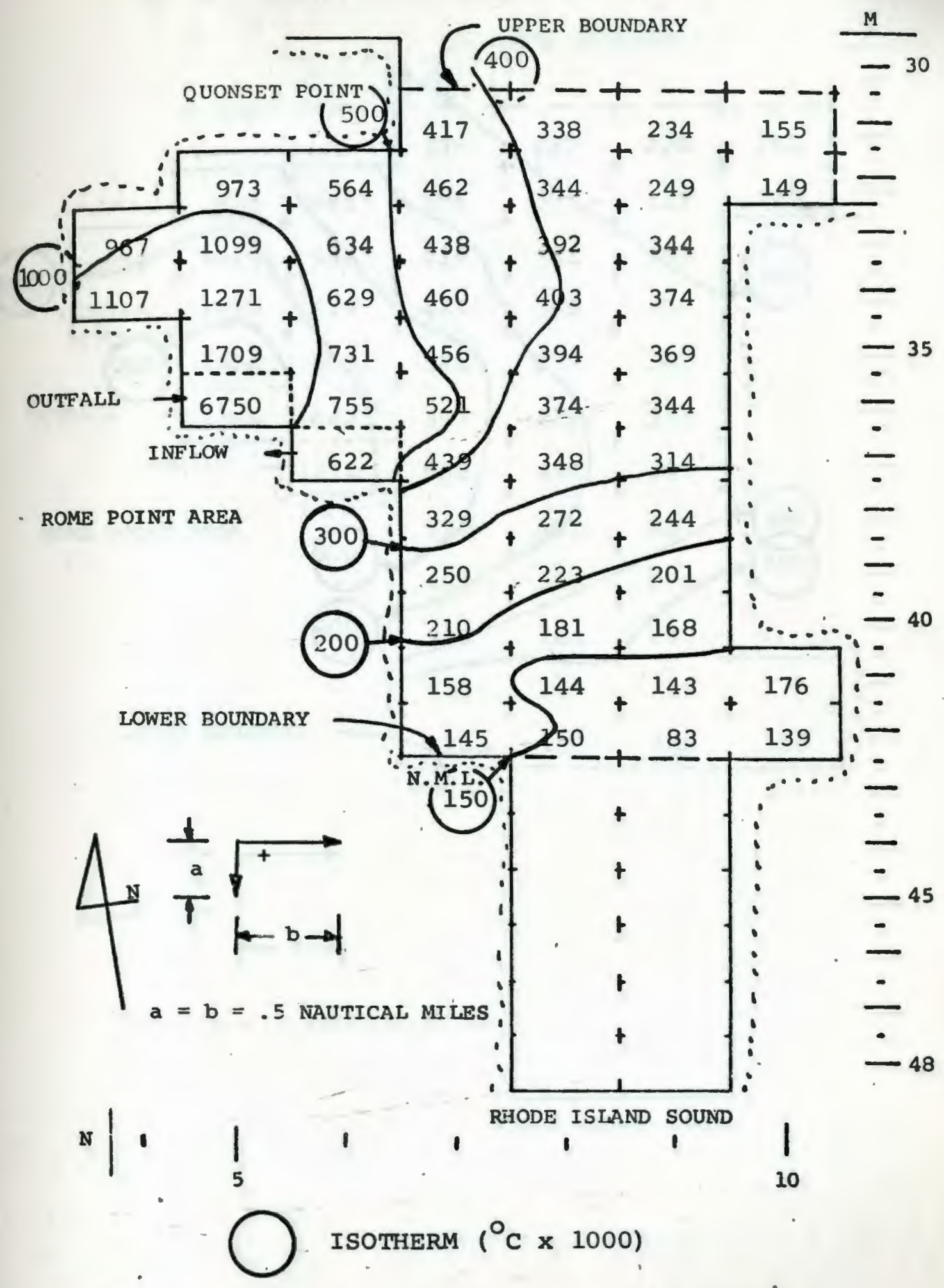

FIGURE 7.7. RUN 4, THERMAL FIELD AT 128 HOURS ALI TEMPERATURES ${ }^{\circ} \mathrm{C} * 1000$ 
Given: QIN $=2000 \mathrm{cfs}, \quad$ TIN $=12^{\circ} \mathrm{C}$

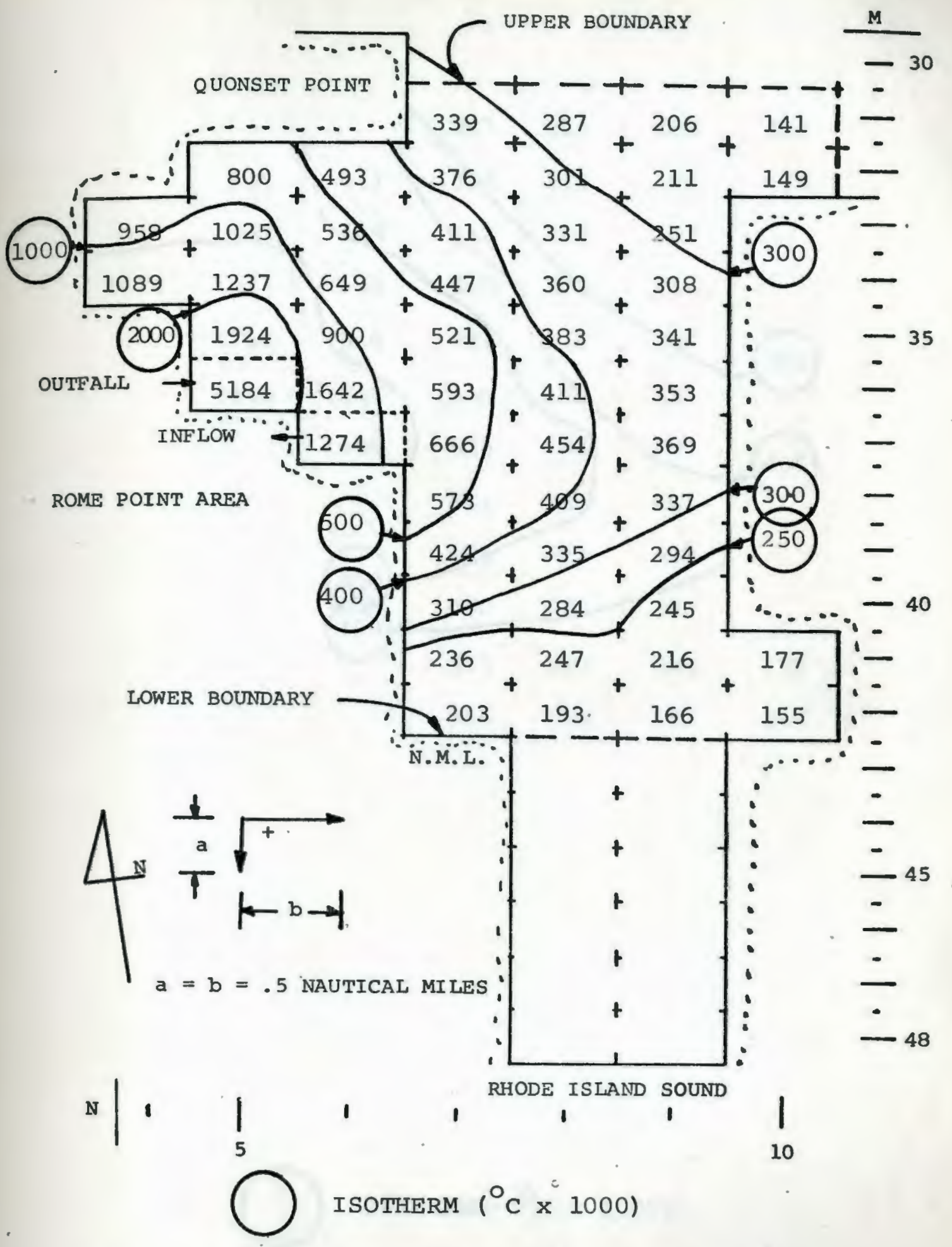

FIGURE 7.8. RUN 4, THERMAL FIELD AT 130 HOURS ALL TEMPERATURES ${ }^{\circ} \mathrm{C} \times 1000$ 
Given: $\operatorname{QIN}=2000 \mathrm{cfs}, \operatorname{TIN}=12^{\circ} \mathrm{C}$

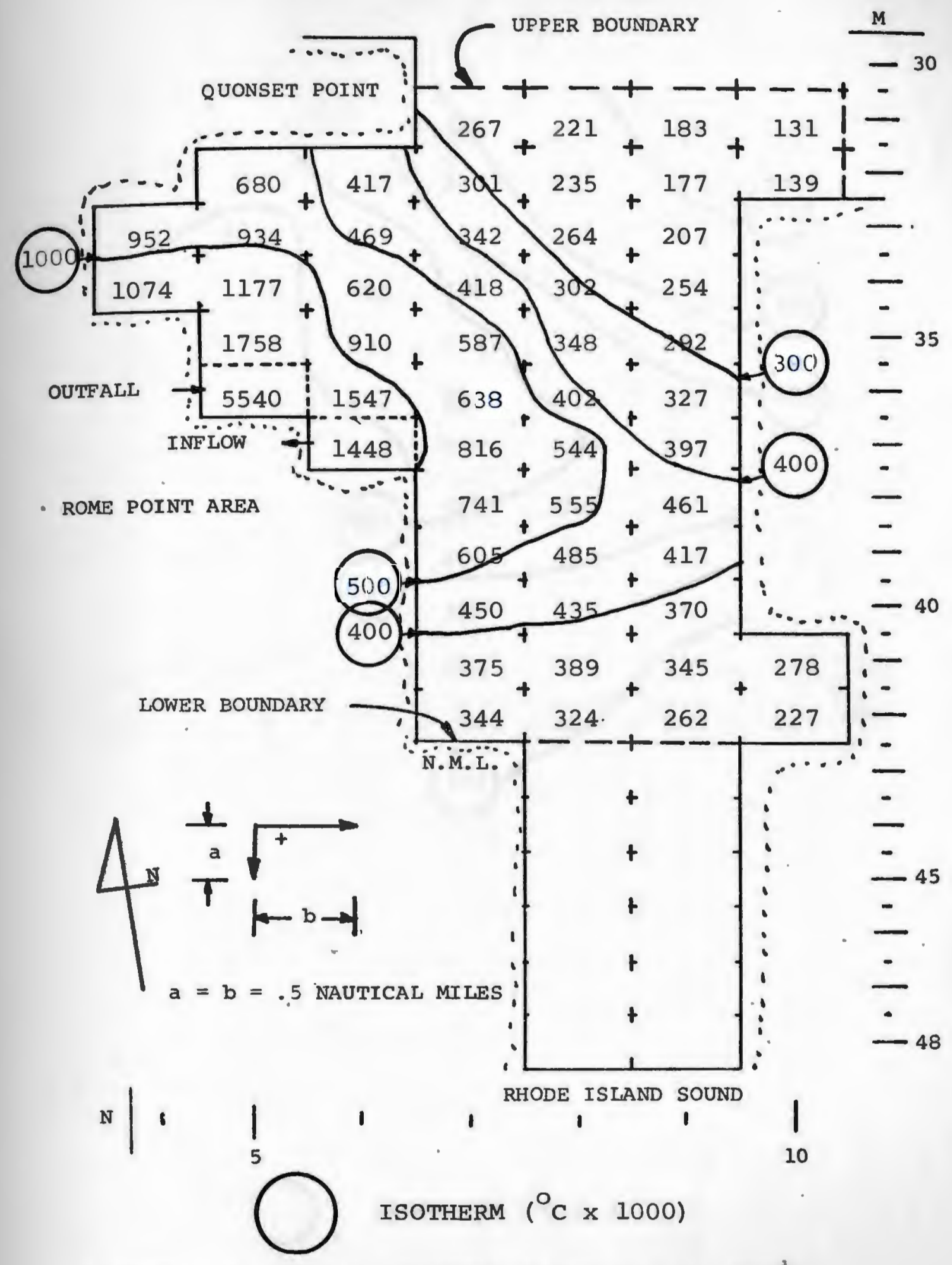

FIGURE 7.9. RUN 4, THERMAL FIELD AT 132 HOURS

ALL TEMPERATURES ${ }^{\circ} \mathrm{C} \times 1000$ 
Given: QIN $=2000 \mathrm{cfs}, \operatorname{TIN}=12^{\circ} \mathrm{C}$

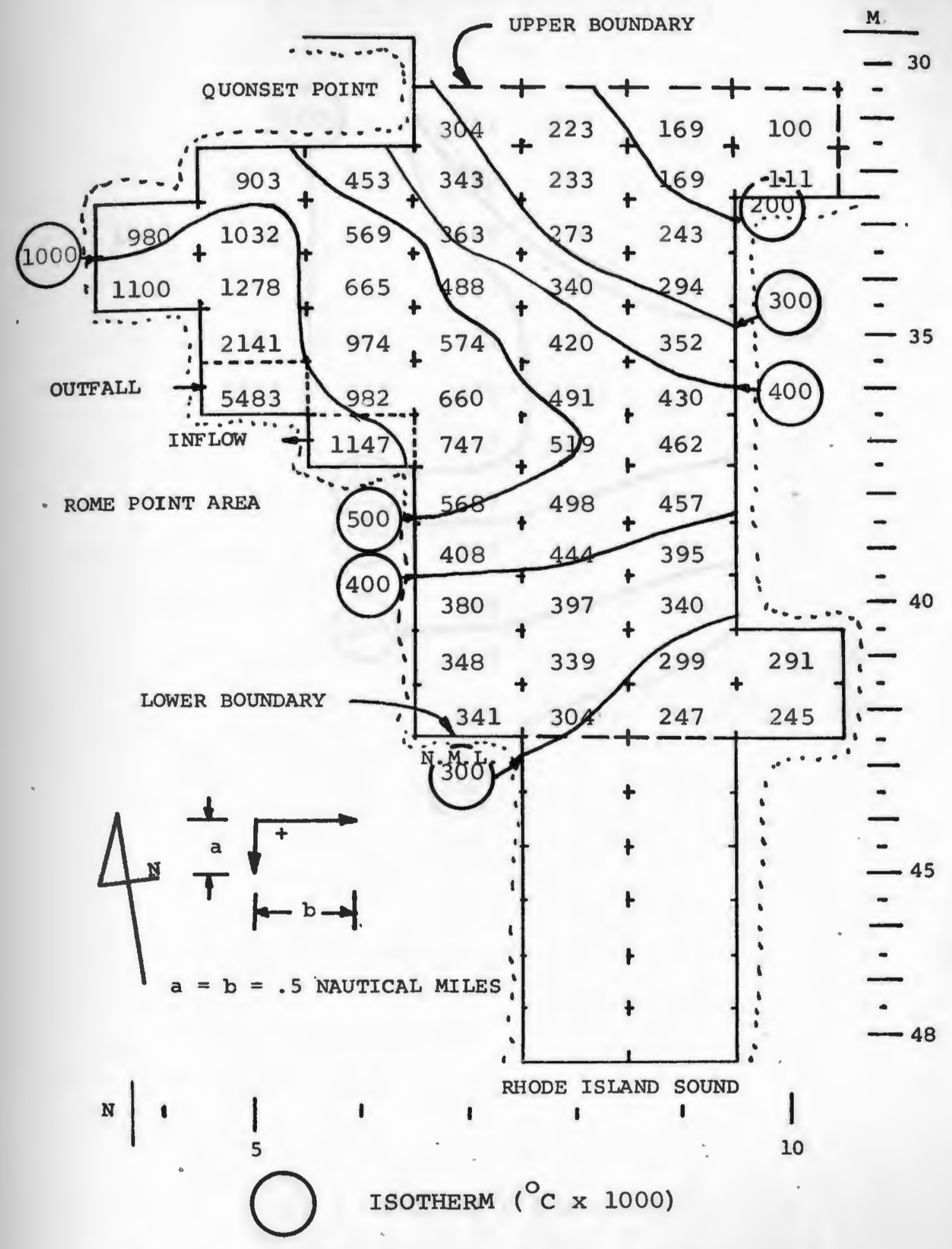

FIGURE 7.10. RUN 4, THERMAL FIELD AT 134 HOURS ALL TEMPERATURES ${ }^{\circ} \mathrm{C} \times 1000$ 
Given: QIN $=2000 \mathrm{cfs}$, TIN $=12{ }^{\circ} \mathrm{C}$

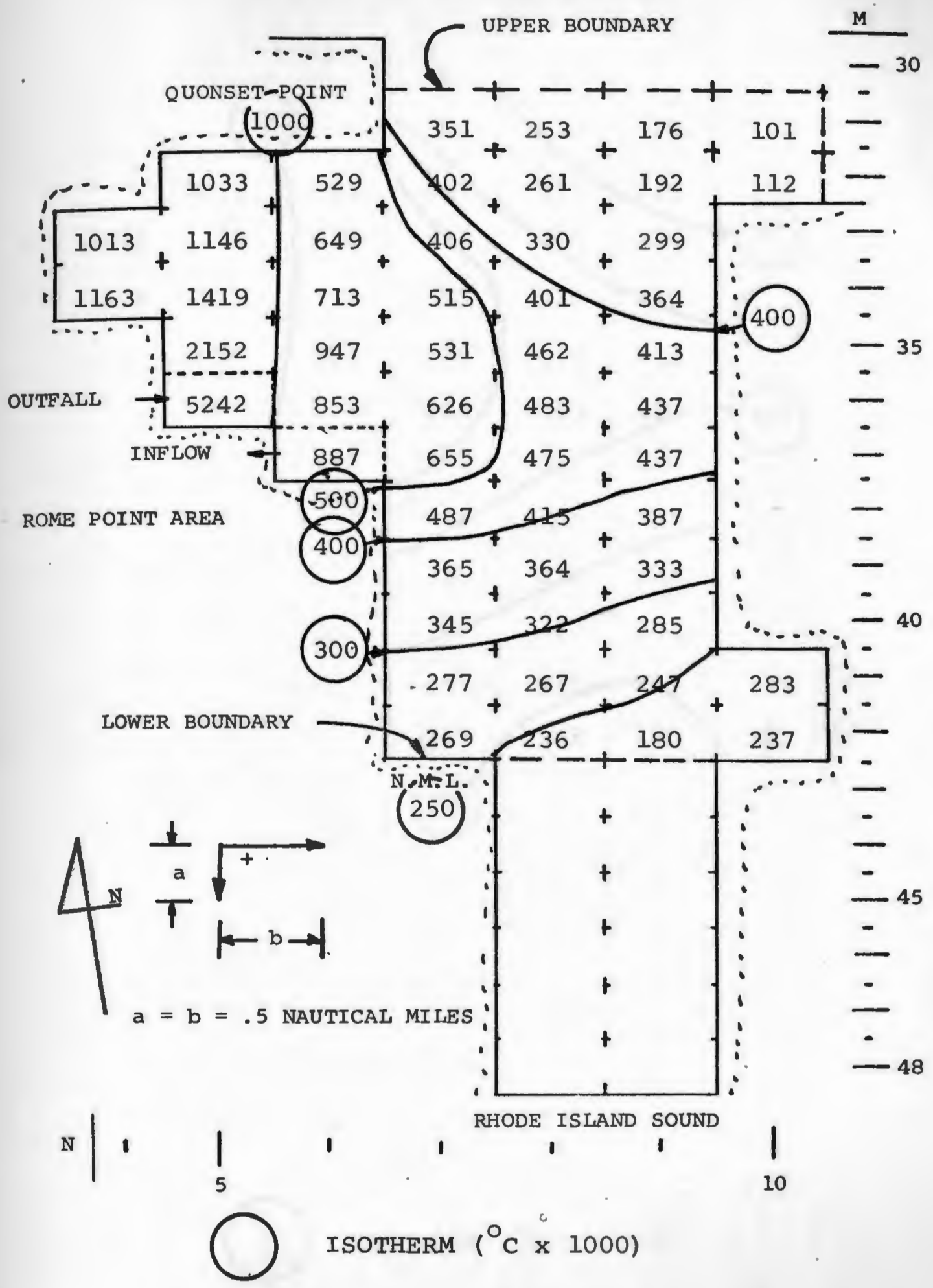

FIGURE 7.11. RUN 4, THERMAL FIELD AT 136 HOURS ALL TEMPERATURES ${ }^{\circ} \mathrm{C} \times 1000$, 
Given: $\mathrm{QIN}=2000 \mathrm{cfs}$, TIN $=12^{\circ} \mathrm{C}$

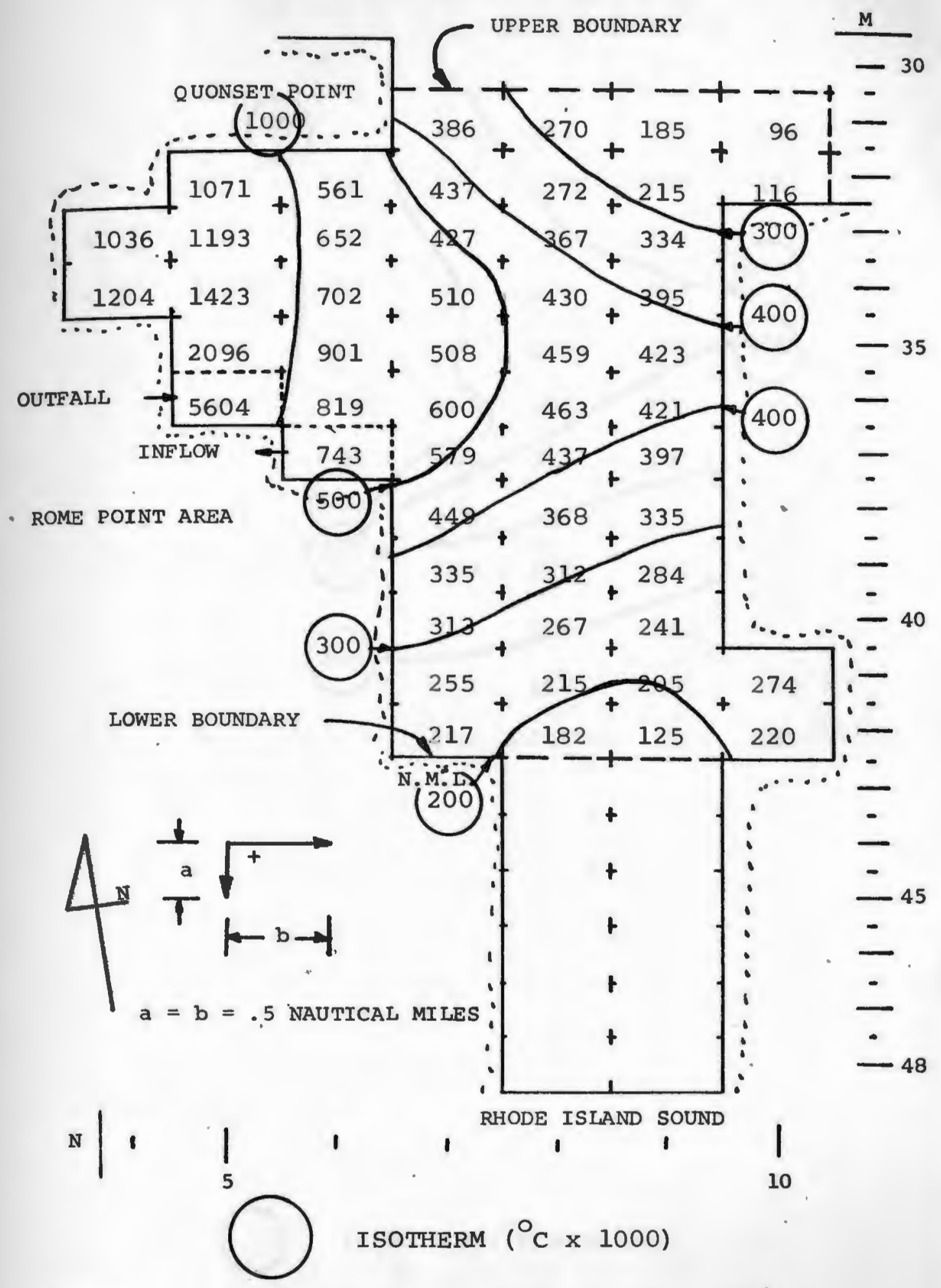

FIGURE 7.12. RUN 4, THERMAL FIELD AT 138 HOURS ALL TEMPERATURES ${ }^{\circ} \mathrm{C} \times 1000$ 
Given: QIN $=2000 \mathrm{cfs}, \quad \operatorname{TIN}=12^{\circ} \mathrm{C}$

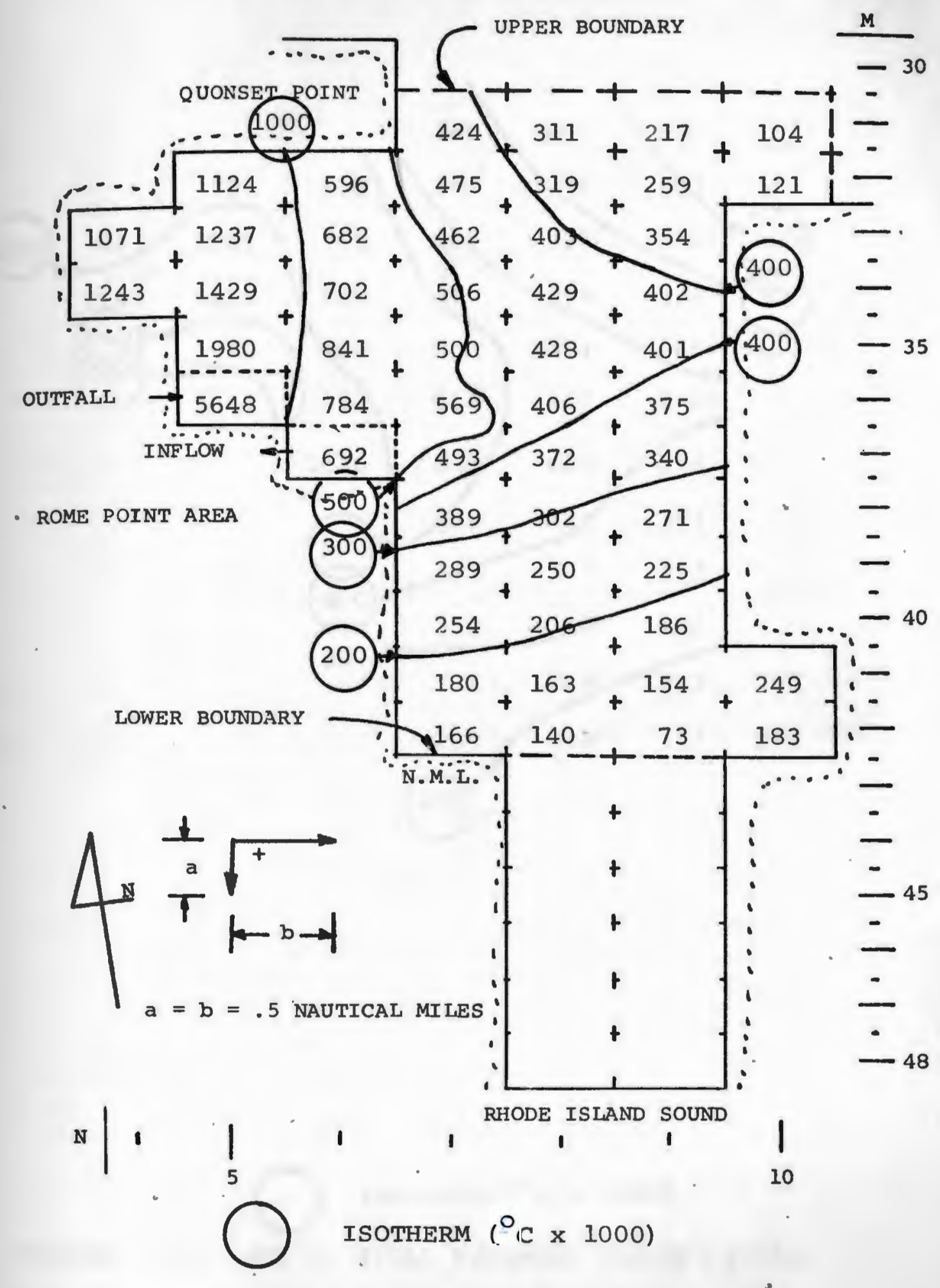

FIGURE 7.13. RUN 4, THERMAL FIELD AT 140 HOURS

ALL TEMPERATURES ${ }^{\circ} \mathrm{C} \dot{\mathrm{x}} 1000$ 


$$
\text { Given: } \text { QIN }=2000 \mathrm{cfs}, \operatorname{TIN}=12^{\circ} \mathrm{C}
$$

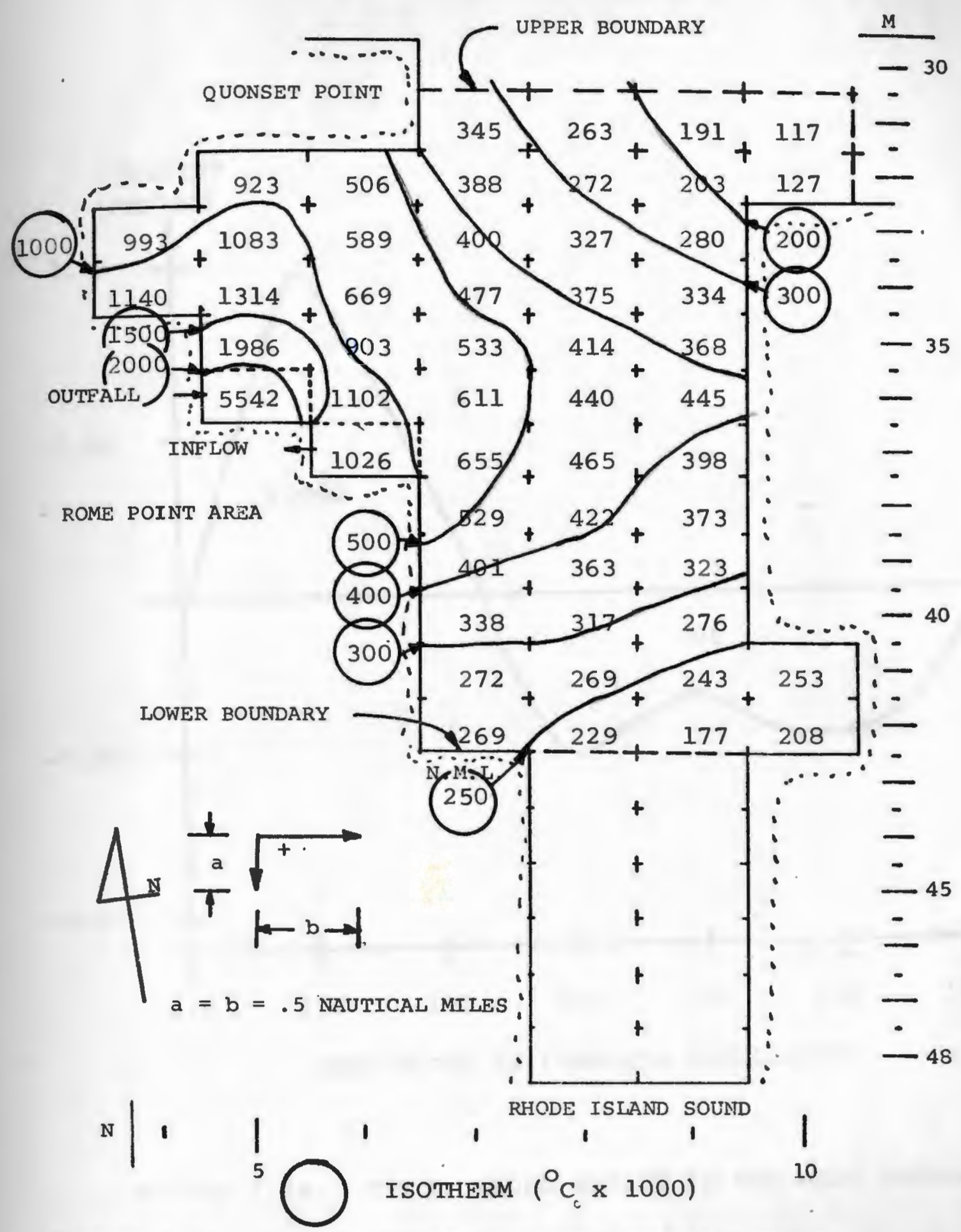

FIGURE 7.14. RUN 4, TIDAL AVERAGED THERMAL FIELD,

$$
\text { 128-140 HOURS }
$$

ALI TEMPERATURES ${ }^{\circ} \mathrm{C} \times 1000$ 


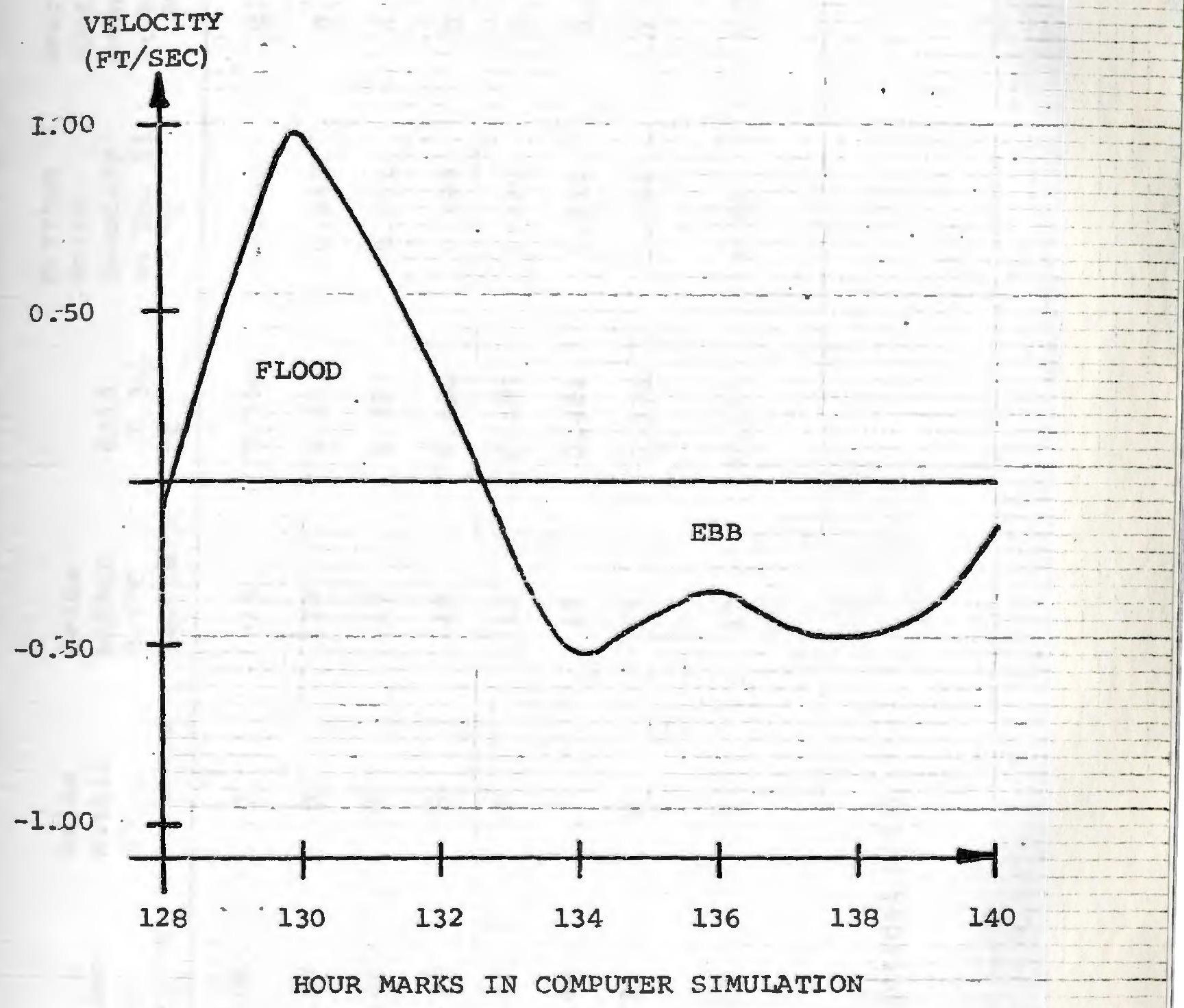

FIGURE 7.15. RUN 4, TIDAL MOTION IN THE WEST PASSAGE 
TABLE 7.2. RUN 4, GENERAL TIDAL AND THERMAL RESULTS FOR RUN 4

\begin{tabular}{|c|c|c|c|c|c|c|}
\hline $\begin{array}{l}\text { Length of } \\
\text { Simulation } \\
\text { (Hours) }\end{array}$ & $\begin{array}{l}\text { Ft/sec } \\
\text { Tidal } \\
\text { Velocity }\end{array}$ & $\begin{array}{l}\text { Grids } \\
\text { Within } \\
\text { I }^{\circ} \\
\text { Isotherm }\end{array}$ & $\begin{array}{l}\text { Grids } \\
\text { Within } \\
0.5^{\circ} \mathrm{C} \\
\text { Isotherm }\end{array}$ & $\begin{array}{l}\text { Grid } \\
(9,36) \\
{ }^{\circ} \mathrm{C}\end{array}$ & $\begin{array}{l}\text { Average } \\
\text { North } \\
\text { Boundary } \\
\text { at Row } 31 \\
{ }^{\circ} \text { C }\end{array}$ & $\begin{array}{l}\text { Average } \\
\text { South } \\
\text { Boundary } \\
\text { at Row } 42 \\
{ }^{\circ} \text { C }\end{array}$ \\
\hline 128 & -0.065 & 7 & 14 & 0.344 & 0.286 & 0.129 \\
\hline 130 & +1.12 & 8 & 17 & 0.353 & 0.243 & 0.179 \\
\hline 132 & +0.36 & 9 & 19 & 0.327 & 0.201 & 0.289 \\
\hline 134 & -0.55 & 8 & 19 & 0.430 & 0.199 & 0.284 \\
\hline 136 & -0.31 & 7 & 17 & 0.437 & 0.220 & 0.231 \\
\hline 138 & -0.44 & 7 & 17 & 0.421 & 0.234 & 0.186 \\
\hline 140 & -0.24 & 8 & 17 & 0.375 & 0.264 & 0.141 \\
\hline Tidal & & & & & & \\
\hline $\begin{array}{l}\text { Average } \\
128-140\end{array}$ & +0.02 & 8 & 17 & 0.445 & 0.23 & 0.220 \\
\hline
\end{tabular}


average transport north of $0.02 \mathrm{ft} / \mathrm{sec}$. In Rose (10) Figures $7 \mathrm{a}, 7 \mathrm{~b}$, and $7 \mathrm{c}$, pages $13-15$, one can see that net transport is variable and of the order of $\pm 0.14 \mathrm{ft} / \mathrm{sec}$ $(4 \mathrm{~cm} / \mathrm{sec})$ depending on wind direction and magnitude. A net transport of $4 \mathrm{~cm} / \mathrm{sec}$ would reduce particle residence time in Rome point area to one or two days.

Evaluation of Table 7.2 leads to the following conclusions:

1. $1^{\circ} \mathrm{C}$ isotherm encompasses an area of 2 square nautical miles (S.N.M.).

2. $0.5^{\circ} \mathrm{C}$ isotherm encompasses an area of 4.25 S.N.M.

3. Average temperature for entire Rome Point area (13.25 S.N.M.) is $0.6^{\circ} \mathrm{C}$ above natural condition.

4. The average value of the upper and lower Rome Point area boundaries is $0.23^{\circ} \mathrm{C}$.

5. Tidal variations cause minor variations in locations of isotherms (See Figure 7.16) below $1.0^{\circ} \mathrm{C}$.

\section{G. LONG TERM VARIATIONS IN SURFACE DISCHARGE BOX FOR A}

\section{HIGH DISPERSION COEFFICIENT}

The complexity of the flow pattern around the Rome Point area causes very interesting tidal variations in heat content for box $n=5, m=36$. Referring to Figure 7.17 
one can appreciate the value of computer modeling especially when with large variations in temperature of the grid due to sudden high velocity conditions at the 78 hour mark.

H. EXPERIMENTAL RUN 5 (FORCED TEMPERATURE RISE WITH 50\% INCREASE IN FLOWRATE)

Run 5 is the same as run 3 with the following exceptions:

VARIABLE NUMBER CONTROL PARAMETER SPECIFICATION

12 QIN (Source Flow Rate, cfs) 3000

15 Plotting Interval (Hours) 36

16 Program Number $\quad 33225$

17 Date of Run 6/2/73

H.1. Discussion

The thermal pattern for grid $n=5, m=36$, run 4 , is compared with run 5 (Figure 7.18 ) to see what effect there will be in temperature field for a 50 percent increase in flowrate, from 2000 to $3000 \mathrm{cfs}$, for the same temperature increase through the condenser. One can see from Figure 7.18 that the estimated 
steady state value is $+9.0^{\circ} \mathrm{C}$ or an 80 percent increase in forced temperature rise for grid $n=5, m=36$. Surrounding grid locations show a similar increase in heat content to balance the warmer input grid.

I. EXPERIMENTAL RUN 6, (FORCED TEMPERATURE RISE UPCON EOUALS 50)

Run 6 is the same as run 1 with the following exceptions:

\begin{tabular}{cll}
$\begin{array}{c}\text { VARIABLE } \\
\text { NUMBER }\end{array}$ & CONTROL PARAMETER & SPECIFICATION \\
\hline 11 & UPCON (Dispersion Coefficient & 50 \\
& Constant Times Elders' Value) & \\
16 & Plotting Interval (Hours) & 36 \\
17 & Program Number & 33374 \\
18 & Date of Run & $6 / 5 / 73$
\end{tabular}

I.1. Discussion

The dispersion coefficient constant (control parameter) was lowered by 50 percent to see what effect this would have on the temperature field. The results have been plotted in Figure 7.18 and are of the same 


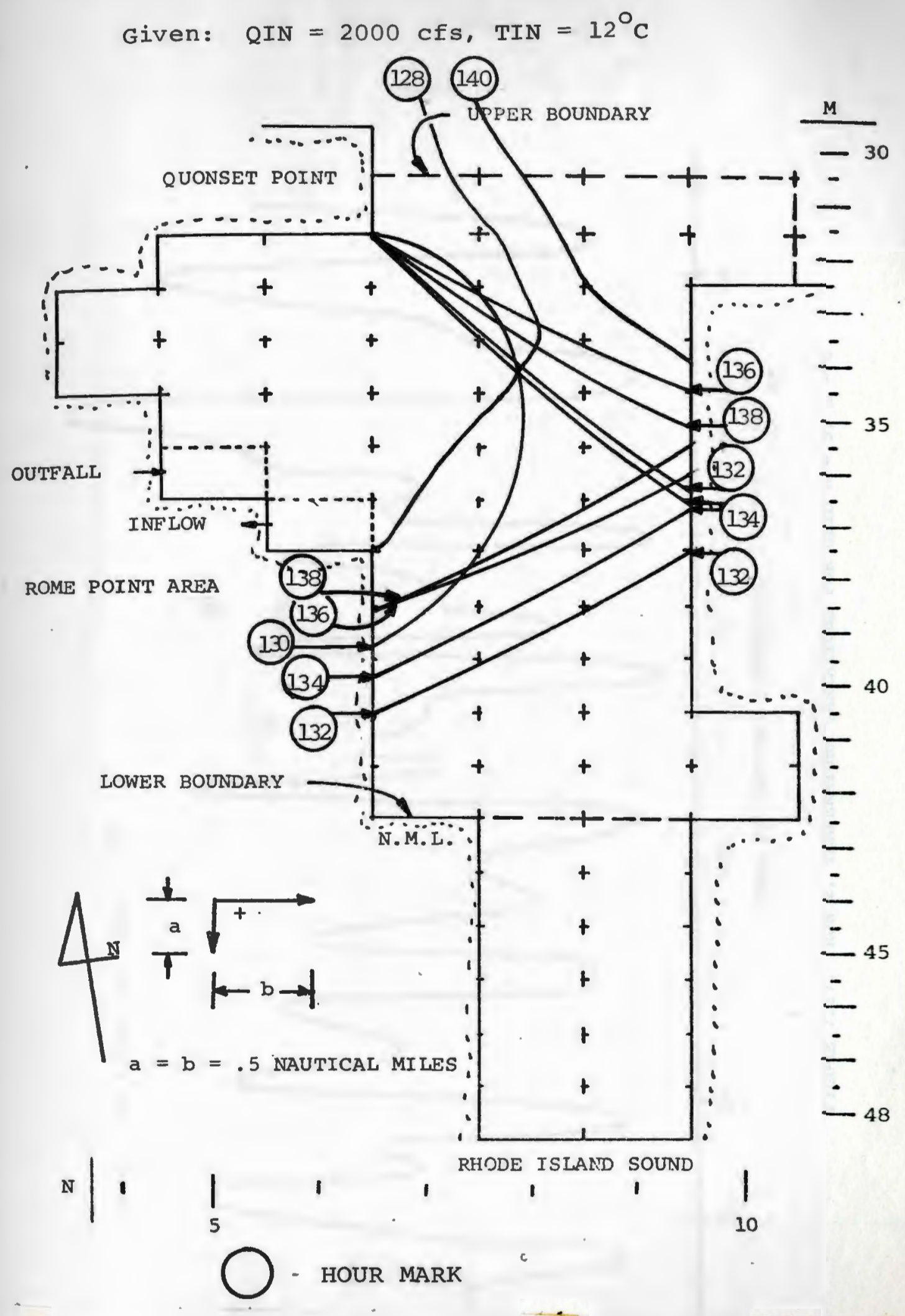

FIGURE 7.16. TIDAL EFFECTS ON THE $0.4^{\circ} \mathrm{C}$ ISOTHERM 


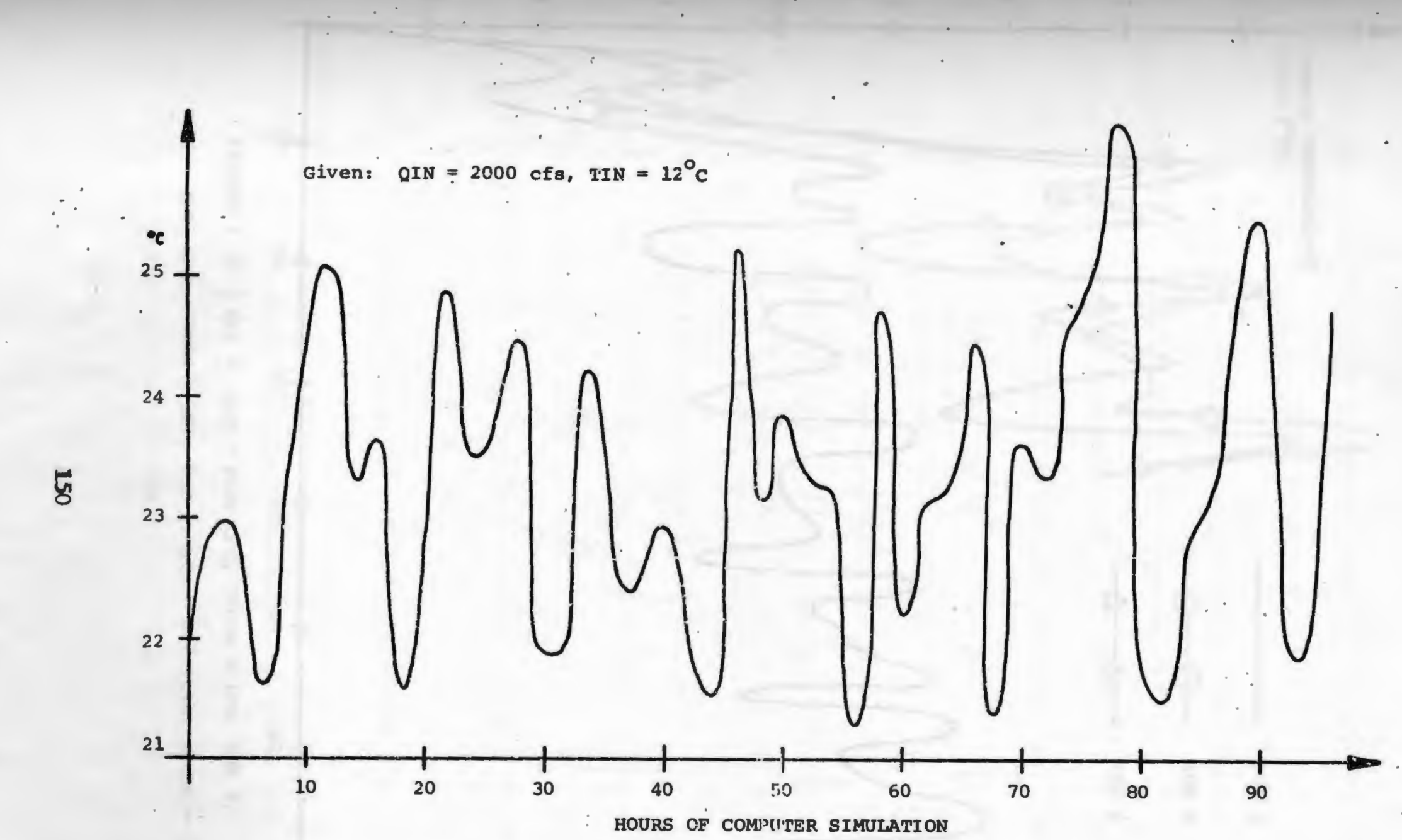

FIGURE 7.17. RUN 2, TERIPERATIIIE VARIATIONS FOR GRID $\mathrm{n}=5, \dot{\mathrm{m}}=6$ 


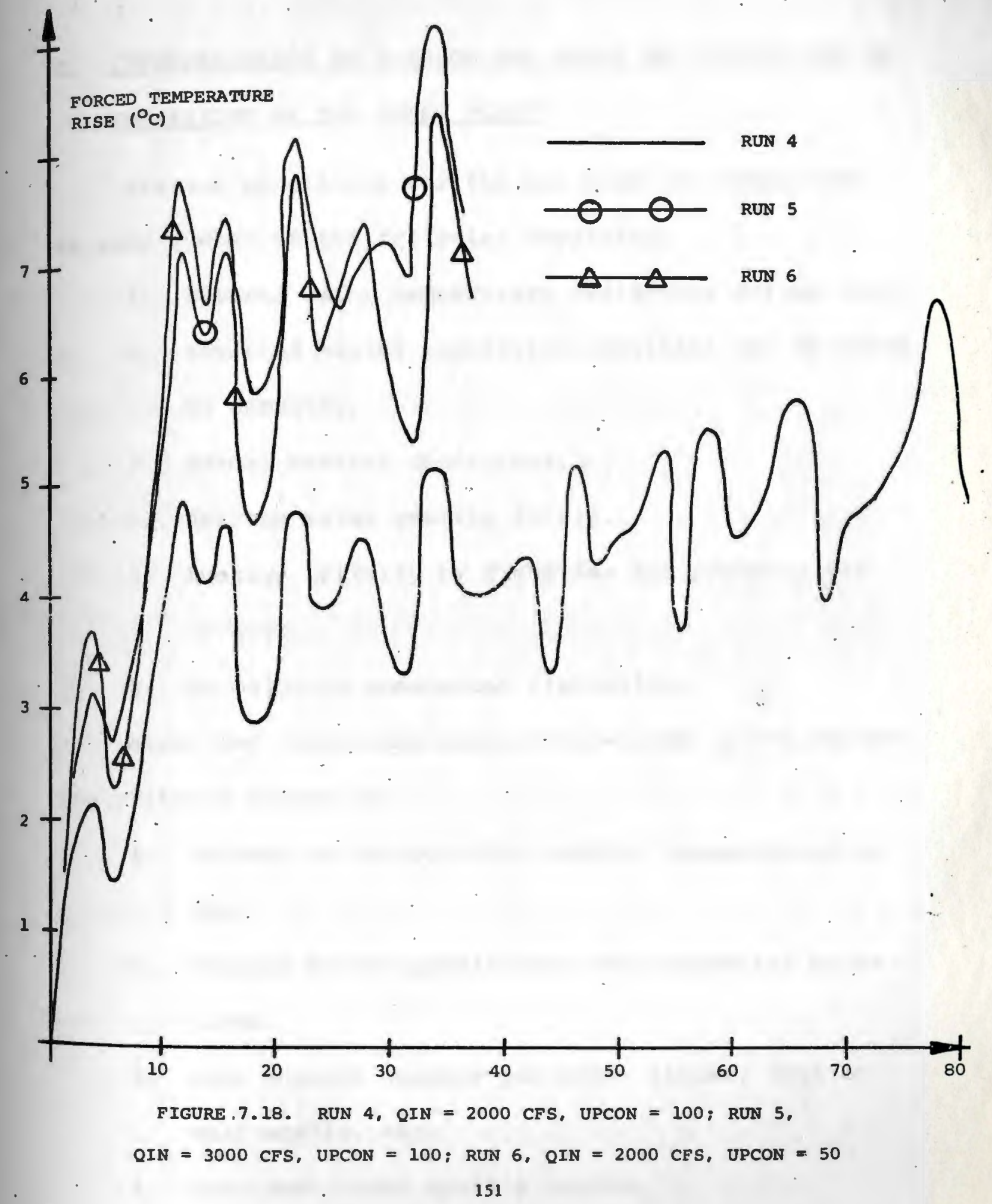


magnitude as run 5 .

J. INTERPRETATION OF AVERAGE AND WORST BAY CONDITIONS ON THE SITING OF THE POWER PLANT

Average conditions for the bay might be summarized as some number of the following occurring:

1. Natural water temperature variations during year.

2. Expected marine population densities can be found by sampling.

3. Normal weather conditions.

4. Average water quality levels.

5. Average activity by fisheries and pleasure interests.

6. No major or unexpected fish kills.

Worst bay conditions would follow some of the following criteria occurring:

1. Extreme or biologically harmful temperatures in bay.

2. Unusual marine populations and unexpected migrations.

3. Very unusual weather patterns, storms, heat or cold spells, etc.

4. Very poor water quality levels. 
5. Unusual activity of bay users.

6. Unexpected major fish kills.

\section{K. GENERAL COMMENTS}

In the presentation of the computational results this report has stressed the forced temperature rise method because it would be applicable for any period of the year. The warm water temperatures during mid summer coupled with peak power production by utility would create the highest temperatures in the outfall area. Whether the highest temperature and the worst temperature are synononous remains a judgment for the biologist who must evaluate the thermal affects of the power plant on marine life throughout the year. The point here is to determine the need, if any, for temperature limitations that would be imposed on power plant operations for various air and water temperature values. Once the operating specifications have been determined, the environmental engineer can utilize his options to meet these criteria. Some engineering options available are:

1. Reduce plant output.

2. Increase flow rate through the plant.

3. Increase dilution in the discharge channel. 
4. Change the outfall location by moving discharge into deeper water.

5. Dissipating heat near power plant through cooling towers or ponds.

Except for 1, these techniques do not reduce or "dissolve" the heat load on the bay environment but rather soften the impact by increasing the total area affected.

The upper temperature limit in the discharge grid would be the total temperature increase of condenser flow water for the entire grid. This value is somewhat ficticious, because with dilution in the normal tidal environment this value is not attainable. As a "worst case" it would be used in conjunction with the forced temperature rise analysis for any part of the year. With the 1800 megawatt sample plant at maximum output, the tidally averaged value for the discharge grid is approximately half the condenser temperature rise. This prediction was made with a value of the dispersion constant coefficient, UPCON, set at 50 . 
VIII. CONCLUSIONS

\section{A. GENERAL}

The thermal model can predict the general spatial temperature distribution in Narragansett Bay for either natural or man made conditions. When isotherms are sketched in by interpolation between grid temperatures, the effect of tidal flushing and heat sources are quite evident. The isotherms drawn for the forced temperature rise above ambient case serve as a valuable guide for environmental impact statements, because they dramatically display the effect of the heated effluent from a power plant. The heat content in a grid is vertically averaged but the Rome Point area is shallow enough to assume a high degree of vertical mixing for good model simulation. This mixing is further added by the variable current direction and magnitude during most of the tidal cycle.

Another challenging area comes from thermal field prediction or the attempt of the model to simulate bay boundary conditions in the form of a boundary value problem for temperature field calculation. The results obtained for the period of simulation, July 14-18, 1957, were of the same order of accuracy as those obtained by MASCH (57). 
Long computer simulation runs of the order of a month would be required to pursue this verification procedure for the empirical heat exchange formulas and the variable boundary conditions. Verification improvements could be made by adjusting the empirical heat exchange formulas and the necessary variable boundary conditions.

When the Rome Point discharge grid temperature is plotted against time, one can observe the characteristic peaks and valleys of tidal flushing but the variations within a tidal cycle are most irregular. The sudden changes in temperature of the discharge grid, as seen in Figure 7.17, are important for physical impact studies. Knowing the general isothermal patterns around the discharge grid, the oceanographer now can make biological observations and recommendations.

The basic model can predict the spatial distribution of any dissolved constituent. For instance, the salinity distribution in the bay would be very valuable for biological models now being developed.

In general summary, the thermal model produces valuable temperature distribution information for both natural and man made conditions. The ability to predict thermal plume patterns for various input and output sites is of great 
value to both the ecologist and the electric utility.

\section{B. SPECIFIC}

The verification of the model indicates no gross or unreasonable values are produced when the approximations used to formulate the model are evaluated. This model has been used to predict Jamaica Bay flushing characteristics and verification accuracy is comparable.

To limit this study, only one specific site at $m=36$, $\mathrm{n}=5$ was chosen. This site enabled a verification of the forced temperature rise criterion. It is felt that this technique produces the most usable output for thermal impact studies.

In Chapter VII, the tidally averaged thermal field shown in Figure 7.14 clearly shows the scale of the spreading of the heat. The $0.5^{\circ} \mathrm{C}$ isotherm encompasses about eight to nine square nautical miles of bay. The tidally varying patterns appear to have surprising similarity beyond the $0.5^{\circ} \mathrm{C}$ isotherm mark. As discussed in earlier chapters, the higher the diffusion coefficient the less variation in heat content from box to box especially near the outfall area. In conclusion, the ground work has been laid for extensive development. Various physical 
testing must be undertaken to pinpoint near field dispersion. This must of course be done in conuunction with computer runs that vary dispersion coefficient and site location. 


\section{RECOMMENDATIONS}

This thesis has established the value of the thermal model to make realistic spatial temperature distribution predictions. Before attempting to develop a better model that would more closely represent the three dimensional structure of Narragansett Bay, one should make salinity predictions. This would establish the ability of the difference scheme to predict the concentration of salinity without the use of the semi-empirical heat balance that occurs at the air-water interface.

As a prelude to a more sophisticated model, one should perform dye dispersion studies in conjunction with model predictions. These studies would indicate the importance of vertical structure on overall bay mixing. Finally, one could develop a two-dimensional width averaged vertically layered model. This would then reveal the importance of the vertical bay structure, especially in the deeper water grids.

It should be noted that Hess (59) is developing a three dimensional tidally averaged model for Narragansett Bay that shows considerable promise for understanding nonreacting constituent distribution of salt.

Research should be planned to bridge the gap between 
the non-reacting concentration models to determine the differences predicted by vertical averaging, width averaging and time averaging on, for example, spatial distribution of salinity. 
APPENDIX A

\section{A. INTRODUCTION}

The physical limitations on the amount of computer core and time available on the present operating computer required a reworking of the computer model into more manageable segments. This reworking enabled one to use a special storage unit, called a disk pack, to facilitate handling. In addition, the introduction of $\mathrm{H}$ level Fortran during the development stage offered a reduction of at least 50 percent in execution time, if the current batch processing mode was upgraded. That is to say, the program in its entirety exceeded the core requirement for Fortran $\mathrm{H}$, optimization leve1 2, for the long runs, making segmentation and disk pack utilization a necessity.

\section{B. TERMINOLOGY}

To understand the workings of the disc pack a review of the technical language (I.B.M., (1) and clayton, (3)) is presented.

Data Sets: A data set is a named, organized, logical collection of records. Generally, this consists of the main control segment, 
subroutines, and the input data for

starting model. A disk pack is used for

the storage of data set records.

Sequential: Means an organized data set that is arranged in a logical, physical order of computational need. This is done to facilitate debugging by the user.

Direct: Each record in the model has independent address.

Partitioned: Combination of the sequential and direct organization. The grouping of these records is sequentially arranged into collections called "members".

OCEPAK: Name of the disk pack used for all computation.

Library: Sum of all the sets of partitioned data sets available in the disk pack that facilitate job execution.

OCESMODS: Name of all the partitioned data sets containing many members which are the source input.

OCECOMP: Name of all partitioned data sets containing compiled modules from ocesmods. 
OCEDATAS: Name of all the partitioned data sets that contain initialization and data information required for execution of the program. You do not compile this information. It is just read by the model.

\section{DISK PACK USE}

The job control language (JCL) for the library creation (IBM, la, 1b) is as follows:

//LIBRARY JOB (INO1 $\varnothing \varnothing, 256,5,5,5 \varnothing \varnothing)$, 'J.J.A.' ,

$$
\text { MSGLEVEL }=1
$$

//BLDSTEP EXEC PGM=IEBFBR14

$/ /$ NEWSRCE DD DS=OCESMODS

$/ / \quad \mathrm{DISP}=(\mathrm{NEW}, \mathrm{CATLG}), \mathrm{VOL}=\mathrm{SER}=\mathrm{OCEPAK}$

$/ / \quad$ UNIT $=2314, \operatorname{SPACE}=(\mathrm{CYL},(15,5,2 \varnothing))$,

// DCB $=($ RECFM $=F B, L R E C L=8 \varnothing, B L K S I Z E=344 \varnothing)$ $(A-6)$

//ADDSTEP EXEC PGM=IEBUPDTE $(\mathrm{A}-7)$

//SYSPRINT DD SYSOUT $=\mathrm{A}$ $(A-8)$

$/ /$ SYSUT1 DD DSN=OCESMODS, DISP=OLD, UNIT

$=2314, \mathrm{VOL}=\mathrm{SER}=\mathrm{OCEPAK}$

$/ /$ SYSUT2 DD DSN=OCESMODS, DISP=OLD, UNIT

$=2314, \mathrm{VOL}=\mathrm{SER}=\mathrm{OCEPAK}$

//SYSIN DD * 
The following data cards for execution appear after the input program JCL:

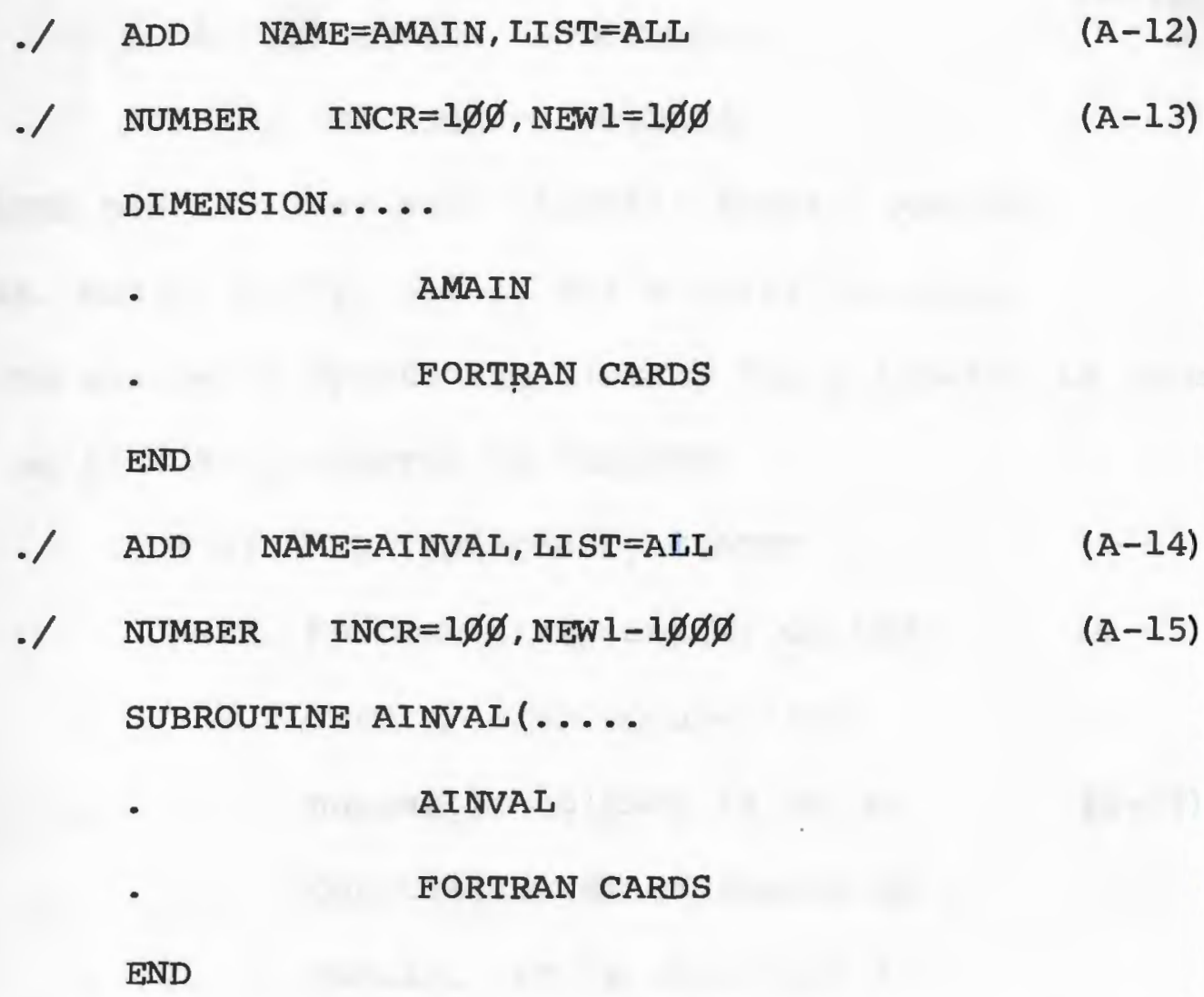

one repeats the above procedure for the remaining modules: APRINT, AHEATN, AOPBD, AUPNFH, AVPMFH, AVPMSH, AUPNSH, AWTDEP, AWTIND, AAZ, AKURIH, ADIVE, AFIND, ADEPTH, ACHEZY, AANLZE, ACHECK, APLOT and ADISPLY. This makes a total of 21 model modules.

To enter data for initilization of the model a partitioned data set, called ocEDATAS was created and filled in the same manner as OCESMODS with the following specific changes : 
on line A-3, OCESMODS to OCEDATAS

$$
\begin{aligned}
& \text { A-5, SPACE }=(C Y L,(15,5,2 \varnothing)) \\
& \text { A-9, OCESMODS to OCEDATAS } \\
& \text { A-10, OCESMODS to OCEDATAS }
\end{aligned}
$$

OCEDATAS module names are: ADATA1, ADATA2, ADATA3,

ADATA4, AD191, AD192, AD193, for a total of seven.

To change or update the library the following is done:

on line A-7, ADDSTEP to CHNGSTEP

A-12, ADD replaced by CHANGE

A-13, Fortran statement(s) on IBM

card(s) with module line

number is columns 73 to 80 ,

for the specified change in

module. It is important to

list the line numbers in

ascending order.

For obvious ease in handling changes it is desirable to stay in the CHNSTEP mode once modules have been added to the library. For any data change or update one should do the following:

on line A-9, OCESMODS to OCEDATAS

A-10, OCESMODS to OCEDATAS

A-17, Specific changes desired 
As an example, a typical deck layout for updating the library would be as follows:

lines $A-1$, LIBRARY JOB $(\ldots .$.

$$
\begin{aligned}
& \text { A-7, //ChNGSTEP } \quad \ldots . \\
& \text { A-8, //SYSPRINT } \quad \ldots . \\
& \text { A-9, //SYSUT1 .. OCESMODS .. } \\
& \text { A-10, //SYSUT2 } 2 \text { OCESMODS .. } \\
& \text { A-11, // SYSIN DD * } \\
& \text {./ change .. Amain } \\
& \text { COL: } \quad{ }^{7} \text { GO TO } 1 \varnothing \quad \ldots \quad{ }^{73} \varnothing \varnothing \varnothing 46 \varnothing \varnothing \varnothing \\
& \text { Iø CONTINUE } \quad \varnothing \varnothing \varnothing 469 \varnothing \varnothing \\
& \text { etc. }
\end{aligned}
$$$$
\text { A-7, //ChNGSTEP } \quad \ldots \text {. }
$$$$
\text { A-8, //SYSPRINT } \quad \ldots
$$$$
\text { A-9, //SYSUTl, .. OCEDATAS .. }
$$$$
\text { A-10，//SYSUT2， .. OCEDATAS . }
$$$$
\text { A-11, // SYSIN DD * }
$$$$
\text { ./ Change .. Adatal .. }
$$$$
\text { COL : } \quad 1 \varnothing \varnothing \varnothing 1 \varnothing \quad \ldots \quad 2 \varnothing \varnothing \varnothing 2 \varnothing \quad \ldots \quad{ }^{73} \varnothing \varnothing \varnothing \varnothing 77 \varnothing \varnothing
$$

$$
\text { etc. }
$$

JCL FOR REMAINING PROGRAM 
After creation of the input partitioned data sets, the next step is to create a third partitioned data set called OCECOMP. This is done by making the following changes:

on line $A-3$, OCESMODS to OCECOMP

$$
\begin{aligned}
& A-5, \quad \operatorname{SPACE}=(\mathrm{CYL},(2,2,2)) \\
& A-6, \text { final line }
\end{aligned}
$$

The primary function of this data set is to store all the compiled modules after they have been updated. Once a program has been compiled it need not be recompiled unless a change is made in the structure of the module. This results in a great saving in compilation time for each run. The necessary JCL is:

$/ /$ EXEC FORTHOL, PARM.FORT-' OPT=2 ', PARM. LKED

$$
\text { = ' LET, LIST, NCAL, XREF (A-20) }
$$

//FORT.SYSIN DD DSN=OCESMODS (AMAIN), DISP $\quad(\mathrm{A}-23)$

$=$ SHR

//LKED.SYSIMOD DD DSN=OCECOMP (MAIN) , DISP

$=O L D$

$$
(A-22)
$$

Repeat set $A-23$ for as many modules as needed in OCESMODS that have just been updated for a maximum of 21 compilations. Note here that AMAIN is the uncompiled module in OCESMODS while MAIN is the same module compiled and stored in OCECOMP. 
Now that after all the modules are compiled they must be included in the object (functional) library through the IINK Editor as follows:

//LKED EXEC PGM=IEWL, PARM= (MAP, LET, LIST, OVLY, XREF)

$$
(A-24)
$$

$/ /$ SYSLIB DD DSN=SYSI. FORTLIB, DISP $=S H R$

$$
(\mathrm{A}-25)
$$

$/ /$ DD DSN=URI. SSPLIB, DISP=SHR $(A-26)$

$/ /$ DD $D S N=U R I . O P O T L I B, D I S P=S H R \quad(A-27)$

//SYSPRINT DD SYSOUT=A (A-28)

//SYSLIN DD DDNAME=SYSIN $\quad(A-29)$

$/ /$ SYSLMOD DD DSN=\&GOSET $($ MAIM) , UNI T $=S Y S D A, D I S P \quad(A-35)$

$$
=(, \text { PASS }) \text {, }
$$

$/ / \quad \operatorname{SPACE}=(3 \varnothing 72,(3 \varnothing, 1 \varnothing, 1))$

$/ /$ SYSUT 1 DD DSN=\&SYSUT1, UNIT=SYSDA, SPACE

$$
=(1 \varnothing 24,(2 \varnothing \varnothing, 2 \varnothing)), \text { SEP=SYSLMOD }
$$

//LKED. OBULIB DD DSN=OCECOMP, DISP=SHR, VOL=SER

$$
\text { =OCEPAK, UNIT-2314 }
$$

//LKED.SYSIN DD *

$(\mathrm{A}-34)$

Since the core restriction of $256 \mathrm{~K}$ is imposed on the fastest turn-around class it is necessary to follow up with the overlay feature (IBM, (2)) that is specified in $\mathrm{A}-24$. The modules in the program must be organized 
into usable groups that minimize the core demand for any one executing group. See Figure A-1, Overlay Flow Chart, for details. Directly after A-34 are the instructions.
COL: ${ }^{7}$ ENTRY MAIN
$(A-36)$
INCLUDE OBJLIB (MAIN)
$(A-37)$
OVERLAY ONE
$(A-38)$
INCLUDE OBJLIB (KURIH, HEATIN, DIVE, FIND, DEPTH,

\begin{tabular}{|c|c|c|}
\hline \multicolumn{2}{|c|}{ CHEZY, CHECK, INVAL) } & $(A-39)$ \\
\hline OVERLAY & ONE & $(A-40)$ \\
\hline INCLUDE & OBJLI B (OPENBD , UPNFHT, VPMFHT & MSHT, \\
\hline \multicolumn{2}{|c|}{ UPNSHT, WATDEP , WATIND) } & $(A-41)$ \\
\hline INCLUDE & OBJLIB (AZ, PRINT, DISPL, PLOT) & $(A-42)$ \\
\hline OVERLAY & ONE & $(A-43)$ \\
\hline [NCLUDE & OBJLIB (ANLYZE) & $(A-44)$ \\
\hline
\end{tabular}

The final JCL required for reading in the initialization values is:

//GO EXEC PGM=*. LKED.SYSLMOD (A-45)

//FT $\varnothing 6 F \varnothing \varnothing 1 \quad$ DD $\quad$ SYSOUT $=\mathrm{A} \quad(\mathrm{A}-46)$

//FT $\varnothing 7 F \varnothing \varnothing 1 \quad$ DD SYSOUT=B $\quad(A-47)$

$/ / F T \varnothing 5 F \varnothing \varnothing 1$ DD DSN=OCEDATAS (ADATA2), DISP=SHR, VOL

$$
=S E R=O C E P A K
$$

$/ / \quad$ UNIT $=2314, \operatorname{LABEL}=(,$, IN $)$ 


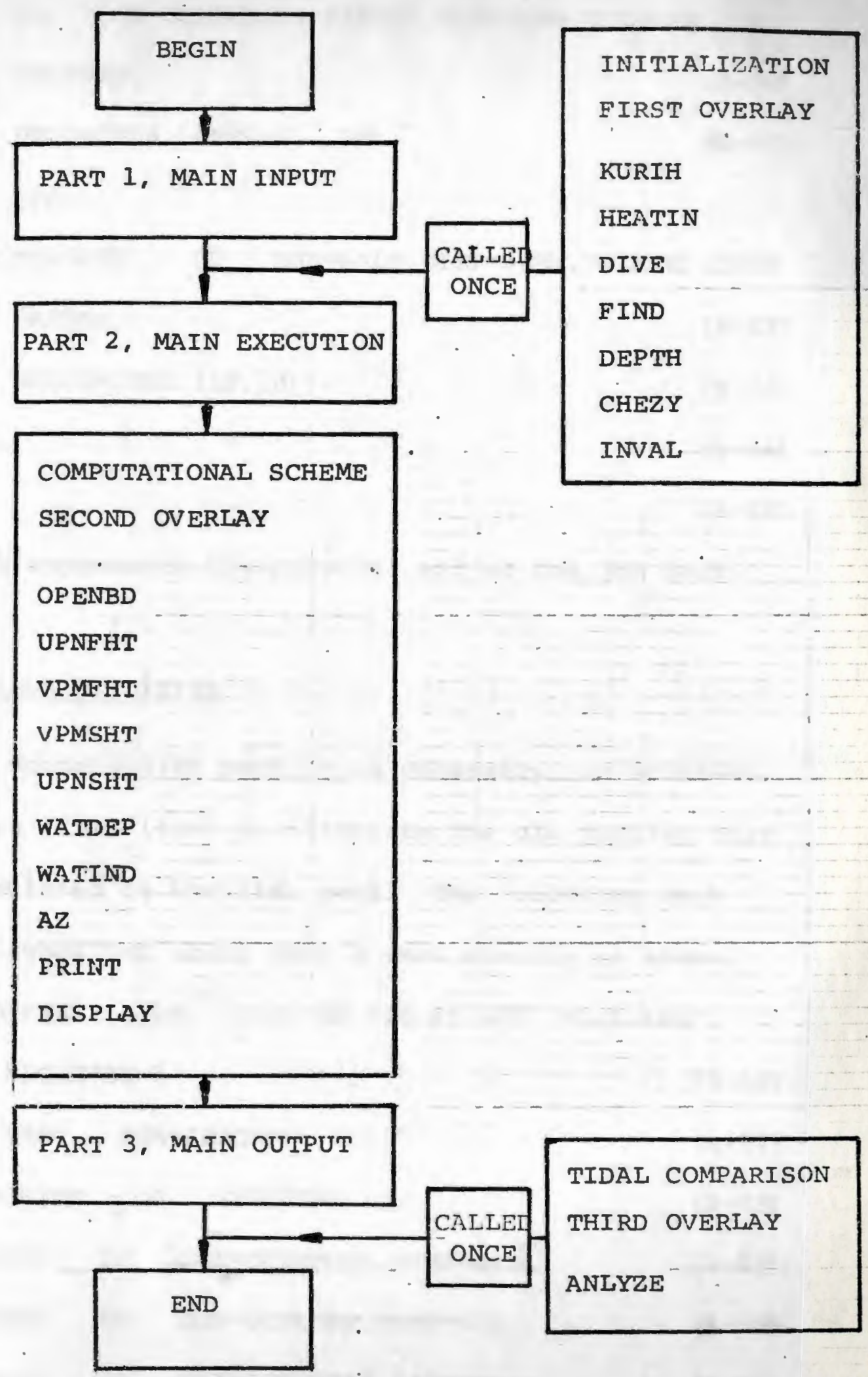

FIGURE A. 1. OVERLAY FLOW CHAATT 
// DD DSN=OCEDATAS (ADATA3), DISP=SHR, VOL=SER =OCEPAK.

$(A-50)$

$/ / \mathrm{UNIT}=2314, \mathrm{LABEL}=(,,, \mathrm{IN})$

$(\mathrm{A}-51)$

etc.

$/ / G O . F T 13 F \varnothing \varnothing 1$ DD DSN=\&ALF, DISP=(NEW, DELETE) , UNIT

=SYSDA,

$(A-52)$

$/ / \quad \operatorname{SPACE}=(\operatorname{TRK},(1 \varnothing, 1 \varnothing))$

$(A-53)$

/)

$(A-54)$

/*

$(A-55)$

where A-55 represents the physical end of the job deck.

\section{DISK PACK UTILITIES}

When using a disk pack it is necessary, on occasion, to compress (IBM, (1c)) or eliminate the old modules that have accumulated on the disk pack. The following deck should be submitted about once a week exactly as shown. //COMPRESS JOB (IN $\varnothing 1 \varnothing \varnothing, 256, \varnothing 5,1 \varnothing)$, 'USERNAME' ,

$$
\text { MSGLEVEL }=1
$$

// EXEC PGM=IEBCOPY $(A-57)$

$/ /$ SYSPRINT DD SYSOUT=A $(A-58)$

$/ /$ INOUTI DD DSN=OCESMODS, DISP=OLD $(A-59)$

$/ /$ INOUT2 DD DSN=OCECOMP , DISP=OLD $(A-60)$

//INOUT3 DD DSN=OCEDATAS, DISP=OLD $(A-61)$ 
From time to time it is convenient to have a total print and punch (IBM, (1d)) of the disk pack. The programs that will perform this function are described below. $/ /$ PTWOH JOB (INO $\varnothing \varnothing, 128, \varnothing 1,1 \varnothing, 35 \varnothing \varnothing)$, 'USERNAME' , MSGLEVEL $=1$

// EXEC PGM=IEBPTPCH $(A-66)$

//SYSPRINT DD SYSOUT=A $(A-67)$

//SYSUT1 DD DSN=OCESMODS, DISP=(OLD, KEEP) , VOL $=\mathrm{SER}=$ OCEPAK, UNI T $=2314$ $(A-68)$ //SYSUT2 DD SYSOUT $={ }_{B}^{A}[$ Gives Printed Output -Choose One $]$ $(A-69)$ //SYSIN DD * COL: $\quad 7$ [Choose one - PRINT PUNCH $]$ TYPORG=PO, MAXFLDS $=1 \quad(A-70)$ TITLE ITEM=(' PRINT AND PUNCH ALL

$\begin{array}{cc}\text { MEMBERS ' }, 1 \varnothing) & (A-71) \\ \text { RECORD FIELD }=(8 \varnothing, \ldots 5) & (A-72) \\ (A-73) \\ (A-74)\end{array}$


Note that one can obtain either punched or printed output (but not both) by picking the "A PRINT", or "B PUNCH" options.

\section{E. ACKNOWLEDGMENT}

Now that the model is fully operational in all modes it would be a great injustice not to cite the very valuable and timely assistance given to me by the entire computer center staff. Specifically, Dave "I can solve your problem" clayton was undoubtedly the individual in the staff I must cite as instrumental in bringing the computer hardware into line. In addition to his daily assistance, he formalized all the above information into a special class especially for the Ocean Engineering Bay Model group.

\section{F. SELECTED BIBLIOGRAPHY}

1. IBM Systems Reference Library, os Utilities, File No. S-360-32, order No. GC28-6586-14, 15th Ed., Dec., 1972 .

TITLES

a. IEBUPDAT

b. IEHLIST

c. IEBCOMPR

\section{PAGES}

173-198

$229-238$

$51-58$ 


\section{TITLES}

d. IEBPTPCH

e. IEBCOPY
PAGES

$141-155$

59-89

2. IBM Systems Reference Library, Linkage Editor \& Loader, File No. 5360-3, Order No. GC28-6538-9, 10th Ed., Jan., 1972, 63-88, Overlay.

3. Clayton, D.M., Computer Lab Newsletter, University of Rhode Island, Vol. 4, No. 7, March, 1973, pp. 9-10. 


\section{APPENDIX B \\ HYDRODYNAMTC FINITE DIFFERENCE EQUATIONS}

A. HYDRODYNAMIC MODEL

The three basic equations, 2-32 through 2-35, may be expressed In finite difference form, using the notation outlined in Equations 2-36 through 2-44. The results are:

A.1 First Half Timestep

$\mathrm{X}$ - Momen tum:

$$
\begin{aligned}
& u^{t+1 / 2}=u^{t}+\frac{1}{2} D T f \overline{\bar{v}}^{t}-\frac{1}{2} \frac{D T}{D L} u^{t+1 / 2} \delta *{ }_{x} v^{t} \\
& -\frac{1}{2} \frac{D T}{D L} U^{t+1 / 2 \overline{\bar{v}} t} \delta_{y}^{*} U^{t}-\frac{1}{2} \frac{D T}{D L} g \delta_{x} \eta^{t+1 / 2} \\
& -\frac{1}{2} \operatorname{DT} R_{(x)}^{t}-\frac{1}{2} T F_{(x)}^{t+1 / 2} \\
& \text { at } X_{c}+\frac{1}{2} D_{L}, Y_{c} \text {. }
\end{aligned}
$$

Conservation of Mass:

$$
\begin{aligned}
\eta^{t+1 / 2=} & \eta^{t}-\frac{1}{2} \frac{D T}{D L} \delta_{x}\left[\left(\vec{h}^{y}+\vec{n}^{x}\right)^{t+1 / 2} u^{t+1 / 2}\right] \\
& -\frac{1}{2} \frac{D T}{D L} \delta_{y}\left[\left(\vec{h}^{x}+\overrightarrow{n^{y}}\right)^{t} v^{t}\right], \\
& \text { at } X_{c}, Y_{c} .
\end{aligned}
$$


Y-Momen tum:

$$
\begin{aligned}
v^{T+1 / 2=} & v^{t}-\frac{1}{2} \frac{D T}{D L} \delta_{x}^{*} v^{t} \overline{\bar{U}} t+1 / 2-\frac{1}{2} \frac{D T}{D L} \delta_{y}^{*} v^{t} v^{t+1 / 2} \\
& -\frac{1}{2} \frac{D T}{D L} g \delta_{y} n^{t}-\frac{1}{2} D T R_{(y)}^{t+1 / 2}-\frac{1}{2} D T F_{(y)}^{t} \\
& \text { at } x_{c}, Y_{c}+\frac{1}{2} D L .
\end{aligned}
$$

\section{A. 2 Second Half Timestep}

$$
\begin{aligned}
& \mathrm{X} \text { - Momentum: } \\
& u^{t+1}=u^{t+1 / 2}+\frac{1}{2} \text { DI } f \overline{\bar{v}}^{t+1 / 2}-\frac{1}{2} \frac{\mathrm{DT}}{\mathrm{DL}} \mathrm{u}^{t+1 / 2} \delta_{x}^{*} u^{t+1 / 2} \\
& -\frac{1}{2} \frac{D T}{D L} \bar{V}^{t+1} \delta_{y}^{*} U^{t+1 / 2}-\frac{1}{2} \frac{D T}{D L} g \delta_{x} n^{t+1 / 2} \\
& -\frac{D T}{D L} R_{x}^{t+1}-F_{y}^{t+1 / 2} \\
& \text { at } X_{c}+\frac{1}{2} D L, Y_{c} \text {. }
\end{aligned}
$$

Conservation of Mass:

$$
\begin{aligned}
& n^{t+1}=n^{t+1 / 2}-\frac{D T}{D L} \delta x\left[\left(\bar{h}^{y}+\bar{n}^{-x}\right) t+1 / 2\right] u^{t+1 / 2} \\
& -\frac{1}{2} \frac{D T}{D L} \delta y\left[\left(\bar{h}^{x}+n^{-y}\right) t+1\right] v^{t+1} \\
& \text { at } X_{c}, Y_{c} \text {. }
\end{aligned}
$$


Y - Momentum:

$$
\begin{aligned}
v^{t+1}= & v^{t+1 / 2}-\frac{1}{2} \frac{D T}{D L} f \bar{U}^{t+1 / 2}-\frac{1}{2} \frac{T}{L} \bar{U}^{t+1 / 2} \delta_{x}^{*} v^{t+1 / 2} \\
& -\frac{1}{2} \frac{D T}{D L} v^{t+1} \delta_{y}^{*} v^{t+1}-\frac{1}{2} \frac{D T}{D L} g \delta_{y} n^{t+1} \\
& -\frac{1}{2} \frac{D T}{D L} R_{y}^{t+1 / 2}-\frac{1}{2} \frac{D T}{D \bar{L}} F_{y}^{t+1} \\
& \text { at } x_{c}, Y_{c}+\frac{1}{2} L
\end{aligned}
$$

where the bottom stress term, $R$, is defined as:

$$
\begin{aligned}
& R_{x}^{t}=g U^{t} \frac{\left[\left(U^{t}\right)^{2}+\left(\bar{v}^{t}\right)^{2}\right]^{\frac{1}{2}}}{\left(\bar{h}^{y}+\bar{n}^{x}\right)^{t}\left(\bar{g}^{x}\right)^{2}} \\
& \mathrm{R}_{\mathrm{y}}^{t+1 / 2}=g \mathrm{v}^{t+1 / 2} \frac{\left[\left(\overline{\mathrm{u}}^{t}+1 / 2\right)^{2}+\left(\mathrm{v}^{t}\right)^{2}\right]^{1 / 2}}{\left(\overline{\mathrm{h}}^{\mathrm{x}}+\bar{n}^{-\mathrm{y}}\right)^{t}+1 / 2\left(\overline{\mathrm{C}}^{\mathrm{y}}\right)^{2}} \\
& R_{X}^{t+1}=g U^{t+1}\left[\left(U^{t+1 / 2}\right)^{2}+(\overline{\bar{V}} t+1)^{2}\right]^{1 / 2} \\
& \left(\bar{h}^{-y}+n^{-x}\right)^{t}+1 / 2\left(\bar{c}^{-x}\right)^{2}
\end{aligned}
$$

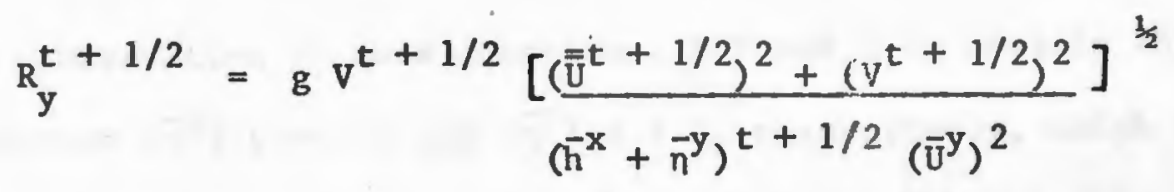


and the surface stress terms, $f$, are defined as

$$
F_{x}^{t}+1 / 2=\frac{k\left(\omega_{x}^{t+1 / 2}\right)^{2}}{\left(\bar{h}^{-y}+\eta^{-x}\right)^{t}}
$$

$$
\begin{aligned}
& F_{y}^{t}=\frac{k\left(\omega_{y}^{t}\right)^{2}}{\left.\sum_{h}^{-x}+n^{-y}\right)^{t}} \\
& F_{x}^{t+1 / 2}=\frac{k\left(\omega_{x}^{t}+1 / 2\right)^{2}}{\left(\bar{h}^{y}+\bar{n}^{-x}\right)+1 / 2} \\
& F_{y}^{t+1}=\frac{k\left(\omega_{y}^{t}+1\right)^{2}}{\left(\bar{h}^{x}+\bar{n}^{-y}\right)^{t}+1 / 2}
\end{aligned}
$$

where

$$
K=\frac{k \rho_{\text {air }}}{\rho_{\text {water }}}
$$

The conservation of mass equations, B.2 and B.6, contain the non-11nearthes $\left(\vec{n}^{-x}\right) t+1 / 2$ and $\left(n^{-y}\right) t+1$, respectively, which are at the same time level as $\eta$ on the left-hand side of the equations. In the solution, these terms are taken at the lower time level in the first approximation and at the same time level ir succeeding iterations. The hydraulic portion of model does contain iteretive procedure but is not used because the Improvement in accuracy was neg 
APPENDIX C

\section{METHOL OF SOLUTION}

The implicit method of solution for $n$ and $u$ tr the first half of the time step is first presented. The solution of $n$ and $v$ in the second is analogous. Starting with equations B.2 and B.1 (in Appendix B), and writing out the finite-difference approximation, we have

$$
\begin{aligned}
& -r_{m-1 / 2} u_{m-1 / 2}+n_{m}+r_{m}+1 / 2 u_{m}+1 / 2=A_{m} \\
& -r_{m} n_{m}+u_{m}+1 / 2+r_{m}+1 n_{m}+1=B_{m}+1 / 2
\end{aligned}
$$

where the coefficients $r$ are

$$
\begin{aligned}
& r_{m \pm 1 / 2}=\frac{1 D T}{2 D L}\left(\bar{h}^{-y}+n^{-x}\right)_{m} \pm 1 / 2 \\
& r_{m}=\frac{1 D T}{2 D L} g
\end{aligned}
$$

and $A_{m}, B_{m}$ are the remaining terms in equations $C .2$ and $C .1$, respectively. Both $\eta$ and $u$ are at the $t+1 / 2$ time level (except for $\bar{n}^{-x}$ in C. 3 , which is at time $t$ ).

Suppose the first computational grid is at $m=2$, and the last is $m=J$. Then the values of $n$ occur with subscripts $m=2,3, \ldots \mathrm{J}$, while $u$ values have subscripts of $m=1 \frac{1}{2}, 2 \frac{1}{2}, \ldots . J+\frac{1}{2}$ (see Figure C.1). 
Solving eq. C.I for $n_{\mathrm{m}}$ at $\mathrm{m}=2$, gives

$$
n_{2}=A_{2}+r_{1 \frac{1}{2}} u_{1 \frac{1}{2}}^{*}-r_{2 \frac{1}{2}} u_{2 \frac{1}{2}}
$$

where $u_{1 \frac{1}{2}}^{*}$ is the velocity at the boundary. For the case of a land boundary, ${ }_{1 \frac{1}{2}}^{*}$ is zero. Equation $C .5$ may be rewritten as

$$
n_{2}=-p_{2} u_{2 \frac{1}{2}}+u_{2}
$$

where

$$
\mathbf{p}_{2}=\mathbf{r}_{2 \frac{1}{2}}
$$

and

$$
n_{2}=A_{2}+r_{1 \frac{1}{2}} u_{1 \frac{1}{2}}^{*}
$$

Equation C. 2 at $m=2$ is

$$
u_{2 \frac{1}{2}}=B_{2 \frac{1}{2}}+r_{2} n_{2}-r_{3} n_{3}
$$

Taking the expression for $\eta_{2}$ from eq. C.6, and substituting into the above,

$$
u_{2 \frac{1}{2}}=B_{2 \frac{1}{2}}+r_{2}\left(-p_{2} u_{2 \frac{1}{2}}+u_{2}\right)-r_{3} n_{3}
$$

or

$$
u_{2 \frac{1}{2}}=-R_{2} \eta_{3}+s_{2}
$$

where

$$
\begin{gathered}
R_{2}=\frac{r_{3}}{1+r_{2} P_{2}} \\
s_{2}=\frac{B_{2 \frac{1}{2}}+r_{2} u_{2}}{1+r_{2} P_{2}} \\
180
\end{gathered}
$$


The next water level, $n_{3}$, is (from eq. C. 1 at $m=3$ )

$$
n_{3}=A_{3}+r_{2 \frac{1}{2}} u_{2 \frac{1}{2}}-r_{3 \frac{1}{2}} u_{3 \frac{1}{2}}
$$

and substituting the expression for $u_{2 \frac{1}{2}}$ from eq. C.10a,

or

$$
\begin{aligned}
& n_{3}=A_{3}+r_{2 \frac{1}{2}}\left(-R_{2} n_{3}+s_{2}\right)-r_{3 \frac{1}{2}} u_{3 \frac{1}{2}} \\
& n_{3}=-b_{3} u_{3 \frac{1}{2}}+n_{3}
\end{aligned}
$$

where

$$
\rho_{3}=\frac{r_{3 \frac{1}{2}}}{1+r_{2 \frac{1}{2}} H_{2}}
$$

and

$$
u_{3}=\frac{A_{3}+r_{2 \frac{1}{2}} s_{2}}{1+r_{2 \frac{1}{2}} R_{2}}
$$

The velocity $u_{3 \frac{1}{2}}$ is obtained from eq. C. 2 at $m=3$ :

$$
\begin{aligned}
& u_{3 \frac{1}{2}}=B_{3 \frac{1}{2}}+r_{3} n_{3}-r_{4} n_{4} \\
& u_{3 \frac{1}{2}}=-R_{3} n_{4}+s_{3} \\
& R_{3}=\frac{r_{4}}{1+r_{3} p_{3}}
\end{aligned}
$$

Or

where

$$
S_{3}=\frac{B_{3 \frac{1}{2}}+r_{3} Q_{3}}{1+r_{3} p_{3}}
$$

181 
This procedure (calculation of $\mathrm{p}_{m}, Q_{m}, R_{m}$, and $S_{m}$ ) is repeated for all $\mathrm{m}$ up to $\mathrm{m}=\mathrm{J}$, where, for a land boundary at $J+\frac{1}{2}$,

$$
n_{J}=-p_{J} u_{J}^{*}+\frac{1}{2}+Q_{J}
$$

and $\eta_{j}$ is easily computed since $u_{J}^{*}+\frac{1}{2}$ is zero.

Suppose, however, that instead of land boundar les, the first $(m=1)$ and last $(m=J+1)$ are water boundaries, with either velocity or water level values given. For a first grid water level alue, $n_{1}^{*}$, eq. C.2 gives

$$
u_{1 \frac{1}{2}}=B_{1 \frac{1}{2}}+r_{1} n_{1}^{*}-r_{2} n_{2}=-R_{1} n_{2}+s_{1}
$$

where $R_{1}=r_{2}$

and $s_{2}=B_{1 \frac{1}{2}}+r_{1} n_{1}^{*}$

For a first gird velocity, $u_{1 \frac{1}{2}}^{*}$, eq. B.5 will suffice. For the case of a last grid water level value, $n_{\mathrm{J}}^{*}+1$, eq. C.2 leisds to

$$
\begin{aligned}
u_{J}+\frac{1}{2} & =B_{J}+\frac{1 / 2}{2}+r_{J} n_{J}-r_{J}+1 n_{J}^{*}+1 \\
& =-R_{J} n_{J}^{*}+1+s_{J}
\end{aligned}
$$

There are three methods of specifying the last grid $(m=J+1)$ velocity. The first is to specify the value $u_{J}^{*}+1+\frac{1}{2}$, and

$$
n_{J+1}=-p_{J}+1 u_{J}^{*}+1+z_{2}+\psi_{J}+1
$$

which involves the calculation of $\eta$ at the boundiscy grid $(a=J)$. 
Secondly, it is possible to calculate $u_{J}+\frac{1}{2}$, from $u_{J}^{*}+1+\frac{1}{2}$ using a flowrate conservation law. Finally, the velocity at $J+\frac{1}{2}$ could be specified and eq. C.21 used directly. This last method is the most efficient, and is the one used in the present model calculations. In general, the coefficients can be written as:

$$
\begin{aligned}
& P_{m}=\frac{r_{m}+\frac{1}{2}}{1+r_{m}-1 R_{m}-1} \\
& u_{m}=\frac{A_{m}+r_{m}+\frac{1}{2} s_{m}-1}{1+r_{m}-\frac{1}{3} R_{m}-1} \\
& R_{m}=\frac{r_{m}}{1+r_{m}-1 P_{m}} \\
& s_{m}=\frac{B_{m}+\frac{1}{2}+r_{m} u_{m}}{1+r_{m}-1 P_{m}}
\end{aligned}
$$

Starting at the lower boundary $(\mathrm{m}=1), \mathrm{R}_{\mathrm{m}}$ and $\mathrm{S}_{\mathrm{m}}$ are calculatad, (from C.23 and C.24 for a water level boundary; $R_{1}: S_{1}=C$ for a land boundary; $\mathrm{R}_{1}-0, \mathrm{~s}_{1}=\mathrm{u}_{1}^{*}+\frac{1}{2}$ for a velocity boundary). Then at the computational levds $(m=2$ to $m=J) A_{m}, P_{m}, u_{m}, B_{m}, R_{m}$, and $S_{m}$ are calculated in that order for each $m$. At $m=J, u_{J}+\frac{1}{2}$ assumes its appropriate value (zero for a land boundary; the specified value for a velocity boundary; or computed from eq. C.25 for a water level boundary). The remaining values of $n$ and $u$ are then obtained from the recursive relations

$$
\eta_{m}=-P_{m} u_{m}+\frac{1}{2}+Q_{m}
$$




$$
u_{m-\frac{1}{2}}=-R_{m} n_{m}+s_{m-1}
$$

for $m$ decreasing from $m=J$ to $m=2$. 


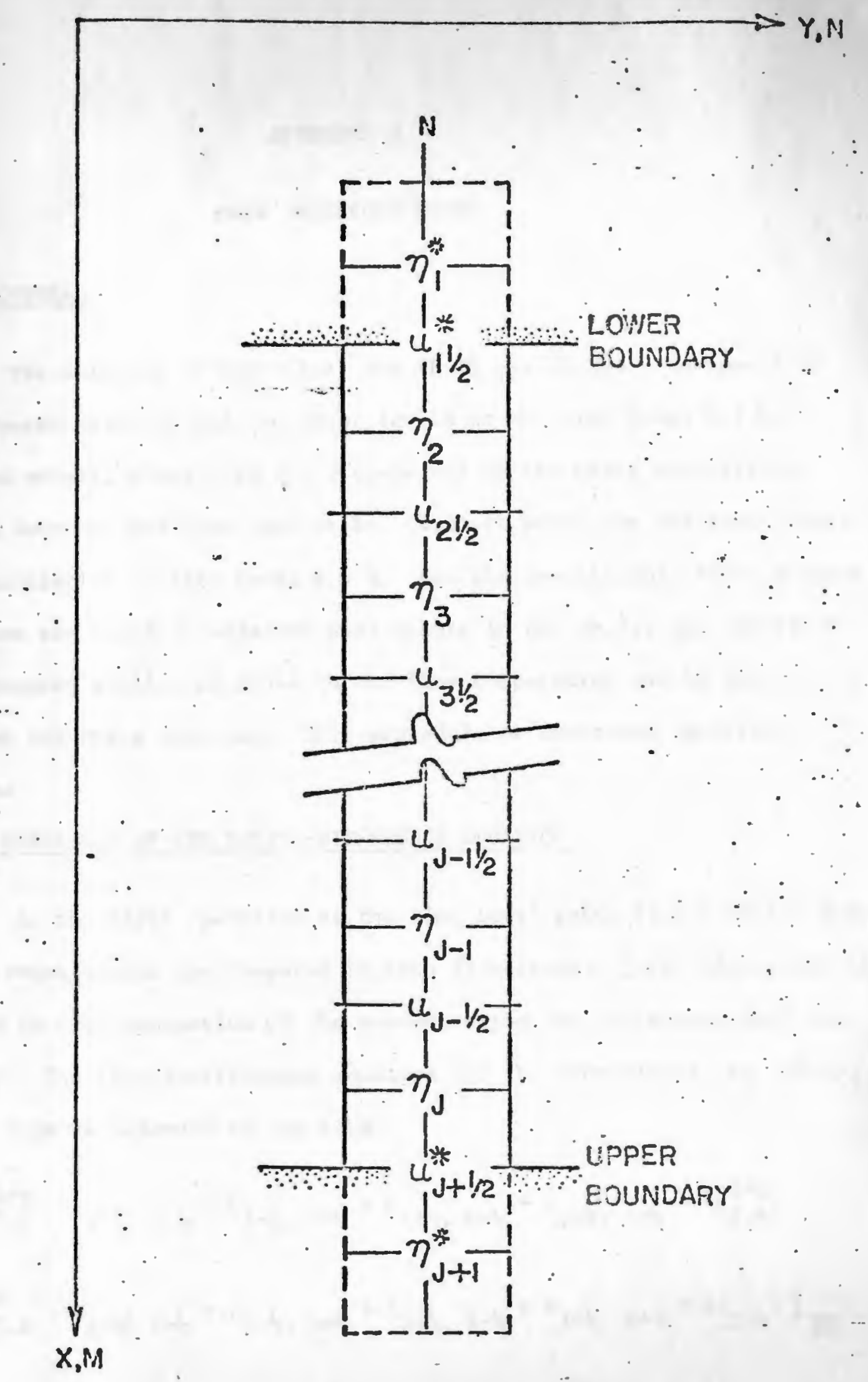

FIGURE C-1: SPATIAL ARRANGEMENT OF VARIARLFS: ON GRIDS 


\section{APPENDIX D}

MASS TRANSPORT MODEL

\section{A. GENERAL}

The solution of Eqs. (B.1) and (B.2) ylelds the $x$ component of the water velocity and the water levels at the time level $n+\frac{1}{2}$. These values, along with the $y$ component of the water velocity at time level $n$, are then used in Eq. (B.3) to solve for the constituent concentration at time level $n+\frac{1}{2}$. For the constituent, three unknown values are found at adfacent grid points in Eq. (B.3), and numerical procedures simtlar to those in the flow computation can be used to solve for these unknowns. This procedure is described in detall below.

\section{B. EXPANSION OF THE FINITE-DIFFERENCE EQUATION}

In the first operation at the time level going from $t$ to $t+\frac{1}{2} D t$, the constituents are computed in both directions. This information is used In the computation of the concentration for the second half time 8tep. The fintte-difference equation for the constituent, Eq. (B.3), can then be expanded in the form:

$$
\begin{aligned}
& {\left[c_{j, k}^{t+\frac{1}{2}}\left(h_{j-\frac{1}{2}, k-\frac{1}{2}}+h_{j-\frac{1}{2}, k+\frac{1}{2}}+h_{j+\frac{1}{2}, k-\frac{1}{2}}+h_{j+\frac{1}{2}, k+\frac{1}{2}}+4 n_{j, k}^{t+\frac{1}{2}}\right)\right.} \\
& \left.-c_{j ; k}^{t}\left(h_{j-\frac{1}{2}, k-\frac{1}{2}}+h_{j-\frac{1}{2}, k+\frac{1}{2}}+h_{j+\frac{1}{2}, k-\frac{1}{2}}+h_{j+\frac{1}{2}, k+\frac{1}{2}}+4 n_{j, k}\right)\right] \frac{1}{2 D t} \\
& -\left[n_{j-1, k}^{t:}+n_{j, k}^{t}+h_{j-\frac{1}{2}, k-\frac{1}{2}}+h_{\left.j-\frac{1}{2}, k+\frac{1}{2}\right)} u_{j-\frac{1}{2}, k}^{t+\frac{1}{2}}\left(c_{j-1, k ; 1}^{t+\frac{1}{2}}+c_{j, k}^{t+\frac{1}{2}}\right)\right.
\end{aligned}
$$


$\left.-\left(n_{j, k}^{t}+\eta_{j+1, k}^{t}+h_{j+\frac{1}{2}, k-\frac{1}{2}}+h_{j+\frac{1}{2}, k+\frac{1}{2}}\right) u_{j+\frac{1}{2}, k}^{t+\frac{1}{2}}\left(c_{j, k}^{t+\frac{1}{2}}+c_{j+1, k}^{t+\frac{1}{2}}\right)\right]\left(\frac{1}{4 D x}\right)$

$-\left[n_{j, k-1}^{t}+n_{j, k}^{t}+h_{j-\frac{1}{2}, k-\frac{1}{2}}+h_{j+\frac{1}{2}, k-\frac{3}{2}}\right) v_{j, k-\frac{k}{2}}^{t}\left(c_{j, k-1}^{t}+c_{j, k}^{t}\right)$

$\left.-\left(n_{j, k}^{t}+n_{j, k+1}^{t}+h_{j-\frac{1}{2}, k+\frac{1}{2}}+h_{j+\frac{1}{2}, k+\frac{1}{2}}\right) v_{j, k+\frac{1}{2}}^{t}\left(c_{j, k+1}^{t}+c_{j, k}^{t}\right)\right]\left(\frac{1}{4 D x}\right)$

$+\left[n_{j-1, k}^{t+\frac{1}{2}}+n_{j, k}^{t+\frac{1}{2}}+h_{j-\frac{1}{2}, k-\frac{1}{2}}+h_{\left.j-\frac{1}{2}, k+\frac{1}{2}\right)} D_{x_{j-\frac{1}{2}}, k}^{t+\frac{1}{2}}\left(C_{j, k}^{t+\frac{1}{2}}-c_{j-1, k}^{t+\frac{1}{2}}\right)\right.$

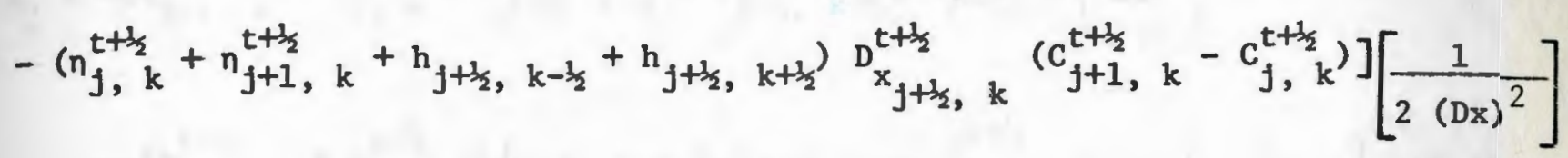

$+\left[\left(n_{j, k-1}^{t}+-n_{j, k}^{t}+h_{j-\frac{1}{2}, k-\frac{1}{2}}+h_{\left.j+\frac{1}{2}, k-\frac{1}{2}\right)} D_{y j, k-\frac{1}{2}}^{t}\left(c_{j, k}^{t}-c_{j, k-1}^{t}\right)\right.\right.$

$\left.-\left(n_{j, k}^{t}+n_{j, k+1}^{t}+h_{j-\frac{1}{2}, k+\frac{1}{2}}+h_{j+\frac{1}{2}, k+\frac{1}{2}}\right) D_{y, k+\frac{1}{2}}^{t}\left(c_{j, k+1}^{t}-c_{j, k}^{t}\right)\right]\left[\frac{1}{2(D x)^{2}}\right]$

$+\left(h_{j+\frac{1}{2}, k+\frac{1}{2}}+-h_{j+\frac{1}{2}, k-\frac{1}{2}}+h_{j-\frac{1}{2}, k+\frac{1}{2}}+h_{j-\frac{1}{2}, k-\frac{1}{2}}+4 n_{j, k}\right) \frac{s_{j, k}^{t}}{4}=0$

where $C_{j, k}^{t+\frac{1}{2}}$ is the concentration of constituent at the grid point $j, k$ for time level $t+\frac{1}{2}$. The dispersion coefficients $D_{x}, D_{y}$ and the source of constituent $S$ can be both space- and time-varying functions in this formulation. Point sources of constituents, such as occur at a power plant outfall, can be included. These procedures used for this part of the computation are described in Leendertse ${ }^{(2)}$.

There are only three unknown variables in Eq. (D.1). They are:

$c_{j ; k}^{t+\frac{3}{2}} ; \quad c_{j-1, k}^{t+\frac{1}{2}} ;$ and $c_{j+1, k}^{t+\frac{1}{2}}$ 
Thus, rewriting Eq. (D.1) after multiplying through by $t_{\text {an }}=t / 2$ glelds

$$
a_{j} c_{j-1, k}^{t+\frac{1}{2}}+b_{j} c_{j, k}^{t+\frac{t}{2}}+c_{j} c_{j+1, k}^{t+\frac{1}{2}}=D_{j}
$$

where:

$$
\begin{aligned}
& a_{j}=-\left(n_{j-1, k}^{t}+n_{j, k}^{t}+h_{j-\frac{1}{2}, k-\frac{1}{2}}+h_{\left.j-\frac{1}{2}, k+\frac{1}{2}\right)} u_{j-\frac{1}{2}, k}^{t}\left(\frac{t_{a n}}{4 D x}\right)\right. \\
& -\left(n_{j-1, k}^{t+\frac{1}{2}}+n_{j, k}^{t+\frac{1}{2}}+h_{j-\frac{1}{2}, k-\frac{1}{2}}+h_{\left.j-\frac{1}{2}, k+\frac{1}{2}\right)} D_{x_{j-\frac{1}{2}, k}^{t+\frac{1}{2}}}^{t}\left[\frac{t_{a n}}{2(D x)^{2}}\right]\right. \\
& c_{j}=-\left[\left(n_{j, k}^{t}+n_{j+1, k}^{t}+h_{j+\frac{1}{2}, k-\frac{1}{2}}+h_{j+\frac{1}{2}, k+\frac{1}{2}}\right)\left(-u_{j+\frac{1}{2}, k}^{t+\frac{1}{2}}\right)\right. \\
& \left.+\left(n_{j, k}^{t+\frac{1}{2}}+-n_{j+1, k}^{t+\frac{1}{2}}+h_{j+\frac{1}{2}, k-\frac{1}{2}}+h_{j+\frac{1}{2}, k+\frac{1}{2}}\right) D_{\frac{1}{t+\frac{1}{2}}}^{t+\frac{1}{2}, k} \frac{2}{D x}\right]\left(\frac{t a n}{4 D x}\right) \\
& b_{j .}=\frac{3}{4}\left(h_{j-\frac{1}{2}, k-\frac{1}{2}}+-h_{j-\frac{1}{2}, k+\frac{1}{2}}+h_{j+\frac{1}{2}, k-\frac{1}{2}}+h_{j+\frac{1}{2}, k+\frac{1}{2}}\right)+n_{j, k}^{t+\frac{1}{2}} \\
& -\left(n_{j-1, k}^{t}+n_{j, k}^{t}+h_{j-\frac{1}{2}, k-\frac{1}{2}}^{t}+h_{\left.j-\frac{1}{2}, k+\frac{1}{2}\right)}^{t} e_{j-\frac{1}{2}, k}^{t+\frac{1}{2}} k\left(\frac{t a n}{4 D x}\right)\right. \\
& +\left(n_{j, k}^{t}=n_{j+1, k}^{t}+h_{j+\frac{1}{2}, k-\frac{1}{2}}+h_{j+\frac{1}{2}, k+\frac{1}{2}}\right) w_{j+\frac{1}{2}, k}^{t+\frac{1}{2}}\left(\frac{t a n}{4 D x}\right) \\
& +\left(n_{j-1 ; k}^{t+\frac{1}{2}}+n_{j, k}^{t+\frac{1}{2}}+h_{j-\frac{1}{2}, k-\frac{1}{2}}+h_{\left.j-\frac{1}{2}, k+\frac{1}{2}\right)}\right]_{x_{j-\frac{1}{2}, k}}^{t+\frac{1}{2}}\left[\frac{t_{\text {an }}}{2(D x)^{2}}\right]
\end{aligned}
$$

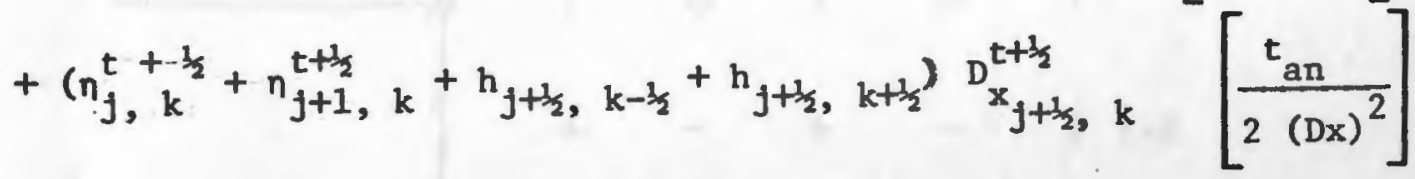


$D_{j}=C_{j, k}^{t}\left[h_{j-\frac{1}{2}, k-\frac{1}{2}}+h_{j-\frac{1}{2}, k+\frac{1}{2}}+h_{j+\frac{1}{2}, k-\frac{1}{2}}+h_{j+\frac{1}{2}, k+\frac{1}{2}}+n_{j, k}^{t}\right]$ $+\left[\left(n_{j, k-1}^{t}+n_{j, k}^{t}+h_{j-\frac{1}{2}, k-\frac{1}{2}}+h_{j+\frac{1}{2}, k-\frac{1}{2}}\right) v_{j, k-\frac{1}{2}}^{t}\left(c_{j, k-1}^{t}+c_{j, k}^{t}\right)\right.$

$-\left(n_{j, k}^{t}+n_{j, k+1}^{t}+h_{j-\frac{1}{2}, k+\frac{1}{2}}+h_{\left.j+\frac{1}{2}, k+\frac{1}{2}\right)} v_{j, k+\frac{1}{2}}^{t}\left(C_{j, k+1}^{t}+c_{j, k}^{t}\right)\right]\left(\frac{t_{a n}}{4 \text { Dx }}\right)$ (D. 7)

$-\left[\left(n_{j, k-1}^{t}+n_{j, k}^{t}+h_{j-\frac{1}{2}, k-\frac{1}{2}}+h_{j+\frac{1}{2}, k-\frac{1}{2}}\right) D_{y j, k-\frac{1}{2}}^{t}\left(c_{j, k}^{t}-c_{j, k-1}^{t}\right)\right.$ $\left.-\left(n_{j, k}^{t}+n_{j, k+1}^{t}+h_{j-\frac{1}{2}, k+\frac{1}{2}}+h_{j+\frac{1}{2}, k+\frac{1}{2}}\right) D_{y j, k+\frac{1}{2}}^{t}\left(c_{j, k+1}^{t}-c_{j, k}^{t}\right)\right]^{\left(t_{a n}\right.}\left(\frac{D x)^{2}}{2}\right)$ $-\left[\frac{1}{4}\left(h_{j+\frac{1}{2}, k+\frac{1}{2}}+h_{j+\frac{1}{2}, k-\frac{1}{2}}+h_{j-\frac{1}{2}, k+\frac{1}{2}}+h_{j-\frac{1}{2}, k-\frac{1}{2}}\right)+n_{j, k}^{t}\right] s_{j, k}^{t}$

For each row $k$, Eq. (D.7) can be written as:

$$
a_{j} c_{j-1}+b_{j} c_{j}+e_{j} c_{j+1}=D_{j}
$$

where the subscripts $k$ and superscript $t+\frac{1}{2}$ are dropped for convenience. Equation (D.8) can be solved for the concentration of constituent at each grid point along row $k$ by a process of elimination of unknowns. To 11lustrate the method, a closed left-hand boundary is assumed at some value of $\mathrm{J}=\mathrm{J}-1, \mathrm{k}=\mathrm{K}$, as shown in Figure $\mathrm{D}-1$.

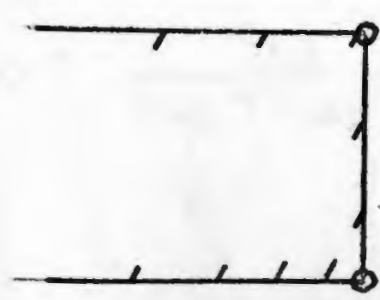

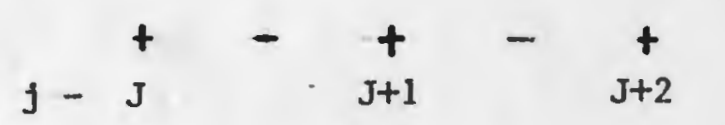


For this case, both the advective and dispersive transport of constituent through the cross section between grid points $\mathrm{J}-1$ and $\mathrm{J}$ is zero. Thus $a_{j}=0$, and Eq. (D.8) can be written as:

$$
b_{J} c_{J}+e_{J} c_{J+1}=D_{J}
$$

For the next point, $f=J+1$, along row $k=k, E q$. (D.8) is written as:

$$
a_{J+1} c_{J}+b_{J+1} c_{J+1}+e_{J+1} c_{J+2}=D_{J+1}
$$

Solving Eq. (D.9) for $\mathrm{C}_{\mathrm{J}}$ ylelds

$$
c_{J}=E_{J+1} c_{J+1}+Q_{J+1}
$$

where

$$
E_{\mathrm{J}+1}=-\frac{\mathrm{e}_{\mathrm{J}}}{\mathrm{b}_{\mathrm{J}}} ; \quad Q_{\mathrm{J}+1}=\frac{\mathrm{D}_{\mathrm{J}}}{\mathrm{b}_{\mathrm{J}}}
$$

Substituting Eq. (D.9) for $C_{J}$ into Eq. (D.10) gives

$$
a_{J+1}\left(E_{J+1} c_{J+1}+Q_{J+1}\right)+b_{J+1} c_{J+1}+e_{J+1} c_{J+2}=D_{J+1}
$$

Solving for $\mathrm{C}_{\mathrm{J}+1}$ ylelds

$$
c_{J+1}=E_{J+2} C_{J+2}+Q_{J+2}
$$

where

$$
E_{J+2}=-\frac{e_{J+1}}{b_{J+1}+a_{J+1} E_{J+1}} ; \quad Q_{J+2}=\frac{D_{J+1}-a_{J+1} Q_{J+1}}{b_{J+1}+a_{J+1} E_{J+1}}
$$


In general, the following recursion formulas are valid:

$$
P_{j}=E_{j+1} C_{j+1}+Q_{j+1}
$$

where

$$
\begin{aligned}
& E_{j+1}=-\frac{e_{j}}{b_{j}+a_{j} E_{j}} \\
& Q_{j+1}=\frac{D_{f}-a_{j} Q_{j}}{b_{j}+a_{j} E_{j}}
\end{aligned}
$$

It is assumed that the right-hand boundary at $j=M, k=K$ is also a closed boundary, as shown in Figure D-2.

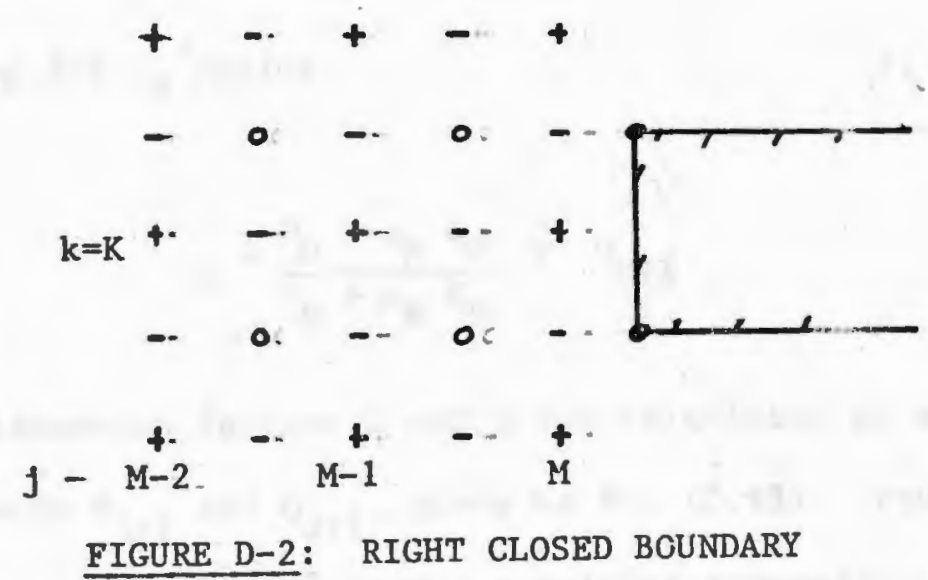

The advective and diffusive transport of constituent through the cross gection between $J=M$ and $J=M+1$ is zero for th: 1 s case, and therefore $E_{M} \equiv 0$. Equation (D.8) for $\mathcal{J}=M$ then becomes

$$
a_{M} c_{M-1}+b_{M} c_{M}=D_{M}
$$


and solving for $C_{M-1}$ yields

$$
{ }_{M-1}=-\frac{b_{M}}{a_{M}} c_{M}+\frac{b_{M}}{a_{M}}
$$

Writing the general recursion formula given by Eq. (D.17) for $j=M-1$ leads to

$$
G_{M-1}=E_{M} P_{M}+Q_{M}
$$

Using Eq. (D.21) in Eq. (D.22) gives

$$
E_{M} c_{M}+Q_{M}=-\frac{b_{M}}{a_{M}} c_{M}+\frac{D_{M}}{a_{M}}
$$

and solving for $C_{M}$ yields

$$
M=\frac{D_{M}-a_{M} Q_{M}}{b_{M}+a_{M} E_{M}} \equiv Q_{M+1}
$$

The recursion factors $E$ and $Q$ are calculated in ascending order, starting with $E_{J+1}$ and $Q_{J+1}$, given by Eq. (D.13). Equations (D.17) and (D.18) are used to calculate the remaining recursion factors to $f=M$, noting that $\mathrm{F}_{M+1} \equiv 0$ since $e_{M}=0$. The concentrations are then computed in descending order, st.arting with $j=M$, using Eq. (D.16).

If Instead of a closed boundary at either end of the computational field, the geography of the region to be modeled requires an open boundary, then the above procedure must be modified slightly. As in the example given for the flow model, it is assumed that part of the left- 
hand boundary, $f=1$, of the computational field contains an open boundary, as shown in Figure D-3. For this case, $E_{2}$ is set equal to zero and $Q_{2}$ is set equal to the concentration of constituent 1 at the open boundary, $C_{1}$. This concentration is a given input variable and is usually a function of time. The methods used to obtain $C_{1}$ for the sample calculations are explained in the next section.

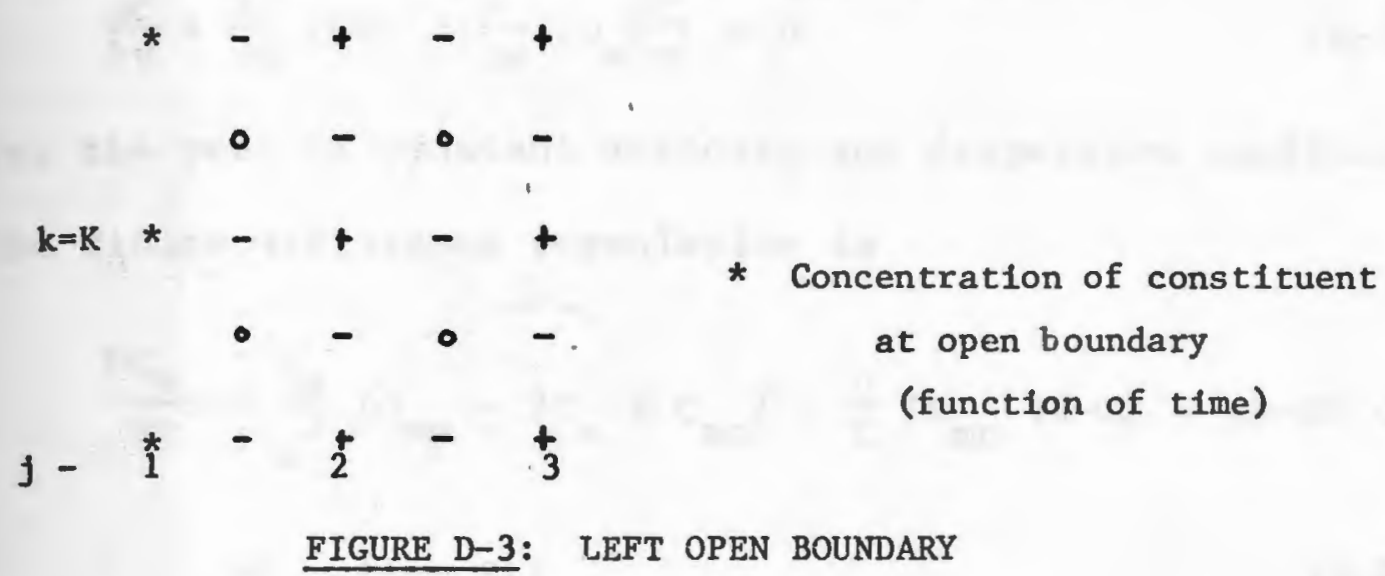

The rest of the recursion factors and concentrations are then calculated in the same way as for a closed boundary. 


\section{APPENDIX E \\ DIFFERENCING SCHEMES AND THEIR EFFECTS}

Consider the one-dimensional convective-dispersion equation

$$
\frac{\partial C}{\partial t}+\frac{\partial}{\partial x}(U C)=\frac{\partial}{\partial x}\left(D_{x} \frac{\partial C}{\partial x}\right)=0
$$

For the case of constant velocity and dispersion coefficient, the finite difference formulation is

$$
\begin{aligned}
\frac{D C_{m}}{D t} & =\frac{D x}{L}\left[C_{m p}-2 C_{m}+C_{m m}\right]-\frac{U}{L}\left[C_{m p}(1-A)+(A-B) C_{m}\right. \\
& \left.-C_{m m}(1-B)\right]
\end{aligned}
$$

where $\mathrm{L}$ is the grid length, $\mathrm{A}$ and $\mathrm{B}$ are parameters with possible values of $0,1 / 2$, or $1, \mathrm{~mm}=\mathrm{m}-1$ and $\mathrm{mp}=\mathrm{m}+1$.

Let us suppose a constant depth and width channel with unit concentration at grid $M$, and zero elsewhere in Figure E.1.

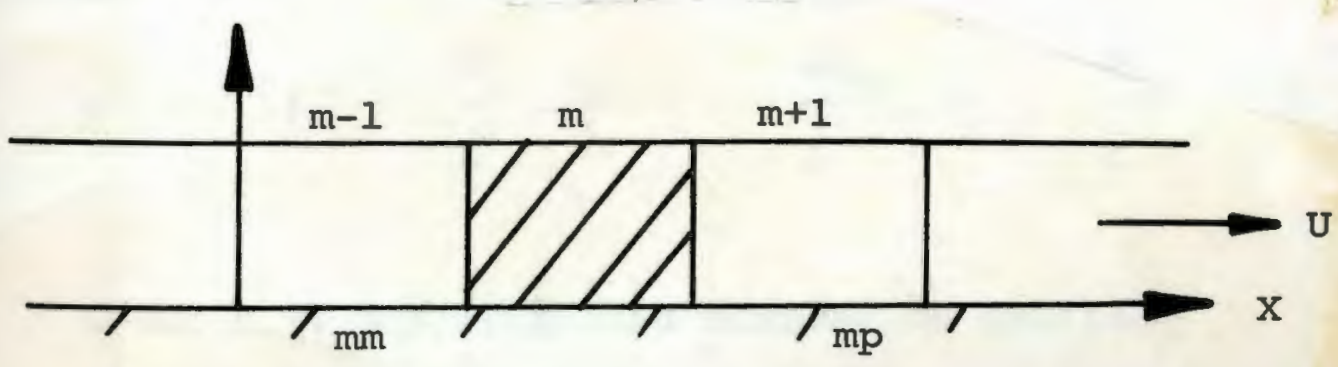

FIGURE E.1. ONE DIMENSIONAL DIFFERENCING SCHEME 
Using a central spatial derivative in the convective term $(A=B=1 / 2)$, the rate of change of concentration, $D C / D t$, may be computed as follows:

$$
\text { at } M \frac{D C_{m}}{D t}=\frac{D_{x}}{L^{2}}\left[C_{m p}-2 C_{m}+C_{m m}\right]-\frac{u}{2 L}\left[C_{m p}-C_{m m}\right]
$$

which becomes, upon substitution of values of $C$ from Figure E-1,

$$
\frac{D C_{m}}{D t}=\frac{D x}{L^{2}}\left[-2 C_{m}\right]=-\frac{2 D x}{L^{2}}
$$

$$
\begin{array}{lllll}
A & B & \frac{D C}{D t} & \frac{D C}{D t} & \frac{D C}{D t} \\
1 / 2 & 1 / 2 & \frac{D_{x p}}{L^{2}}-\frac{u}{2 L} & -\frac{2 D_{x}}{L^{2}} & \frac{D_{x}}{L^{2}}+\frac{u}{2 L} \\
1 & 0 & \frac{D_{x}}{L^{2}} & -\frac{2 D_{x}}{L^{2}}-\frac{u}{L} & \frac{D_{x}}{L^{2}}+\frac{u}{L} \\
0 & 1 & \frac{D_{x}}{L^{2}}-\frac{u}{L} & -\frac{2 D_{x}}{L^{2}}-\frac{u}{L} & \frac{D x}{L}
\end{array}
$$

TABLE E.1. DIFFERENCING SCHEMES ON SPATIAL CONCENTRATION GRID 
The results for grids $M, M M$, and $M P$ are given in the table. If the dispersion coefficient, $D_{x^{\prime}}$ is small (less than $25 \mathrm{yd}^{2}$ ), this scheme results in a negative concentration at the grid immediately upstream from the grid with unit concentration.

To overcome this, the upstream differencing technique may be used to advantage. That is, instead of using a central difference in the spacial term, a backward difference is used (with velocity in (t) $-\mathrm{x}$ direction), which is obtained by setting $A=1$, and $B=0$. Applying this at $M$, we have

$$
\begin{aligned}
\frac{D C_{m}}{D t} & =\frac{D}{L^{2}}\left[-2 C_{m}\right]-\frac{u}{L}\left[C_{m}-C_{m m}\right] \\
& =-\frac{2 D}{L^{2}}-\frac{u}{L}
\end{aligned}
$$

The results for $\mathrm{M}, \mathrm{MM}$, and $\mathrm{MP}$ are shown in Table E.1. The upstream concentration is now positive. However, this scheme results in an increase in effective dispersion. This may be seen by making the substitution for $A=1$, $B=0$ into Equation $E-1$.

Consider the consequences of using a mixture of the two schemes. By adding the rates of increase of concentration for the three grids M, MM, MP for the upstream scheme 
$(A=1, B=0)$, the sum is zero, indicating that mass is conserved. However, if a central derivative is used at grid MP, its increase is

$$
\frac{D C_{m p}}{D t}=\frac{D_{x}}{L^{2}}+\frac{u}{2 L}
$$

The sum for the three grids is then

$$
-1 / 2 \frac{U}{L}
$$

indicating that mass is lost. Thus a mixture of the two schemes is to be avoided. For the velocity conditions below

$$
\begin{aligned}
& \text { Case } u \text { greater than } 0 ; A=1, B=0 \\
& \text { A } \\
& v \text { greater than } 0 ; \quad A=1, B=0 \\
& \text { Case } u \text { less than } 0 ; \quad A=0, B=1 \\
& \text { B } \\
& \checkmark \text { less than } 0 ; \quad A=0, B=1
\end{aligned}
$$

the upstream differencing would be

$$
\begin{array}{ll}
\text { Case A } & \frac{\partial C}{\partial x}=\frac{1}{2 L}\left[2 C_{m}-2 C_{m-1}\right] \\
\text { Case B } & \frac{\partial C}{\partial x}=\frac{1}{2 L}\left[2 C_{m+1}-2 C_{m}\right]
\end{array}
$$

where $\mathrm{L}=$ is length of grid

The second term in Equation $E-4, \frac{\partial}{\partial x}$ (UC) is now analyzed for $U \frac{\partial C}{\partial x}$ according to Figure E.2 


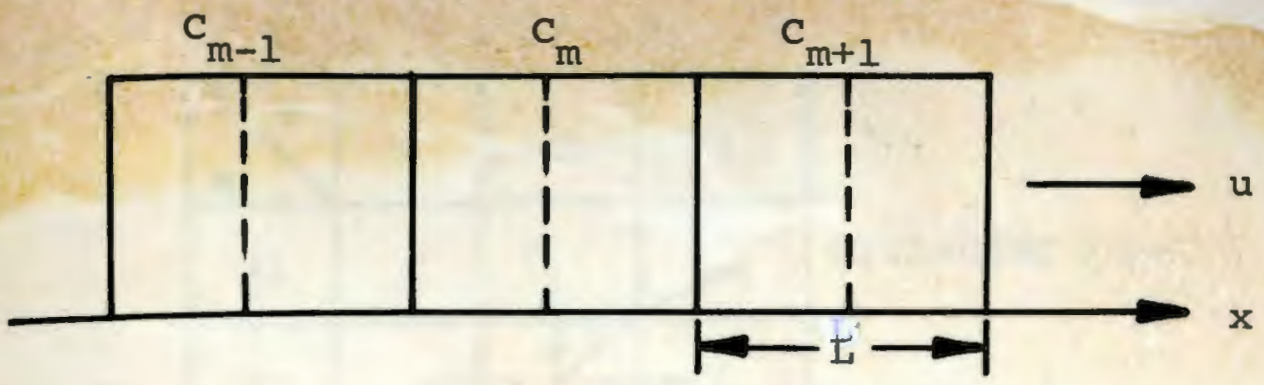

FIGURE E.2. ONE DIMENSIONAL CONCENTRATION SCHEME

and we have

$$
U \frac{\partial C}{\partial x}=u\left[(1+A) c_{m+1}-2(A-B) c_{m}-(1-B) C_{m-1}\right] \frac{1}{2 I}
$$

for centered derivative $A=1 / 2$ and $B=1 / 2$, we have

$$
=\left(c_{m+1}-c_{m-1}\right) \frac{u}{2 L}
$$

\section{A. UPSTREAM DIFFERENCING IN A CONSISTENT DIVERGENT FLOW}

\section{PATTERN}

It was discovered that for the grid point $\mathrm{N}=10$, $M=32$ the upstream differencing scheme is unstable. This is shown by first referring to Figure E.3., and noting the general divergent flow condition that exists especially with regard to their velocity component.

Since we have Case A, Equation E.I is supposed to be applicable which it normally would be if the component was 


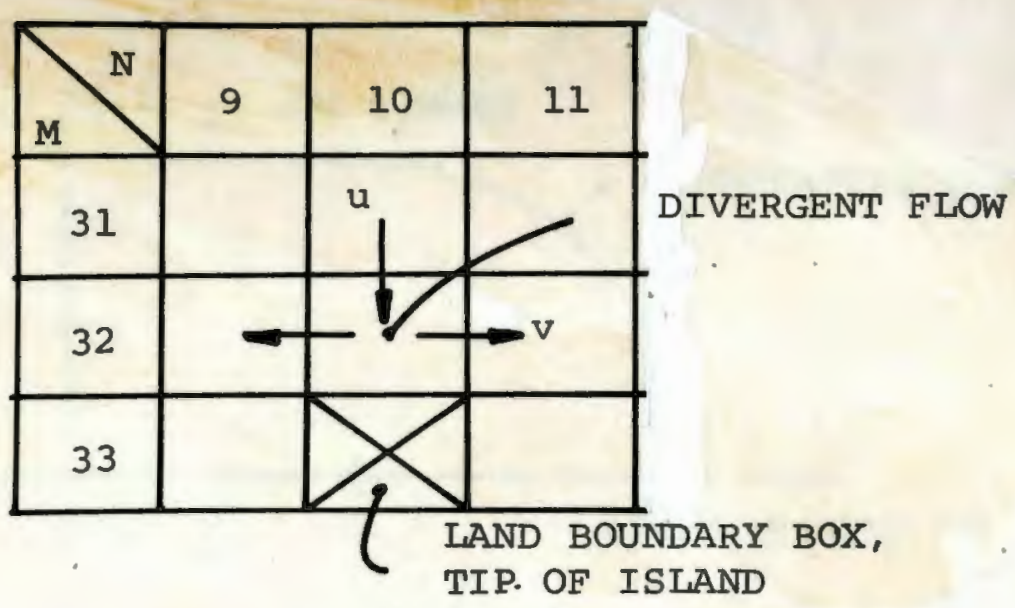

FIGURE E.3. DIVERGENT FLOW AROUND THE NORTH TIP OF CONANICUT ISLAND, JAMESTOWN, RHODE ISLAND

not plus (easterly) over $90 \%$ of the time. The result is that the $c_{m-1}$ term is forced to change sign by the differencing scheme, which means that the $\frac{\partial C}{\partial x}$ term is larger than it should be, which in turn increases the net advective transport out of the box, giving the response shown in Figure E.4.

Considering the divergent flow and artificial diffusion enhancing properties of the upstream differencing scheme, it was decided to make initial prediction runs using the central differencing scheme. 


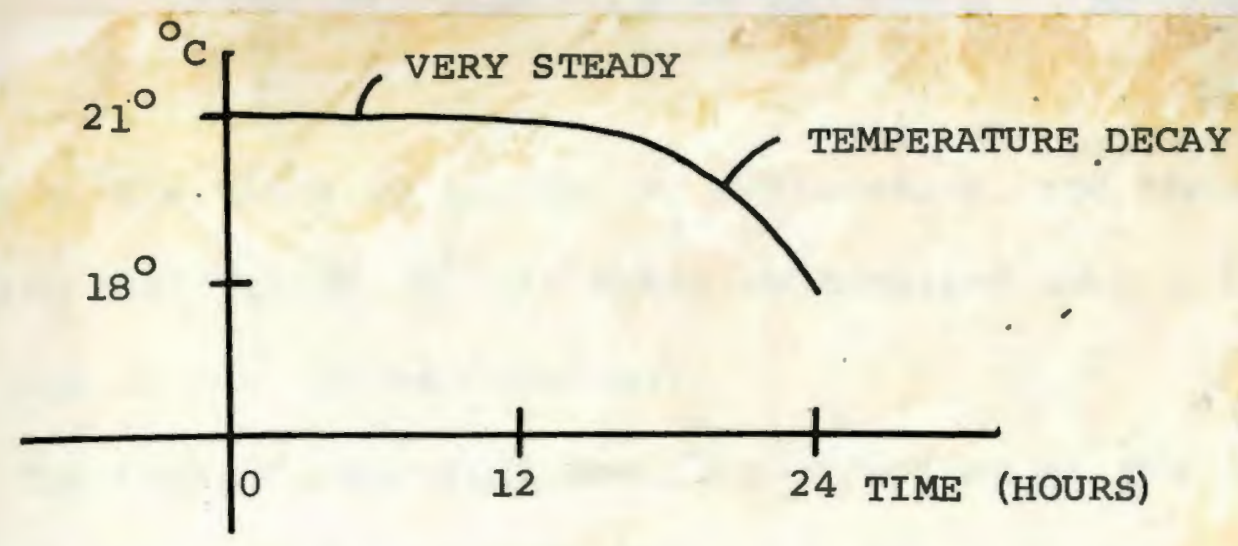

FIGURE E.4. DIVERGENT FLOW INSTABILITY

B. CONSERVATION OF MASS

An attempt was made to check on the mass-conserving properties of several approximations to the convectivedispersion concentration equation

$$
\frac{\partial C}{\partial t}+U \frac{\partial C}{\partial x}-D_{x} \frac{\partial c^{2}}{\partial x^{2}}=0
$$

which have been used in mathematical models. The approximations involve the use of various differencing schemes on the convective term, and modifications of the dispersion coefficient, $D_{x^{\prime}}$ if applicable.

In finite-difference form, the above equation may be written as

$$
\frac{C_{m}^{+}-c_{m}^{0}}{t}+\frac{U}{2 L}\left[2(1-A) c_{m p}^{+}+2(A-B) c_{m}^{+}\right.
$$




$$
\begin{array}{r}
\left.-2(1-B) C_{m m}^{+}\right]-\frac{D_{x}}{L^{2}}\left[C_{m p}^{+}-2 C_{m}^{+}+C_{m m}^{+}\right]=0 \\
(E-16)
\end{array}
$$

where $U$, the velocity in the $(+) x$-direction, and the dispersion coefficient, $D$, are taken as constant over $x$ (as they are in the uniform channel).

The terms $\mathrm{C}$ represent the concentrations at the center of each grid, with the superscript (+) denoting the upper time level, and the $(0)$ the lower time level. The subscripts denote the grid number in the $x$-direction, with $M P=M+1, M M=M-1 . \quad$ The above finite-difference equation is written for grid M.

The dispersion coefficient, (refer to Figure E.4), $D$, is calculated from the velocity, $u$, the depth, $H$, and the Chezy coefficient, $c_{z}$, in the general form

$$
\begin{aligned}
\frac{\partial C}{\partial t}= & -u \frac{\partial C}{\partial x}=-u\left[(1-A) C_{m p}+(A-B) C_{m}\right. \\
& \left.-(1-B) C_{m m}\right] \frac{1}{L}
\end{aligned}
$$

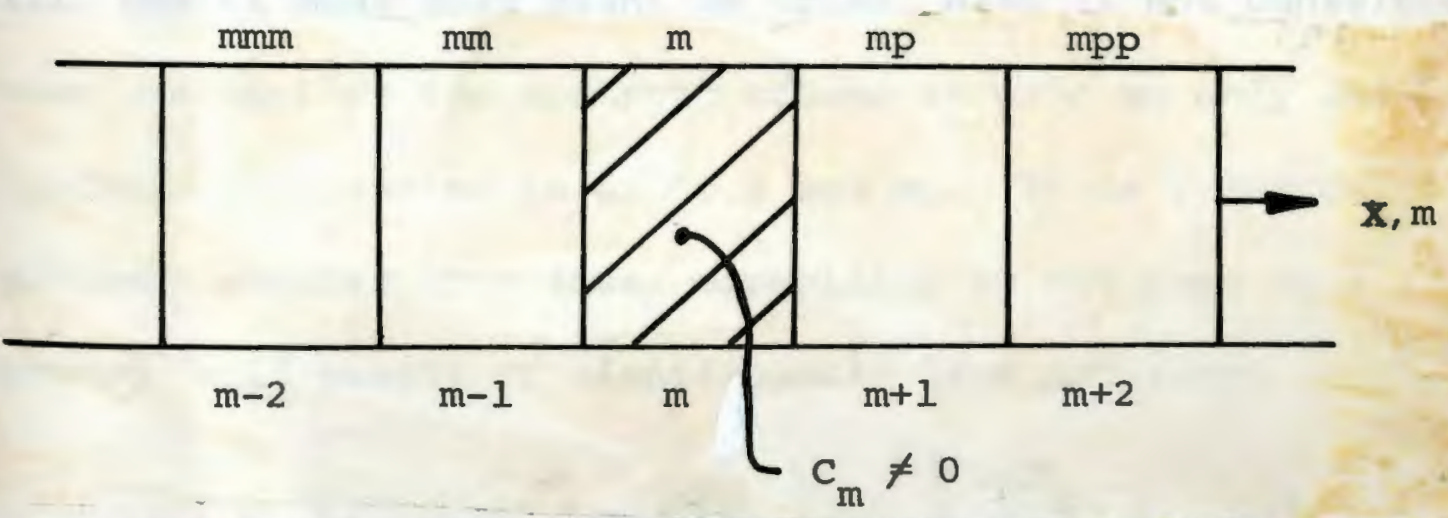

FIGURE E.5. ONE DIMENSIONAL FIVE GRID SCHEME 
for $c_{m} \neq 0.0$, and $E=u / L$

$$
c_{m p}=c_{m m}=0=c_{m p p}=c_{m m m}
$$

Case I upstream: aII $\mathrm{M}=1, \mathrm{~B}=0$

$$
\begin{array}{ll}
\mathrm{m}=\mathrm{m} & \mathrm{DC} \mathrm{m}_{\mathrm{m}}=-\mathrm{E}\left(\mathrm{C}_{\mathrm{m}}-\mathrm{C}_{\mathrm{mm}}\right)=\mathrm{EC} \mathrm{m}_{\mathrm{m}} \\
\mathrm{m}=\mathrm{mp} & \mathrm{DC} \mathrm{mp}_{\mathrm{mp}}=-\mathrm{E}\left(\mathrm{C}_{\mathrm{mp}}-\mathrm{C}_{\mathrm{m}}\right)=+\mathrm{E} \mathrm{C}_{\mathrm{m}} \\
\mathrm{m}=\mathrm{mm} & \mathrm{DC_{mm }}=-\mathrm{E}\left(\mathrm{C}_{\mathrm{mmm}}-\mathrm{C}_{\mathrm{mm}}\right)=0
\end{array}
$$

Case II no upstream $A=B=I / 2$

$$
\begin{array}{ll}
\mathrm{mm} & \mathrm{DC}_{\mathrm{mm}}=-(\mathrm{E} / 2)\left(\mathrm{C}_{\mathrm{m}}-\mathrm{C}_{\mathrm{mmm}}\right)=-\mathrm{EC}_{\mathrm{m}} / 2 \\
\mathrm{~m} & \mathrm{DC}_{\mathrm{m}}=-(\mathrm{E} / 2)\left(\mathrm{C}_{\mathrm{mp}}-\mathrm{C}_{\mathrm{mm}}\right)=0 \\
\mathrm{mp} & \mathrm{DC}_{\mathrm{mp}}=-(\mathrm{E} / 2)\left(\mathrm{C}_{\mathrm{mpp}}-\mathrm{C}_{\mathrm{m}}\right)=+\mathrm{EC}_{\mathrm{m}} / 2
\end{array}
$$

Case III upstream at mm only

$$
\begin{array}{ll}
\mathrm{mm} & \mathrm{DC}_{\mathrm{mm}}=-\mathrm{E}\left(\mathrm{C}_{\mathrm{mm}}-\mathrm{C}_{\mathrm{mmm}}\right)=0 \\
\mathrm{~m} & \mathrm{DC} \mathrm{C}_{\mathrm{m}}=-(\mathrm{E} / 2)\left(\mathrm{C}_{\mathrm{mp}}-\mathrm{C}_{\mathrm{mm}}\right)=0 \\
\mathrm{mp} & \mathrm{DC} \mathrm{mp}_{\mathrm{mp}}^{\cdot}=-(\mathrm{E} / 2)\left(\mathrm{C}_{\mathrm{mp}}-\mathrm{C}_{\mathrm{m}}\right)=+\mathrm{EC}_{\mathrm{m}} / 2
\end{array}
$$

For Cases I and II mass is conserved if schemes are consistent, that is either upstream of central differencing is used exclusively in computational procedure. In Case III, one of many that might be tried, mass is not conserved when one applies the upstream scheme at grid $\mathrm{mm}$ on $\mathrm{l}_{\mathrm{Y}}$ and central differencing in grids $m$ and mp. It is a matter of judgment whether this loss, especially in the area of a source, will result in significantly less accuracy. 
Appendix F

Sample Program For Thermal

Model Segments 


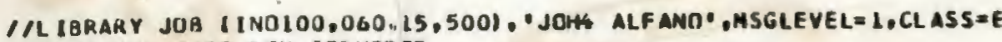

//SYSPRINT DO SYSUUTIA

ISYSLTI OD DSN $=0$ CESMDOS,OI SP $=0$ LD UNI $T=2314, V O L=S E R=O C E P A K$

I ISYSUT 2 DU DSN=OCESMOSS.D ISP=OLO,UNI $T=2314, V Q L=S E R=O C E P A K$

IISYSIN DO

IEF 2361 ALLOC. FOR LI BRATY CHNGSTEP

IEF 2371 631 ALLOCATEU OU SYSPRINT

IEF 2371241 ALLOCATED IO SYSUTI

IEF2371 241 ALLOCATFD TO SYSUT2

IEF 2371601 ALLOCATED TO SYSIN

IEF 2851 SYS73156. IJ03132.RF 000.LI BRARY,R0000055 DELETED

IFF?.95I VUL SER NUS= - . KEPT

IEF $23 E 1$ OCESMIJDS

KEPT

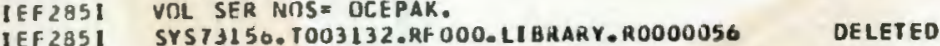

IEF 2851 VOL SER NOS=

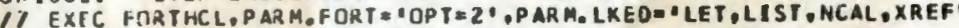

XXOEFAUL T PROC L 1 B L $=5 S P$ LIBZ=OPLOT

XXFחRT EXFC PGIY=IEKAAOD,REGION=228K

XXSYSPRINT DO SYSUUTFA

XXSYSPLUCH ON SYSOUT $=\Delta$

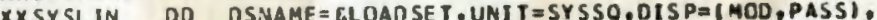

IFFO53! SUISTITLTIUN ICL - OSMAME = GLCADSET, UNIT $=S Y S S H, 0$ ISPEIMOO. PASSI

$X X \quad S P A C E=(1680,150,10)), D C B=(2 E C F M=F B, B L K S 12 E=1600, L R E C L=80$ )

I /FURT .SYSIN DO OSN=OCE SYUOS (AMAIN), OISP =SHR

IEF 2361 ALLOC. FOR LIBRARY FORT

IE+237! 631 ALL DCATEU TO SYSPRIN

IEF 2371660 ALLIJCAIED TO SYSPUNCH

IEF 2371240 ALLOCATEO TO SYSLIN

IFF 2371241 ALLUCATED TO SYSIN

IEF 2851 SYS73156.TOJ3132.RFJOO.LIBRARY.ROONOOST DELETEU

IEF 2351 YOL SER NOS=

IEF 2351 SYST3156.TOU3132.RFOUO.LIGRARY.LOAOSET PASSED

IFF 2851 VOL SER NIST COB101.

IEF 2851 UCESWIIOS

KEPT

VOL SER HISS OCEPAK.

URIJUII STEP EXECUTION TIME 18 MIAS.

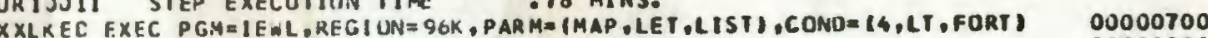

XXSYSLIB DO DSNAME $=5 Y S 1$.FDRTLIB,DISP SHA

$X X$ DJ DSNAME $=U K 1 . E L I B 1 . L 1 B, 015 P=S H R$

IFF653I SUASTITLIION JCL DSNAME =URI. SSPLIB.DISPESHR

IFF653I SUSSTITLTIDN JCL - USNAME $=$ URI. SSPLIB
$X X$

EF6531 SUTSTI TUTIUY JCL - USNA PE = URI. OPLCTLI B.OISPESMR

00000100

00000200

00000300

00000400

$\bullet 00000500$

00000600

XXSYSPRIHT DO SYSOUT $=A$

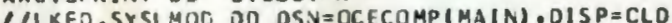

$X / S Y S L M O D$ DO DSUAME $=$ EGUSE TIMAIN), UNIT $=S Y S D A, U I S P=1, P A S S I$.

IEF 6531 SUPSTITLTION JCL - DSNAME = GGOSE T (HAINI, UNIT SYSOA,DISPE (,PASS)

SPACE $=(3072,(30,10,1))$

XXSYSL IN DO DSYAME = ELTADSET,DISP $=$ (OLD, DELETE)

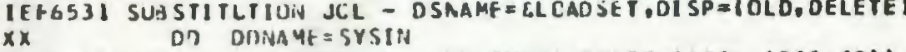

00000800

00060900

00001000

00001100

$\div 00001200$

00001300

00001400

00001500

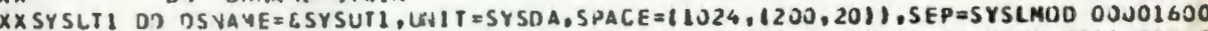

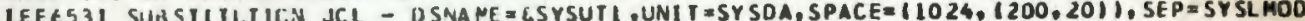

If 2361 ALLUC. FUR LI:HARY LKFU

IEF 2371 l3J ALLICATFD TO SYSL 18

IFF 2371244 ALLOCAPED IO 


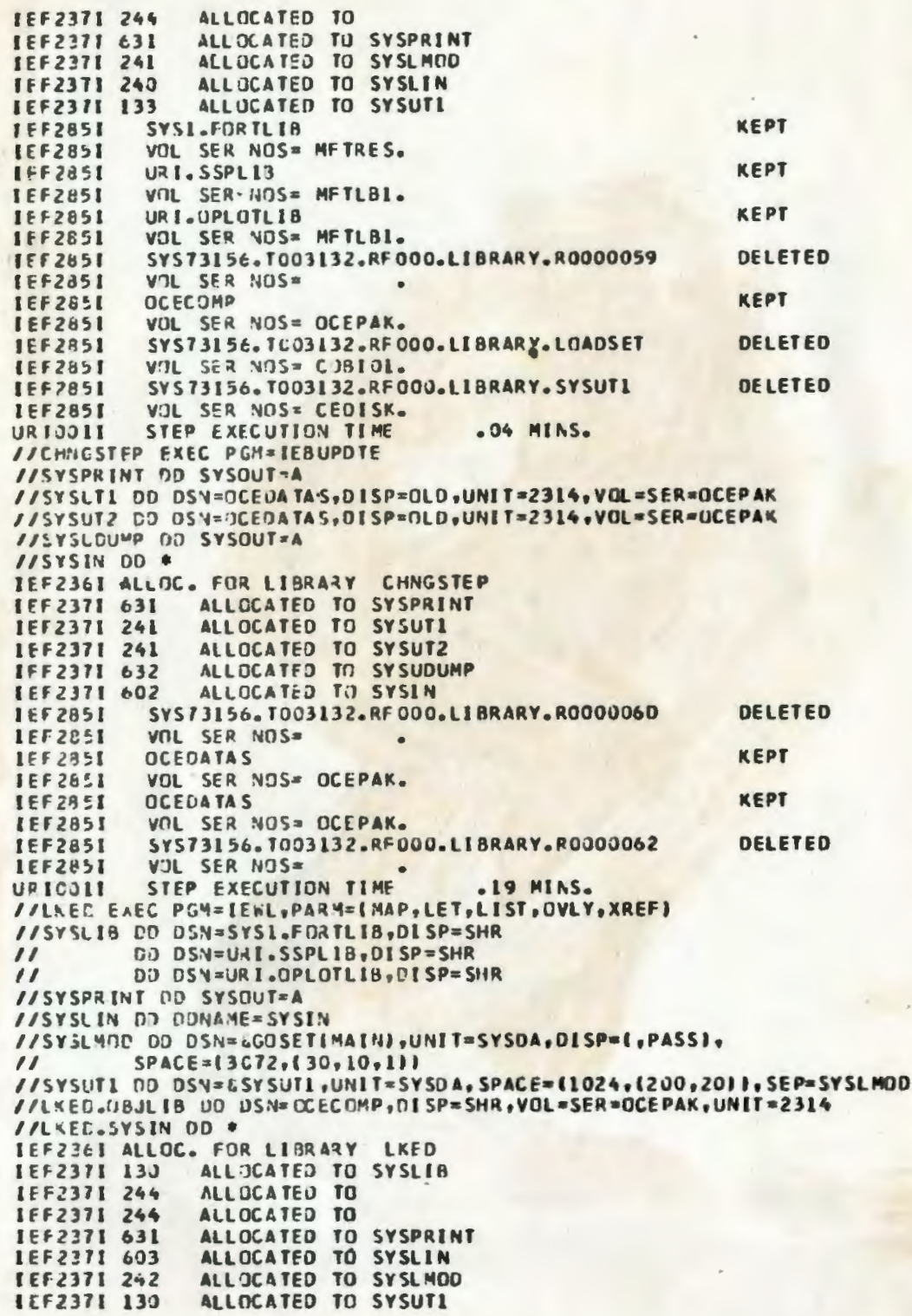


IEFZ371 24) AILIICATFD II OAJLIA

IEF 285I SYSL.FURTLIO

IEF 2 BSI VIL SFR HOS MFTRES.

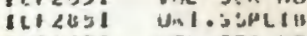

IEF.285I VISL SER NTS MFILAL.

IEF235I URI.GDLOTLIB

IEF285I VCL SER NIS= MFTLBI.

IFF"2251. SYSTS156.TOO3132.RF ODO.LI BRARY.ROOONOO3

IEF 2351 VOL SER HIS =

IEF 2BSF. SYST315E.ICO3132.RF 0OO.LI GRARY. POOOOO64

IEF $295 \mathrm{I}$ VOL SER NUS

IFF285I SY573156.T003132.RF OOO.LIBRARY.GOSET

IEF 2851 Y.L SEP. NOS = CHAPAX.

IEF28SI SYSI3156. T003132.RFUOO.IIBAARY.SYSUTI

IEF 2 BSI VOL SER NUS $=$ MFTRES.

IEF 2 HSI OCECUAH

IF 2851 VIL SER HOS OCEPAK.

UR 10O11 STEP EXECUTION TIME

IIG) EXEC PGM= . LKED.SYSLMUD

IIFTCGFDOI DO SYSDUT:A

IIFTCTFCOL DO SYSOUTAB

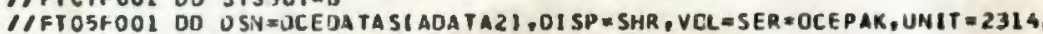
( LASEL $\neq(, \cdots, I N)$

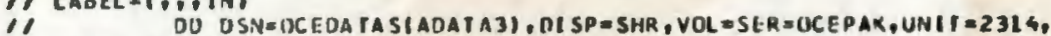

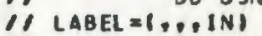

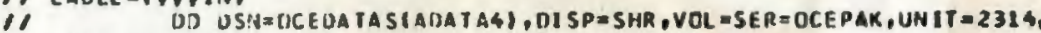
$1 / \mathrm{LABEL}=(\ldots . \mathrm{IM})$

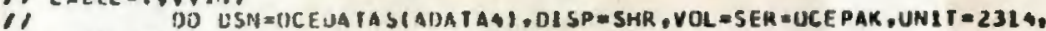

(1) $L A B E L=(, \cdots, N)$

( /GT.FII IFOOI DO DSN E GALF, DI SP = (NEW,DELETE), UNIT=SYSOA,

(1) SPACE $=(\operatorname{TRK}, 110,10)\}$

18

IFF 23CI ALLDC. FOR LIGRARY GO

IEF 237 I 242 ALLOCATEO II PGM=*.DD

IEF $2371 \mathrm{C3}$ I ALI JCATED IO FTOSFOOL

IEF $237 I$ COL ALLOCATFD IO FTOTFOOI

IEF $237 ! 241$ ALL JCAIEO TO FI05F OCI

IEF $237: 24 L$ ALLDCATFO TD

IEF 2371241 ALLOCATED TO

IEF2371 241 ALLOCATED TO

IEFZ37! 130 ALLOCATED TO FIIBFOO

IEF 2851 SYST3156.T003132.KF 000.LIBRARY.GOSET

IEF 2 ESI VOL SFR NOS= CHMPAK

IEF265I SYST315E.1003132.RF OOD. LIBRARY.ROO0OO65

XEPI

Mt PI

KEPT

DELETEO

DELETED

PASSED

DELETED

KEPY

IEF. 2851

V.L SER NUS $=$
SYST315C.TOJ3132.RF OOO.LIBPARY.ROOOOOO66

IEF 285 I

JEF 2851

IEF:85I

YOL SER NOS:

OCECATAS

.

VOL SER NOS= OLEPAK.

IEF2BSI OCEDATAS

IFF 2 Z5I YOL SER NOS* OCEPAK.

IEF 2851 OCEDATAS

IEFZE:I VDL SER NOS= OCEPAK.

IEF28SI DCEDATAS

IEFZESI VOL SER NOS = UCEPAK.

IEF 2651 SYST3L.TO03132.RFOOO.LIBRARY.ALF

IFF 285

IFF 2851

4910081

1+1 ess

SYS7 3L. T003132.RFO00.LIBRARY.ALF

YTL SER NOS * MF TriE 3 .

STFO EXECUTICN II NF, 49.26 MINS.

is: 7851

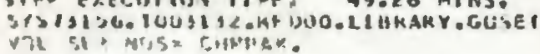

passeo

DELETEO

DELETEO

KEPI

KEPT

KEPT

KEPT

oeleted

OFLETEO 
-I CHANGE NAME $=$ AMAIN,LIST=ALL

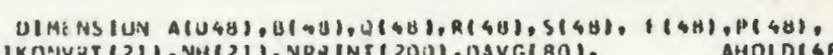

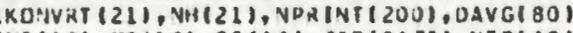
AHOLD(48)

c 2NS(1J), MS(I)), S5(IJ), LIF(0175), NTP(10), 21H(0175), 21610175$)$

vouviunu 00001100 00001300 CDMMON SE $(2,1,48)$, SEP(21,48), V(21,48), VP $(21,48), U(22,48), U P(21,48), 00002400$ C C(21,48),NBD(B5), MBO(85),MUBD(4),N.7BD(4),H(21,48), 00001500

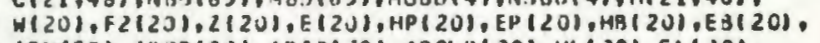
ARA (20), ARGP (20), ARGa(20), ARGL B(20), HL(20),EL(20),

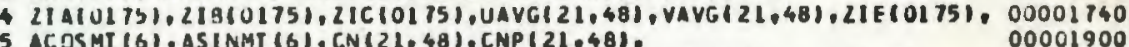

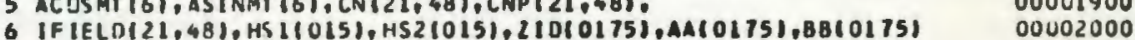
LOGICAL READIN, UOSAL, RDCNP, DELTAT

DATA YR,DAY, THR,TMIN /57..195.17.048./

DATA MSOJRC, NSOURC M, $1 \%$

DATA AL, AL, SALRIS, TMHOPE, TR IVER, T SOUNO/1012.7.10.73.32.5,22.75, $122.2,18.50 \%$

DATA HINU.SEINV, PI, CMANN,WX,WY, CORAG, CRHO 10.,0..3.1415927. $1.015,0,0 ., 0025, .001141$

SET EXECUTION PARAMETERS

IMUDES - I UPSTREAM DILFERENC ING

IMOUES = I CENTRAL OIFFERENCING

IMDOES $=2$

IPUNCH $=340$

$A T=120$
EXTRAB
APRT

C IPRINO WILL SPECIFY TIME TMAT VARIAQLES ARE DISPLAYEO IPRIND= 15

ILO $=1$

C SUMMING MUDES REQUIRED FoR disPlaYS

SUMZ IG $=0.0$

$\operatorname{SUM} 210=3.0$

$\operatorname{SUM} 2 I F=0.0$

$\operatorname{SUM} 21 H=0.0$

SUMAA $=5.0$

SUA $51=540$

NMS = MAX $5 T+1$

I $D Y=1$

HSIIIOY) 2000

ROC NP= FALSE.

C ROCNP FOR REAOING IN PREVIDUS VALUES OF CNP

REAUIN=.TRUE.

UOSAL $=$, TRUE.

IRMS $=1000$
00002100

05002200 0.0002500 00002400 00002500

00002600

00002700 00002800 00002700 00003000 00003100 000 00003400 00350 0003600 00003650 00003700 00003800 00003900 00004000 00004100 00004200 00004300 00004400 00004500 00004600 00004700 0004900 00400 00005100 00005200 00005300 00005400 00005500 00005600 00005700 00005800 00005900 
IMOOE I = I DELTAT = TRUE.

$T R N A=21.3$

IFIDELTAT) GO 102873

Go 102815

2873 I $8 \mathrm{NB}=0.00001=$

IMNOPE $=.05001$

TSOUND $=.00001$

2875 CONIINUE

C DIF 2875 CONTION CONSTANT IS UPCON

CIS AHOUT 350 YOSUSEC

UPCON=05O.

\section{PONEH PLANT}

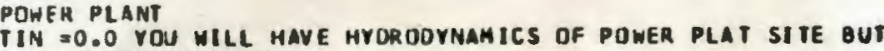
NO THERMAL LOAO ON BAY

IF EFFECTS OF PONER PLANT ARE OESIRED SET TIN EQUAL TO 12.

$T I N=12$.

C SITE SELECTION. SEE HEATIN FOR DETAILS ON LOCATIONS
SITE $=100$.

LNL $=0$
AHHO $=27 . * 1.940 * 11.00+0.000841 * 5 A L R 15-0.000100 *$ TSOUNDI

00006500 00006600 00006700 00006900 0006900 00700 00007200 00037300 00007400 00007500 00007500 00007700 00007800 00007800 00038000 00000100 00008200 00008300 00008400 00008500 00008600 0000870 00068900 00000 009100 00009200 00009300 00009400 00009530 00009600

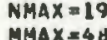
ANGLAT $=41.6$ $\mathrm{NI}=1$

$M 0 B O(1)=0103042$

MUBก $121=480 \mathrm{d091}$

$403013)=4811131$

NUAD $(1)=1923242$

NUAD $\{2\}=0410112$

MI NON $=4$

NINDO $=3$

00009100

00009800

00009900

00010000

00010100

00010200

00010300

00010400

00010500

00010600

NSEC T $=80$

00010000

87 CONTINUE

00010000

00010900

00011100

ARG = ANGLAT *3.141592 7/100. 
2000 HST $=0$

$I P=1$
$C I=A I+A G / A L$

C2 $=A T / A L$

C3=AT/4.

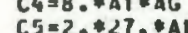

C 27 IS THR CUFT TO CUYOS CONVERSION ANO 2 IS FOR. DISPLAYIMG ACTUAL CROSSECTICNAL FLOW IN FOR RIVER

(at)

$C T=40.00 *$ SURT (AG)

$C B=1.1 A L$

$C 9=1.1 \mid A L * 21$

clo $=0$.

$\mathrm{CII}=\mathrm{CT}$

$C 12=0$.

C14 $=1.114 .0 A L$

C14El. $14,0 A L I$
$008 M=1$, MMAX

DO $N=1$ MMAX

$S E(A, \mu)=0.0$

$S E P(N, M)=0.0$

$C N(A, M)=0.0$

CNP $(N, M)=J .0$

$\operatorname{UAVG}(N, Y)=0.0$

AVG $(N, M)=0.0$

$V P(N, M)=0.0$

$U P(N, M)=0.0$

$V(N, M)=0$.

$U(N, M)=0$.

$C(N, M)=0$.

$H(N, M)=0$.

6 $F(N)=F F$

RANOU.O

CALL KURIHIMAXS T, AT, NTERM, FEHECX, YR, DAY, THR, TMIN, TSI

CALL RURE HTMAXS, AT,

CALL OIVE INMAX, MMAXI

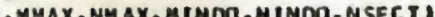

CALL DEPT HINMAX, MMAX)

CALL CHE ZYINMAX, MMAX, CMANNI

CALL CHECXINMAX, MMAX)

L: $13 \circ 1$

$M=18 *(i-1)$

REAO(S,25) INPRINT (N), N=M,L

25 FDRMATIIBT 4 !

26 CONTINUE

DO $62 \quad M=1$, MMAX

DAVG $(M)=0$

DEP $=0.0$

OD 1 i
SuUt1 200

00011400

00012500

00011600

000itroo

00011800

00011900

00012000

00012100

00012200

00012300

00012400

00012500

0012600

00012700

000

00013000

00013100

00013200

00013300

00013400

00013500

00013600

00013700

00013800

00013900

00014000

00014100

00014200

00014300

0014400

0014500

00014700

00014750

00015000

00015100

00015200

00015300

00015400

00015500

00015600

00015700

00015800

00015900

00016000

00016100

00016200

0016300 
61 CONTINUE

DAVGIYia 300
ConTINUE

CoNT

NUM
$\mathrm{DEP}=0.0$

$D E P S O=0.0$

GRIONI $=0.3$

1 IF (NUM.EQ.NINOI GO TO

NSRCH $=$ NBOINJMI/ 10000.30

$N=$ NBJINJMI/10000 $-N S R C H * 100$

MF $=$ NRD (NUM)/ $100-N S H C H * 10000-N * 100$

I NDO(NUM)-NSRCH 1000000-N*10000-MF*100

$M N=N-1$

$K=M F$

NGR $1 D=L-K+1$

GRIONZ = NGRIO

C USEU ONAY IF NO SE VALUES ARE REAO IN

\section{$002 M=K, L$}

$D E P=D E P+H(N, M)$

DEPSQ DOEPSQ HS JRT (HS $N, M)$

DI $M I=M$

$0 \mid M I=01 M I-1$.

$C N(A, M)=T$ AVH

CNP $(N, M)=T B$ Q $Q$

SEP $(N, M)=S E$ INA $(1,-01 M 1 / 46.1+N 1 M V$

$2 S E\left(N_{0} M\right)=S E 1 M V *(1,-01 月 1 / 46.1+H I N V$ RUM: NiJM+L

GO) TO 7
CIIVII INUE

CIIVIINUE

$C_{N}(3,1)=T$ TRB

CNP $\{3,1)=$ TBAB

CN $(4,11$. TBNE

CN $(10.23)=1$ BNB

CN 19.23$)=18 N B$

CN $(19,26)=$ T BNB

CNP $(19,24)=$ T BNB

$C N(U B, 48)=18 N B$

CNP $(08,48)=T$ TNB

CN $(09,49)=$ IBNH

CNP $(09.48)=1$ SNB

CN $(11,4 \theta)=T$ BNB

CNP $(12,49)=1 B N B$

CN $(12,48)=$ TANB

CNP $(12,48)=T B N B$

CN $(13,48)=78 N B$
CNP $(13,48)=T 8 N B$

unulossu

00016600

00016700
00016800

00016800

00017000

00017100

00017200

00017300

00017400

00017500

00017600

00017700

00017300

00017900

00018000

00018100

00018200

0018300

00100

00018600

0018700

00018800

00018900

00019000

00019100

00019200

00019300

00019400

00019500

00019600

00019700

00019800

00019900

002000

0002

00020300

0020400

00020400

00020500

00020700

00020800

00020900

00021000

00021100

00021200

00021300

00021400

00021500

00021600 


$$
N A=1
$$

5 IFIAA.EO.MINOOI GO TO 3

$M=M C 8 D$ INAI/ 100000

NBUT FMOSOINAI/ 1000

NTOP $=$ MOBOU(NA)/10 $\rightarrow$ M* 10000

DO $32 \mathrm{~N}=\mathrm{NHOT}$, NT OP

DIMI=M

DEP =

$32 S E(N, H)=S E I N Y *(1,-D \mid M 1 / 46,1+H I N V$

$$
N A=N A+1
$$

3) $N A=1$

33 IFINA. EQ.NINDOI GO TO 34
N=NOBUINA)II 100000

MLEF $=$ NOBDIMAI/1000 $-N * 100$

MR $16=$ NDSD $(N A) / 10$

$-N * 100$

DO 35 M= MLEF, MRIG

DIYI $=M$

DIMI $=$ IMI-1.

SE $\left(N_{0}, M\right)=$ SEINVE(1.-DIML/46.1+HINV 00024100

NA=NATI

00024200

0,0024300

CONTIMUE

00021700

00021920

00022000

00022100

$01) 022200$

00022300

00022400

00022500

00022600

00022700

00022800

00022900

0023000

00023100

00023300

00023400

00023500

00023600

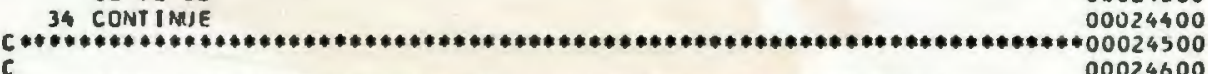

C CALL INUALIMHAX, NHAX, GRIONI DEP, DEPSO,READIN, ROCNP,DAVGI $\quad 00024600$

C CALL MEATININS, MS, 55, TIN, YZ,SITE,NINPUT:OIMI 00024800

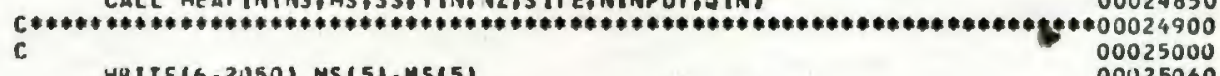

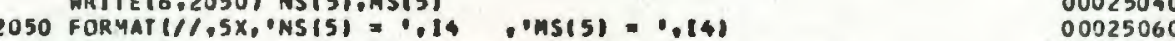

40 ISTEP $=2$.

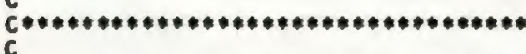

CALL PRINTIISTEP, NST, NPRINT, , NMAX, MMAX, IP, AT, HTOT, HA,BH. [HE, HC, SAVE, IPUNCH]

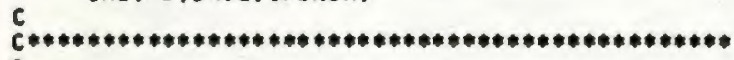

BB ISTEPAI

NST $=$ NST $T+1$

2001 IFINST.GT.MAXSTI GO TO 501

00025200

00025300

00025400

00025500

00025600

00025700

00025800

00025900

002

0026100

002630

002600

00026500 


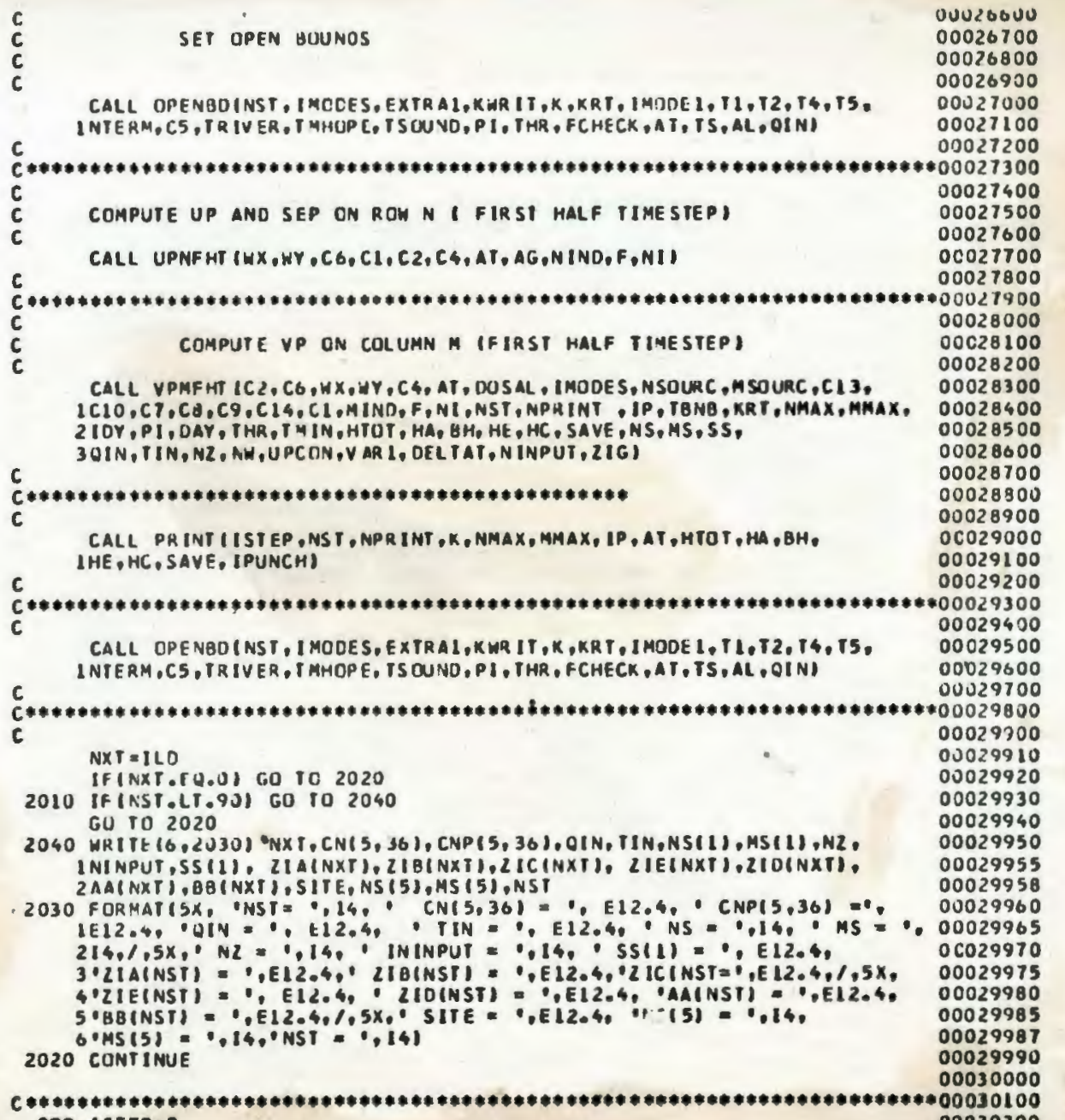

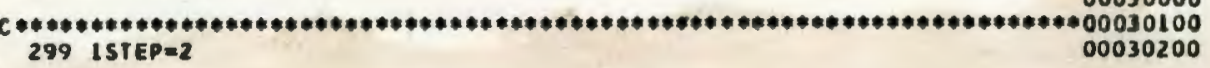



CALL UPNSH

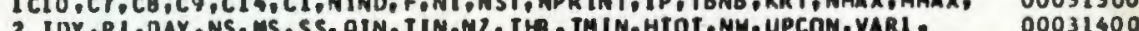
2 Toriplon,

SUM1=0.

00031500

00031700

00031800

00031900

000319000

SUM $=0.0$

\section{BAY MREA}

NUM $=1$

17 IFINUM.EO.NINDI GO TO 36

NSRCH $=$ NHDI NUMIS 10000 -NSRCHE1 00

MF $S$ NBO (NUM)/100-NSRCH*100UO-N*100

$L=$ IBD (NUM) -NSRC+* $1000000-N * 10000-M F * 100$

$N N=N-1$

NGRIO = L-MF*

GR1ON2 = NGRIO

GRICTI E GRIDT L + GR IDM

00032100

00032200

00032300

00032400

00032500

00032600

00032100

00032800

00032900

00033000

0033100

00033300

00033400

SUMIUT $=C N P(N, M) *\left(.25 *\left(H(N, M)+H(M N, M)+H(N, M H)+H\left(N M_{0} M M\right)+S E P(N, M)(1) 00033600\right.\right.$ Th SUM $=$ SUM+SUMTHT

SU:IL $=$ SUML +C.NP $(N, M)$

00033800

22 CONTINISE

NUM=NUMEL

36 SUMZIG = SUMLIGRIDTI SUMZIG

CONSTAN SHIUULO EOUAL (AL*\&2)*9*DENS*9/5

CONSTA $=1.00$

SUMZID=CONSTA*SUM+SUMZID

IFIRODINST, IPRINUT.EO.0) CO TO 45

GO TO 41

00033900

IF(OELTATI GO 1047

IIDIILD) =SUALIOIIPRINL

00034000

00034100

00034200

00034300

00034400

00034500

00034600

00034700

00034800

00035000

00035100

0035200

ZIGIILDI)SUMZ IG/ IPR INL

00035200

00035300 


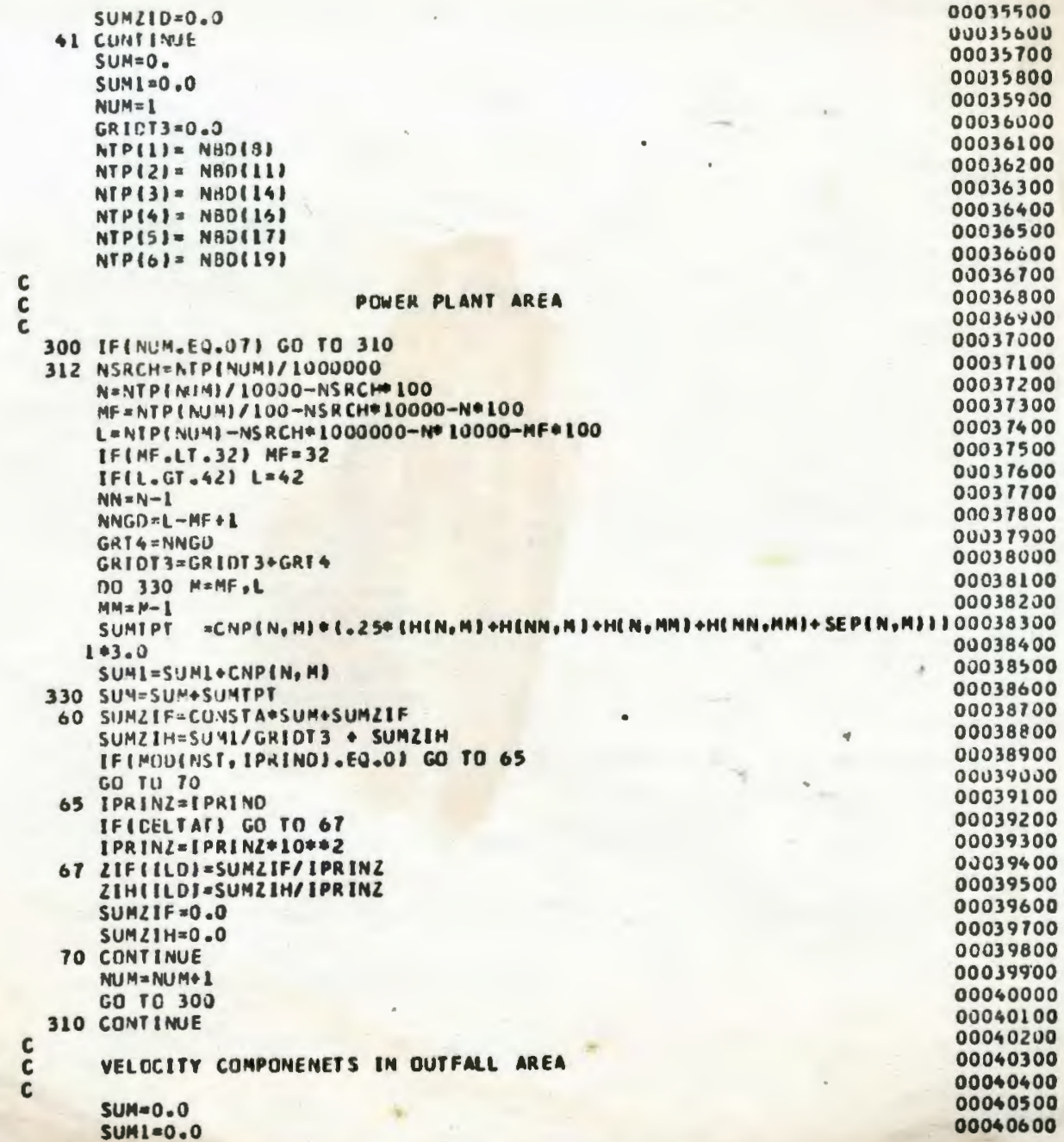




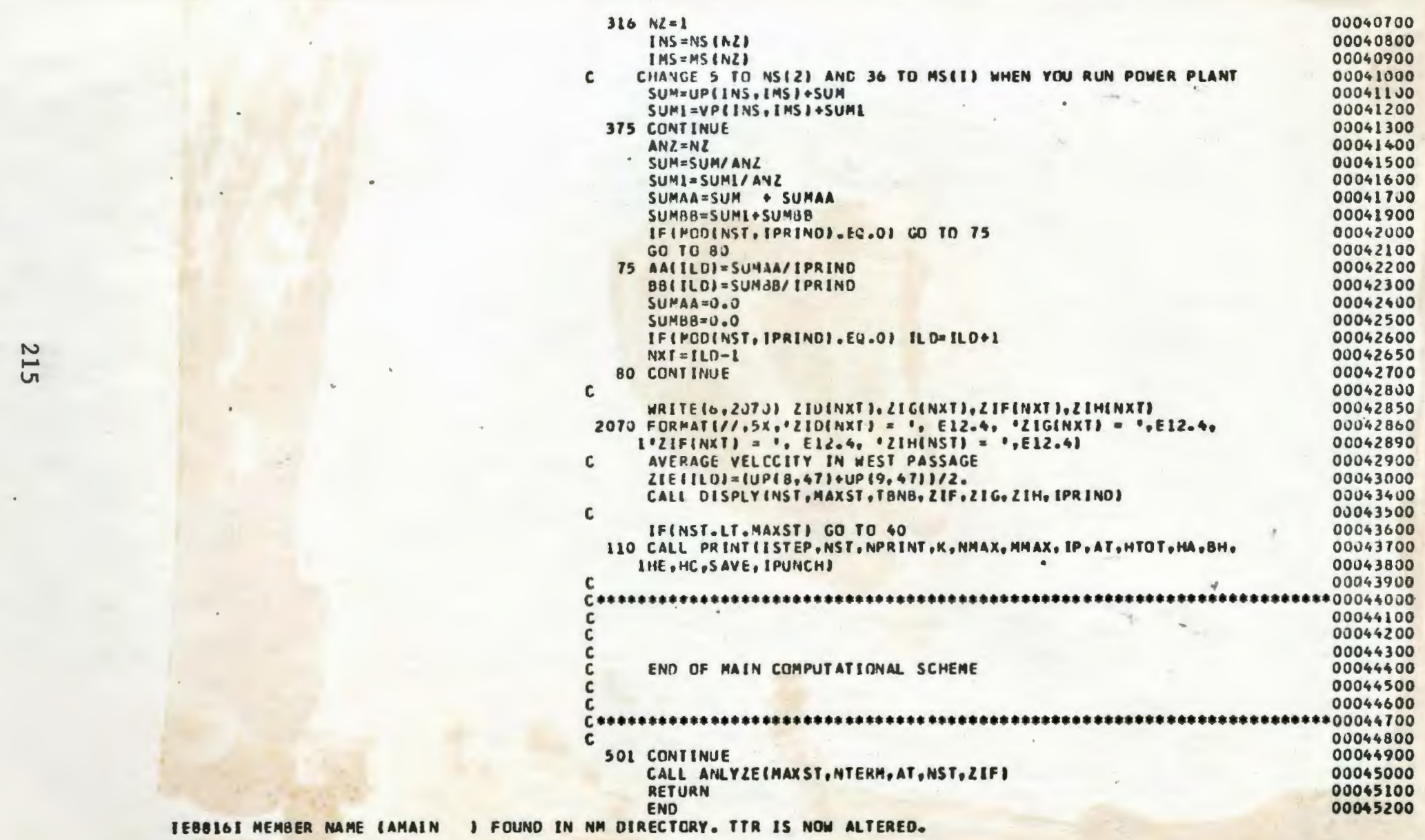


If CHANGE NAME =AVPMFH, LI SIEALL
SURROUTINE VPMFHTIC2, C6,WX,WY, C4,AI, DUSAL, I YODE S, NSOLAC,

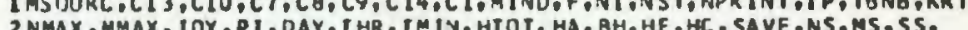
$30 I N, T I Y, N 2, N A, U P C O N, V A R I, 0 E L T A T, N I N P U T, Z I G)$

0001200

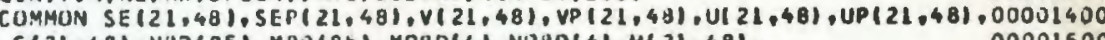
C 00001500 2 WRNI201

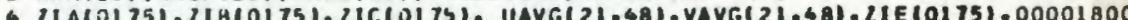
5 ACOSMT (6), ASINMT (6), CN(2) 48$)$, CNP (21, 48),

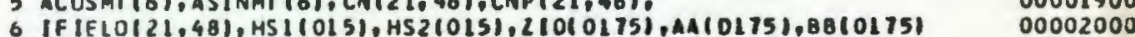
DI MENS I ON A(790),B(48),P(48), O(48),R(4B),5(48), F(4B), 00002100 IKUNYRT I211, NH(2 I), NPR INT (200), DAYGIBO), $\quad 00002200$ $2 M S(10), N S(10), 55(10), 216(1)$

EXTRAL $=1.0$

NijM $=1$

IDGICAL DUSAL, DELTAT

201 IFINUM,EQ.MINOI GO TO 202

c CONIINUE $* * * * *$

ASKCH $=M 80$ (NUM) / 1000000

-MSRCHQ10000 - HE 100

MSRCLA 100000 -

00002300 00002400 00002500 00002600 00002700 00002800 00002900 00003000 00003100 00003200 0003300 0003400 000350 00003700 00003800 00003800 00004000 00004100 00004200 00004300 II $=L-1$

$N F F=N F-1$

$\begin{array}{ll}M M M \\ M M & =M+1\end{array}$

$1 A=\mathrm{MSRCH} / 10$

2903 CONTINUE

$00220 \mathrm{~N}=\mathrm{NF}, \mathrm{L}$

$\mathrm{NN}=\mathrm{N}-\mathrm{l}$

$A L F A C=.5$

BETAC $=5$

GA.4MAC $=$.

DELTAC -5

G0 10206

GO 10210

211 CONTINUE

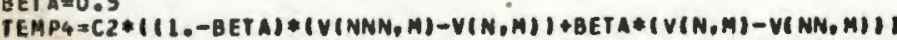

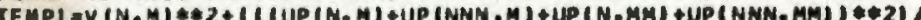

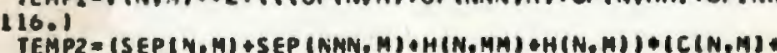
CINNA, MII I:E 2
00004400

00004500

00004600

00004700

00004300

00004900

.00005000

00005100

00005200

0005300

0005500

0005600

00005600

0 Cu05700

C0005900

00006000 


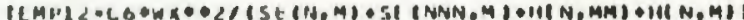
TEMP $3=1 .+C 4 * 5$ G TEMP $3=1 . / T$ TEP 3

DEL TA $T=0.5$

TEMPLOS $V(N$, AMM $)$

IFITEMPIU.EJ.U.I TEMPIOE VIN, RMI

TEMPII $=V(N, M, Y)$

IF (TEMPIL.EO.J.) TEMPIL: V(N.MMMI

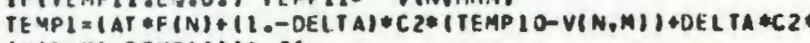
IIV(N,M)-TEMPIUI).25

204 YP(N,M)=Tr.4P 30

-

2- CL*ISE(NYN,M)-SEIN, MII)

COMPUTE CNP ON RUN $M$ ISECONO HALF TIMESTEP

$$
\text { If (GOSAL) GO IO } 213
$$

13 CONTINUT

IFIIMNDES.EQ.1I GO TO TO96

GO TO 70.98

1096 ALFAC $=0.0$

BE TAC $=1.0$

$G A 4 M A C=0.3$

IF (UI $N, M), G T, 0.0)$ BETAC=0.0

IF $(V(N, M), G T, 0,0)$ GAMAAC= 1 .

Ga 10703 ,

NeXI THE I WILL CHAMge A1,A2,81,02 TO = 1.

7098 AL $=1$.

A2 $=1$.

$B 1=B 2=1.02$

ALF $A C=.5$

BETAC $=.5$

OELTAC $=5$

$\cos (1)$

$B 2=0$

1099 CONTINUE

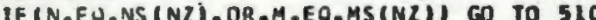
GO 10520

5 LO CINTINUE

FIM.EO.MSINLI) GO TI 512

Gu ro 5 is

512 CONTINUE

IFINAN.EQ.NS INL) . ANO.VINUMI.GT.O

IF (NN.EQ. NS INZ). AND +V (N, M) .LT .0.0) DELTAC $=1.0$

IFIN.EQ.NSINZI) GO TO 514

GO TO 520

514 IF $(U I N, M), G T \cdot 0.0)$ BETAC=0,0

IF $\{U(N, M) \cdot C T, 0.0)$ ALF $A C=0.0$

noomian

00006300

00006400

00006500

00006640

00006700

00006900

00006900

00007000

00007100

0007300

0007400

0001400

00001630

00001700

00007800

00007900

00008000

00008100

00008200

00008300

00008400

00008500

00008600

00008700

00008900

OOCC8900

00609000

00009100

0009200

009

0000500

unv04000

00003700

$00 \mathrm{c} 09800$

00009850

00009900

00010000

00010100

00010200

00010300

00010400

$0 \mathrm{col} 0500$

00010600

00010700

00010800

00010900

001100 


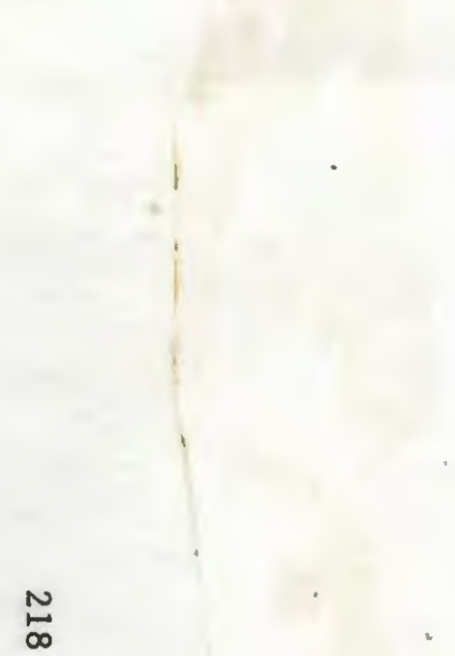

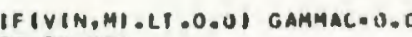

Go 10520

MS (NZ) $A N D, U(N, M), L T, 0.0)$ BETAC $=1.0$

IFIMMM,EQ.MS (NZ). AND.U(N, H) .GT,0.0) ALFAC $=1.0$

520 CONTINUE

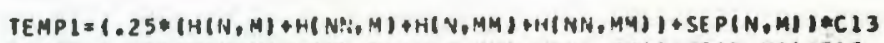

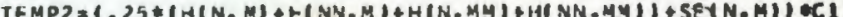

TENP3 =.5 \& $(H(N), M)+H(N D, M M)+S E(N, N)+S E(N N, M))$

TEMPG, $5 E(H)(N, M)+H(A, M M)$ +SE (N, M) \& SE (NNN, M) )

$T E M P 5=.5 *\left(H(N, M M)+H\left(N N_{,}, M M\right)+S E(N, M)+S E(N, M M)\right)$

TE $4 P G=.5 *\left(H(N, M)+H\left(N V_{,} H\right)+S E(N, M)+S E(N,(A M Y))\right.$

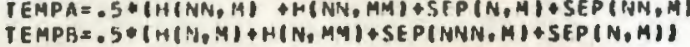

c

DYNM=C7 *ABS (VF $(N, M))$ TEMPA/ I. S*IC (N, M) +C(NNN, M) I) +C 10

OY NNM=C $C * A B S(V P(N A, M))$ T EMPA/,$S *(C(N, M)+C(N N, M)))+C 10$

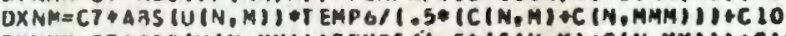

DXNMMECT OABS

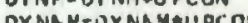

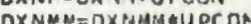

TEMP $20=T E M P 3 * A 2 * Y P(A M, M) * C B$

TEMP $21=T$ T MPA AO DY YYMM CO

TEMPZ2 =TEMP \& $A 2 * Y P(M, M) * C B$

TE $4 P 2.3=T E M P Q$ \& $O Y A M * C Q$

TEMP24= IEMP5*ALU IN, $M M 10$

TEMP25 = TEYPS OXNMM० C9

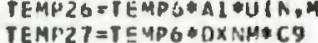

TEMP3O= SEP(NAN, M)

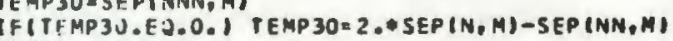

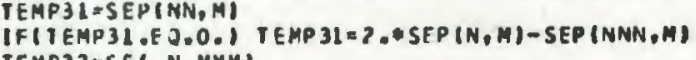

TEMP32=SER N, MAMAI

TEMP 32=2.*SF(N,M)-SEIN,MM)

$P(M)=-1(11$. DELT AC $)$ *TEMP 20 $T$ TEMP 211

Q(N) =TEMP 1+CAMMAC T TEMP22+TEMP 23-DEL TAC* TEMP 20+TEMP 21

I $-B 2 * C 14 *\left(Y P(N A, M) * V P\left(A_{0} H\right)\right) *(T E M P 30-T E M P 31)$

R (N): (1. -GAMMAC) *TEMPZZ-TEMP23

$S(N)=-C N(N, M M) *(11,-E E T A C) * T H A P 26+T E M P 25)$

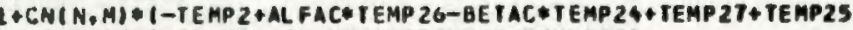

2-BI*C14*IU(N.M)+U(N, MM)) ITEMP32-TEMP33)

$3+C N(N$, RMM $) * 1(1,-A L F A C) *$ TEMP 26-IEMP 27 )

1806 CONTINUE

00011500

00011500
00011700

00011800

00011900

00012000

00012100

00012200

00012300

00012400

00012500

00012600

00012700

$00 C 12800$

00012900

00013000

0013100

00013300

0013400

00013500

00013600

00013700

00013300

00013900

00014000

00014100

00014200

00014300

00014400

00014500

00014600

00014700

00014000

00015000

00015000

00015200

00015200

00015400

00015500

00015600

00015600

00015800

00015900

00016000

00016100

00016200

00019900 
INS = NS ININPUT I
IMS
INS ININPUTI

IMS 2 MSININPIIT)

GD 1053.0

$5(N)=5(N)-5 S(N L) * I T I N$ - CNPIINS, IMS IN)

NPLUS = MPAINT (IP) -29

IFIAST.EQ.NPLUSI CO TC 1903

[FINST.ED. I] GO TO 1903

Go io 190

1903 ISUM $=0.0$

$S D X A M=0.0$

SOY $A M=0.0$

SOX

SOYANM $=0.0$

1904 SOXAM= SOXNM+DXNM

SOYNA= SOYNM.DYNA

SOY MMY $=5$ DY HNA + DY NNA

ISUM $=$ I SUY+ 1

2901 IFINSI.CO-NPRINI IIPII GO TO 1909

IFINST.EQ.MAXSTI GO TO 1909

Go 10 1908

1909 SDYNM $=$ SOY NM/ ISUM

SDXAMM = SDXNMM/ ISUM

SOYANM = SDYNNM/ISU

SUXAM = SOX HM/ISUM

ANS $=N S$ (N2)

MHS * MS (NL)

WRITE $(6,7121)$ HMS, MMS, SOXNM, SOYNH, SOXNMM, SOYNMH

15, $3 x_{0} \cdot$ OXNA1, $12,1, \cdot, 12, \cdot 1=", 00022800$

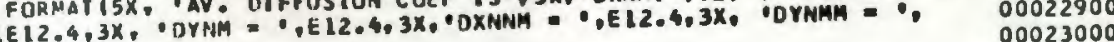
$2 E 12.4 i$

1908 COHTINUE

30 CDNTINUE

II IN.FG.INS. AND, H.EQ. IMSI GO TO

$526 S(N)=5(M)+S S(N 2) *$ CNPIINS, (MS)

$N L=N Z+1$

527 CONIINU

C heat exchange caluclations

EXTRAL = EXTRAL L 1 TO 1730

GO TO 1732

1730 IFIEXIRAI.EO.2.) Co ro 3035

GO TO 1508

3035 CONTINUE

MORE TEMP CALCUALTICNS YEAaAaA

FINST.EO.NPAIMT IIPI) GO TO 1500

(XFA TPRINT (IP) - is

00020000

00020200

00020300

00020400

00020450

00020460

00020500

00020100

00020800

00020900

00021000

00021100

00021200

00021300

0021500

0021900

00021950

00022000

00022100

00022300

00022400

00022500

00022600

00023100

00023200

00023300

00023400

0002350

00023700

003700

00023900

00024000

00024100

00024200

00024300

00024400

00024500

00024600

00024700

00024800

00024900

00025000 


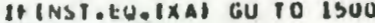

Go 10 isus

1500 If INST. EQ.1I CO TO $15 \mathrm{CZ}$

60101506

1502 TWBAY $=$ TBN

TEQ $=1 B N B$

1506 CONTINUE

作

ICLOCVR, ANG, EXTRAI, TIME, QC, HA, EA, PMA, NST, EXTRAC, THR, TMINI

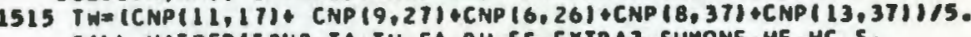
CALL haTOEPITHNG, Ta, TH, EA,OH, ES,

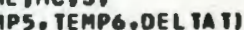
15OB CUNIINJE

C IKRTI

$$
\text { TKRTI }
$$$$
\text { HC * ABS (HA*COS (ANG/5T.1) }
$$$$
\text { IF (TEO.LE.70.) } 60 \text { TO } 25
$$$$
\text { Go } \mathrm{Tu} 30
$$

25 BETA $* 5553$ CBEIA $=-20.15$ GO 1040

30 BEIA $=.7174$ CBETA $=-33.60$

40 CONIINIE $21 * * .51 *$ WFAC

$X=13.7$
$E E=E S$

$X E=E S$
$T A=1.8 * 1 A+32$.

$T H=T N * 1.8+320$

SIGNI $=E E-E$

$H R=1001$. *(TEO/460.+1.)*\$4 * SUMONE*ISIGNI) *26*5UMONE*(TEQ-IAI (

$1.26+B F T A \mid l$ I $T A=(T A-32,1) 5,19$

TA= $=17 \mathrm{~A}=32.1 \pm 5.19$

HTOE $=$ HTEO/104.*24.*3600*3.1

HTOE = HT OE $\$ 5.019 .0$

IFINST.EU.NPRINTIIPI) CO TO 1533

IFINST.EQ.IXA) GO TO 1533

GO TO ISII

1533 CONTINUE

IF(EXTRAL .NE.2.) GO TO 1511

1536 CaNTINUE

WRI TE16,IS3SI BC,PMH, EA,WC, SUMONE, $X$, ES,HTOT, HA, BH, HE,HC, TH

1535 FORMAT f $3 x_{0}$,
00023100 00025200 00025300 00025400 00025500 00025600 00025700 00025800 00025900 00026000 0026100 00200 00026400 00026500 00026600 00026650 00026100 00026800 00026900 00027000 00027100 00027200 00027300 00027400 00027500 00027600 00027700 0002750 002790 0028 00028200 00028300 00028400 00028500 00028600 00028700 00028800 00028900 00029000 00029500 00029505 00029600 00029700 00029750 0029760 列 002990 


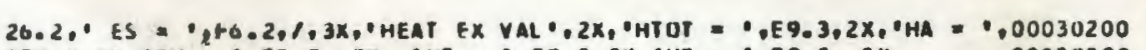

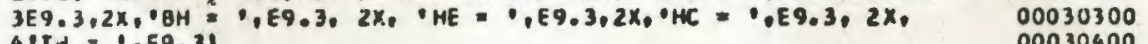
$4, T, 1,0,9.31$ 1511 CONIINUE

c

00030500

HEAT INPIJT

HEA IMPUT COMVERTEC INTO IEMPERATURE 00030800

00030900

HIOI $=$ HT OT 1.1

HIPREX = HT OI * (CM (N, M) ..000001/NSTI/ITW*.00010/NSI)

$\begin{array}{ll}\text { HTPREX }=\text { HTOTOT } & 00031350\end{array}$

$S(N)=S(N)$ - MTPRBX

220 CONTINUE

FIDOSALI GO IO 1131

00031400

Go TO214 Go ro 113

1131 CONTINUF

$\triangle(N F F)=C N P$ (NFF, $M)$

IF (MSRCH.EQ.0) AINFFI $=0$ 。

$B(N F F)=0$.

DO 232 N=NF, L

$\mathrm{NN}=\mathrm{N}-1$

$F 1=0(N)-P(N) * B(N N)$

$A(N)=\{-S(Y)-P(N)$ A) NNI) $/ F$

2 CONTINUE

CNP $(L, M)=A(L)-A(L) * C N P(L L L, M$

00031500

00031600

00031700

00031800

00031900

00032000

00032100

00032200

00032300

00032400

00032500

00032730

00032800

00032900

00033000

DO $233, J=1, N X$

DO 233 J $21, N X$ (Y)

$N=L-J$

$C N P(N, M)=A(N)-B(N) * C N P(N P, M)$

00033100

00033200

3 CONTINUE

210 CO TU 214

210 CDNTINUE

IF (IB.EQ.0) TEMPL=O.

IF(1H.EQ.2) TEMPL $=$ VP

IF 1 I 18. EC.

205 TEMPIO=VIL. MAM

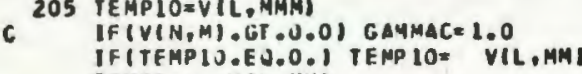

IFITEMPILEO

$933 L L L L+1$

BETA $=0$.

TEMPQ $=C 2 * B E T A *(V(L, M)-V(L L, M))$

TEMPI $=V(L, H) \oplus \bullet 2+I I(U P(L, H)+U P(L, M M I) * 21 / 16$.

$T E M P 2=(S E P I L, H)+S E P(L L L, M)+H(L, M H)+H(L, M I)+(C(L, M)+C(L L L, M)) *+2$

00033300

00033400

00033500

00033600

00033700

00033800

00033900

00034000

00034100

00034200

0034300

0034500

00034600

00034700

00034800

00034900

00035000

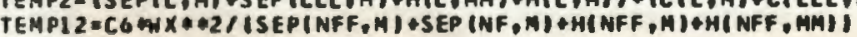


TEMP $\}=1$ - +C 4 * SOKT ITEMP II/TEMP Z + TEMP + TEAP IZ TEYPJ=L. T TEMP3

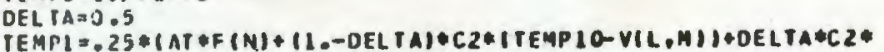

IIVIL,M)-TEMPLIII

(

$1-C L *(S E(L L L, M)-S E(L, Y))$

$209 \mathrm{VP}(L, M)=T E M P$

206 CONIINUE

IFIIA,FO.OU TFMPI $=0$.

YPINFF, $M$ )

Go ro 201

GO 10208

IF (VIN,M).LT.0.0) DELIAC= 1.0

TEMUIG=VINFF, YMHI

IFIIEMPIO.EJ.D.I IEMPIO= VINFF, MMI)

936 TE YPII $Y$ Y $N F F, M Y 1$

IFITEMPII,EO.0. IEMPII= VINFF, 4MM)

938 BETA 1 .

TEMPL $=C 2 *(1,-B E T A) *(Y(N F, M)-Y(N F F, M))$

作

TEMP2 $=(S E P(N F F, M)+S E P(N F, M)+H(N F F, M)+H(N F F$, MH) $)$

IIC(NF, M) +C(NFF, MI) $\$ 2$

TEMP3 $=1$ 1. OCA $\#$ CR1 IIEMP IU/TEMP 2+IEMPA

IEMP $3=1 . / T E M P 3$

OELTA $=J .5$
TEMP $=.25 *(A T * F(N)+(1,-D E L, T A) * C 2 *(T E M P 10-V(N F F, M)\}$

1 OOELTA*CZ *(VINFF, M)-TEMPIIII

1 -CI*ISE (NF, M)-SE (NFF, MIIII

I YP(AFF, $M$ ) $=T$ TEMPI

Go To 211

214 MUM= NUMOL

GD TO 201

202 CONT INUE

RETURI
00035400

00035500

00035600

00035700

00035800

00035900

00036000

00036100

00036900

(1)

0037200

00037300

00037400

00037500

00037600

00037700

00037800

00037900

00038000

00038100

$00 C 38200$

00038300

00038400

00038500

00038600

00038700

00038800
00038900

00038900

0039100

00039200

00639300

00039400

00039400
00039500

00039600

00039700

00039800

00039900

IEB816I MEMBER MAME (AUPAFH, FOUND IN MM DIRECTORY. TIK IS NOW ALIEREO. 
of CHAMSEE NAME =AUPNSH, LI ST T ALL
SUBRCUI INE UPNSHT IC2, CG,HX,WY,C4,AT, DOSAL, IMOOES, NSOUAC, HSOURC, OOCOIOOO ICI $, C I O, C 7, C B, C 9, C 14, C I, N I N !), F, N I, N S T, N P R I N T, I P$, IBNB,KRT, $\quad 00001100$ ZAMAX, MMAX IOY, PI, CAY, AS, MS, S5, OIN, IIY,NL, IHR, IMIN, HIOT, NH, 3UPCCN, VARI, VINPUT)

CUMMCN SE $(21,48)$, SEP $(21,48), V(21,48)$, VP $(21,48), U(21,48), U P(21,48), 03$ I $C(21,48), N 3)(85), M O D(A 5), M O B O(4), N B B D(4), H(21,48)$

$W(20), F 2(2 J), 2(20), E(2 J), H P(20), E P(2 C), H B(20), E B(20)$,

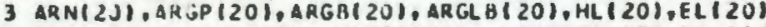

4 IIA(0175), 2IB(0175), 21C(0175), UAVG(21,48), VAVG(21,48), 21E(0175),

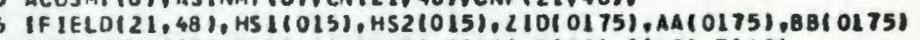
DIMENS IOY A( (990), B(48), P $(48), 0(46), R(48), S(48), F(48)$.

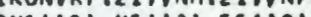
AHOLDi(4), NS $(10)$, MS $(10), 55(10)$

COGICAL DOS

$$
\text { NUM }=1
$$

340 IFINUM.EQ.NINDI GO TO 402

1021 /ASRCHENAD(NUM)/ 1000000

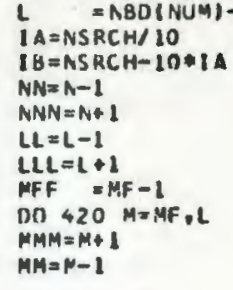

DELTAC $=.5$

GAMMAC $=5$

AIFAC $=0.5$

IF (P.EQ.MF) 60 TO 406

IF (M.EQ.LI GO TO 410

411 CONT I NUJE

ALPHA 00.5

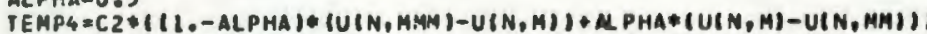

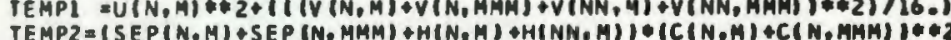

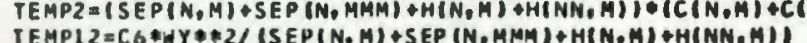

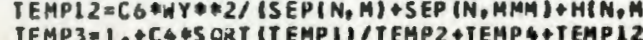

TEMP $3=1 .+C 4 \$ 5$ CRT

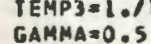

GAMMA $=0.5$.

IF (TEMP 1O.EQ.D., TEMPIO= U(NN, M) 00001300 00501500 00051600 00001700 (1) 000 00002000 00002100 0002200 002300 0002500 000250 0,0002100 00002800 00002900 00003000 00003100 00003200 00003300 00003400 00003500 00003600 00003700 00003800 00003900 00004000 00054100 0004200 00004400 00004500 00004600 00004700 00004800 00004900 00005300 00005100 00005200 00005300 $000 \mathrm{C} 4400$ 00005500 00005600 00005700 00005800 00005900 
978 TEMPII $=U\left(N N_{1}, M\right)$

FITEMPIL.EJ.0.) TEMPIL = UINNN,HI

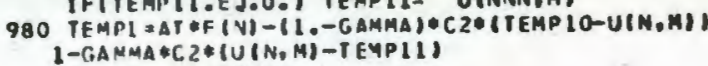

TEMPL $=.25$ "T EMPL

404 UP $(N, M)=[E M P 3 *$

$1 \quad(1)(N, M)+T E M P L(V P(N, M)+Y P(N, M M M)+Y P(N N, M)+V P(N N, M N M))$

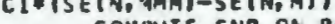

I FIRST half TIMESTEP

2 CONTINUE

If (cos $A L)$ GO Tn 413

413 CONTINUE

(FIIMODES.EQ.1) GO TO 7196

TFIIMUDES

7196 ALFAC $=0.0$

BET $A C=1.0$

GAYMAC $=0.0$

FFIUIN,M).GT .0.0) ALFAC $=1.0$

IF IU(N,M).GT.0.0) BETAC=0.0

If $(V(N, M) \cdot G T \cdot 0.0)$ GAMMAC= 1.0
If $(V I N, M) . G T .0 .0)$ DELTAC $=0.0$

GO TO 7199

$\begin{aligned} 7198 \quad A 1 & =1.0 \\ A 2 & =1.0\end{aligned}$

C CHANGEO BL ANO 82

$A L F A C=.5$

BETAC $=.5$
GAMHAC $=-5$

GAMAAC $=.5$
DELTAC $=.5$

AI $=0$.

1199 CONTINUE

IF (N.EO,NS(NZ), OR,M.EQ.MS (N2)) GO TO 510 GO TO 520

510 Continue

IF (N.EO. US (NI)) GO TO 512 GOTOS 515

512 CONTINUE

IF (NNN.EO.NS (NZ) . ANO,V $(N, M), G T .0 .0)$ GAMMAC $=1.0$

IF $(A N, E Q$. NS $(N Z)$, AND $V(N, M), L, T, 0.0)$ DEL TAC $=1.0$

IFIN.EQ.NSINZII) GO TO 514

GO TO 520

514 IF IUIN, HI.GT.0.01 BETAC $=0.0$

If $(U(N, M) . L T . U .0)$ ALFAC $=0.0$

IF $(V(N, M) . L T .0 .0)$ GAMAAC $=0.0$

GO TO 520

515 IF (MM. EQ. MS (NZ) _ AND.U (N, M) -LT.0.0) BETAC $=1.0$

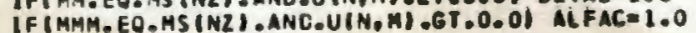

520 CONTINUE

conranue 
430 CUNI INUF

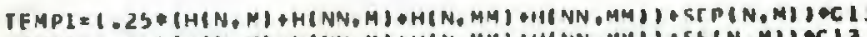

TFMD? $=1.2$ ', $D$ CHIN,

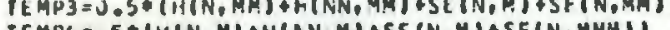

TEMPG $=5$.

TEAPS: SO

IEMPA $=0,5 *\left(H(N, M M)+H\left(N N_{0} M M\right)+\operatorname{SEP}(N, 4)+S E P(N, M M)\right.$

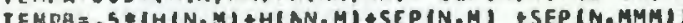

OXNH=C7*ABS (UP $(N, M)) * T E M P Q /(.5 *(C(N, M)+C(N, M M M)))+C 10$

OXYMM $=C 7 \& A B S$ (UPP $(N, M M))=1$ EMP ANC $.5 *(C(N, M)+C(N, M M)))+C 10$

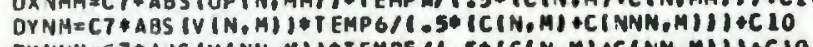

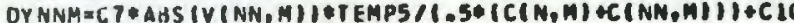

$D X M M=D \times A M A U P C O N$

DXNMMEUXNMM $+U$ PCOH

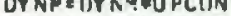

TEMP2J $=$ TEAP 3*AL UUP IN, MAT)CE

IEMPLI I TEMP A* OXNMME CQ

TEMH $2=T E M P \&$ \& 1 *UP $|A, M| * C$

TEMP23 $=$ TEMP BO OXNMACQ

TH.MP $24=\left(E M P S * A 2 * V\left(N N_{1} M\right) * C\right.$

TEMF25 = TEMPSOOYNNMC

TEMP $30=S E P$ IN MMM

IF I TEMP 3J.EU.U.) TEMP30-2. *SEP (N,M)-SEPIN, MM)

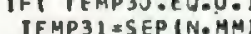

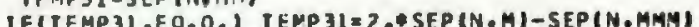

TEMP32=SEINNN, MI

IF IIEMP32.EO. O. T TFMP 32=2.0 SE (N, M) I-SE (NN, M)

TEMPJ $3=S E(N R, M)$

IFI TEMP 33.EQ.0.) IEMP 3 3=2.*SE (N, M )-SE INMN, M

$P(M)=-(11 .-B E T A C)+T E M P 20+1 E M P 21)$

$Q(M)=I$ IEPI +ALFAC*TEMP 22 + TEMP23-BE TAC *TEMP 20 + TEMP2L -BL *C14*

IUP(N,MM) +UP(N, M) ) $($ TEMP $30-T$ EMP 310

$R(M)=(1,-A L F A C)+T E M P 22-T E M P 23$

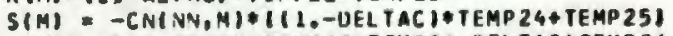

TER-DELTAC*TEMP24 + TEMP 27+ TEMP25

COLCI

C NOTE DISCOVERED ON 31 JULY 72 THAT LINE 0953/3 HAO CNIN, MAM

INSTEAD OF CN (NMMN, M)

INS=NSININPUT)

IMS = MS (NINPUT)

IF(NS (NZ).EO.N-AND.M.EQ.MSINZ)I CO TO 525

GO 10530
00012100

0onilizan

0001300

00011500

0011500

00011800

0 COL119.00

00012000

00012000

00012200

00012300

00012400

00012500

00012600

00012700

00012800

00012900

00013000

00013100

00013200

00013400

00013500

0013600

00013700

00013800

00013900

000140,00

00014100

00014200

00014300

00014500

00014600

00014700

00014800

00014900

00015000

0015100

00015300

0015300

0005500

00015600

00015700

00015800

00015900

00016000

00016100

00016200 
S2S S(4) $=5(4)-5 S(N 2)+11$ IN + CNPIINS, IMSI) IFIA.EE.INS. ANO.M.EO.IMSI GO TO 526

526 SIM) SS(M) *SS (NZ)*CNPIINS, IMS)

$N Z=N Z+1$
CONIINUE

$$
T W=(C N P(11,17)+\operatorname{CNP}(9,27)+C N P(6,26)+C N P(0,37)+C N P(13,37)) / 5 \text {. }
$$
HTPRBX $=$ HT OT $+(C N(N, M)+.000001 / N S T) /(T M+.00010 / N S T)$ $H T P R B X=H T$ OT

$S(M)=S|M|-H T P R B X$

420 COVTINUE

$$
\text { If(OUSAL) GO TO IIIs }
$$

G 10414

1115 CONTINUE

$\triangle(M F F)=C N P(N, M F F)$

IF INS KCH.EQ.OI AIMFF I=O.

$B(M F F)=0$.

DO $432 \quad M=M F, L$

$F=C(M)-P(M) * O \mid M M)$

(M)+P(M)*AIMM) I/F

G(M)
CONI INUE.

32 CONTINUE

IFINSRCH,EO.01 CMPINOLI=AILI

PX $=1-M F$

$00+33 \mathrm{~J}=1, \mathrm{Mx}$

$M=L-J$

$=A(M)-B(M, C N P(N, H P)$

433 CONTINUE

GO 10414

410 CONTINUE

IF $(18 . E Q .2)$ TEMPI=UP(N,L)

IF $(1 B \cdot E 0.0)$ TEMPL $=0$.

GO TO 409

405 TEMPIO=UINNN,L

C IFIUIN,MI.GT.0.0) ALFAC $=1.0$

IFIUIN,MI.GT 0.01 ALFAC $=1.0$
IFIIEMPIO,FQ.0.1 TEMPIO

1001 TEMPII $=U\left(N N_{,} L\right)$

C INSERTED FOLLCIING THC CAROS 24 AUG

INSERTED FOLL CWING THC CAROS 24 AUC

ALFA $=0$.

TEMPA $=C$ Z + ALPHAFIU(N,L)-UIN,LL)

TEMPL $=U(N, L) * 2+(1|Y| N, L)+V(N N, L)] * 2) / 16$ -

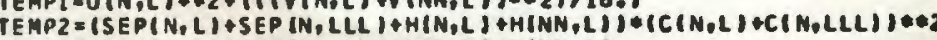
TEMPI $2=S E P I N, L)$ \& EP (N,LLL IOH(N,L) +H(NN,L)

TEAP 12=CG*HY**2/TEMPI2

TEMP $3=1$ + +C4*S QRT ITEMP II/TEMP2 *TEMP4 +TEMP 12

00016300

00016400

00016500

00016700

00016800

00016900

00017000

00017100

00017200

00017250

00017300

00017400

00017500

00017600

00017700

00017800

00017900

00018000

00018100

00018200

00100

0018500

00018500

$0 \mathrm{CO18700}$

00018800

00018900

00019000

00019100

00019200

00019300

00019400

00019500

00019600

00019700

00019800

0019900

0020

05020200

0,020300

00020400

00020500

00020600

00020700

00020800

00020900

00021000

00021100

0002120

00021300 
406 IFI(A.EO.1) GO TO 407

60 TO 408

C IF(UCN,M).LT-0.02 EETAC=1.0

TEMPIO=U(NNN, MFF)

TF(TEMPIJ.EO.0.) TEMPIO* UINN, RFF

00022000

00022100

00022400

00022500

00022600

00022700

00022800

00022900

1006

TEMHIL=U(NIN, MFF)

00023000 ALPAS=1.

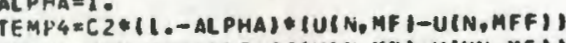

00023200

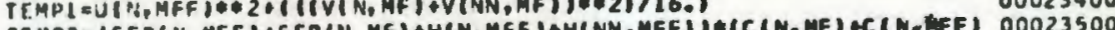

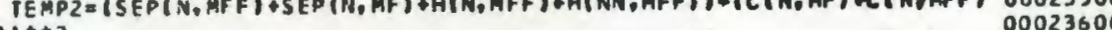
$11 * * 2$

IFNPI $=S E P\left(N_{0} M E F I+S E P(N, M F)+H(N, M F F\right.$ IOHINM, MFFI

00023600

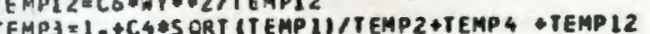
GAMA TEMPI*-25*(AT *F (N)-11.-GAMMA) *C2*(TEMP1O-UIN,MFFI)-GAMMA*C2* 00024200 IIU(N, MFF) - TEMPIIII TEMPI = TEMP 3*IU (N, MFF) \& TEMP L * (VP $(N, M F) * V P(N N, M F))$

$1-C I N(S E(N, M F)-S E(N, M F F))$

408 UP (N, MFF) $=T E M P$ I

$$
\begin{aligned}
& \text { GO } \text { In }_{N U M} \rightarrow 1 \\
& \text { G }
\end{aligned}
$$

$614 N U M=N U M+1$

$$
\text { Go TO } 340
$$

RETURN

00024400

00024500

00024600

00024700

00024800

00024900

00025000

00025100

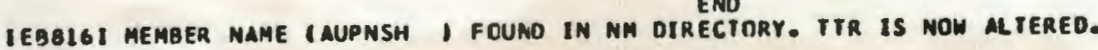



If CHANGE NAME $=$ AWTDEP, $L I S T=A L L$
I NUMBER INCR $=100$, NE WI 1000
SURROUT IVE WATDEP IT BNB, IA,TH, EA, BH, ES, EXTKA 3, SUMONE, HE, HC, S IHTOT, EXTRAA, N,NST, ICY, HA, HS, WC, HFACT, HA, ANG, TE HP 5, TERPG, DEL IAT 00001100 (CI21.4B), NADIB5), IC(21,48) (2) 00001500

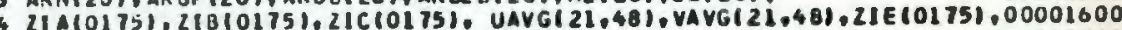
5 ACCSMT (6), ASINMT (6), CN(2), 48), CNP(21, 40). 00001700

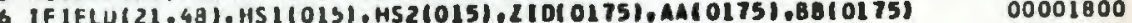
DINENSTON 5148 I TO FROM Y DIRECTION

WC $=$ MINTJ FRUA $X$ DCRECTION

WC $=A B S(W A * \operatorname{COS}(A N G / 57.1))$

WB = ABSINAGSINIANG/57.1)

EXTRAS $=0.0$

2969 TAE

(FIDELTAT) GO TO 100

GO TO 200

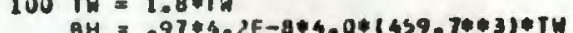

BH $=97 * 4.2$

BETA $=67$

ME $=$ SUMOYF BETAPT

IF IHE

HC $=26$ SSiJ

$H A=0.0$

HA $=0.0$.

HSZIIOY) $=0.0$

$T H=T H \neq 5.0 / 9.0$

GO 10300

$200 \quad A=457.9$

$T H=1.8 * T+N+32$.

$B H=1.97 * 4.2 E-8) *(1 T H+A$

$E S=99,-96 . * \cos 13.14 * 1111 \mathrm{TW}-30.1 / 50.1 * 33 .+7.1 / 100.1$

(1)

SUMCNE $=11.4 * W A$

(IH-TAI

\section{HE $=$ SUMUNE * $(E S-E A)$}

$S I G N=E S-E A$

IFISIGN.LT.J.OI HE=O.

$T H=1 T H-35$

HTOT - HS2IIOYI + HA - BH - HE - HC

hTOT HSZTIOY HA

CONYERTING HTUT INTO DEG CENT

0
00001900

00002000

00002100

00002200

00002300

00002500

(2)

(1)

000300

0003100

00003200

00003300

00003400

00003500

00003600

00003700

05003800

0003900

0004200

00004300

00004400

0004600

00006700

00004800

00004900

00005000

00005100

00005200

00005300

00005400

00005500

00005600

00005700

00005800 00005900 

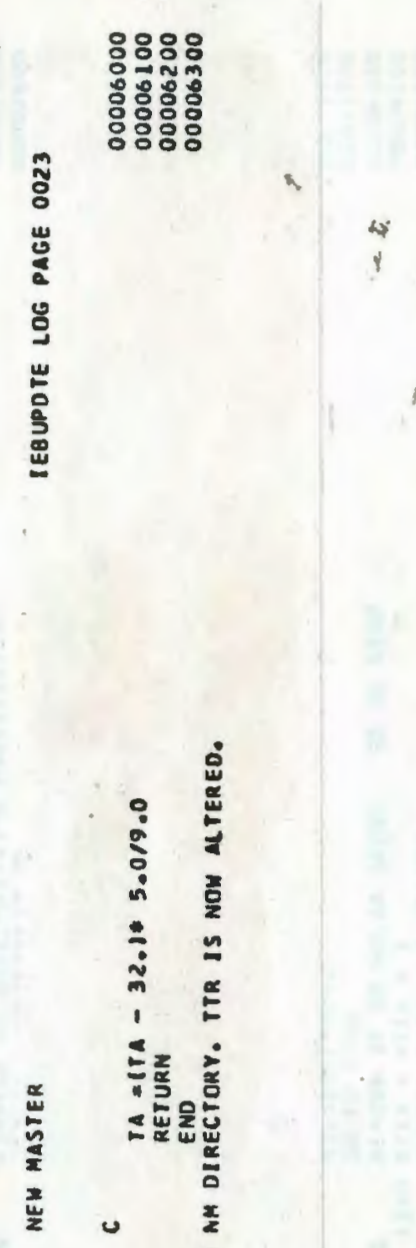

妾

言

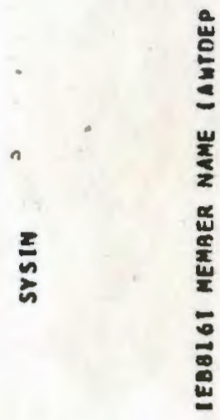




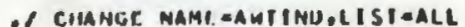
I MUMBER INCR $=100, \mathrm{NEHI}=1000$
SUBRIUIT IVE WAT INOIICY,AT,PI, OAY, TBNA, TA, WA, WH, WC, WFACT,RH, ICLCCYR, AVG, FXIRAI, TIME, BC, HA, EA, PMY, NST, EXTRAZ, IHR, IMINI 00001100

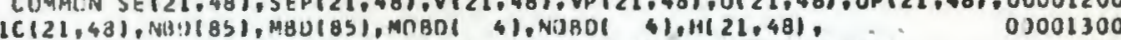
2 W(2U),F2(20),2(20), (120),HP(2)),EP(20),HQ(20),EB(20), OOOC14OO 3 ARN(20), ARGP(20), ARGB(20), ARGL B(20), HL(20),EL(20), 0J0015 4 ZIA(0175), 21810175), 2IC(0175), UAVG(21,48),VAVG(21,48), 21E(0175),00001600 5 ACOSMT(6), ASINMT (6), CN(21,48), CNP(2l,48), 00001700

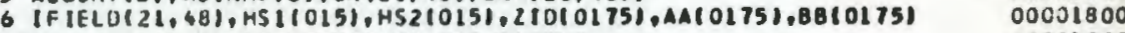
725 REAUI5,6JJ) TA,RH,HS211,,WA,ANG, CLDCVR

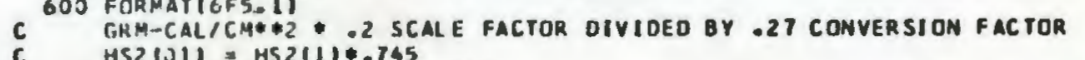
HS2 $(J 1)=H S 2(1) * .745$

CCNYERT TO BTUIFTH+2 - DAY

HS2

TA, RH,

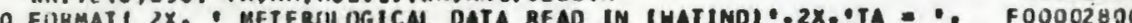

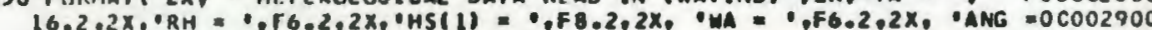

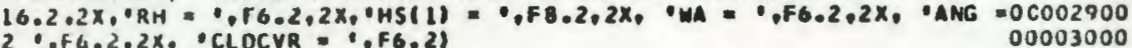

HA $=H A+1.152$

WFACT $=1.0$

KTIX $=0$

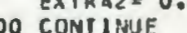

CONTIWHE

$\begin{aligned} & 10 Y * 1 \\ & H 51(I D Y)\end{aligned}=100$

GO TO 5300

REMOVF IF NO

1540 XIIK $=$ KIIK + I

INITIAL. TIME $=7$ OCL.CCK

2872 TIMEX $=$ THR

2891 XONE $=$ TIMEX- 7.0

IF (XONE.GT. . . T GO TO 2865

2963 DEHSIIIDY) /(1.7+(HSIIIDY)-200.1/350.)

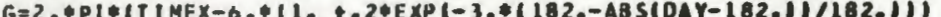
$T=24 . *(1 .--2 * \operatorname{CoS}(2+* P 1 * 0 A Y / 365)$.

HSI $(I O Y)=D * S I N(G / T)$

HS2 (IOY) $=17.85 \%$ HS $2($ ICY C FIGURE SULAR ENERGY INPUT ON PER HOLR BASIS, MULTIPLY BY 12 SO
C YOU AVERAGE IN ON PER OAY BASIS

300 TA = THNB + 10.*1SIN13.14*ITIHEX-2.1/24.11)*3

5300 CONTINUE

DE.0O.AND.TA.LE.79.9911 CO TO 5218

5215 PMH $=96.5-90 . * \cos ($ PI*(IIIA-30.) $/ 70.1 * 51 .+4.1) 1180.1$
00002000

00002100

00002200

0002300

(1)

00003100

00003200

003500

00003600

00003700

00003800

00003900

00004000

00004200

0004300

000450

00004500

00004600

00004700

00004800

00004900

00005000

00005100

00005200

00005300

00005400

00005500

00005600

00005700

00005800 
SYSIM

$\underset{\omega}{\omega}$
NEM MASTE

ril 111$) 3760$

5218 IFI.NOT.ITA.GE,80.00.ANO.TA.LE.89.99II GO 10522

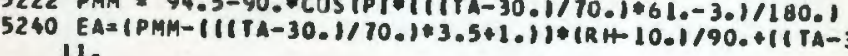

11.

$B C=79-79-10$

$T A=(T A-B)$

CONTINUE

RETURN

IEBeI6I MEMBER NAME IAWTIND, FOUNo IN MM DIRECTORY. TTR IS NOM MTERED.
IFOUPOTE LOG PAGE OOZS

00006000 00006100 00006200 00006300 00006400 00005600 00006700 00006800 00006900 00007000 
-1 CIMHGGF NAME-AMLOLIST-ALL
SUBRUUIINE AZIZONE I, ZCNE 2, ZNNE 3, 2ONE4, ZONE5, 2ONE6, TWBAY, NMAX, MMAX, 000JIJJU

INST,KRT)

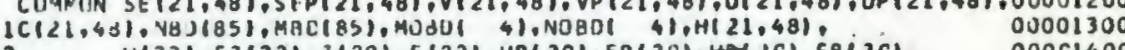
2 H(20),F2(20), 2(20),E(20), HP(20),EP(20),HAI\&C),EB(2C), OOOC1400 3 ARNI2U1, AHGP (2U), ARGBI 201, AHGL H(20), ML (20), ELI 20), 00001500 4 L(A10175), Z1B(0175), Z1C(0175), UAVG(21,4B), VAVGI 21,48), 2(E (0175), 00001600 5 ACOSMT (6), ASINMT $(6)$, CN $(21,48)$. CNP $(21,48)$, 0001700 6 IFIELDI21,48), HSIIJI5), HS2 1015$), 210(0175), A A(0175), B B(0175) \quad 00001800$ TEMP OF BAY UETERMIAATION FROM SIX ARBIIRARY ZONES 00001900

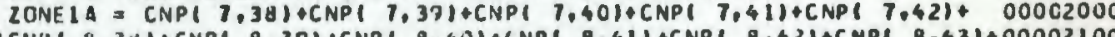
ICNP ( 8,36$)+C N P(8,39) \mid C N P(8,40), C N P(8,41)+C N P(8,421+C N P(8,431+00002100$ 3 CNP $(9,391+C N P 1-9,401+C 4 P(9,41)+C N P(9,42)+C N P(9,43)+C N P(9,441+00002300$

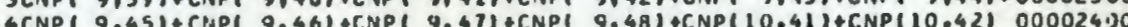

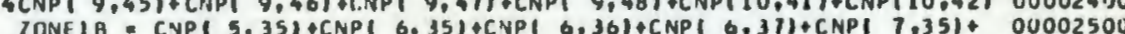
ICNP( 7,36) + CNP( 7,371+CNP( 8,351+CNP( 8,36)+CNP( 8,371+0 0002600 2CNP( 9,35$)+C$ CNP( 9,36$)+C N P(9,371$ ZONEIC $=$ CNPI $4,331+C N P\{4,141+C N P|5,321 \cdot C N P| 5,331+C N P \mid 5,341+00002000$ ICNP $(6,32)+C N P(6,33)+C N P(6,34)+C N P(1,31)+C N P(7,32)+C N P(7,33)+000 C 2900$ 2CNP( 7,34)+CNP( 8,31)+CNP( $8,321+C N P(8,33)+C N P(8,34)+C N P(9,31)+00 C 03000$ उCNP( 9,321 ICNPI 9,33 , CNP( 9,36$)$

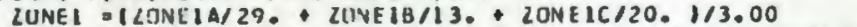

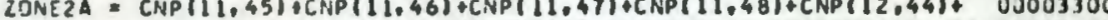
ICNP $(12,45)+C$ NP $(12,46)+C N P(12,4)+C N P(12,48)+C N P(13,40)+C N P(13,41)+00003400$ 2CNP $113,421+C, 9 P(13,43)+C N P(13,44)+C N P\{13,451+C N P(13,46)+C N P(13,47) 00003500$ JCNP $\{13,48)+C N P(14,40)+C N P(14,4))+C N P(14,42)+C N P(14,43)+C N P(14,44)+00003600$ 4 CNP $(15,4)+C N P(15,41)+C N P(15,42)+C N P(15,43) \quad 0003700$ 2ONE 28 LOYP $110.311+C N P(10,321+C N P 111,311+C N P(11,32)+C N P 111.33), 00003300$ ICNP $(11,341+C N P(12,31)$-CNP $(12,32)+C N P(12,33)+C N P(12,34)+C N P(12,35)+0 C C C 3900$ CNP (13, 33)

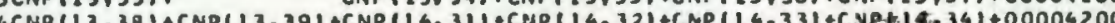
5 CNP (14, 35) CNP(14, 36) CNP(14,37) CCNP(15, 3 $1+C N P(15,32)+C N P(15,33)+C N P(15,34)+C N P(1) 35)+C N P(15,36)+00004400$ TCNP (15.37)+CNP(16.31) CNP(16.32)+CNP(16.33)+CNP(17,311 ZONEZ =120YE2A127. ZONE2B/44. I/2.00

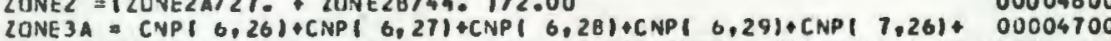
ICNP $(7,27)+C N P(7,28)+C N P(7,29)+C N P(7,30)+C N P(8,26)+C N P(8,27)+00004800$ 2CNP( 8,23$)+C N P(8,29)+C N P(8,30)+C N P(9,26)+C N P(9,27)+C N P(9,28)+00004900$ CCNP $(9,29)+C N P(9,30)+C N P(10,26)+C N P(10,27)+C N P(10,28)+C N P(10,29)+00005000$ 4 CNP $(10,30)+C N P(11,26)+C N P(11,27)+C N P(11,28)+C N P(11,29)+C N P(11,30)+00005100$ SCNP $(12,26)+C N P(12,27)+C N P(12,28)+C N P(12,29)+C N P(12,30) \quad 0005200$ ZUNE3B = CNP( 2,201,CNPI 2, 211+CNPI 2,221+CNPI 3,201+CNPI 3,21)+ 00005300 ICNP( 3,22$)+C N P(4,20)+C N P(4,21)+C N P(4,22)+C N P(5,20)+C N P(5,211+00005400$ 2CNP $15,221+C N P 15,231+C N P(5,24)+C N P 16,211+C N P Y 6,221+C N P 16.231400005530$ CCNP $(6,26)+C N P(0,25)+C N P(7,22)+C N P(7,23)+C N P(7,24)+C N P I 7,25)+00005600$ 4CNP( 0,22$)+C N P(8,23)+C N P(8,24)+C N P(8,25)+C N P(9,22)+C N P(9,24)+00005700$ CCNP

(2ONE 38/31. 112.00 


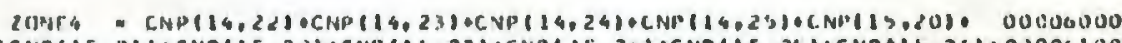
ICNP $(15,21)+C N P(15,22)+C N P(13,23)+C N P(15,24)+C N P(15,23)+C N P(1\}, 26)+00006100$ CNP 116.220 SCNP $(17,25)+C N P(1), 26)+C(1 P(17,27)+C N P(17,28)+C N P(17,29)+C N P(17,3 C)+000 C 6500$ GCNP $(18,23)+C N P(18,24)+C N P(19,23)+C N P(19,24)$ ZONE 4 = ZUNE4/39. ZUNE5A $=$ CNP( 8,16$)+C N P(8,17)+C N P(8,18)+C N P(8,19)+C N P(8,20)$ + $00 C C 6800$ ICNP( $8,211+C N P(9,14)+C N P(9,15)+C N P(9,16)+C N P(9,17)+C N P(9,18)+00006900$ 2 CNP 9,19$)+C N P(9,20)+C N P(9,21)+C N P(10,14)+C N P(10,15)+C N P(10,16)+00007000$ 3 CNP $(10,17)+C N P(10,28)+\quad$ +NP $(10,19)+C N P(10,20)+C N P(10,21) 00007100$

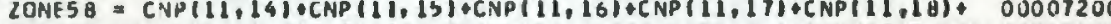
ICNP $(11,19)+C H P(11,201+C N P(1,21)+C N P(11,22)+C N P(12,14)+C N P(12,151+00007300$ 2 CNP $(12,16)+C N P(12,17)+C N P(12,18)+C N P(12,19)+C N P(12,20)+C N P(12,21)+00001400$ 3 CNP $(12,22)+C N P(12,23)+C N P(12,24)+C N P(13,16)+C N P(13,17)+0007500$ 4 CNP $\{13,18\}$ * CNP $\{13,19)+C N P\{13,20)+C N P(13,21)+C N P(13,22)+00007600$ SCNPII3, $231+$ CNP 113,241

ZUNES = (ZONESA/22. ZONE5B/29.1/2.00 00007800 ZONE6 = CNPI $2,41+C N P 1$ 2,5 I+CNPI 3,1 1+CNPI 3,2 1+CNPI 3. 31. 00007900

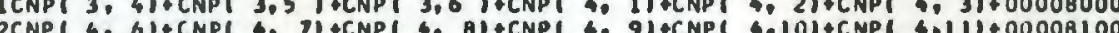

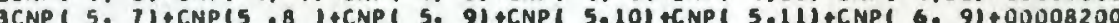

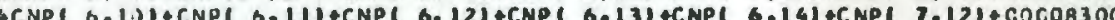

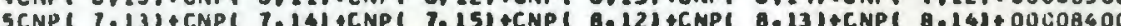

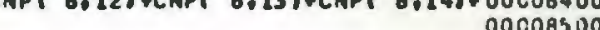
ZONES - ZONEG/36. THOAY = IZDIE 1*62. + ZONE 2* 71. + ZONE3*65. + ZONE 4*39. + ZONE5*51. +00008700 IZONE6*36.1/324. 00003800 SU:M $=0.0$

- $2 . \quad 00008900$

Dif 10 M=1, MMAX

Di) $10 \quad N=2, N 4 A X$

00009000
00009100

IFIIFIELDIN,MI,EQ.0) GO TO 10

$A N=N^{-1}$

00009300

$M M=M-1$

IFIM.EQ.L MMAM

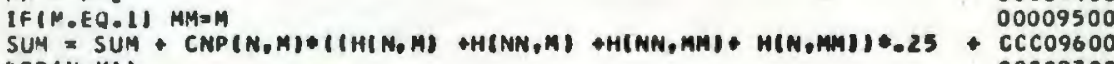

ISEP $(N, M))$

300 CONIINUE

IFIKRTEEO.0I GO TO $400 \quad 00010100$

RETURN

00010300

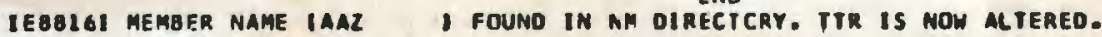


- I CHANGE NAME=AOIVE,LIST=ALL

SOMMOUT INE DIVERNAAX, MMAXX

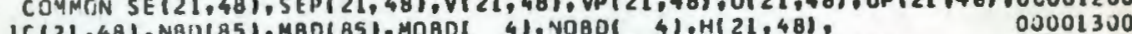

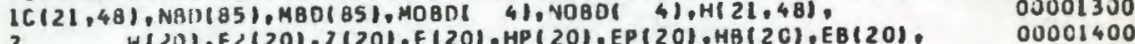
2 W(20),F(2), $2(20), E(20), H P(20)$,EP(2O),HA(2C),EB(20). 00001400 3 ARNIZU). ARGP(20), ARTAR

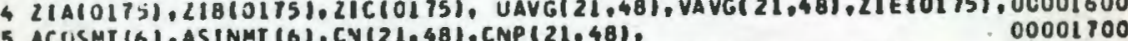
IFIELOI DIMEASICN NOI40I 03001900 $\begin{array}{ll}0 & 0002000 \\ & \end{array}$ DO I N = I. NMA

$T N I=S M V C S I$

NO(N) $=\mathrm{N}$

WRITE $(6,6)$ (NO(N), N=1, NMAX)

DO $2 \mu=1$, MMAX

00002100

DO $10 N=1$, NMA

00002200

00002300

00002400

10 CONIINUE

DO 2 N $N=1, N M A X$

2 HIN,M) =FLOAT INBD(N))

REIURN

FURNAT 132121

FTRMATIIH, $12,3 x_{0} 32121$

作

FOKMAIIIHO, $2 \mathrm{H} \mathrm{H}_{0} 3 \mathrm{X}_{3} 32(2)$

00002500

00002600

00002700

00002800

00002900

0003000

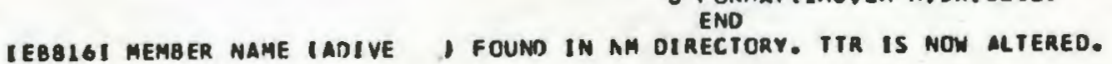

00003100

0003300

00003300

00003400

00003500

00003600
00003700

00003800

00003900 
SUAROUT INE PLOT INO, $, A_{,}, 4, M L$, NS)

CUMMON SEI21,40),SEP(21,48),V(21,48), VP(21,48),U(21,48),UP(21,48),00001100

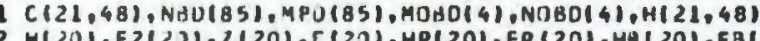

W(20)

ARA

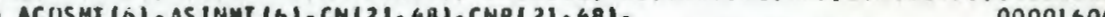

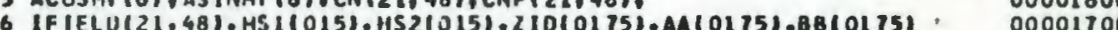

c 6 a

SUBRTUIINE PLOT 00002100

PLOT SEVERAL CROSS-VARIAALES VERSUS A BASE VARIABLE

CALL HLOT (NO, A, N, H, NL, NS)

00002500

00002600

00002700

00002800

DESCRIPT ION OF PARANETERS

ND - CHART NUMBSR I3 DIGIIS MAXIMUMI

- matrix of Data TO BE plotTED. FIRST COLUMN REPRESENTS SUCCESSIVE COL UMNS ARE TME CROSSVARIABLES IMAXIMUM IS 9 ).

- - number of colums in matoix a leoual to tme total

. NUMBER OF YAR IABLESI. MAXIMUA is 10

NL - NUMAER OF LINES IN THE PLOT. IF O IS SPECIFIED. 50

LINES ARE USEO. ORDER CROER

SORTING IS NOT NECESSARY IALREADY IN ASCENDING OROERI.

SORIING IS NECESSARY.

REMARKS

NONE

SUBRUUTINES AND FUNCTION SUBPROGRAMS REQUIRED NONE

1 FORMATIIIIIIIIIII/.60X,7H CHART 13.111111111111

00005400

00005600

00005700

2 FORMAT IIH ;FIL.4,5X,101ALI

123456789:

00005700
00005800

0005800

G Format (IOAL)

7 FORMAT IIH . 16x.101H. 


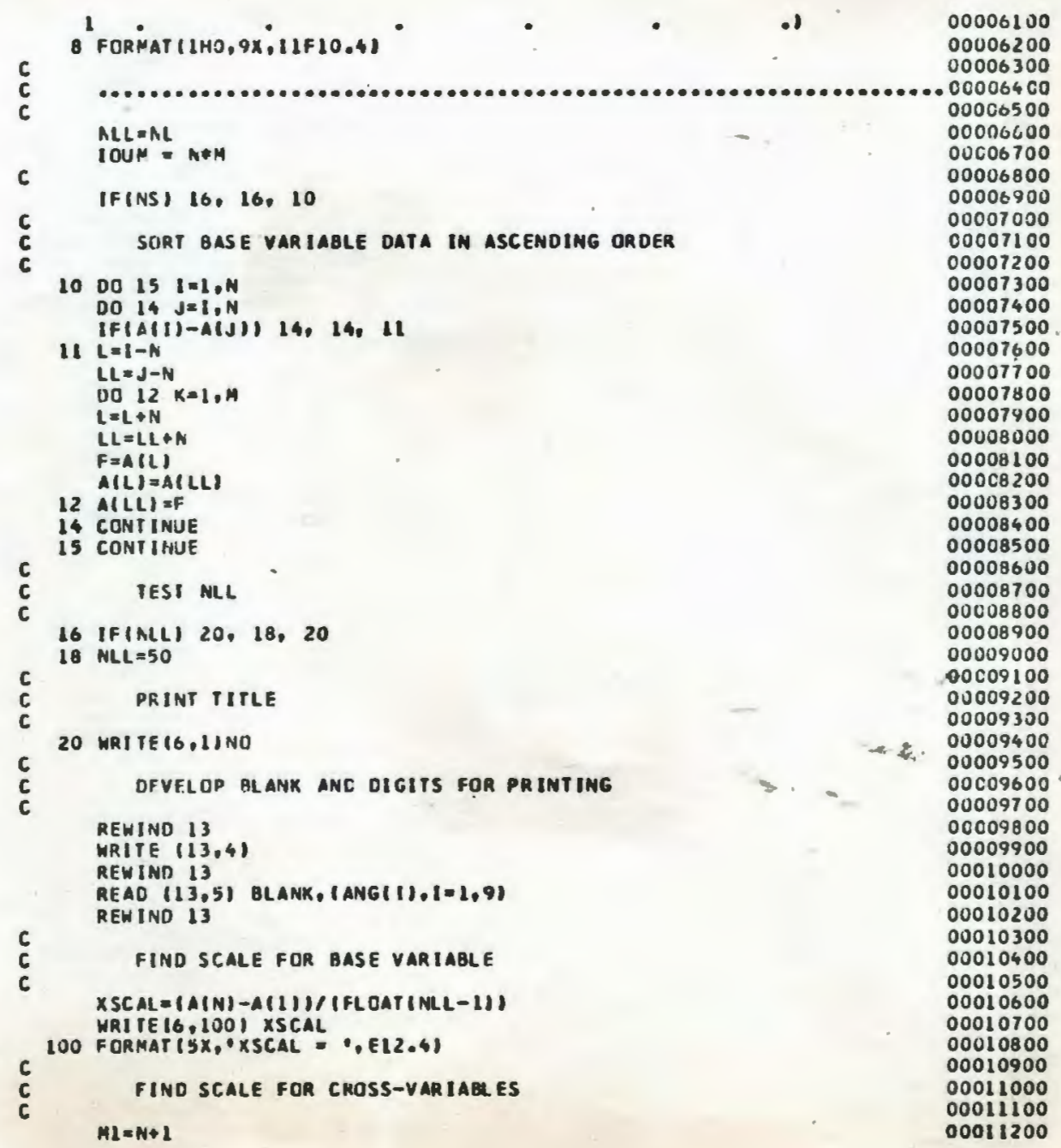




\section{$Y M T N=A(M I)$}

YMAX $=$ YMIN

$M 2=M * N$

DO $40 \mathrm{~J}=\mathrm{ML}, \mathrm{MZ}$

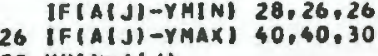

$Y M[N=A \mid J]$

60 ro 40

30 YMAXEAT

YSCAL $=(Y$ MAX $-Y M I N) / 100.0$

YRITE(b.110) YSCAL

110 FORMAT ISX, YYSCAL - , E12,4,11

c FINI base VARIABLE PRINT position

$X B=A \mid I I$

$X B=A$
$L=1$
$M Y=N-1$

$i=1$

$45 \begin{aligned} 1 & =1 \\ & =1-1\end{aligned}$

IF(AIL)-XPRI $50,50,70$

$c$
$\mathbf{c}$
$c$

50 on $55 \quad 1 X=1,101$

55 BUTIIX] = BLANK

$0060 \mathrm{~J}=1 . \mathrm{Mr}$

$L L=L+J * N$

INI]YSCALI+1.0

DUT I JPI = ANG (

c

PRINT LINE ANO CLEAR, OR SKIP RIIE $16,21 \times P R$, IOUT (I2), 12=1, 101 $L=L+$

60 TO 80

70 MRITE 6,3$)$

$80 \mathrm{t}=1+1$

IFII-NLL) 45, 84, 86

$84 X P R=A(N)$

GO 1050

C PRINT CROSS-VARIABLES MUMBERS

86 WRITE(6,7) YPR III $Y$ YMIN

90 YPR $(K N+1)=Y P R(K N)+Y S C A L * 10.0$ YPR
YLI $=Y M A X$
00011300

00011400

00011500

00011600

00011700

0011000

0012000

00012100

00012200

00012300

00012400 *

00012500

00012600

00012700

00012800

00012900

00013000

00013100

00013200

00013300

00013400

00013500

00013600

00013700

00013800

001300

0014100

0014200

00014300

00014400

00014500

00014600

00014700

00014800

00014900

00015000

00015100

00015200

00015300

00015400

001550

001560

0015800

0015900

0 0016000

00016100

00016200

00016300

00016400 

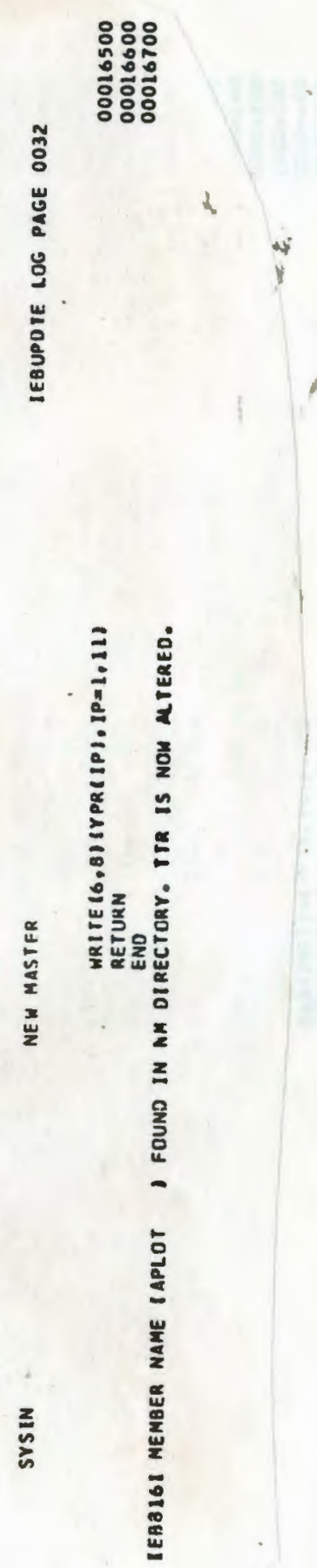
SUBRCUTINF. OISPLYINST, MAXSI, T PAAB, 2 IF 2 IC, LIH, IPRINOI

00001000 CUMMIIN SE(21,48), SEP(21,481,V $(21,48), V P(21,48), U(21,48), U P(21,48), 00001100$ IC(21.48), YRO 3 ARN(20),ARGP(20) ARA 5 ACCSMI 6 (, ASINMT 16$), C N(21,481$, CNP(21,48). G IFIELO(21,48), HSI(015),HS2(015),Z10(0175),AA(01751,BB(0175) 00001700 DIMENSICN T536(125),T636(125), T637(125),T5351(25),T635(125), 00001800 $17735(125),[736 \mid 125), 1737(125),[5341125), T 6341125), 171411251,00001900$ 21834(125), T8351125), T836(125).T837(125),T838(125),A(1250), 00002000 32 IFII), 2 IGII), 2IHII)

INNER TEMPERATURES AROUND ROME PT

00002100

00002200

00002300

00002400

00002500 NHOLO $=$ NST

IFINST.EQ.1) MOEL

410 CONI INUE.

IFIMNDINST, IPRINDI, EU OI GO TO 409

00002600

00002700

00002800 CO 10600

409 NST $=$

IF IIBAH - EO-0.00001) IBNB=1.0

T536 (NST) =CNP $(5,36)$ IT HNB

000300

T637NSI =CNP(6, 367 BNB

T535 INSTI = CNP (5, 35I IT BNB

T635 INST) = CNP (B. 35 )

T735 INT) = CNP $(7.351)$ T ANB

$736(N 5)=$ ( $)$ CNP $(7,36) / T$ BNA

7737 (NST) =CNP $(7,37) / 1$ UNA

OUTER IEYPE hatURES arCUNO ROME PT

$T 534$ (NST) $=$ CNP $(5,34)$ /T BNA

1534 (NST) $=$ CNP $(5,34) / T$ BNB

TO34INSTI $=$ CNP 16,34 I/T TNB

T734(NST) =CNP(T, 34 IT TENB

TA3 4 (NST) $=C N P(8,34) / T B N B$

$1835(\mathrm{NST})=C N P(8,35) / T B N B$

TOS

TO3B(NSTI CNP I 38 I/T BNB

$\cos (\cos )$

c

\section{IFINHDLD.EO-MAXST) GO TO 301}

GO TO 400

301 CONTINUE

$N()=1$

00003100

00003200

00003200

00003300

00003400

00003500
00003600

00003700 00003800 06003900 00004000

00004100

00004200

00004300

00004400

00004500

00004600

00054700

00004900

00405000

00005100

00005200

00005600

00005700

00005800

00005900

00006000

00006100

00006200

$N=N S T$

00006300 


$$
\begin{aligned}
& N S=0 \\
& O D 100 N=1, N S T \\
& N 1=N S T+N \\
& N Z=A S T+2+N \\
& N 3=N S T+3+N \\
& N 4=A S T+4+N \\
& N 5=N S T+5+N \\
& N G=N S T+6+N \\
& N 7=A S T+7+N \\
& N B=N S T+B+N \\
& A(N)=N \\
& A(N 1)=T 536(N) \\
& A(N 2)=T 636(N) \\
& A(N 3)=1031(N) \\
& A(N 4)=T 535(N) \\
& A(N 5)=T 635(N) \\
& A(N 6)=T 735(N) \\
& A(N 7)=T 736(N) \\
& A(N B)=T 737(N)
\end{aligned}
$$$$
A(N B)=\{737(N)
$$$$
\text { CONTINUE }
$$

00006400

0000650

00006630

00606700

00006800

00006900

00007000

00007100

00007200

00007300

00007400

00007500

000760

00007800

0007900

00008000

00008100

00008100

00008200
00008300

00008400

WRITE(6:120)

IER RADIUS OF WRITEI6.125I 5X. ALL OF THE fOL

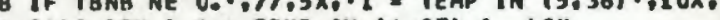
$2,2=$ TEMP IN 16,36$), 10 x_{0} \cdot 3$ = TEMP IN $16,371 \% 10 x_{1}$ $4{ }^{16}=$ TEMP IN 17,35$) \%, 11 x_{0}, 7$ - TEAP IN $(7,36) \% 12 x_{0} \cdot 8$ - TEMP INO0000200 $517.371 \%$

$$
\mathrm{N}=\mathrm{NST}
$$

CALL PLOT IN: $, A_{,}, N_{0} M, M, O I$

OO $200 \mathrm{~N}=1, \mathrm{NST}$

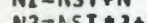

$M 3=M S T+3+N$

Nat $=45+4+N$

NS $=$ NST $* 5+N$

$N G=N S T * B+N$

$N 7=N S T * 7+N$

$N B=N S T=8+N$

$A(N)=N$

$A(N 1)=T 534(N)$

$A(N 2)=1634(N)$

$A(N 3)=T 734(N)$

$A(N 4)=T 834(N)$

$A(N 5)=T B 35$ (N)

$A(N G)=T 836(N)$

AlNTI $=1837$ (N)

$A(N B)=T 838$ (N)

200 CONTINUE
WITE 16,2401 


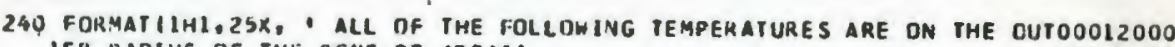
ER RADIUS OF THE RCKE PT AREA'I

00012100 FURMAII 5X, ALL OF THE FOLLOWING TEMPERATURES ARE IN DEG C. 00012300 LOIVIDEO BY 1BNB IF TBNB NE $0.0^{\circ}, 1 /, 5 X_{0} \cdot 1=\operatorname{TEMP}$ IN $(5,34) \cdot .10 x_{0}, \quad 00012400$ 2 0 ,

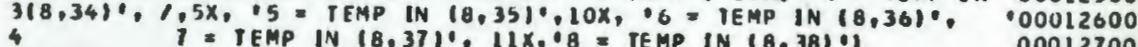
$\begin{array}{ll}N=N S T & 00012700 \\ & 00013200\end{array}$ CALL PLOT INO, A, N, M, NL.01 $\quad 00013250$ HRITE 16,350$)$, 00013300

350 FURMATIIHL,5X,11 - WE IGHTEO AVERAGE ALL TEMP IN BAY IOEg CI, /5X, 000I3500 1. 2 " WEIGHTE AV. CF ALL TEMP AROUND RUME PT-I DEg C $10.1 \%$. $25 x,-3$ - AVERAGE UP VELOCITY IN WEST PASSAGE IN YOS/SEC?. \% 00013700 $31,5 x_{0}+4$ aVERAGE UP VELOCITY IN OUTFALL AREA BOXS 00013800 $41,1,5 x_{0}, 5$. AVERAGE VP VELOCITY IN OUTFALL AREA., $/, 5 X$, 00013900

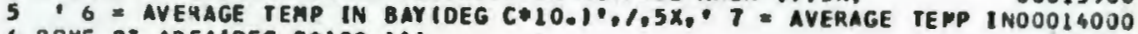
6 ROME PT AREALEE C*100.1\% NOI3

$N=N S T$

$M=8$

NLO = NST

$340 \mathrm{~N}=\mathrm{L}, \mathrm{NST}$

$\mathrm{NL}=\mathrm{AST}+\mathrm{N}$

$N 3=30 A 5 I+N$

$N N_{0}=40 A S T+N$

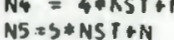

NS $=6 * N S T+N$

$N 7=7 * N S T+N$

$A(N)=N$

$A \mid N I)=Z(O \mid N)$

$A(N Z)=Z I F(N) / 10$.

$A(N 3)=Z(E(N)$

$A(N 4)=\triangle A(N)$

$A(N S)=$ BAIN)

340 AINT) $=$ LIHINST) 100 .

CALL PLCT INO, A, N, M, AL,O)

00014100

00014200

00014300

00014400

00014500

00014600

00014700

00014800

00014900

00015000

00015100

00015300

00015400

00015500

00015600

00015700

00015800

00015900

00016300

00016100

00016200

00016300

00016400

00016500

ZIO = AVERAGE HT IN EACH BOXIMAINI. 2IE= VELOCITY AT MOUTH OF 00016600

00016700 NCTE THAT AaINI IS OIVIDED or 10**-3

NOTE THAT ZIE(M) IS DIVIOED BY $200^{\circ}$

400 CONT INUE

IFITBNA.EQ.1.) TENA 0.00001
RETURN

00016800

00016900

0017600

(00017600

00017800

00017900

IEBB16I MFMBER NAME (AOISPLY I FOUND IN NH DIRECTORY. ITR IS NOW ALTEKEO. 
-I CHANGE NAME =AANLZE, LI ST=ALL $\begin{array}{lr}\text { SHBRUUT INE ANLY ZE(YAXST, NTERM, AT, NST, ZIF) } & 00001000 \\ \text { COMMON SE }(21,48), S E P(21,48), V(21,48), V P(21,48), U(21,48), U P(21,48), 00001100\end{array}$

00001000 IC (21,48), NBD(85), MBC(85), MUBOT 4), NOBDI 4),HI 21,48), 2 W(20),F2(20),Z(20),E(20),HP(20),EP(20),HB(20),EB(Z0). 00001300 3 ARN120), ARGP(20), ARGB(20), ARGL B(20), HL(20), ELI 201. 00001400 4 2IAIO175), 2IB10175), 2IC(0175), UAVG(21,48), VAVGI 21,401, ZIE(0175), 0C001500 5 ACOSMT(6), ASINMI (6), CN(21,48), CNP(21,48), 00001600 6 IF IELOI21,43), HS1(015).HS2(015).210101751.AA101751,8810175) 00001700 DIMENSION XIA10175),ALINE(65),2IFI1). 00001800

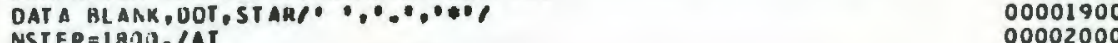
NSTEP=1800. TAY

000200 DL INE $(K)=$ = BLANK

IF I MAXST.GT . 175 I MAXST. 175

DO $30 \mathrm{~N}=1$, 4 AXST, NSTEP$$
0020 \quad 1=1.17
$$

$20 \mathrm{~S}=\mathrm{F} 2(1)+2(I) * \operatorname{COS}(H(I) * T+A R N(I))+5$ $x(A|N|=5$

$30 \mathrm{~T}=\mathrm{T}+\mathrm{L} .0$

LA $=0$

DO $40 \mathrm{~N}=1$, MAXST, NSTEP

IFIABS IZIAINI).GT.ZA) ZA=ABSIZIAIN)
IFIARSIXIAINII.GT.ZA) ZA=ABSIXIAINI)

$25=2 A$

WRITE $(6,45)$

OO $60 \mathrm{~N}=1$, MAXST, NSTEP

AD 60 NE 1. Maxst

$J M=31,+(L I A(N) / Z S)+30$.

JS 31 .

ALINE(JS) $=0$ TI

HRITE $(0,50)$ N, ZIA(N), XIAC(N), (N INE(J), J= 1,61$)$

ALINE ( JMI OBLANK

c ALTINE

$$
T=0.0
$$

OO $90 \mathrm{~N}=1$, MAXST, NSTE

$S B=0.0$

00 $80 \quad[=1,17$

$80 S A=F 2(1) * H B(1) * C O S(M(1) * T+A R G B(t))+5 B$

$x[A(N)=5 B$

$\begin{aligned} & x=T+1.0 \\ Z A=0 . & \end{aligned}$

DO 100 N=1, MAXST, NSTEP

IF IABS IZIBIN)).GT.ZA) ZA=ABS(ZIB(N))

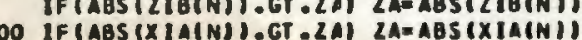

00002200

00002400

00002450

00002500

00002600

00002700

00002800

00002900

00003000

00003100

00003200

00003300

00003400

00003500

00003600

00003800 .

00003900

00004000

00004100

00004200

00004300

00004400

00004500

00004600

00004700

00004800

00004900

00005000

00005100

00005200

00005300

00005400

00005600

00005600

0005800

00005900 


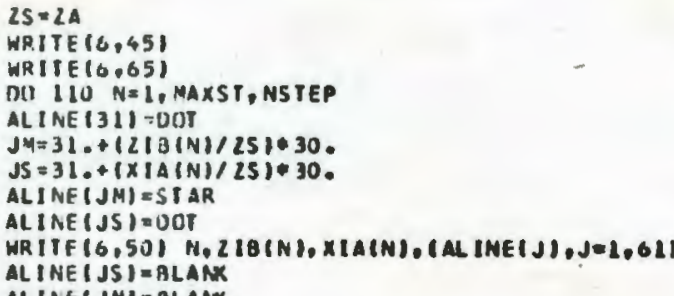

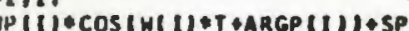

$X(A \mid N)=5 P$

$150 \quad T=T+1.0$

$\begin{aligned} & 2 A=0.0 \\ & D O \\ & 100\end{aligned}=1$, MAXST, NSTEP

IFIABSIZICINII-GT.ZAS ZA=ABSILICIN)

160 IFIABSIXIACYII) GT 2 IAI $Z A=A B S I X$

$25=24$

WRITE $(6,45)$

HRITE (6, 4 B)

OO $170 \mathrm{~N}=1$. MAXST, NSTEP

AL INE $(3[)=$ DUT

J5 $=31$. + IXIAINI)

$J M=31 .+(2 I C, N) / 2 S) * 30$

ALI NE $(J M)=5$ TAR

ALTNE

ALINE( JS ) $=B L A R K$

130 CONIINUE

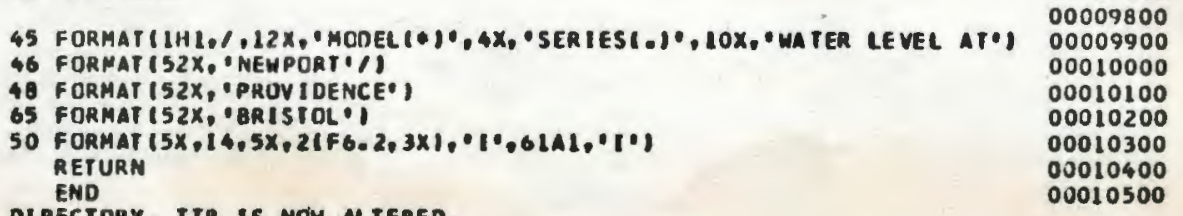

TES816I MEMBER NAME (AAMLZE I FOUNO IN MH DI RECTORY. ITR IS MOM aLTERED.

IEB8I8I HIGHEST CONDITION CODE WAS OOO00000

IEBBIGI END OF JOB IEBUPDTE. 
COMPILER OPTIONS - NAME = MAIA, CPT=02, LINECNT $=60,512 \mathrm{E}=0000 \mathrm{~K}$,

ISN 0002

ISN 0003

ISN 0004

ISN 0005

SN 0006

ISN 0007

ISN 0008

$\stackrel{N}{E}$
DIMENSI SAURCE \&E BCDIC, NUL IS T, NODECK, L CAD, MAP, NUED IT, MOID, NOXREF DIMENSR SOURCE

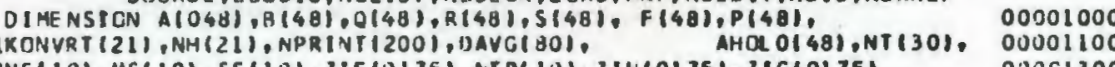

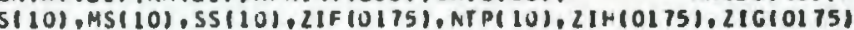

0.0061200
00001300

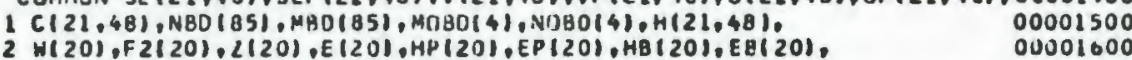

3 ARN(20), ARGP(20), ARGB(20), ARGLB(20), HL (20), EL(I20), 00001700

4 21A101751,21810175), 2IC10175), UAVG(21,48), VAVG121,481, 21E(01751, 00001740

5 ACOSMT(6), ASINMT(6),CN(21,48), CNP(2),48), 00001900

C IFIFLD(21,48),HSII015).H521015).21C(0175),AA(0175),8D(0175) 00002000

LOGICAL READIN,DOSAL,RDCNP,DELTATT $\quad 00002100$

00002300

00002400

00002500

00002600

00002700

00002800

00002900

000300

00003200

00003300

00003400

00003500

00003600

00003650

00003700

00003800

00.503900

$0 \mathrm{C004000}$

00004100

00004200

00004300

00004400

00004500

004700

00004800

00004900

00005000

00005100

00005200

00205300

00005400

00005500

00005600

00005700

$0<005800$

00005900

00006000

00006100

00006200

0006300 
ISN OC3?

ISN 0031

ISN 0032

ISN 0035

SN

ISN 0037

ISN 0038

1 SN 0040

,

ISN 004

SN 004

ISN 0043

SN 0044

ISN 004

ISA 0046

ISN 0047

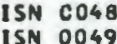

ISN 0049

ISN 0050

ISN 0051

ISV 0053

ISN 0054

ISN 0055

ISN 0056

ISN DOST

ISN 0058

ISN 0059

ISN 0060

ISN 0062

ISN 0062

ISN 0064

ISN 0065

ISN 0066
ISN 0067

ISN 0068

ISN 0069
C If DELIAT is true model wILl Calcualte temperature above ambiemt o000s5ug OELTATE.TRUE.

IFIOELTATI GO TO 2873

Go $\operatorname{tn} 2875$

2873 TBVB $=0.00001$

TMHOPE $=.00001$

TRIVER=.00001

2875 Continue

DIFFUSION CONSTANT IS UPCON

C FDR UPCON $=500$ THE ORDER OF MAGNITUDE OF HICHEST OLFFUSION COEF IS ABOUT 350 YDSQ/SEC

UPCON=050.

\section{POWER PLANT}

POWER PLANT

IN $=0.0$ YOU WILL HAVE HYORODYNAMICS OF POMER PLAT SITE BUT
NO THER MAL LOAO ON BAY IF EFFECTS OF POMER PIANT ARE OESIREO SET TIN EQUM TO 12. $r I N=12$.

C SITE SELECTION. SEE heATIN fon OETAILS ON LOCATIONS SITE SELECTI
SI TE $=100$.

c

LNL $=0$

c

$A R H O=27 . * 1.940 * 11.00 * 0,000841 * 5 A L A 15-0.000100 * 15 O U N O 2$

$N \rightarrow M X X=19$
$\operatorname{MMAX}=48$

ANGLAT $=41.6$

$N I=1$

MNBD ( 1$)=0103042$

$M(18 D(2)=4808091$

MกคO $(3)=481113$

NOBD $11=192324$

$\mathrm{NOBO}(2)=0410112$

MIND $=4$

NSEC T $=80$

CT CONTINUE

$A R G=$ ANGLAT*3.14159271180.

ARG $=$ ANGLLAT*3.14159271180.

2080 NSI $=0$

CI $I=A T H A G / A L$.

C $2=A T / A L$

C $3=A T / 4$.

$C 4=8 . * A T * A G$

C 27 IS FOR CUFt to CuYOS CONYERSION ANO 2 IS FOR OISPLAYING 27 ISTUAL CROSSECTIONAL FLCW IN FOR RIVER $C 6=2 . * C D R A G * C R H O *(1.687 / 3,1 * * 2 * A T$ C7 $=4000$ (50R IIAGI
0006000

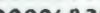

00006900

00307000

00007100

00007200

00007300

00007400

00007500

00007600

00007700

00007800

00007900

00008000

00008100

00008200

00008300

00008400

0008500

00870

000

000900

00009000

00009100

00009200

00009300

00009400

00009500

00009600

00009700

00009800

00009900

$0 \mathrm{CO} 10000$

00010190 t:

- 00010300

00010500

00010680

00010700

00010800

00010900

04011000

00011100

00011200

00011300

0 CO11400

00011500

00011600

00011700

00011800

00011900

00012000

0012100 
$C N P(N, M)=0.0$

CALL KURIHIHAXST, AT , ATERM, FCHECK, YR, CAY, THR,TMIN,TSI

00014300

00014400

00014500

00014600

00014700

0014750

001500

CALL FIND IMIND, NIND, MAX, MMAX, MINOO,NINOO,NSECTI

CALL OEPTH (NMAX, MMAX)

CALL CHEZY (AMAX,MMAX, CMANAI

CALL CHFCKINMAX, MMAXI

00015200

00015300

00015400

00015500

00015600

$\operatorname{lin}=18 * 1$

$M=18 *(1-1) \quad+L$

00015700

00015800

26 CONTIVUE

DO $62 M=1$, MMAX
DAVG $(M)=0.0$

$D E P=0.0$

DO GI $N=1$, RMAX

IF $(H(N, M), E Q .0 .0)$ GO TO $6 L$

00016000

$00016200^{2}$

00016300

00016430

90016500

$D E P=D E P+1$.

61 CONTINUE

OAVGI M) = 3, *DAVG (M) / DEP

00016600

0016700

00000

0016900

00017100

NUM $=1$

$D E P=0.0$

$G R \operatorname{LNI=0.0}$

7 IFINUM.EQ.NINDI 60 TO 3

NSRCH $=$ NBD ( NUM) $/ 1000000$
$\mathrm{N}=\mathrm{NHO}(\mathrm{NUM}) / 10000$
- HSRCH 100
MF NBD(NUM) $/ 100-N S R C H * 10000-N * 100$
L $=$ NBD ( NUM) $-N S R C H * 1$ OOOOOO N* 10000-MF*100
$N N=N-1$

00017200

00017300

00017400

00017500

00017600

00017700

NGR IO $=L-K+1$

00017900

00018000 


ISN 0130
ISN 0131

ISN 0132
ISN 0133
ISN 0134
ISN 0135
ISN 0136
ISN 0137
ISN 0138
ISN 0139
ISN 0140
ISN 0141
ISN 0142
ISN 0143
ISN 0144
ISN 0145
ISN 0146
ISN 0167
ISN 0148
ISN 0149
ISN 0150
ISN 0151
ISN 0152
ISN 0153
ISN 0154
ISN 0155
ISN 0156
ISN 0157
ISN 0158
ISN 0159
ISN 0160
ISN 0161
ISN 0162
ISN 0163
ISN 0164
ISN 0165
ISN 0166
ISN 0168
ISN 0169
ISN 0170
ISN 0171
ISN 0172
ISN 0173
ISN 0174
ISN 0175
ISN 0176
ISN 0177
ISN 0178
ISN 0179
ISN 0181
ISN 0182
ISN 0183
ISN 0184
ISN 0185
ISN 0186

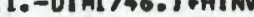

SE $(N, M)=$ SEINY*(1.-0IHI/46.) +HIN

00019100 NUM $=$ NUM+1

GO TO $?$
CONTINUE

CN $(3,1)=$ TANB

CNP $(3,1)=$ TBNB

$C N(4,1)=$ TRNB

CNP(4,1) = TBNB

CN $(19,23)=18 N B$

CNP(19, 23)=

CNP $(19,24)=T B N B$

CN. $(08,48)=T H N$

CNP $(08,48)=$ TANB

CN $(09,48)=18 N B$

CNP $(0 \%, 48)=18 N A$

CN $(11,48)=$ TBNB

CNP $(11,48)=$ TBNB

CN $(12,4 B)=1 B N B$

CNP $(12,48)=18 N B$

CN $(13,4 B)=$ TANB

CNP I $13,4,13)$, TIINA

DEPS 3. WDFP /GRIDNL

DEPSA 3 . * $1 D E P S O * 21$

$$
N A=1
$$

5 IFINA.FO.M(NDO) GO TO 31

1100000

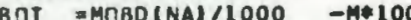

NTOP $x$ MOBDINA) $/ 10-M * 10000$ - NBOT 1100

OO $32 \quad y=N B$ T MTOP

(20019200

00019300

00019400

00019500

00019600

00019700

00019800

60019900

0002000

00020100

00200

0

00020500

00020600

00020700

00020800

00020900

00021000

00021100

00021200

00021300

00021400

00021500

OCJ21600

0021700

$002180 \%$

0002190

00022100

0022200

00022300

00022400

00022500

00022600

00022700

$D I M I=D ! M I-1$.

SEP $(N, M)=S E I N V * 11,-D I M I / 46-10 H I N Y$

00022800

SE(N,M) = SE INV* 11 - DIML/46.) + HINY

00022900

00023000

00023100

00023200

00023300

$N A=1$

33 IFINA.EO.NINDOI GO TO 34 $N=N O B$ ( NA) 1100000

$M R I G=$ NOBD ( NA) 110

$-N * 100$

DO 35 M=MLEF, MRIO

(1)

00023500

00023600

0003800

0023800 
ISN 0187

ISN 0188

ISN 0190

ISM 0191

ISN 0192

ISH 0193

SN 0194

ISN 0195
ISN 0196

I5N 0197

(

ISN GISA

ISN 0199

ISN 0200

ISN 0203

ISN 0204

ISN 0205

ISN 0206 c

c
SEP $(N, M)=S E[N V * 11,-D[M 1 / 46,1+H I N Y$

IOHINV

$\mathrm{NA}=\mathrm{NA}+1$

Gu TO 33

00024300
00024400

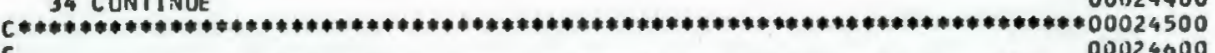

CALL INVALIMNAX,NMAX,GRICNL,DEP,OEPSQ,READIN,ROCNP,OAVGI 00024700

C CALL HEATININS, MS, SS, IIN,NZ, SITE,NINPUT, OIMI 00024800

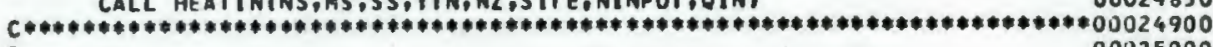

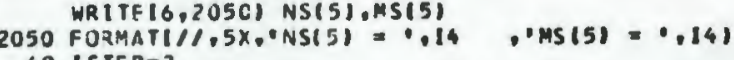

40 IS TE $P=2$

$c$

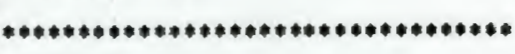

CALL PRINTIISTEP, NST, NPRINT, K, MMAX, MMAX, IP, AT, HTOT, HA, BH, IHE, HC, SAVE, IPUNCHI

C

年

89 ISTEP=1

NST $=$ NST+1

$K=2 * N S T-1$

2001 IFINST.GT.MAXSTI GO TO 501

C

C SET CPEN BOUNOS

CALL DPE NBOIRST, IMOOES, EXTRAL, KHRIT, K, KRT, IMOCE , TL, T2, T4, T5,

$c$

c

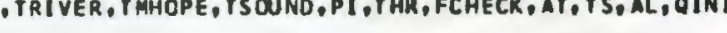

COMPUTE UP AND SEP CA RCH N ( FIRST HALF TIMESTEP )

CALL UPNFHT (WX, HY, C6, CL, C2, C4, AT, AG, NIND, F, NI)

00025000

00025040

00025060

00025100

00025200

00025300

00025400

00025500

00025600

0 C025800

0,025800
00025900

00025900

00026100

00026100

00026200

00026400

00026500

00026600

00026700

00026800

00026900

00027000

00027109

00027200

00027300

00027500

00027500

00027700

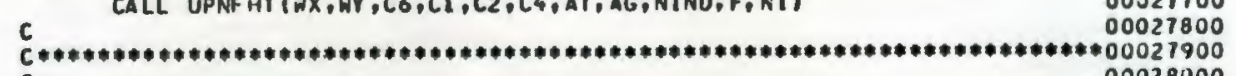

$\begin{array}{ll}C & 00028000\end{array}$

C COMPUTE VP CN COLUMN M IFIRST HALF TIMESTEP)

C CALL VPMFHTICZ, CS,WX, WY, C4, AT, UOSAL, I MOOES, NSOURC, MSOURC, CL 3, $\quad 00028300$

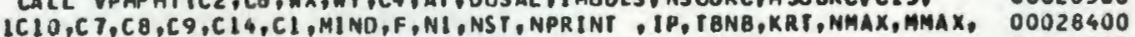
$210 Y, P I, D A Y, T H R, T H I M, H T O T, H A, G H, H E, H C$, SAVE, NS, MS, SS, 00028500 $30 I N, T I N, N Z, N W, U P C O N, V A R I$, DELTAT, NINPUT, ZIGI 00028600

c

C.

CALL PRINTIISTEP, NST, NPRINT, K, NHAX, MMAX, IP, AT, HTOT, HA, BH,

00028700

00028700
00028800

00020900

00029000

00029100

c.

[HE , HC, SA VE, I PUNCH) 
ISN 0207

ISN 0208

ISN 0211

ISN 0211

ISN 0216

ISN 0215

ISN 0216

ISN 0217

SN 0219

SN 0220

ISN 0221

ISN 0223

I SN 0224

ISN 0225

I SN 0227
I SN 0228

ISN 0229

ISN 0230

ISN 0231

ISN 0232

ISN 0233

ISN 0234

ISN 0235

ISN 0236

ISN 0237

ISN 0238
CALL OPENBDINST, IMODES,EXTRAL, KWRIT, K, KRT, IMOOEL, T1,T2,T4, T5, 00029500

$$
N \times T=110
$$

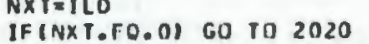

2010 IFINST.LT.90I GO TO 2040

$\begin{array}{ll} & 00029940 \\ 2040 \text { WRITE } 16,2030) \text { NXT,CN(5,36),CNP(5,36),OIN,TIN,NS }(1), M S(1), N 2, & 00029950\end{array}$ ININPUT, S5 (1), ZIALNXT),ZIB(NXT),ZICINXT), ZIE(NXT),ZIO(NXI), 00029955 2AA(NXT),BB(NXI),SIIE,NS(5),MSIS),NST 00029958

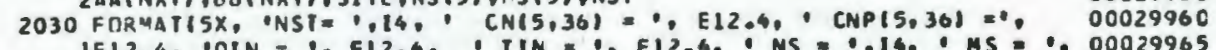

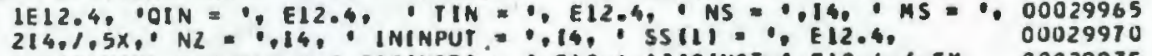

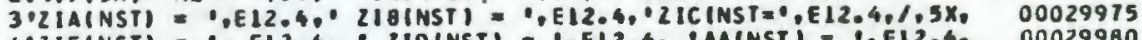

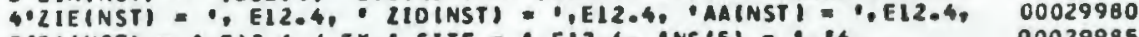

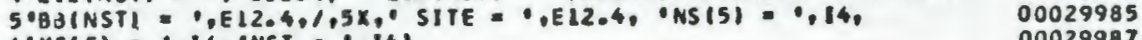
$6 \cdot M S(5)=1,14, \cdot N S T=1,141$

00029987 00329990 2020 CONTINUE

299 ISTEP $=2$

c ISTEP $P=2$
$K=2 * N S T$

00030200 00030300 00030400
00030500 $\begin{array}{ll}\text { COMPUTE VP ANO SEP CN COLUMN M ISECOND HALF TIMESTEPI } & 00030600 \\ \text { VPMSHTIWX,WY,C6,CL,C2,C4,AT, AG,NINO,F, NII } & 00030700 \\ 0 & 00630800 \\ \end{array}$ $\begin{array}{ll}\text { COMPUTE VP ANO SEP CN COLUMN M ISECOND HALF TIMESTEPI } & 00030600 \\ \text { VPMSHTIWX, WY,C6,CL,C2,C4,AT, AG,NINO,F, NII } & 00030700 \\ & 00630000\end{array}$

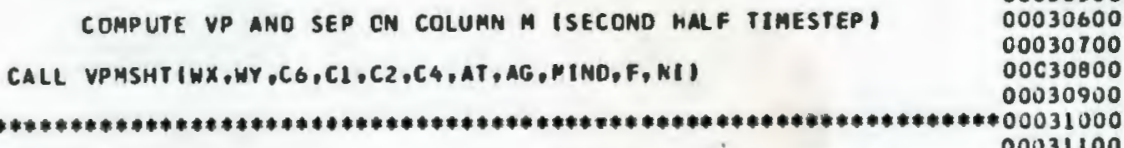

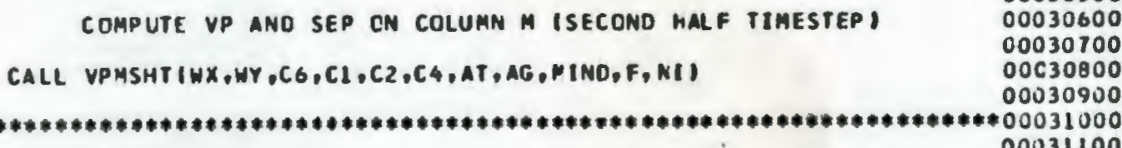

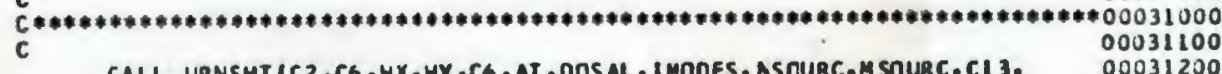

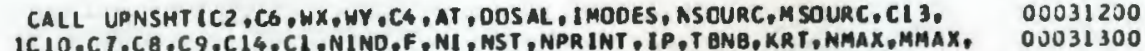
$\begin{array}{ll}\text { ICLO,C }, C B, C Q, C 14, C 1, N I N D \text {, F, NI, MST, NPR INT, IP, T BNB, KRT, MMAX, MMAX, } & 00031300 \\ 2 & 00031400\end{array}$

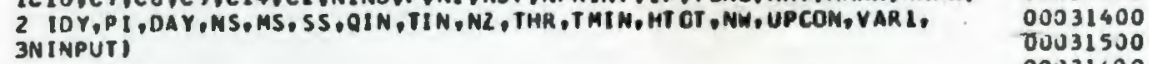

c

SUMIEO.

C SUM $=0.0$

c

$$
\text { NUM }=1
$$

BAY AREA

00031600

00031700

00031800

00031900

00032000

00032100
00032200

00032200
00032300

00032300
00032400

00032500

00032600

00032700

00032800

NSRCH $=$ NBO I HUMI 11000000

$N$ N $N$ NBD (NUM) 1000000 -NSRCH 100

00032900

MF $\quad$ =NBD (NUM) $-N S R C H * 1000000-N * 10000-M F * 100$

00033000

$N N=N-1$

NGRID = L-MF+

GRION2=NGRID
GRIDTI=CRIOTI+GRIONZ

00033100

00033200

00033300

00033400

$M M=M-1 \quad 00033500$

SUMTHT CNP $(N, M) *(.25 *(H(N, M)+H(N N, H)+H(M, M M)+H(N M, H M)+S E P(M, M) D 100033600$

I*3.0

00033700 
ISN 0239

ISN 0240

ISN 0241

ISN 0243

ISN 0244

ISN 0245

ISN 0246

ISN 0248

ISN 0249

ISN 0250

ISN 0252

ISN 0253

ISN 0254

ISN 0255

ISN 0256

ISN 0257

ISN 0250

ISN 0260

ISN 0261

ISN 0262

ISN 0262

ISN 0264

ISN.0265

ISN 0266

ISN 0267

ISN 0268

ISN 0270

ISN 0271

ISN 0272

ISN 0274

ISN 0276

ISN 0278

ISN 0279

ISN 0280

ISN 0281

ISN 0282

ISN 0283

ISN 0284

SN 0285

ISN 0286

ISN 0267

ISN 0288

ISN 02.83

ISN 0291

ISN C292

ISN O29

isN 0296

ISN 0297

ISN 029
SUM I F SUMI + CNP IN,M)

$N U M=$ NUM+1

36 SUYZIG SUMLGRIOTL SURLIG

CINSTIAN SH(JULD EQUAL (AL *2)*9*DENS*9/5

SUMZ TOECONSTA. SUMA SUMZIO

60 to 41

45 IPRINZ=IPRINO

IF(DELTAT) GO TO 47

IPRINL=IPRINL*I0**4

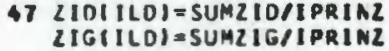
$2 I G(I L D)=S U M 2$
SUM2 $I 6=0.0$

I CONTINUE

SUM $=0$.
SUM $1=0.0$

NUM:1

GRIOT $3=0.0$

NTP $(1)=$ MBD $(8)$

NTP(2) = NAD (11)

NTP $(3)=$ NAD $(14)$

NTP(4) $=$ NBD(16)

NTP(5) $=$ NBD 117$)$

c

$N T P(6)=N B D(19)$

\section{poner plant area}

300 if I NUM.EQ.07) GO TO 310

12 NSRCH=NIPINUMJTIJO0000

MENTPINIMSHOOJO-NSRCH*100

$000-N * 100$

政

IFIMF OLT.32) MF $=32$

$N N=N-1$

NNGO $=L-M F+L$

GRT $4=N N G D$

GRIOT3=GRIDT3+GRT4

DO $330 \mathrm{M}=\mathrm{MF}, \mathrm{L}$

SUMtP

3.0

SUM $1=$ SUM $1+$ CAP $(A, m)$

330 SUME SUA+ SU.MTP T

SUMZIF = CONSIA ESUM+ SUMZIF

SUARTH= SUMITORIOT 3 + SUMZIH

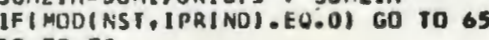

60 TO 70

5 IPRINL=IPRINO

(FIOELTAT) GO TO 67

67 ZIF IILD) = SUMZIF IIPRIMZ

ZIHIILOI= SUHZIHISPRIMZ

SUMZ I $F=0.0$
00033900

00034000

00034200

00034300

00034400

00034500

00034500

00034700

00034800

00034400

00035000

00035100

00035200

0003500

0035500

00035600

00035700

00035800

00035900

00036000

00036100

00036200

00036300

00036400

00036500

00036600

00036700

00036600

00036900

00037000

003710

0037250

00037400

000

00037600

00037700

00037800

00037900

$0 \mathrm{C} 038000$

00038100

00038200

100036300

00038400

00038500

00038600

00038100

00038800

00038900

000

00039100

000390

00039400

00039500

00039500 


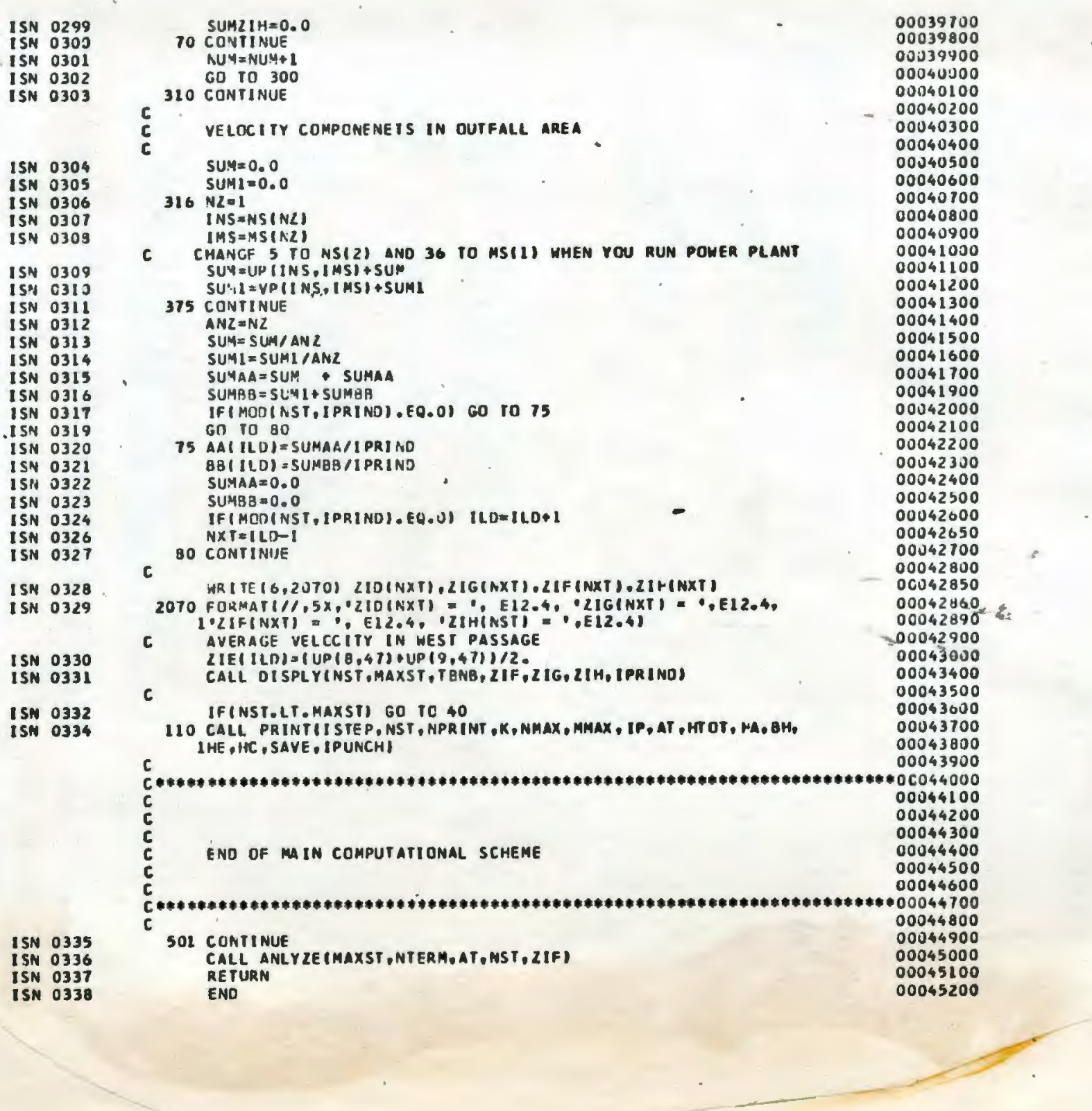




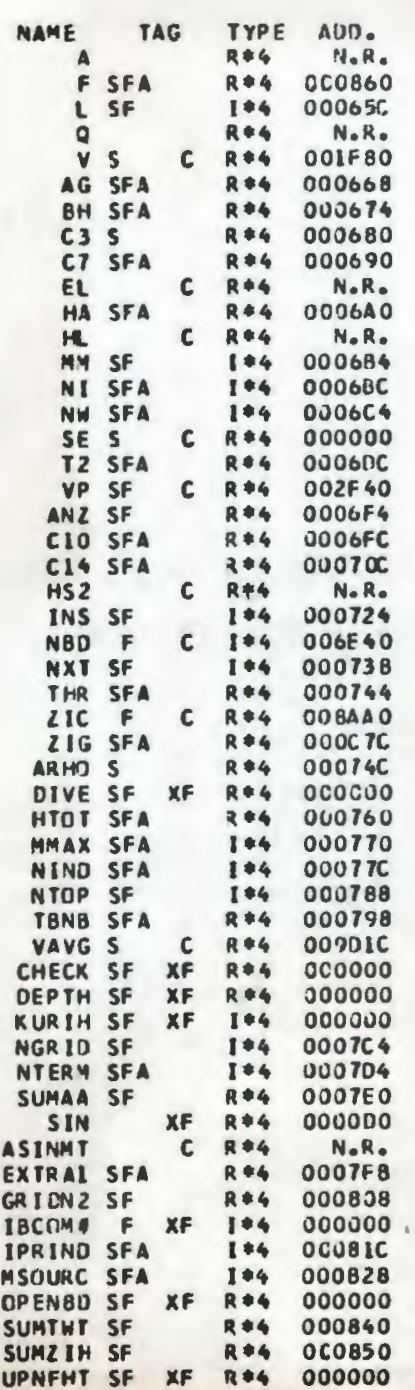

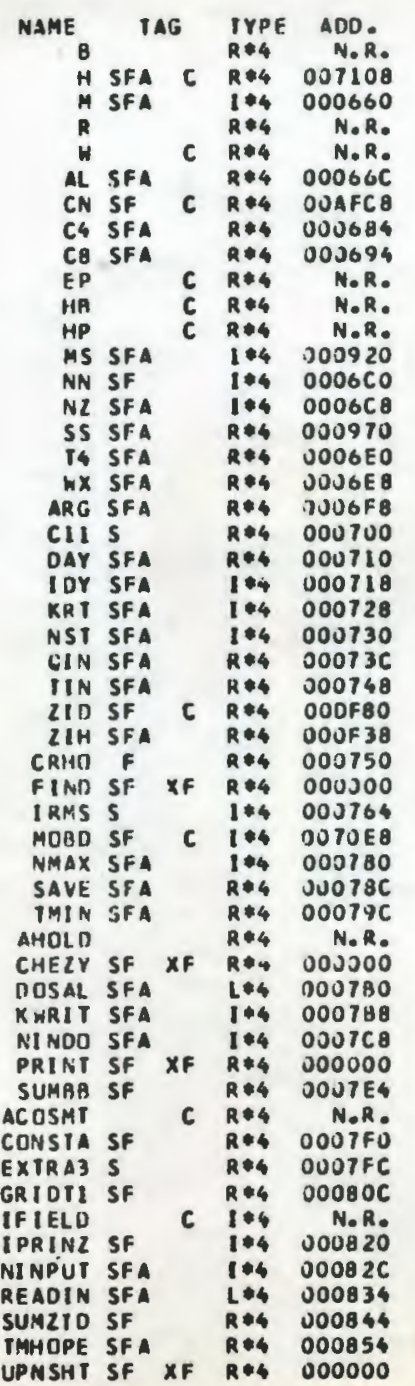

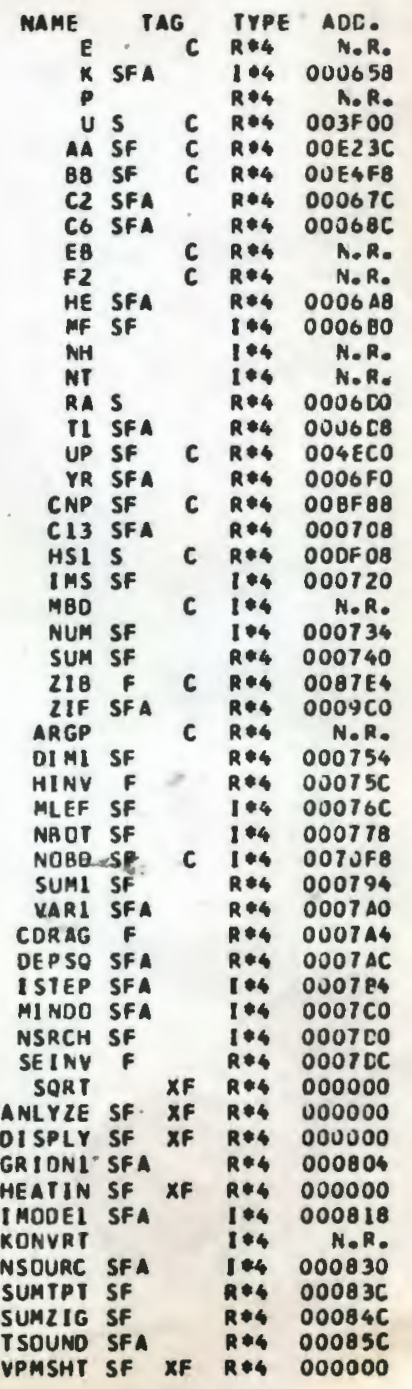

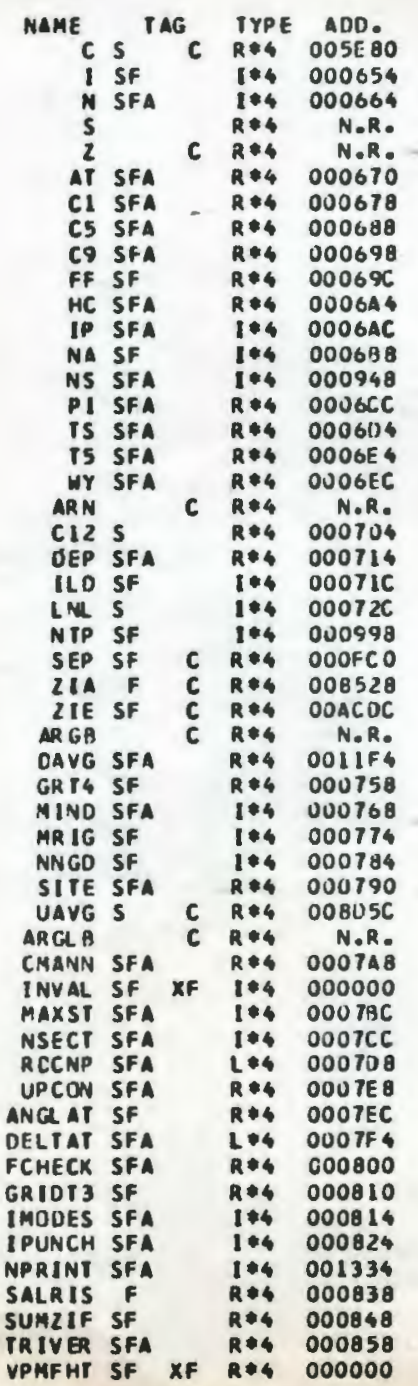


PAGE DIO

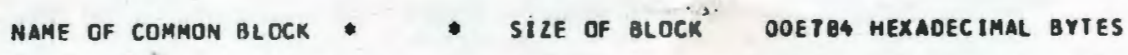

\begin{tabular}{|c|c|c|}
\hline $\begin{array}{l}\text { VAR. NAME } \\
\text { SE }\end{array}$ & $\begin{array}{c}T Y P E \\
R * 4\end{array}$ & $\begin{array}{l}\text { REL. }{ }_{00000} \text {. } \\
000000\end{array}$ \\
\hline u & $R * 4$ & $003 F 00$ \\
\hline MBO & $1 * 4$ & N.R. \\
\hline 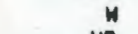 & $R * 4$ & N.R. \\
\hline MP & $R=4$ & $M_{-} R_{\text {. }}$ \\
\hline $\begin{array}{l}\text { ARN } \\
\text { HL }\end{array}$ & $\begin{array}{l}R \neq 4 \\
R \neq 4\end{array}$ & $\begin{array}{l}N_{0} R_{0} \\
N_{0} R_{0}\end{array}$ \\
\hline $21 \mathrm{IC}$ & $R \neq 4$ & OOBAAO \\
\hline $\begin{array}{l}A \operatorname{COSNT} \\
\text { IFIELD }\end{array}$ & $\begin{array}{l}2 * 4 \\
1 * 4\end{array}$ & $\begin{array}{l}\text { NeRe } \\
\text { N.R. }\end{array}$ \\
\hline AA & $R: 4$ & OOE $23 C$ \\
\hline
\end{tabular}

Var. NAME TYPE ReL a ADDR. SEP REA DONFCO LP RE OOAECO F2 TES OOTOEB

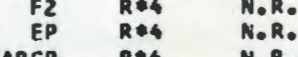
ARGP R०4 N.R. EL REA DOBDSC ASINAT

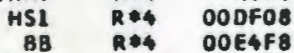

VAR. NAME TYPE RE THE

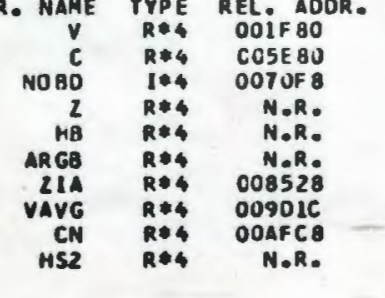

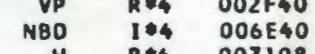

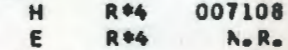
EB $R+4 \quad N_{-} R_{0}$ ARGLB R*4 NoR: 218 R*4 $0087 E 4$ 2IE R*4 ODACOC $\begin{array}{lll}C N P & R * 4 \\ 210 & 008 F 88 \\ R & 00 D F 80\end{array}$ 


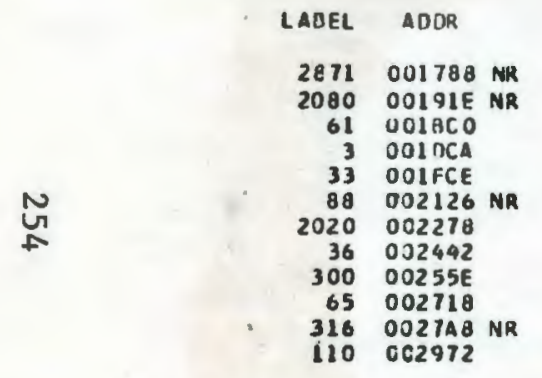

$\begin{array}{rl}\text { LASEL } & \text { ACDR } \\ 2873 & 001832 \\ 6 & 001 A 88 \\ 62 & 00180 E \\ 5 & 001 E B U \\ 35 & 0020 A 2 \\ 2001 & 002144 \\ 299 & 002278 \\ 45 & 002484 \\ 312 & 002564 \\ 67 & 002734 \\ 375 & 0027 F 6 \\ 501 & 002976\end{array}$
LABEL ADDR
2875001846
- 0U1A98
$32001 C 20$
$32 \quad 0020 C_{6}$
$2010 \quad 002190$
$170022 \mathrm{C} 2$
47002412
$3300026 C A$
$10 \quad 002780$
002860
LABEL ADOR
B7 0018FO NR
$26 \quad 001 B 3 E$
31001096
$40 \quad 002114$
$2040 \quad 002140$
$2200240 A$
41 0024F 2
60 0026E6
31000279
80 0028FG

PAGE OII

501002976

-OPTISINS IN EFFECT* . NAME = MAIN,OPT=02,LINECAT=60,SILE=0000K,

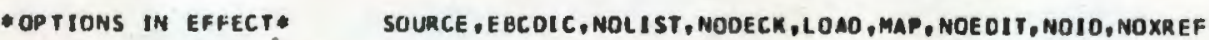

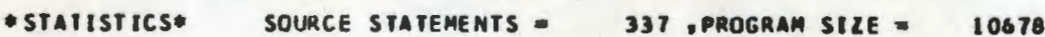

*STATISTICS* No oIAgnostics generated

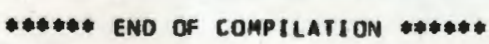

203K BYTES OF CORE NOT USED 
F 44-LEVEL LINKAGE EOITOR OPTIONS SPECIFIED LET,LIST, NCAL, XREF

IEHOSEL DIVE

IFWUCL F (III)

IENC461 CHECK

IEHOGGL CFEP

IEUCA6I DEPTH

IE 0461 KURIH

IE $B 04$ P PHIMT

IEGOGEI PORT

IFHOUEL SIN

IEWO4GI SN YZE

IEHOAGI OISPLY

IEWO461 MEATIN

IEW0461 IBCOMN

IFWC46L OPETBD

IEW046I UPNFHF

IEN0461 UPNSHT

IEW0461 VPMFHT

IEN0461 VPMSHT

CROSS REFERENCE TABLE .

CONTROX SECTION

$\begin{array}{lrr}\text { NAME } & \text { DRIGIN } & \text { LENGTH } \\ \text { MAIN } & 00 & 2986 \\ \text { BLANKCEM } & 2988 & \text { E784 }\end{array}$

LOCATICN REFERS TO SYMBOR IN CONTRUL SECTICN

1664

$166 \mathrm{C}$.

1674

$167 \mathrm{C}$

1680

$168 \mathrm{C}$

1694

1690

$16 A 4$

$164 C$

1684

$16 \mathrm{C} 4$

$16 \mathrm{CC}$

ENTRY AODRESS
DIVE

CHECK

DEP TH

KURIH

ANLYZE

OPENBD

UPNSH

VPMSHT

00
ENTRY

mane Location maMe Location maMe location maMe Location
LOCATION REFERS TO SYMBEL IN CONTROL SECTION

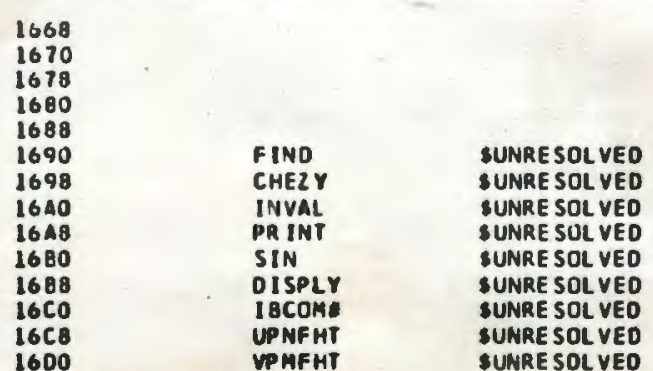


F44-LFVEL LINKAT, FUITOM RPIIONS SPECIFIED MAP,LET,LIST, RVLY, XREF

DEFAULT UPFIONIS) USEO - SILE=1122800,163841

IEHCCCO ENTRY MAIN

JEWOCOO INCLUEE UHJLIBIMATNS

DVERLAY T.NE:

IENONOO

TEW 0000

IEW

IEM 0000

INCLUUE DBJLIBIKURIH,DIVE,FIND,DEPIH,CHE2Y,CHECK, INYAL)

INCLUUE OBJLIB(HEATIN)

OVERLAY CNE

INCL UDE OBJLIB B OPENBD, UPMFHT, VPMFMT, VPMSHT, UPNSHT, MATDEP, , ATINO

INCLUDE OBJLIBCDISPLY,PLCT)
INELUDE OBJLIBIANLYZI

EWOOOO

IEW OONQ
***HAIN DOES NOT EXIST BUT HAS BEEN ADDED TC OATA SET

CRDSS RCFERENCE TABLE

CONTROL SECTION

GIN LENGTH SEG. NO.

\begin{tabular}{|c|c|c|}
\hline $\begin{array}{l}\text { S SECTAB } \\
\text { MAIN } \\
\text { IHC SLOG }\end{array}$ & $\begin{array}{r}00 \\
28 \\
29 E 0\end{array}$ & $\begin{array}{r}24 \\
2986 \\
186\end{array}$ \\
\hline IHCSATN2* & 2898 & ICB \\
\hline IHCSSCN * & 2068 & 109 \\
\hline IHCSEXP & $2+48$ & 192 \\
\hline IHCFR XPR * & 30E 0 & 183 \\
\hline IHC ЕСОМН: & 3268 & F41 \\
\hline IнССОмн2* & $41 B O$ & 650 \\
\hline IHCSSORT * & 4810 & 145 \\
\hline IHCFCVTH* & 4958 & 1190 \\
\hline IHCEFNTH* & 5AF 8 & 512 \\
\hline IrCEFIOS* & 6010 & 1378 \\
\hline IHCERRM * & 7388 & $5 B C$ \\
\hline $\begin{array}{l}\text { IHCUOP T } \\
\text { IHCETRCH* }\end{array}$ & $\begin{array}{l}7948 \\
7<48\end{array}$ & $\begin{array}{l}300 \\
28 E\end{array}$ \\
\hline $\begin{array}{l}\text { IHCUATBL } \\
\text { BBLANKCOM } \\
\text { BENTAB }\end{array}$ & $\begin{array}{r}7 E D B \\
8020 \\
16708\end{array}$ & $\begin{array}{r}148 \\
E 784 \\
C C\end{array}$ \\
\hline
\end{tabular}

OCATION

NAME LOCATION

NAME LOCATION

NAME LOCATION

\begin{tabular}{|c|c|c|c|c|c|c|c|}
\hline ALCGLO & 2950 & ALOG & $29 F 8$ & & & & \\
\hline ATAN2 & 2898 & ATAN & $28 A C$ & & & & \\
\hline $\cos$ & 2068 & SIN & 2080 & & . & & \\
\hline EXP & $2 f 48$ & & & , & & $y$ & \\
\hline FRXPR: & 30EO & & & - & & & \\
\hline І всом: & 3268 & Fotocs: & 3324 & INTSHTCH & $418 E^{-}$ & $=$ & \\
\hline SEQOASO & 4528 & & & 3 & $=$ & & \\
\hline SORT & 4810 & & & & & & \\
\hline $\begin{array}{l}\text { AOCCN } \\
\text { FCVIOUTP }\end{array}$ & $\begin{array}{l}4958 \\
4 F 90\end{array}$ & $\begin{array}{l}\text { FCVAOUTP } \\
\text { FCVEOUTP }\end{array}$ & $\begin{array}{l}4102 \\
5492\end{array}$ & $\begin{array}{l}\text { FCVLOUTP } \\
\text { FCVCOUTP }\end{array}$ & $\begin{array}{l}4 A 92 \\
56 A C\end{array}$ & $\begin{array}{l}\text { FC VZOUTP } \\
\text { INTESWCH }\end{array}$ & $\begin{array}{l}48 E 2 \\
5993\end{array}$ \\
\hline ARITHE & 5AFB & AOJSWTCH & $5 E 64$ & & & & \\
\hline frocs" & 6010 & F IUC S BEP & 6016 & & . & & \\
\hline ERRMCN & 7388 & I HCERRE & 7340 & & & & \\
\hline IHCTRCH & $7 C_{48}$ & ERRTRS & 7650 & & & & \\
\hline
\end{tabular}


nAME ORIGIN LENGTH SEg. NO.

LOCATION REFERS to SYMBOL IN CONTROL SECTION SEg. NO. LOCATICN REFERS TO SYMadL IN CONIROL SECTION SEG. MO.

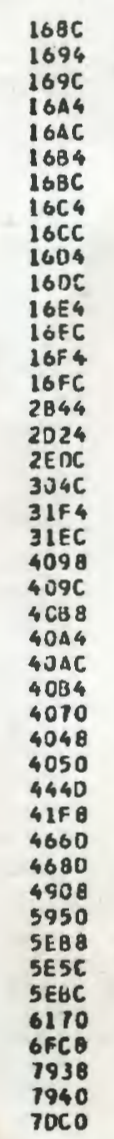

DIVE

CHECK.

DEP IH

KURIH

SIDRT YZE

HEATIN

OHENBS

VPMSHT

IHCERRA

IHEERRM
IHC. ERRM

IHEERR:4

IHCERRM

EXP

ADCUN"

IICUDP T

FC VL nut

FC VCUUTP

FCVZOUTP

IHC COYH2
I HCC COMH2

IHCCO'AHZ

I HC EC NAH

IHC EC OMH

IICECOMH
IHCEC.NMH

IHCERRM

IHC $\equiv R R M$

INISWTCH

IHC NOP T
FIOC SU

IHCERRM

IBCOM:

I $\triangle$ COM

F IOCSBE

AOCONE
DIVE

CHECK

DCPIH

KURIH
IHC SSORT

ANL YZE

MEATI

UPNSHT

UPNSHT

VPMSHT

IHCERR

I HCERRM

IHCERRA

IHCEKRM

IHC SEXP

IHCFCVTH

IHCEFNTH

IHCUOPI

IHCFCVTH

IHCFCVTH

(HCCOMM?

HCCCMH2

HCECON

IHCERRM

IHCECOMH

IHCFCCMH

IHCERRM

IHCERHM

IHCECCPH

I HC UCP I

IICEF IOS

IHCERRM

IHCECCMH

IHCECCHH

IHCE FIOS
IHCFCVTH
1690

1698

1640
1648

1648
1680

1688

$16 C 0$
$16 C 8$
$16 C 0$

16100
1608

$16 \mathrm{E8}$

$10 \mathrm{FE}$

2808
$2 C 109$
$2 E 98$

2E 98

3050

$31 F 0$

$31 \mathrm{~EB}$

4090

$\triangle O B C$

$40 A 0$
$40 \triangle 8$

$40 A 8$
40 HO

4044

4014

4054

4054
4450

$41 F 4$

4670

$48 E 0$

5954

SE 84

$5 E 60$

SECO

$5 F 2 C$

$6 F 85$

7934
7936

$708 \mathrm{C}$
$70 \mathrm{C} 4$
FINO

CHELY

PRIN

DISPLY

DISPLY

IBCOMI
UPNFHT

VPMFHT

IBCOMA

IBCOM:

IBCUM:

jвсOM:

becin.

ALOG

SEODASO

Flocs:

ADJSWTCH

FCVEOUTP

FCVINUTP

FCVAOUTP

THCERRE

IHC COMHE

IHCCOMHE

IHC ECOMH

IBCOME

IHCECUMA

IBCOHA

I BCOMA

IBCOM:

INT 6 SWCH

ADCON

IHCERR M

IHCLATBL

IHC UOP I

IHC IRCH

IOCOM
FIOCSBEP
FIND

CHE2Y

PUINI

IHC SSEN

DISPLY

IHCECOMH

VP MF HI

IHCEC OMH

IHCEC OMH

IHCECOMH

IHCECOMH

IHCECOMH

IHC SL OG

IHCC OMHZ

IHCEF IOS

IHCEF NTH

IHCFCVIH

IHCFC VTH

THCFCV

IHCС ОМн?

IHCCOMHZ

IHC ECOMH

IHCEC OMH

IHCECOMH

IHCEC OMH

IHCECOMH

IHCECOMH

IHCFCVTH

IHCFCVIH

IHCERRM

IHC UA TBL

IHCUOPT

IHCE TRCH

IHCECONH
IHCEFIOS 
CUNTROL SECTION

\begin{tabular}{|c|c|c|}
\hline KUR IH & 16848 & $204 C$ \\
\hline oIv & $188 F 8$ & $30 \mathrm{C}$ \\
\hline INC & $18 C 08$ & GEC \\
\hline EEP TH & 19uca & $33 A$ \\
\hline HEZYY & $19 A 08$ & $3 \mathrm{CA}$ \\
\hline ECK & $1900 B$ & 432 \\
\hline & 14210 & CB4 \\
\hline 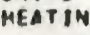 & IAE 98 & 430 \\
\hline
\end{tabular}

LOCATION REFER TD SYMBOL IN CONTROL SECTION SEg. NO. LOCAIION REFERS TO SYMBOL IN CONTROL SECTION SEG. NO.

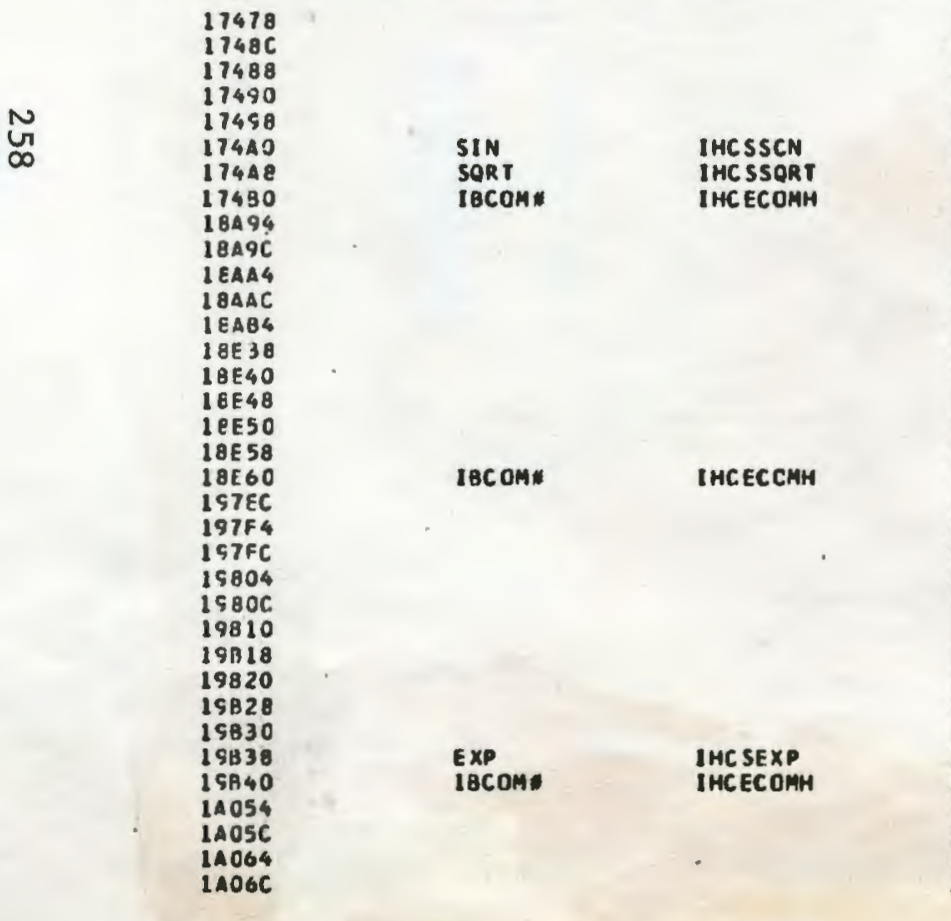

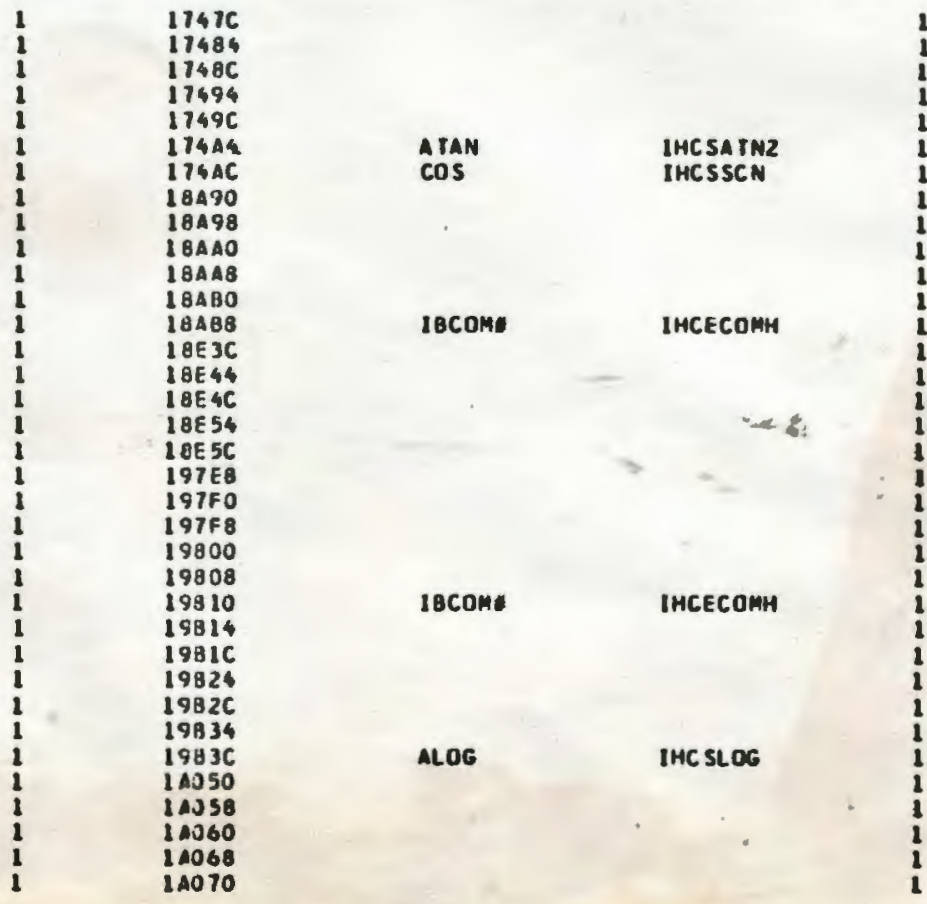




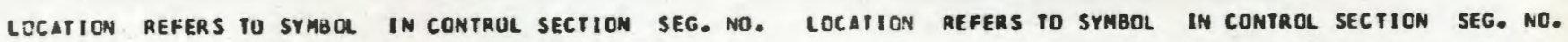

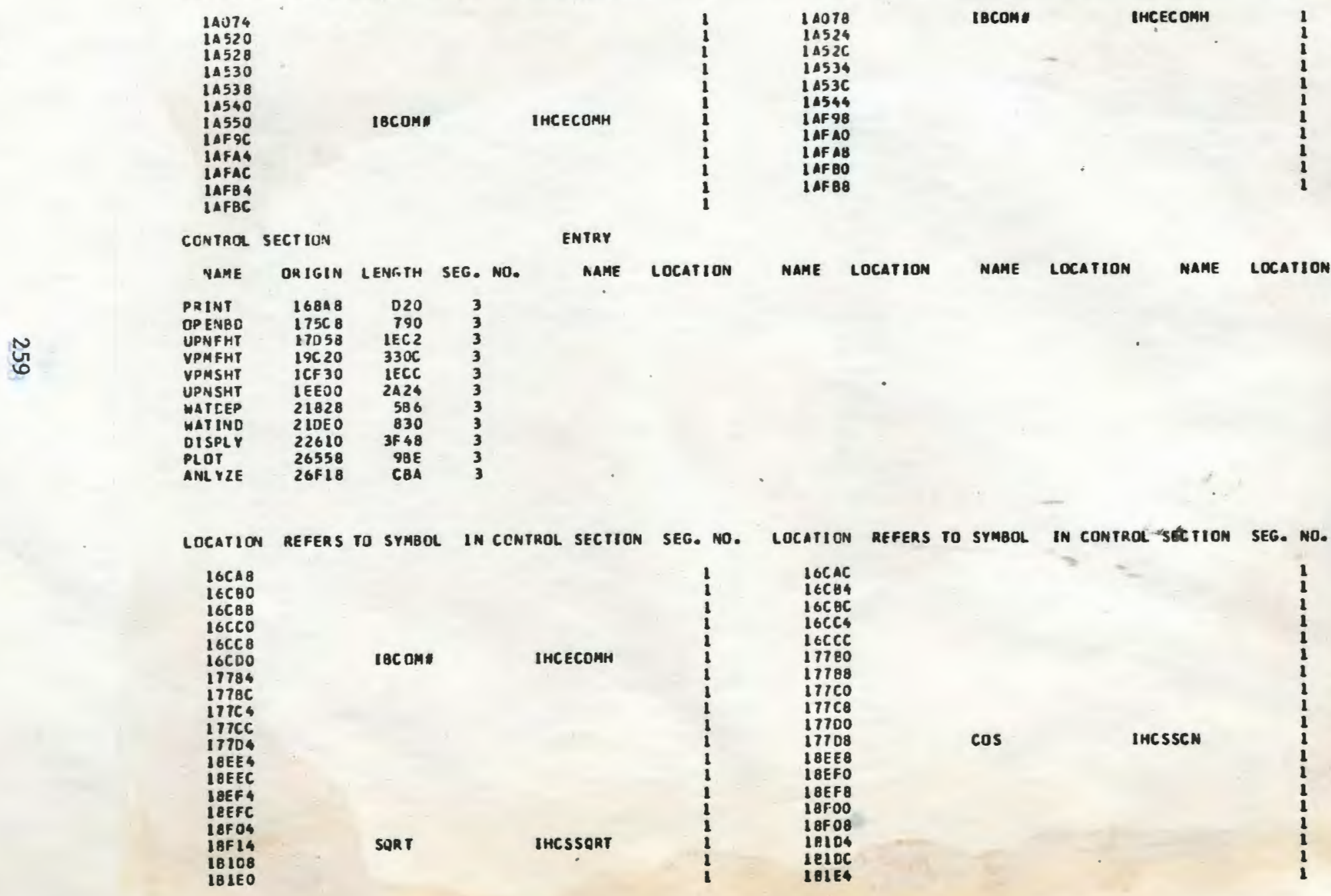




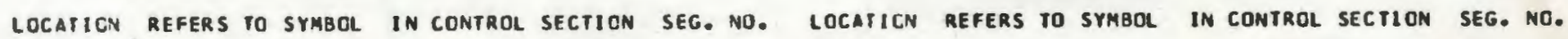

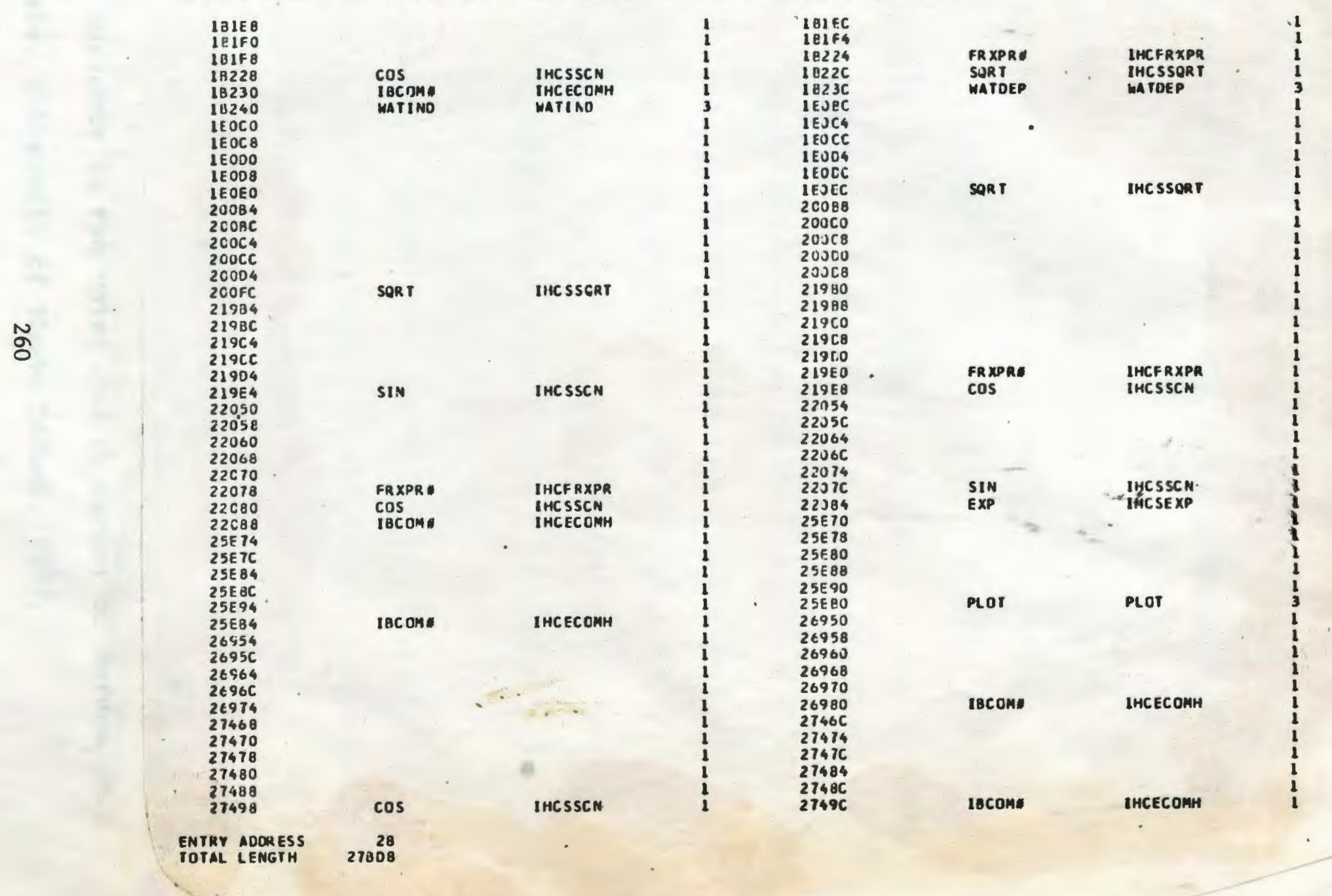




\section{REFERENCES}

1. Leendertse, J.J.., "Aspects of a Computational Model for Long-Period Water Wave Propagation", Rand Corp., Santa Monica, California: Rand Memorandum, RM-5294-PR, May 1967.

2. Leendertse, J.J., "A Water Quality Simulation Model for Well1 Mixed Estuaries and coastal Seas: Vol. I Principles of Computation", Rand Corp., Santa Monica, California: Rand Memorandum: RM-6230-RC, 1970.

3. Leendertse, J.J., "A Water Quality Simulation Model for Well Mixed Estuaries and Coastal Seas: Vol. II Computation Procedures", Rand Corp., Santa Monica, California: Rand Memorandum: RM-6230-RC, 1971.

4. Hess, Kurt A., "A Numerical Tidal Model of Narragansett Bay", Sea Grant Report, University of Rhode Island, Department of Ocean Engineering, 1972.

5. Environmental Protection Agency, Estuarine Modeling: An Assessment, Tracor Water Pollution Control Research Series, 16070 DZV, washington, D.C.: Government Printing office, February 1971.

6. Grimsrud, G.P., Mathematical Modeling of Tidal Heights and Currents in the Point Judith Harbor of Refuge, M.S. Thesis, University of Rhode Island, 1970. 
7. Hicks, S.D., The Physical Oceanography of Narragansett Bay, Limnology and Oceanography, v.4(3), pp. 316-327, 1959.

8. Ippen, A.T.,. Ed., Estuary and Coastline Hydrodynamics, New York, McGraw-Hill, 1966.

9. Saila, S.B., et al, Final Report Preliminary Site Evaluation Study, Rome Point, North Kingstown, Rhode Island, URI Contract No: 98-20-7081, December 1969.

10. Rose, V.C., Kowalski, T., and Sturges, W.T., Circulation Study: Summary of Results, University of Rhode Island, July 1971.

11. Parker, F.L., and Krenkel, P.A., CRC: Physical and Engineering Aspects of Thermal Pollution, cleveland, Ohio: CRC Press, 1970.

12. Edinger, J.E. and Geyer, J.C., Heat Exchange in the Environment, cooling water Studies for Edison Electric Institute, Johns Hopkins University, 1965.

13. Environmental Protection Agency, Research on the Physical Aspects of Thermal Pollution, Cornell Aeronautical Laboratory, Inc., 16130 DPU, Washington, D.C.: Government Printing office, February 1971.

14. Environmental Protection Agency, Mathematical Models for the Prediction of Temperature Distributions Re- 
sulting From the Discharge of Heated Water Into Large Bodies of Water, Koh, R.C.Y., and Fan, Loh-Nien, 16130 DWO, Washington, D.C.: Government Printing Office, October 1970.

15. Harleman, Donald R.F., et al, Engineering Aspects of Heat Disposal From Power Generation, Published notes, Massachusetts Institute of Technology Summer Session, June 1971.

16. Spaulding, Malcolm L., Two Dimensional, LaterallyIntegrated Estuarine Numerical Water Quality Model, Ph.D. Thesis, University of Rhode Island, 1972.

17. Batelle-Northwest Report, Nuclear Power Plant siting, Appendix C.

18. Brown, George A., Surface Heat Transfer, (Unpublished, OCE 532 Class Notes), University of Rhode Island, October 15, 1971, pp. 1-56.

19. Wonderlich, W.O., "Heat and Mass Transfer Between a Water Surface and the Atmosphere", Internal Memorandum, T.V.A. Engineering Lab, Norris, Tennessee, 1968.

20. List, R.T., Ed., Smithsonian Meterological Tables, Smithsonian Institution, 6th Edition, 1966.

21. Anderson, E.R., "Energy Budget Studies", Part of "Water Loss Investigations - Lake Hefner studies", 
Technical Report U.S.G.S. Prof. Paper 269, 1954.

22. Swinbank, W.C., "Long-Wave Radiation From Clear Skies", Quarterly Journal of the Royal Meterlogical Society of London, Vol. 89, July 1963.

23. Mitchell, A.R., Computational Methods in Partial Differential Equations, J. Wiley, '1969, p. 225.

24. Harleman, Donald R.F., et al, Engineering Aspects of Heat Disposal From Power Generation, Massachusetts Institute of Technology Summer Session, June 1972.

25. Koberg, G.E., "Methods to Compute Long Wave Radiation From the Atmosphere and Reflected Solar Radiation From a water Surface", U.S.G.S. Professional Paper, 1962.

26. Marciano, J.J., and Harbeck, G.E., "Mass Transfer Studies", Vol. 1, Lake Hefner Studies, Geological Survey Circular 229, 1952.

27. Bird, R.B., Stewart, W.E., and Lightfoot, E.N., Transport Phenomena, John Wiley and Sons, Inc.. New York, 1960.

28. Elder, J.W., "The Dispersion of Marked Fluid in Turbulent Shear Flow", Journal of Fluid Mechanics, Vol. 5, 1959, p. 544.

29. Wilson, J.R., and Masch, F.D., Field Investigation of 
Mixing and Dispersion in a Deep Reservior, The University of Texas, Hydraulic Engineering Lab Report 10-6701, June 1967.

30. Holley, E.R., "Unified View of Diffusion and Dispersion", Proceedings of the American Society of Civil Engineers, Vol. 45, No. HY2, 1969.

31. U.S. Department of the Interior, Fish and Wildlife Service, "Surface Wave Temperatures Along Atlantic and Gulf Coasts of the United States", Special Scientific Report, Fisheries No. 214.

32. Narragansett Marine Lab, No. 53-10, "Inshore Survey Project, Final Harbor Report, Narragansett Bay and Its Approaches, Physical Oceanography Appendix A Data Report", Helen H. Wehe, April 1953.

33. U.S. Department of Interior, Fisheries and Wildife Service, "Seasonal Abundance of Clam Larvae in Rhode Island Waters, 1950-1952", Special Scientific Report, Fisheries No. 117.

34. Hicks, Frazier and Garrison, "Physical Effects of Proposed Hurricane Protection Structures on Narragansett Bay Under Normal Conditions", Narragansett Marine Lab Report 56-12, 1956, Chapter III, Distribution of Temperature and Salinity. 
35. Hicks, "Hurricane Protection Report of Physical Oceanography, Cruise No. 18 and 19", September 1956, Narragansett Marine Lab, Report 56-17.

36. U.S. Department of Interior, Fisheries and Wildlife Service, Special Science Report, by D.F. Bompus, Fisheries No. 233.

37. U.S. Department of Interior, Fisheries and wildife Service, "Physical Oceanographic Studies of Narragansett Bay 1957-1958", by Steacy Hicks, Special Science Report, Fisheries No. 457.

38. U.S. Department of Interior, Fisheries and wildife Service, "Oceanographic Observations, 1957", by C. Godfrey Day, Special Science Report, Fisheries No. 282.

39. Herman, Sidney S., The Planktonic Fish Eggs and Larvae of Narragansett Bay.

40. U.S. Department of Interior, Fisheries and Wildlife Service, "Oceanographic Observations 1959", by C. Godfrey Day, Special Science Report, Fisheries No. 359.

41. U.S. Department of Commerce, "Surface Water Temperature and Salinity - Atlantic Coast", C \& GS Publication 31-1, First Edition, Washington, D.C.: U.S. 
Printing office, 1960.

42. U.S. Department of Health, Education and Welfare, "Effects of Proposed Hurricane Barriers on Water Quality of Narragansett Bay", Corps of Engineers, 1959.

43. U.S. Department of Interior, Fisheries and Wildife Service, "Oceanographic Observations 1960", by C. Godfrey Day, Special Science Report, Fisheries No. 406.

44. Shonting, David H. and Cook, Gerald S., on the Seasonal Distribution of Temperature and Salinity in Rhode Island Sound, Limnology and Oceanography, 15(1): 100-12, January 1970.

45. U.S. Department of Commerce, "Surface Water Temperature and Density Atlantic Coast", C \& GS Publication 31-1, Third Edition, Washington, D.C.: U.S. Government Printing Office, 1968.

46. Jeffries, H.P., "Surface Temperatures, 1967 - Fox Island, Whale Rock", Unpublished, University of Rhode Island, September 1969.

47. Environmental Protection Agency, "Water Temperature Statistics - Narragansett Bay, Rhode Island, March 1971 - November 1971", Unpublished, National Marine 
Water Quality Laboratory, West Kingston, Rhode Island, 1972.

48. Bay Watch, "Water Hose Sampling", Unpublished, University of Rhode Island, 1972 .

49. Masch, F.D. and Brandes, R.J., "Tidal Hydrodynamic Simulation in Shallow Estuaries", Ưniversity of Texas at Austin, Hydraulic Engineering Lab Technical Report HYD 12-7102, August, 1971.

50. Henderson, F.M., Open Channel Flow, MacMillan Company, 1966.

51. U.S. Department of Commerce, Tidal Current Tables, Atlantic Coast of North America, N.O.A.A., 1971.

52. Schureman, P., Manual of Tide Observations, U.S. Coast and Geodetic Survey, Special Publication No. $198,1941$.

53. U.S. Geological Survey, Surface Water Records for Massachusetts, New Hampshire, Rhode Island, and Vermont.

54. Haight, F.J., Currents in Narragansett Bay, Buzzards Bay, and Nantucket and Vineyard Sounds, U.S. C \& GS Special Publication No. 208, 1938.

55. Binkerd, R., Some Measurements of Currents on Narragansett Bay Using Floats, with a New Application 
for Pole Floats, M.S. Thesis, University of Rhode Island, 1972 .

56. U.S. Department of Commerce, Weather Bureau Local Climatological data, Providence, Rhode Island (T.F. Green Airport), U.S. Government Printing Office, Washington, D.C.

57. Masch, Frank D., et al, "Influence of Tidal Inlets on Salinity and Related Phenomena in Estuaries", Hydraulics Lab, University of Texas at Austin, 1970.

58. Hicks, et al, "Physical Oceanography of Narragansett Bay and Rhode Island Sound", IPS Final Report, Narragansett Marine Lab, University of Rhode Island, 1952 .

59. Hess, Kurt A., "A Three Dimensional, Time Averaged, Numerical Salinity Model for Narragansett Bay", Unfinished Ph.D. Dissertation, University of Rhode Island, August, 1973. 